\title{
Optimising patient selection to improve outcome in advanced ovarian cancer
}

Citation for published version (APA):

Timmermans, M. (2019). Optimising patient selection to improve outcome in advanced ovarian cancer. [Doctoral Thesis, Maastricht University]. Ridderprint. https://doi.org/10.26481/dis.20190830mt

Document status and date:

Published: 01/01/2019

DOI:

10.26481/dis.20190830mt

Document Version:

Publisher's PDF, also known as Version of record

\section{Please check the document version of this publication:}

- A submitted manuscript is the version of the article upon submission and before peer-review. There can be important differences between the submitted version and the official published version of record.

People interested in the research are advised to contact the author for the final version of the publication, or visit the DOI to the publisher's website.

- The final author version and the galley proof are versions of the publication after peer review.

- The final published version features the final layout of the paper including the volume, issue and page numbers.

Link to publication

\footnotetext{
General rights rights.

- You may freely distribute the URL identifying the publication in the public portal. please follow below link for the End User Agreement:

www.umlib.nl/taverne-license

Take down policy

If you believe that this document breaches copyright please contact us at:

repository@maastrichtuniversity.nl

providing details and we will investigate your claim.
}

Copyright and moral rights for the publications made accessible in the public portal are retained by the authors and/or other copyright owners and it is a condition of accessing publications that users recognise and abide by the legal requirements associated with these

- Users may download and print one copy of any publication from the public portal for the purpose of private study or research.

- You may not further distribute the material or use it for any profit-making activity or commercial gain

If the publication is distributed under the terms of Article $25 \mathrm{fa}$ of the Dutch Copyright Act, indicated by the "Taverne" license above, 


\section{OPTIMISING PATIENT SELECTION TO IMPROVE OUTCOME IN ADVANCED OVARIAN CANCER}

Maite Timmermans 
Optimising Patient Selection to Improve Outcome in Advanced Ovarian Cancer (c) Copyright 2019 - Maite Timmermans, Rotterdam, the Netherlands

All rights reserved. No part of this thesis may be reproduced or transmitted in any form or print, photoprint, microfilms or other means, by any reason, without prior written permission of the author.

$\begin{array}{ll}\text { ISBN } & \text { 978-94-6375-346-3 } \\ \text { Cover design } & \text { Gijs Matthee } \\ \text { Layout } & \text { Nikki Vermeulen - Ridderprint } \\ \text { Printing } & \text { Ridderprint - www.ridderprint.nl }\end{array}$

The studies described in this thesis were supported by the Dutch Cancer Society, grant number: IKNL 2014-6838

This thesis was accomplished with financial support from the Dutch Cancer Society, Netherlands Comprehensive Cancer Organisation (IKNL), Maastricht University Medical Centre (MUMC+) and Stichting Olijf.

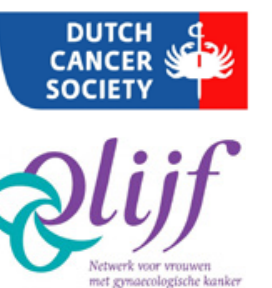




\section{OPTIMISING PATIENT SELECTION TO IMPROVE OUTCOME IN ADVANCED OVARIAN CANCER}

PROEFSCHRIFT

ter verkrijging van de graad van doctor aan de Universiteit Maastricht, op gezag van de Rector Magnificus, Prof. dr. Rianne M. Letschert volgens het besluit van het College van Decanen,

in het openbaar te verdedigen

op vrijdag 30 augustus 2019 om 14.00 uur

door

Maite Timmermans 


\section{Promotores}

Prof. dr. R.F.P.M. Kruitwagen

Prof. dr. K.K. Van de Vijver (Universitair Ziekenhuis Gent, Gent)

\section{Copromotores}

Dr. M.A. van der Aa (Integraal Kankercentrum Nederland, Utrecht)

Dr. G.S. Sonke (Antoni van Leeuwenhoek- Nederlands Kanker Instituut, Amsterdam)

\section{Beoordelingscommissie}

Prof. dr. C.H.C. Dejong (voorzitter)

Prof. dr. F. Amant (Antoni van Leeuwenhoek- Nederlands Kanker Instituut, Amsterdam)

Dr. M. de Boer

Prof. dr. V.E.P.P. Lemmens (Integraal Kankercentrum Nederland, Utrecht)

Prof. dr. E.J.M. Speel 



\section{TABLE OF CONTENTS}

CHAPTER 1 General introduction 9

PART I SURVIVAL AND TREATMENT OF PRIMARY OVARIAN CANCER IN THE NETHERLANDS

CHAPTER 2 No improvement in long-term survival for epithelial ovarian cancer patients; a population-based study between 1989 and 2014 in the Netherlands

CHAPTER 3 Centralization of ovarian cancer in the Netherlands: hospital of diagnosis no longer determines patients' probability of undergoing surgery

CHAPTER 4 Outcome of surgery in advanced ovarian cancer varies between oncological regions; opportunities for improvement in the Netherlands

PART II PROGNOSTIC FACTORS THAT AFFECT SURVIVAL IN OVARIAN CANCER PATIENTS

CHAPTER 5 Perioperative CA125 decline is an independent prognostic factor in advanced ovarian cancer patients

CHAPTER 6 Interval between cytoreductive surgery and adjuvant chemotherapy is associated with overall survival in patients with advanced ovarian cancer

CHAPTER 7 Localisation of distant metastases defines prognosis and treatment efficacy in patients with FIGO stage IV ovarian cancer

PART III

\section{OPTIMISING PATIENT SELECTION FOR PRIMARY SURGERY OR CHEMOTHERAPY}

CHAPTER 8 Neoadjuvant chemotherapy or primary debulking surgery in FIGO IIIC and IV patients; results from a survey study in the Netherlands 
CHAPTER 9 A preoperative clinical model to assess the probability of complete primary cytoreductive surgery for advanced stage ovarian cancer patients

CHAPTER 10 The prognostic value of residual disease after neoadjuvant 189 chemotherapy in advanced ovarian cancer; a systematic review

CHAPTER 11 Summary

CHAPTER 12 General discussion

CHAPTER 13 Valorisatie 245

CHAPTER 14 Epilogue 253 (Dankwoord, Curriculum vitae, List of publications) 

1

General introduction 

The studies presented in this thesis were aimed at improving clinical outcome for epithelial ovarian cancer (EOC) patients. Randomised controlled trials (RCTs) are considered the gold standard for establishing efficacy of new therapies in an era of evidence based medicine. However, due to the strict inclusion criteria, the outcomes of RCTs are often not generalisable to daily clinical practice. EOC typically develops at an older age and the majority of patients is diagnosed with advanced stage disease ${ }^{1,2}$. Consequently, patients are more fragile and cannot always undergo standard treatment. Especially these patients are underrepresented in $\mathrm{RCTs}^{3}$. Therefore, population-based studies, which are limited in establishing causality, provide a unique insight into treatment and survival effects in the general population. All studies in this thesis are based on data from the Netherlands Cancer Registry, which is a nationwide population-based cancer registry and covers all newly diagnosed cancer patients in the Netherlands since 1989. Complementary data were obtained to gain more insight in treatment patterns across the Netherlands.

The studies presented in this thesis are divided into three separate parts. In part I we focus on differences in treatment patterns and survival outcomes for EOC patients. In part II, we aim to gain insight into prognostic factors that affect clinical outcome, and in the last part of this thesis, we highlight the importance of patient selection for the primary treatment of ovarian cancer.

\section{PART I: SURVIVAL AND TREATMENT OF PRIMARY OVARIAN CANCER IN THE NETHERLANDS}

Ovarian cancer is the seventh most common cancer, and the most lethal gynaecological cancer worldwide ${ }^{4-6}$. In the Netherlands, about 1,300 patients are diagnosed yearly ${ }^{7}$. Most patients present with non-specific symptoms such as abdominal pain, bloating or fatigue. Due to the aggressive nature of EOC, in combination with a lack of specific symptoms, the vast majority of patients is diagnosed in advanced stage disease. The most commonly adopted staging system in gynaecological cancers is the Federation of Gynaecology and Obstetrics (FIGO) system, and FIGO stage is an important prognostic factor for overall survival. Patients who are diagnosed with early stage EOC (FIGO IA-IIA) have a five-year survival of $80-95 \%$, while this is only $30-46 \%$ for advanced stage patients (FIGO IIB-IV) ${ }^{8,9}$. As a result, treatment differs between early and advanced stage patients.

Current management for early stage ovarian cancer is a surgical staging laparotomy, consisting of a hysterectomy, bilateral salpingo-oophorectomy, (infracolic) omentectomy, 
lymph node sampling and biopsies on different prescribed locations ${ }^{10}$. The goal of this intervention is to ensure that the tumour is limited to the ovaries, fallopian tubes and the uterus. In case of lymph node involvement or tumour spread to other pelvic or intraperitoneal tissues, patients are regarded as advanced stage patients. For patients diagnosed with advanced stage disease, surgery is combined with platinum-based chemotherapy ${ }^{10}$. The surgical intervention, which is called cytoreductive surgery, consists of a hysterectomy, bilateral salpingo-oophorectomy, (infracolic) omentectomy and removal of all macroscopic tumour in the abdomen.

Adjuvant chemotherapy is recommended in advanced stage disease, and may be used in high-risk patients with early stage disease ${ }^{11}$. The chemotherapeutic agents used in ovarian cancer evolved over the last decades. In the 1980's, first-line systemic treatment of EOC consisted of cisplatin in combination with cyclophosphamide. Subsequently, carboplatin was introduced, which was found to have a more favourable toxicity profile when compared to cisplatin ${ }^{12}$. Paclitaxel replaced cyclophosphamide as first-line regimen in the $1990{ }^{\prime} \mathrm{s}^{13}$, and the combination of carboplatin and paclitaxel is still advised as first-line treatment combination. The backbone of efficacy relies on the treatment effect of carboplatin, which can also be combined with other chemotherapeutic agents.

In chapter $\mathbf{2}$ we describe the results of a study on changes in treatment patterns over the last 25 years for EOC patients in the Netherlands. Moreover, we describe the effect of these changes on long-term survival for patients with EOC.

Survival of patients with advanced stage disease strongly depends on the ability to minimise residual disease during cytoreductive surgery ${ }^{14,15}$. Patients with no macroscopic residual disease after surgery (i.e. complete cytoreductive surgery), have the best prognosis. Optimal cytoreductive surgery (residual disease of $\leq 1 \mathrm{~cm}$ in maximal diameter) offers a survival advantage over patients with a suboptimal cytoreduction $(>1 \mathrm{~cm}$ of residual disease in maximal diameter ${ }^{16-18}$. This suggests an amendable role for cytoreductive surgery, and highlights the importance of high-quality surgical care in the primary treatment for EOC. Research has shown that cytoreductive surgery performed in high-volume hospitals by experienced gynaecologic-oncologists leads to improved surgical outcomes and survival rates $^{19-21}$. Consequently, this led to a gradual centralisation process in the Netherlands since 2005. In 2012, a national consensus was reached to restrict the performance of cytoreductive surgery to hospitals which carried out a minimum of twenty cytoreductive surgeries on an annual basis. The initial diagnosis is, however, still made in virtually all 
Dutch hospitals regardless of their specialisation. In chapter $\mathbf{3}$ we evaluated whether the management of patients with advanced EOC patients depends on the hospital of initial diagnosis, both before, during and after centralisation was established.

Besides the national consensus on centralisation of surgical care, more emphasis was placed on regional multidisciplinary tumour board meetings. All patients diagnosed with EOC should be discussed with gynaecological-oncologists, medical oncologists, pathologists and radiotherapists, prior to treatment ${ }^{22}$. In the Netherlands, patients are treated within different geographical regions, with their own regional multidisciplinary tumour board meeting. This allowed us to study differences in treatment patterns, surgical outcomes, and survival differences between geographical regions in the Netherlands (chapter 4).

\section{PART II: PROGNOSTIC FACTORS THAT AFFECT SURVIVAL IN OVARIAN CANCER PATIENTS}

The diagnosis of EOC patients is based on imaging techniques (such as vaginal ultrasound and/or computed tomography (CT) scans), histological or cytological confirmation and Cancer Antigen 125 (CA125) serum levels. CA125 is expressed on the ovarian tumour cell surface, but is a non-specific tumour marker for ovarian cancer as a considerable number of patients have normal CA125 levels ${ }^{15,23,24}$. Monitoring CA125 serums levels can, however, be useful in controlling treatment effect and is commonly used during chemotherapeutic treatment. It has been suggested that the perioperative decline in CA125 is a better marker for residual cancer burden, and therewith long-term outcome, than the surgeons' estimation of residual tumour volume. The latter is hampered by the subjective intraoperative assessment of gynaecologists and does not account for initial disease burden ${ }^{25,26}$. In chapter $\mathbf{5}$ we evaluated the prognostic value of perioperative CA125 change in advanced EOC patients.

Despite the generally accepted use of chemotherapy in advanced stage EOC patients, there is no guideline on the optimal time interval between cytoreductive surgery and the start of chemotherapy. It is assumed that adjuvant chemotherapy should be initiated as soon as possible, as this may prevent early tumour growth, but studies in ovarian cancer report conflicting results ${ }^{27-29}$. In chapter 6 we evaluated the time interval between surgery and adjuvant chemotherapy as prognostic factor for overall survival. 
Following the recognition that patients with FIGO stage IV represent a heterogeneous group with possible survival differences, the FIGO staging system was updated in $2014^{30,31}$. FIGO IV disease is characterised by distant metastases, such as malignant pleural effusion, parenchymal liver metastasis or extra-abdominal lymph node metastases. The new classification distinguishes between patients with malignant pleural effusion (FIGO IVa), and patients with either abdominal parenchymal invasion or extra-abdominal metastases $\left(\right.$ FIGO IVb) ${ }^{30,31}$. From earlier studies, it remained questionable if this new classification provided additional prognostic information for FIGO IV patients. Some studies even proposed a new sub-classification ${ }^{32-34}$. Moreover, treatment effects may differ between the different subtypes of FIGO stage IV disease. In chapter $\mathbf{7}$ we evaluated the prognostic effect of different localisations of metastases and established treatment efficacy in those groups.

\section{PART III: OPTIMISING PATIENT SELECTION FOR PRIMARY SURGERY OR CHEMOTHERAPY}

The mainstay of therapeutic management consists of platinum-based chemotherapy and cytoreductive surgery. Patients were traditionally treated with primary cytoreductive surgery (PCS) followed by adjuvant chemotherapy, but neoadjuvant chemotherapy (NACT) followed by interval cytoreductive surgery (ICS) has been introduced as an alternative treatment approach with non-inferior survival rates $^{35,36}$. Initial disease burden and experience of the surgical team, affect the probability of achieving complete cytoreductive surgery. NACT may decrease initial tumour load, resulting in a higher number of complete cytoreductive surgeries and reduced morbidity from the surgical intervention ${ }^{35-38}$. A downside of NACT is a higher probability to develop early platinum resistance, as large tumour volumes are exposed to chemotherapy ${ }^{39,40}$. Nowadays, there is a lively debate about the most optimal treatment sequence, and in chapter $\mathbf{8}$ we evaluated the current opinions about PCS and NACT-ICS in FIGO IIIC and IV patients among all Dutch gynaecologists and medical oncologists.

It has been shown that patients with no residual disease after cytoreductive surgery (either upfront or interval surgery) have the best survival rates ${ }^{14,35,36}$. This led to a change in paradigm, where no macroscopic residual disease is nowadays the goal of cytoreductive surgery. Residual disease of any diameter is therefore an undesirable outcome in the treatment of advanced ovarian cancer. The tumour spread and resectability of all macroscopic tumour can preoperatively be predicted by CT-scans. Sensitivity and specificity of CT is rather low unfortunately, and is highly dependent on the expertise of the consulted radiologist. 
Multiple studies tried to predict the outcome of surgery based on computer tomography (CT) scans. However, the vast majority of CT based models are not externally validated or lack discriminative ability ${ }^{41,42}$. In order to improve the success rate of performed surgeries and to prevent unnecessary morbidity from futile primary laparotomies, a preoperative clinical model to predict the outcome of cytoreductive surgery is of paramount importance for optimal patient selection. Therefore, in chapter $\mathbf{9}$ we aimed to develop a prediction model based on simple patient- and tumour characteristics to estimate the probability to achieve no macroscopic disease at primary surgery.

The likelihood of successful surgery is higher after NACT, while this does not translate into prolonged survival when NACT-ICS is compared to PCS. Therefore, it appears that the prognostic effect of the amount of residual disease is different after primary versus interval cytoreductive surgery. In chapter 10, we aimed to summarise the prognostic effect of the amount of residual disease after NACT-ICS on overall survival through the method of a systematic review.

Finally, a summary and discussion of observed outcomes will be presented in chapter $\mathbf{1 1}$ and chapter 12. Moreover, a valorisation chapter is presented in chapter 13. 


\section{REFERENCES}

1. Maas HA, Kruitwagen RF, Lemmens VE, Goey SH, Janssen-Heijnen ML. The influence of age and co-morbidity on treatment and prognosis of ovarian cancer: A population-based study. Gynecol Oncol. 2005;97(1):104-9.

2. Schuurman MS, Kruitwagen R, Portielje JEA, Roes EM, Lemmens V, van der Aa MA. Treatment and outcome of elderly patients with advanced stage ovarian cancer: A nationwide analysis. Gynecol Oncol. 2018;149(2):270-4.

3. Zulman DM, Sussman JB, Chen X, Cigolle $\mathrm{CT}$, Blaum CS, Hayward RA. Examining the evidence: A systematic review of the inclusion and analysis of older adults in randomized controlled trials. J Gen Intern Med. 2011;26(7):783-90.

4. Sant M, Chirlaque Lopez MD, Agresti R, Sanchez Perez MJ, Holleczek B, BielskaLasota $M$, et al. Survival of women with cancers of breast and genital organs in europe 1999-2007: Results of the eurocare-5 study. Eur J Cancer. 2015;51(15):2191-205.

5. Siegel RL, Miller KD, Jemal A. Cancer statistics, 2018. CA Cancer J Clin. 2018;68(1):7-30.

6. Torre LA, Trabert B, DeSantis CE, Miller KD, Samimi G, Runowicz CD, et al. Ovarian cancer statistics, 2018. CA Cancer J Clin. 2018.

7. Intergraal kankercentrum nederland nederlandse kankerregistratie. Https:// www.Cijfersoverkanker.NI/nkr/. Accessed august 2018.

8. Zapardiel I, Diestro MD, Aletti G. Conservative treatment of early stage ovarian cancer: Oncological and fertility outcomes. Eur J Surg Oncol. 2014;40(4):387-93.
9. Satoh $T$, Hatae $M$, Watanabe $Y$, Yaegashi $\mathrm{N}$, Ishiko O, Kodama S, et al. Outcomes of fertility-sparing surgery for stage i epithelial ovarian cancer: A proposal for patient selection. J Clin Oncol. 2010;28(10):172732.

10. Integraal kanker centrum nederland - epitheliaal ovariumcarcinoom versie 2.0 (2012). Https://www.Oncoline.NI/ ovariumcarcinoom. Accessed september 2018 .

11. Lawrie TA, Winter-Roach BA, Heus $P$, Kitchener HC. Adjuvant (post-surgery) chemotherapy for early stage epithelial ovarian cancer. Cochrane Database Syst Rev. 2015(12):CD004706.

12. McGuire WP, Rowinsky EK, Rosenshein NB, Grumbine FC, Ettinger DS, Armstrong DK, et al. Taxol: A unique antineoplastic agent with significant activity in advanced ovarian epithelial neoplasms. Ann Intern Med. 1989;111(4):273-9.

13. McGuire WP, Hoskins WJ, Brady MF, Kucera PR, Partridge EE, Look KY, et al. Cyclophosphamide and cisplatin compared with paclitaxel and cisplatin in patients with stage iii and stage iv ovarian cancer. $\mathrm{N}$ Engl J Med. 1996;334(1):1-6.

14. Chang SJ, Hodeib M, Chang J, Bristow RE. Survival impact of complete cytoreduction to no gross residual disease for advancedstage ovarian cancer: A meta-analysis. Gynecol Oncol. 2013;130(3):493-8.

15. Bristow RE, Tomacruz RS, Armstrong DK, Trimble EL, Montz FJ. Survival effect of maximal cytoreductive surgery for advanced ovarian carcinoma during the platinum era: A meta-analysis. J Clin Oncol. 2002;20(5):1248-59. 
16. Bookman MA, Brady MF, McGuire WP, Harper PG, Alberts DS, Friedlander M, et al. Evaluation of new platinum-based treatment regimens in advanced-stage ovarian cancer: A phase iii trial of the gynecologic cancer intergroup. J Clin Oncol. 2009;27(9):1419-25.

17. Chiva LM, Castellanos T, Alonso S, GonzalezMartin A. Minimal macroscopic residual disease $(0.1-1 \mathrm{~cm})$. Is it still a surgical goal in advanced ovarian cancer? Int J Gynecol Cancer. 2016;26(5):906-11.

18. Winter WE, 3rd, Maxwell GL, Tian C, Carlson JW, Ozols RF, Rose PG, et al. Prognostic factors for stage iii epithelial ovarian cancer: A gynecologic oncology group study. J Clin Oncol. 2007;25(24):3621-7.

19. Bristow RE, Chang J, Ziogas A, Randall $\mathrm{LM}$, Anton-Culver $\mathrm{H}$. High-volume ovarian cancer care: Survival impact and disparities in access for advanced-stage disease. Gynecol Oncol. 2014;132(2):403-10.

20. Dahm-Kahler P, Palmqvist C, Staf C, Holmberg E, Johannesson L. Centralized primary care of advanced ovarian cancer improves complete cytoreduction and survival - a population-based cohort study. Gynecol Oncol. 2016;142(2):211-6.

21. Eggink $F A, M o m ~ C H$, Kruitwagen RF, Reyners AK, Van Driel WJ, Massuger LF, et al. Improved outcomes due to changes in organization of care for patients with ovarian cancer in the netherlands. Gynecol Oncol. 2016.

22. Querleu D, Planchamp F, Chiva L, Fotopoulou C, Barton D, Cibula D, et al. European society of gynaecologic oncology quality indicators for advanced ovarian cancer surgery. Int J Gynecol Cancer. 2016;26(7):1354-63.
23. Bruney L, Conley KC, Moss NM, Liu Y, Stack MS. Membrane-type i matrix metalloproteinase-dependent ectodomain shedding of mucin16/ ca-125 on ovarian cancer cells modulates adhesion and invasion of peritoneal mesothelium. Biol Chem. 2014;395(10):1221-31.

24. Rump A, Morikawa Y, Tanaka M, Minami S, Umesaki N, Takeuchi $\mathrm{M}$, et al. Binding of ovarian cancer antigen ca125/muc16 to mesothelin mediates cell adhesion. J Biol Chem. 2004;279(10):9190-8.

25. Eskander RN, Kauderer J, Tewari KS, Mannel RS, Bristow RE, O'Malley DM, et al. Correlation between surgeon's assessment and radiographic evaluation of residual disease in women with advanced stage ovarian cancer reported to have undergone optimal surgical cytoreduction: An nrg oncology/gynecologic oncology group study. Gynecol Oncol. 2018.

26. Prefontaine $M$, Gelfand AT, Donovan JT, Powell JL. Reproducibility of tumor measurements in ovarian cancer: A study of interobserver variability. Gynecol Oncol. 1994;55(1):87-90.

27. Alexander $M$, Blum $R$, Burbury $K$, Coutsouvelis J, Dooley M, Fazil O, et al. Timely initiation of chemotherapy: A systematic literature review of six priority cancers - results and recommendations for clinical practice. Intern Med J. 2017;47(1):16-34.

28. Mahner S, Eulenburg C, Staehle A, Wegscheider K, Reuss A, Pujade-Lauraine E, et al. Prognostic impact of the time interval between surgery and chemotherapy in advanced ovarian cancer: Analysis of prospective randomised phase iii trials. Eur J Cancer. 2013;49(1):142-9. 
29. Flynn PM, Paul J, Cruickshank DJ, Scottish Gynaecological Cancer Trials G. Does the interval from primary surgery to chemotherapy influence progression-free survival in ovarian cancer? Gynecol Oncol. 2002;86(3):354-7.

30. Mutch DG, Prat J. 2014 figo staging for ovarian, fallopian tube and peritoneal cancer. Gynecol Oncol. 2014;133(3):401-4.

31. Prat J, Oncology FCoG. Staging classification for cancer of the ovary, fallopian tube, and peritoneum. Int J Gynaecol Obstet. 2014;124(1):1-5.

32. Ataseven B, Harter P, Grimm C, Heitz F, Heikaus S, Traut A, et al. The revised 2014 figo staging system for epithelial ovarian cancer: Is a subclassification into figo stage iva and ivb justified? Gynecol Oncol. 2016;142(2):243-7.

33. Nasioudis D, Chapman-Davis E, Frey MK, Caputo TA, Witkin SS, Holcomb K. Should epithelial ovarian carcinoma metastatic to the inguinal lymph nodes be assigned stage ivb? Gynecol Oncol. 2017;147(1):81-4.

34. Tajik P, van de Vrie R, Zafarmand MH, Coens C, Buist MR, Vergote I, et al. The figo stage iva versus ivb of ovarian cancer: Prognostic value and predictive value for neoadjuvant chemotherapy. Int J Gynecol Cancer. 2018.

35. Vergote I, Trope CG, Amant F, Kristensen GB, Ehlen T, Johnson N, et al. Neoadjuvant chemotherapy or primary surgery in stage iiic or iv ovarian cancer. N Engl J Med. 2010;363(10):943-53.

36. Kehoe S, Hook J, Nankivell M, Jayson GC, Kitchener H, Lopes T, et al. Primary chemotherapy versus primary surgery for newly diagnosed advanced ovarian cancer (chorus): An open-label, randomised, controlled, non-inferiority trial. Lancet. 2015;386(9990):249-57.
37. Fagotti A, Ferrandina G, Vizzielli G, Fanfani F, Gallotta V, Chiantera V, et al. Phase iii randomised clinical trial comparing primary surgery versus neoadjuvant chemotherapy in advanced epithelial ovarian cancer with high tumour load (scorpion trial): Final analysis of peri-operative outcome. Eur J Cancer. 2016;59:22-33.

38. Yang L, Zhang B, Xing G, Du J, Yang B, Yuan $Q$, et al. Neoadjuvant chemotherapy versus primary debulking surgery in advanced epithelial ovarian cancer: A meta-analysis of peri-operative outcome. PLoS One. 2017;12(10):e0186725.

39. da Costa AA, Valadares CV, Baiocchi G, Mantoan H, Saito A, Sanches S, et al. Neoadjuvant chemotherapy followed by interval debulking surgery and the risk of platinum resistance in epithelial ovarian cancer. Ann Surg Oncol. 2015;22 Suppl 3:S971-8.

40. Rauh-Hain JA, Nitschmann CC, Worley MJ, Jr., Bradford LS, Berkowitz RS, Schorge $\mathrm{JO}$, et al. Platinum resistance after neoadjuvant chemotherapy compared to primary surgery in patients with advanced epithelial ovarian carcinoma. Gynecol Oncol. 2013;129(1):63-8.

41. Rutten IJ, van de Laar R, Kruitwagen RF, Bakers FC, Ploegmakers MJ, Pappot TW, et al. Prediction of incomplete primary debulking surgery in patients with advanced ovarian cancer: An external validation study of three models using computed tomography. Gynecol Oncol. 2016;140(1):22-8.

42. Rutten MJ, van de Vrie R, Bruining $A$, Spijkerboer AM, Mol BW, Kenter GG, et al. Predicting surgical outcome in patients with international federation of gynecology and obstetrics stage iii or iv ovarian cancer using computed tomography: A systematic review of prediction models. Int J Gynecol Cancer. 2015;25(3):407-15. 




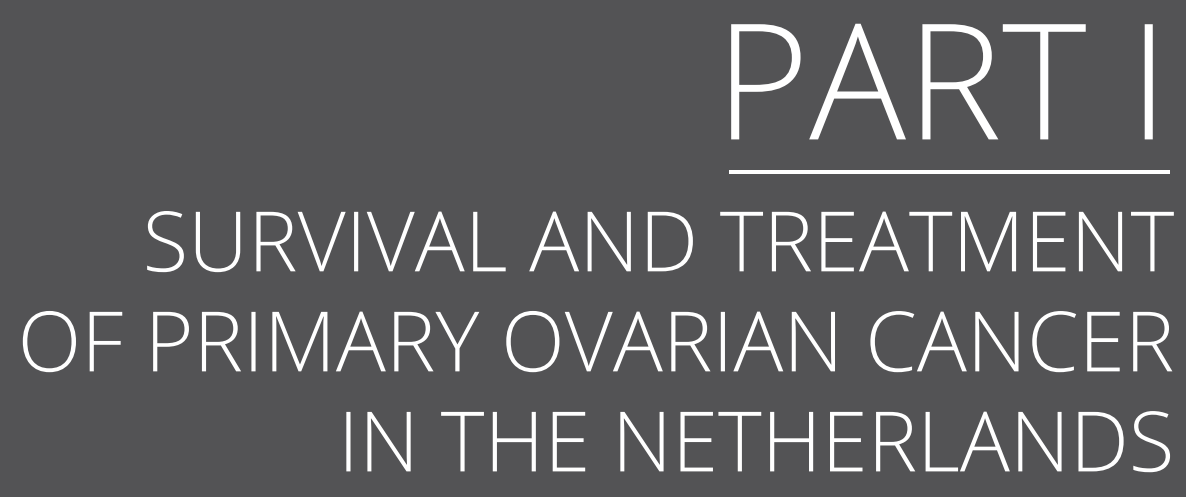





\section{2}

No improvement in long-term survival for epithelial ovarian cancer patients: a population-based study between 1989 and 2014 in the Netherlands

M. Timmermans, G.S. Sonke, K.K Van de Vijver, M.A. van der Aa, R.F.P.M. Kruitwagen 


\section{ABSTRACT}

\section{Aim}

This study investigates changes in therapy and long-term survival for patients with epithelial ovarian cancer (EOC) in the Netherlands.

\section{Methods}

All patients with EOC, including peritoneal and fallopian tube carcinoma, diagnosed in the Netherlands between 1989 and 2014 were selected from the Netherlands Cancer Registry. Changes in therapy were studied and related to overall survival (OS) using multivariable Cox regression models.

\section{Results}

A total of 32,540 patients were diagnosed with EOC of whom 22,047 (68\%) had advanced stage disease. In early stage, lymph node dissection as part of surgical staging procedures increased over time from $4 \%$ in 1989-1993 to 62\% in 2009-2014 ( $P<0.001)$. In advanced stage, the number of patients receiving optimal treatment with surgery and chemotherapy increased from 55\% in 1989-1993 to 67\% in 2009-2014 ( $P<0.001)$. Five-year survival rates improved in both early stage (74\% versus $79 \%$ ) and advanced stage ( $16 \%$ versus $24 \%$ ), as well as in all patients combined (31\% versus 34\%). Ten-year survival rates, however, slightly improved in early stage (62\% versus $67 \%$ ) and advanced stage (10\% versus $13 \%$ ) but remained essentially unchanged at $24 \%$ for all patients combined.

\section{Conclusion}

Despite intensified treatment and staging procedures, long-term survival for women with EOC has not improved in the last 25 years. The observed improvements in 5-year OS reflect a more prolonged disease control rather than better chances for cure. Furthermore, the apparent better long-term outcome, when early- and advanced-staged patients are analysed separately, is largely due to improved staging procedures and the ensuing stage migration. These effects disappear in a combined analysis of all patients. 


\section{INTRODUCTION}

Epithelial ovarian cancer (EOC) is the most lethal gynaecologic cancer worldwide ${ }^{1}$. The 5 -year overall survival (OS) rates range between $30 \%$ and $46 \%{ }^{2,3}$. Due to a lack of specific symptoms, patients are often diagnosed with advanced stage disease, which is associated with poor prognosis and 5-year OS rates of 14-29\%

Patients who are diagnosed with early stage disease are recommended to undergo a complete staging procedure, consisting of inspection of the abdominal cavity, omentectomy, adequate lymph node sampling and several prescribed biopsies. If patients cannot be staged properly adjuvant chemotherapy is recommended ${ }^{5,6}$.

Current management for advanced EOC patients consists of debulking surgery in combination with platinum- and taxane-based chemotherapy. Complete resection of all macroscopic tumour is an independent factor for prolonged survival and is therefore an important goal during debulking surgery ${ }^{7,8}$. The timing of surgery is an ongoing topic of debate; patients were traditionally treated with primary debulking surgery (PDS) but neoadjuvant chemotherapy followed by interval debulking surgery (NACT-IDS) could be an alternative for advanced stage patients ${ }^{9,10}$.

Improvements in therapy and diagnostic work-up should ultimately lead to better diseasefree survival and OS for EOC patients. Multiple international studies were conducted, which analysed trends in survival. Outcomes varied, but most studies reported improved 5-year survival rates ${ }^{11-28}$ (S7). In combination with a decline in incidence for ovarian cancer, among others due to the introduction of the oral contraceptive pill, these studies often result in decreasing ovarian cancer mortality rates ${ }^{28-31}$.

The population-based study of van Altena et al. analysed trends in relative survival for both early- and advanced-stage EOC until 2009 in the Netherlands ${ }^{19}$. Since this publication, the role of adequate staging surgery for early stage patients and the introduction of NACT for advanced stage patients have been put forward as important factors for prolonged $\mathrm{OS}^{5,32}$. Therefore, we analysed whether long-term survival has indeed improved for both earlyand advanced-stage patients with respect to these changes in treatment.

\section{METHODS}

Patients were selected from the Netherlands Cancer Registry (NCR), which is a populationbased registry with coverage of all newly diagnosed malignancies in the Netherlands since 1989. Dedicated registration clerks routinely extract patient information from medical records within the hospitals. Information on vital status and date of death were obtained from the municipal demography registries ${ }^{33}$. 


\section{Study population}

All consecutive patients diagnosed with EOC, including peritoneal and fallopian tube carcinoma (International Classification of Diseases for Oncology (ICD-O)-O codes C48.1, C48.2, C56.9 and C57.0), in the Netherlands between 1989 and 2014 were selected from the NCR ${ }^{34}$. Trends in therapy and survival were studied separately for early (International Federation of Gynaecologists and Obstetricians (FIGO) IA-IIA) and advanced stage patients (FIGO IIB-IV). FIGO stage 2009 was derived from the tumour-nodal-metastasis (TNM) staging system and based on postoperative findings $\mathrm{s}^{35}$. If patients did not receive surgery or when patients underwent NACT-IDS, clinical tumour stage was used to avoid down staging. Debulking surgery is registered nationwide from 2004, and outcome of surgery was defined as optimal if macroscopic residual lesions were smaller than one centimetre in maximal diameter. In 2010, complete debulking surgery was implemented in the NCR defined as no macroscopic residual disease.

\section{Statistical analysis}

Patients were distributed among period groups according to their date of diagnosis to analyse differences over time for the following time periods; 1989-1993, 1994-1998, 19992003, 2004-2008 and 2009-2014. Trends in therapy were analysed using the CochraneArmitage test for trends, and patients were divided in two age groups (<65 years at diagnosis and $\geq 65$ years). OS was defined as the date of diagnosis until death or last followup date for patients who were still alive (1 February 2017) and was analysed by KaplanMeier survival curves and multivariable Cox regression models. A separate analysis was performed on the Eindhoven Cancer Registry data to adjust our models for comorbidity, which is solely collected in this region of the Netherlands ${ }^{36}$. Besides OS, relative survival analysis was conducted using the Pohar-Perme estimator. Since age influences the cancerspecific hazard, this method accounts for this heterogeneity by age-standardisation ${ }^{37}$. Furthermore, multivariable relative survival analysis was calculated using Poisson regression modelling. A $P$-value<0.05 was considered statistically significant. Statistical analyses were performed using STATA/SE, version 14.1 (Stata Corp. College Station, Texas, USA).

\section{RESULTS}

Between 1989-2014, 32,540 patients were diagnosed with EOC in the Netherlands. The mean age at diagnosis increased from 63 in 1989-1993 to 66 years in 2009-2014 $(P<0.001)$. The number of advanced stage patients increased over time from 4,049 (67\%) in 1989-1993 to 5,945 (76\%) in $2009-2014$, most strikingly due to an increase of FIGO stage IIIC (19\% in 
$1989-1993$ to $42 \%$ in 2009-2014, $P<0.001)$. The number of adenocarcinoma not otherwise specified (NOS) decreased over time, whereas the number of patients diagnosed with serous EOC increased. Since 1999, serous EOC was the most common histologic subtype (table 1).

Table 1: Characteristics of all epithelial ovarian cancer patients diagnosed in the Netherlands between 1989-2014, by period of diagnosis $(N=32,540)$

\begin{tabular}{|c|c|c|c|c|c|c|}
\hline & $\begin{array}{r}1989-1993 \\
n(\%)\end{array}$ & $\begin{array}{r}1994-1998 \\
n(\%)\end{array}$ & $\begin{array}{r}1999-2003 \\
n(\%)\end{array}$ & $\begin{array}{r}2004-2008 \\
n(\%)\end{array}$ & $\begin{array}{r}2009-2014 \\
n(\%)\end{array}$ & p-value \\
\hline Age & & & & & & $<0.001^{+}$ \\
\hline$<65$ & $3,067(50.5)$ & $3,041(47.7)$ & $2,987(49.4)$ & $3,068(49.3)$ & $3,314(42.4)$ & \\
\hline$\geq 65$ & $3,009(49.5)$ & $3,332(52.3)$ & $3,053(50.6)$ & $3,159(50.7)$ & $4,510(57.6)$ & \\
\hline Mean $\left(S^{a}\right)$ & $62.7(13.9)$ & $64.0(13.7)$ & $64.0(13.4)$ & $64.5(13.2)$ & $66.3(12.9)$ & $<0.001^{\ddagger}$ \\
\hline FIGO stage & & & & & & $<0.001^{+}$ \\
\hline$|A-| \mid A$ & $1,551(25.5)$ & $1,577(24.8)$ & $1,402(23.2)$ & $1,282(20.6)$ & $1,436(18.4)$ & \\
\hline$\| B-I I B$ & $1,889(31.1)$ & $1,308(20.5)$ & $1,004(16.6)$ & $736(11.8)$ & $918(11.7)$ & \\
\hline IIIC & 1,163 (19.2) & $1,834(28.8)$ & $2,026(33.6)$ & $2,226(35.7)$ & $3,249(41.5)$ & \\
\hline IV & $997(16.4)$ & $900(14.1)$ & $894(14.8)$ & $1,125(18.1)$ & $1,778(22.7)$ & \\
\hline Unknown & $476(7.8)$ & $754(11.8)$ & $714(11.8)$ & $858(13.8)$ & $442(5.7)$ & \\
\hline Histologic type & & & & & & $<0.001^{+}$ \\
\hline Serous & $1,616(26.6)$ & $2,000(31.4)$ & $2,332(38.6)$ & 2,918 (46.9) & $4,030(51.5)$ & \\
\hline Mucinous & $864(14.2)$ & $819(12.8)$ & $613(10.2)$ & $485(7.8)$ & $551(7.0)$ & \\
\hline Endometrioid & $560(9.2)$ & $612(9.6)$ & $588(9.7)$ & 617 (9.9) & $661(8.4)$ & \\
\hline Clear-cell & 238 (3.9) & $260(4.1)$ & $279(4.6)$ & $310(5.0)$ & $365(4.7)$ & \\
\hline Adenocarcinoma NOS ${ }^{b}$ & $2,510(41.3)$ & $2,234(35.1)$ & 1,759 (29.1) & $1,435(23.0)$ & $1,571(20.1)$ & \\
\hline Other & $288(4.8)$ & $448(7.0)$ & 469 (7.8) & $462(7.4)$ & $646(8.3)$ & \\
\hline Grade & & & & & & $<0.001^{+}$ \\
\hline I & 708 (11.6) & 704 (11.0) & $548(9.1)$ & $564(9.1)$ & 622 (7.9) & \\
\hline II & $1,301(21.4)$ & $1,293(20.3)$ & $1,165(19.3)$ & $1,013(16.3)$ & 740 (9.5) & \\
\hline III & $2,081(34.3)$ & $2,238(35.1)$ & 2,299 (38.0) & $2,245(36.0)$ & 2,619 (33.5) & \\
\hline Unknown & 1,986 (32.7) & $2,138(33.6)$ & $2,028(33.6)$ & $2,405(38.6)$ & $3,843(49.1)$ & \\
\hline Total & $6,076(18.7)$ & 6,373 (19.6) & $6,040(18.6)$ & 6,227 (19.1) & $7,824(24.0)$ & \\
\hline
\end{tabular}

a SD: standard deviation, ${ }^{b}$ Adenocarcinoma NOS: adenocarcinoma not otherwise specified, ${ }^{+}$Chi-square test, ${ }^{\ddagger}$ ANOVA test 


\section{Trends in therapy}

In early stage patients an increase in second-look surgeries was observed (1\% in 1989-1993 and $17 \%$ in 2009-2014, $P<0.001$ ). Staging procedures more often consisted of lymph node dissections (4\% in 1989-1993 and 62\% in 2009-2014, $P<0.001$ ). Furthermore, the use of adjuvant chemotherapy increased from 31\% in 1989-1993 to 46\% in 1999-2003; hereafter, it decreased to 35\% in 2009-2014 (S1). Specific subgroups of high-risk patients more often received adjuvant chemotherapy, including clear-cell histology (odds ratio (OR) 2.5, 95\% confidence interval (CI) 2.1-3.1) and grade III tumours (OR 5.5(4.6-6.6)).

The percentage of advanced stage patients receiving optimal treatment with surgery and chemotherapy increased from 55\% in 1989-1993 to 70\% in 2004-2008. Since 2008, this percentage declined to $67 \%(P=0.001)$, but this decline was absent in patients aged $>65$ years. Simultaneously, a decrease in the use of chemotherapy only was seen for all patients, from $23 \%$ in $1989-1993$ to $12 \%$ in 2004-2008 with an increase in $2009-2014$ to $15 \%$. The number of patients who received no therapy remained essentially stable over time, and the use of radiotherapy in this population was negligible (0.5\%, S2).

PDS followed by adjuvant chemotherapy was preferred as first-line treatment for the majority of patients with advanced stage EOC, but in the most recent period (2009-2014), NACT-IDS was more frequently used compared with PDS (S2). Furthermore, an increase in complete/optimal surgery was observed in the last period (75\% 2004-2008 and 82\% 20092014, $p<0.001$ ), where patients undergoing NACT-IDS had a higher probability of complete/ optimal debulking (OR 1.7(1.4-1.9)).

\section{Survival analysis}

In early stage patients, 5-year OS increased from 74\% in 1989-1993 to 79\% in 2009-2014. Long-term survival, at 10 years, increased from 62\% in 1989-1993 to 67\% in 2004-2008 (table 2). Relative survival analysis was also conducted but trends did not differ from OS analysis (S5-S6). When corrected for age, tumour stage, histologic type and differentiation grade this increase was statistically significant (hazard ratio (HR) 0.8(0.7-0.9)). Moreover, patients who underwent a lymph node dissection as a part of their surgical staging procedure experience improved survival (HR 0.70(0.63-0.78)). Also the administration of adjuvant chemotherapy in patients without lymph node dissection contributes to improved survival (HR 0.8(0.7-0.9)).

In advanced stage patients, 5-year OS increased from 16\% in 1989-1993 to 24\% in 20092014. Ten-year survival increased from $10 \%$ in $1989-1993$ to $13 \%$ in $2004-2008$. This effect persisted after adjustment for patient and tumour characteristics (HR 0.6(0.6- 
0.7)). Median OS improved from 15 months in 1989-1993 to 25 months in 2009-2014. The effects for OS were attenuated when correcting for treatment combination but remained statistically significant (HR 0.7(0.7-0.8), S3). Patients treated with surgery and chemotherapy experienced comparable trends in survival over time (HR 0.6(0.5-0.6)), but their survival was higher than the entire cohort (5-year survival rates in 2009-2014 34\% and $24 \%$ respectively). In contrast, survival rates remained similar over time for patients who did not receive this treatment combination (HR 1.0(0.9-1.0)). The trends in survival in the Eindhoven region were consistent with those in the complete dataset, and adjustment for comorbidity did not alter the results (data not shown).

Table 2: Crude observed 5- and 10-year overall survival (OS) and adjusted hazard rates (HR) for all EOC patients by period of diagnosis and stage at diagnosis $(\mathrm{N}=32,540)$

\begin{tabular}{|c|c|c|c|c|c|c|c|c|c|}
\hline & \multicolumn{3}{|c|}{ FIGO IA-IIA } & \multicolumn{3}{|c|}{ FIGO IIB-IV } & \multicolumn{3}{|c|}{ All patients combined } \\
\hline & $\begin{array}{r}5 \text {-year } \\
\text { OS }\end{array}$ & $\begin{array}{r}10 \text {-year } \\
\text { OS }\end{array}$ & $\begin{array}{r}\text { HR } \\
(95 \% \mathrm{Cl})^{+}\end{array}$ & $\begin{array}{r}5 \text {-year } \\
\text { OS }\end{array}$ & $\begin{array}{r}10 \text {-year } \\
\text { OS }\end{array}$ & $\begin{array}{r}\mathrm{HR} \\
(95 \% \mathrm{Cl})^{+}\end{array}$ & $\begin{array}{r}5 \text {-year } \\
\text { OS }\end{array}$ & $\begin{array}{r}\text { 10-year } \\
\text { OS }\end{array}$ & $\begin{array}{r}\mathrm{HR} \\
(95 \% \mathrm{Cl})^{+}\end{array}$ \\
\hline 1989-1993 & 74.4 & 62.4 & reference & 16.0 & 9.8 & reference & 31.1 & 23.5 & reference \\
\hline 1994-1998 & 75.1 & 62.7 & $\begin{array}{r}1.00 \\
(0.90-1.13)\end{array}$ & 18.1 & 9.9 & $\begin{array}{r}0.91 \\
(0.87-0.95)\end{array}$ & 31.7 & 22.7 & $\begin{array}{r}0.95 \\
(0.91-0.99)\end{array}$ \\
\hline $1999-2003$ & 75.5 & 63.2 & $\begin{array}{r}0.90 \\
(0.80-1.02)\end{array}$ & 24.7 & 13.3 & $\begin{array}{r}0.73 \\
(0.70-0.77)\end{array}$ & 35.1 & 24.2 & $\begin{array}{r}0.80 \\
(0.77-0.84)\end{array}$ \\
\hline 2004-2008 & 78.9 & 67.2 & $\begin{array}{r}0.81 \\
(0.71-0.92)\end{array}$ & 24.7 & 12.6 & $\begin{array}{r}0.69 \\
(0.66-0.73)\end{array}$ & 34.6 & 23.0 & $\begin{array}{r}0.74 \\
(0.71-0.77)\end{array}$ \\
\hline 2009-2014 & 79.1 & N.A. ${ }^{1}$ & $\begin{array}{r}0.75 \\
(0.65-0.87)\end{array}$ & 24.1 & N.A. ${ }^{1}$ & $\begin{array}{r}0.62 \\
(0.59-0.65)\end{array}$ & 33.7 & N.A. ${ }^{1}$ & $\begin{array}{r}0.65 \\
(0.62-0.68)\end{array}$ \\
\hline
\end{tabular}

${ }^{1}$ N.A.: not applicable (10 year follow-up not yet available), ${ }^{\dagger}$ Adjusted for age, stage at diagnosis, histologic type and differentiation grade

In all patients combined, short-term OS improved until 1999-2003 (five-year survival rates being 31\% in 1989-1993 and 35\% in 1999-2003). After this period, 5-year OS remained stable (35\% in 2004-2008 and 34\% in 2009-2014). OS at 10-years did not improve, and the cure rate for EOC patients was still not more than 24\% (24\% in 1989-1993 and 23\% in 2004-2008, S4). A sensitivity analysis including only patients who survived the first 5 years did not show any improvement in long-term survival over time for all patients combined (HR 1.0(0.9-1.2)). 


\section{DISCUSSION}

Despite all efforts in intensifying treatment, this study showed that overall long-term survival for patients diagnosed with EOC has not improved in the last 25 years. Patients were more often diagnosed with advanced stage disease, suggesting improved surgical staging, and more frequently received optimal treatment according to contemporary standards. This resulted in prolonged disease control, as shown by the improved shortterm survival, but not in better cure rates.

Between 1989 and 2014, an increasing number of early stage patients underwent lymph node dissection as part of their surgical staging procedure, whereas adjuvant chemotherapy was largely restricted to specific high-risk groups. Advanced stage EOC patients were increasingly treated with the combination of (debulking) surgery and chemotherapy. Furthermore, an increase in the use of chemotherapy only is seen in the last period, which could imply that these patients were up for NACT-IDS but were considered ineligible for debulking surgery. Still, $13 \%$ of patients did not receive any therapy, and this percentage is consistent over the decades.

In the last two periods, NACT-IDS became an alternative for advanced stage patients and is currently used for the majority of these patients in the Netherlands ${ }^{32}$. Some have criticised this trend and stated that the non-inferiority character of NACT-IDS is caused by poor surgical results of PDS with rather low percentages of patients with no macroscopic residual tumour after surgery ${ }^{38,39}$. In our study we showed that the rate of complete/ optimal surgery did increase over time in both the patients treated with PDS and NACT-IDS. This might be explained by a more accurate selection for patients who could be optimally debulked in the primary setting ${ }^{40,41}$. In addition, EOC care is increasingly centralised in the Netherlands, resulting in a higher percentage of surgeries performed by registered gynaecologic oncologists ${ }^{32,42,43}$.

Short- and long-term survival seem to improve over time when early and advanced stage patients are analysed separately. However, long-term survival at 10 years does not improve in a combined analysis of all patients. In addition 5-year survival rates also remain stable at 35\% after 1998 in all patients combined. The discrepancy between a combined analysis and an analysis stratified by stage can be explained by stage migration. Patients were more often diagnosed in advanced stage disease. Probably due to improved routine preoperative imaging, the introduction of diagnostic laparoscopy and improved staging procedures. Therefore initially low-stage patients, with, for example, undetected lymph node metastases, are now diagnosed as advanced stage patients. This improves outcome rates for both groups but not for all patients together. It is not possible to correct for stage 
migration in statistical analyses. So survival trends in selected patient groups, for example, only advanced stage patients, should be interpreted with caution ${ }^{44}$.

Survival rates in single- or multi-centre studies tend to be higher than those in populationbased studies. In the latter, information about therapy or stage is often lacking, but by the near completeness and high quality of the registered data in the NCR, we can provide high quality population-based research ${ }^{33}$. In this study, we showed that 5-year survival rates for advanced stage patients in the entire cohort versus those who were treated with surgery and chemotherapy differed by almost $10 \%$. And, since we have shown by stratified analysis that improvements in short-term overall survival were mainly, although not entirely, caused by treatment associated factors comparison between different types of studies is complicated.

The majority of published population-based studies report improved 5-year (relative) survival rates ${ }^{11-28}$ (S7). In combination with a decline in incidence, this often results in optimistic conclusions about mortality from ovarian cancer ${ }^{28-31}$. Other population-based studies, however, indicate levelling in 5-year survival in the early $21^{\text {st }}$ century as we found ${ }^{4,45,46}$. Moreover, with the extended follow-up available in our study, we were able to show that 10-year survival rates did not improve between 1989 and 2014 (S4). Thus, although changes in diagnosis and therapy have extended the duration of disease control, the cure rate of patients remains unchanged. Two other studies with extended follow-up until 10-year confirm our findings ${ }^{16,19}$.

Survival rates in our study are lower than most of the other population-based studies in high-income countries, and even lower than previous Dutch studies. This may be the result of different inclusion criteria. In contrast to other studies, our study is the only populationbased study that included primary peritoneal ovarian cancer patients as well (S7). This diagnosis is associated with worse prognosis because, by definition, it cannot be limited to the ovaries. Contemporary clinical trials in ovarian cancer typically include primary peritoneal cancers because they are considered as one entity, justifying our decision to include these patients in our analyses ${ }^{35,47}$.

The limitations of this study are mainly related to the lack of detailed information about chemotherapy agents and schedules. Information about surgical procedures and the result of debulking surgery was also lacking for earlier years. Furthermore, performance status and comorbidity were available for a limited number of patients only, but multivariable analyses in this subgroup did not indicate any effect of these variables on our main outcome measures. In addition, we objectified a 'shift' in histological subtype (i.e. from adenocarcinoma NOS to serous), which is probably explained by the improved classification and increase in surgical procedures. 
To truly analyse the changes in long-term OS with respect to changed treatment protocols in the most recent years, most importantly the introduction of NACT-IDS, the follow-up of this last period must be extended. However, we do not expect that these changes increase OS drastically because the use of NACT-IDS is based on non-inferiority in randomised controlled studies ${ }^{9,10}$. In addition, period analysis was not performed on this cohort because 5- and 10-year survival rates are quite stable for the past 15 years.

The population-based character and therefore inclusion of all EOC patients, including primary peritoneal and fallopian tube cancers, in our analyses provide information on the varied presentation of this patient group. The combined and stratified analysis by stage shows that optimistic trends in survival should be interpreted with caution. The lack of improvements in long-term OS urges us to put major efforts into improving cure rates for women with EOC.

\section{Acknowledgements}

The authors thank the registration team of the Netherlands Comprehensive Cancer Organisation (IKNL) for the collection of data for the Netherlands Cancer Registry.

\section{Funding}

This work was supported by Dutch Cancer Society [IKNL2014-6838]. 


\section{REFERENCES}

1. Sankaranarayanan R, Ferlay J. Worldwide burden of gynaecological cancer: The size of the problem. Best Pract Res Clin Obstet Gynaecol. 2006;20(2):207-25.

2. Sant $M$, Chirlaque Lopez MD, Agresti R, Sanchez Perez MJ, Holleczek B, BielskaLasota $M$, et al. Survival of women with cancers of breast and genital organs in europe 1999-2007: Results of the eurocare-5 study. Eur J Cancer. 2015.

3. Howlader N NA, Krapcho M, Miller D, Bishop K, Altekruse SF, Kosary CL, Yu M, Ruhl J, Tatalovich Z, Mariotto A, Lewis DR, Chen HS, Feuer EJ, Cronin KA (eds). . Seer cancer statistics review, 1975-2013, national cancer institute.

4. Chen T, Jansen L, Gondos A, Emrich K, Holleczek B, Katalinic A, et al. Survival of ovarian cancer patients in germany in the early 21st century: A period analysis by age, histology, laterality, and stage. Eur J Cancer Prev. 2013;22(1):59-67.

5. Kleppe $M$, van der Aa MA, Van Gorp T, Slangen BF, Kruitwagen RF. The impact of lymph node dissection and adjuvant chemotherapy on survival: A nationwide cohort study of patients with clinical early-stage ovarian cancer. Eur J Cancer. 2016;66:83-90.

6. Lawrie TA, Winter-Roach BA, Heus P, Kitchener HC. Adjuvant (post-surgery) chemotherapy for early stage epithelial ovarian cancer. Cochrane Database Syst Rev. 2015(12):CD004706.

7. Hoskins WJ, McGuire WP, Brady MF, Homesley HD, Creasman WT, Berman $M$, et al. The effect of diameter of largest residual disease on survival after primary cytoreductive surgery in patients with suboptimal residual epithelial ovarian carcinoma. Am J Obstet Gynecol. 1994;170(4):974-9; discussion 9-80.
8. Chang SJ, Hodeib M, Chang J, Bristow RE. Survival impact of complete cytoreduction to no gross residual disease for advancedstage ovarian cancer: A meta-analysis. Gynecol Oncol. 2013;130(3):493-8.

9. Vergote I, Trope CG, Amant F, Kristensen $\mathrm{GB}$, Ehlen $\mathrm{T}$, Johnson $\mathrm{N}$, et al. Neoadjuvant chemotherapy or primary surgery in stage iiic or iv ovarian cancer. N Engl J Med. 2010;363(10):943-53.

10. Kehoe S, Hook J, Nankivell M, Jayson GC, Kitchener H, Lopes T, et al. Primary chemotherapy versus primary surgery for newly diagnosed advanced ovarian cancer (chorus): An open-label, randomised, controlled, non-inferiority trial. Lancet. 2015;386(9990):249-57.

11. Gondos A, Bray F, Hakulinen T, Brenner H, Group ESW. Trends in cancer survival in 11 european populations from 1990 to 2009: A model-based analysis. Ann Oncol. 2009;20(3):564-73.

12. Chirlaque MD, Uhry Z, Salmeron D, SanchezZapata MI, Zannoni GF, Navarro C, et al. Trends in net survival from ovarian cancer in six european latin countries: Results from the sudcan population-based study. Eur J Cancer Prev. 2017;26 Trends in cancer net survival in six European Latin Countries: the SUDCAN study:S107-S13.

13. Oberaigner $\mathrm{W}$, Minicozzi $\mathrm{P}$, Bielska-Lasota $M$, Allemani $C$, de Angelis $R$, Mangone $L$, et al. Survival for ovarian cancer in europe: The across-country variation did not shrink in the past decade. Acta Oncol. 2012;51(4):441-53.

14. Klint A, Tryggvadottir L, Bray F, Gislum M, Hakulinen T, Storm HH, et al. Trends in the survival of patients diagnosed with cancer in female genital organs in the nordic countries 1964-2003 followed up to the end of 2006. Acta Oncol. 2010;49(5):632-43. 
15. Hamidou Z, Causeret S, Dabakuyo TS, Gentil J, Arnould L, Roignot P, et al. Populationbased study of ovarian cancer in cote d'or: Prognostic factors and trends in relative survival rates over the last 20 years. BMC Cancer. 2010;10:622.

16. Tretarre B, Molinie F, Woronoff AS, Bossard $N$, Bessaoud F, Marrer E, et al. Ovarian cancer in france: Trends in incidence, mortality and survival, 1980-2012. Gynecol Oncol. 2015;139(2):324-9.

17. Brenner $\mathrm{H}$, Stegmaier $\mathrm{C}$, Ziegler $\mathrm{H}$. Trends in survival of patients with ovarian cancer in saarland, germany, 1976-1995. J Cancer Res Clin Oncol. 1999;125(2):109-13.

18. Doufekas K, Olaitan A. Clinical epidemiology of epithelial ovarian cancer in the uk. Int J Womens Health. 2014;6:537-45.

19. van Altena AM, Karim-Kos HE, de Vries E, Kruitwagen RF, Massuger LF, Kiemeney LA. Trends in therapy and survival of advanced stage epithelial ovarian cancer patients in the netherlands. Gynecol Oncol. 2012;125(3):649-54.

20. Ojamaa K, Veerus $P$, Baburin A, Everaus $\mathrm{H}$, Innos $\mathrm{K}$. Time trends in ovarian cancer survival in estonia by age and stage. Int J Gynecol Cancer. 2017;27(1):44-9.

21. Laurvick CL, Semmens JB, Holman CD, Leung YC. Ovarian cancer in western australia (1982-98): Incidence, mortality and survival. Aust N Z J Public Health. 2003;27(6):588-95.

22. Tracey EA, Roder DM, Francis J, Zorbas HM, Hacker NF, Bishop JF. Reasons for improved survival from ovarian cancer in new south wales, australia, between 1980 and 2003: Implications for cancer control. Int J Gynecol Cancer. 2009;19(4):591-9.

23. Barnholtz-Sloan JS, Schwartz AG, Qureshi F, Jacques S, Malone J, Munkarah AR. Ovarian cancer: Changes in patterns at diagnosis and relative survival over the last three decades. Am J Obstet Gynecol. 2003;189(4):1120-7.
24. Chan JK, Cheung MK, Husain A, Teng NN, West $D$, Whittemore AS, et al. Patterns and progress in ovarian cancer over 14 years. Obstet Gynecol. 2006;108(3 Pt 1):521-8.

25. Akhtar-Danesh N, Elit L, Lytwyn A. Temporal trends in the relative survival among patients diagnosed with ovarian cancer in canada 1992-2005: A population-based study. Gynecol Oncol. 2011;123(2):192-5.

26. Or Knudsen A, Schledermann D, Nyvang GB, Mogensen O, Herrstedt J, Academy of Geriatric Cancer R. Trends in gynecologic cancer among elderly women in denmark, 1980-2012. Acta Oncol. 2016;55 Suppl 1:65-73.

27. Wong KH, Mang OW, Au KH, Law SC. Incidence, mortality, and survival trends of ovarian cancer in hong kong, 1997 to 2006: A population-based study. Hong Kong Med J. 2012;18(6):466-74.

28. Karim-Kos HE, Kiemeney LA, Louwman MW, Coebergh JW, de Vries E. Progress against cancer in the netherlands since the late 1980s: An epidemiological evaluation. Int J Cancer. 2012;130(12):2981-9.

29. Webb PM, Green AC, Jordan SJ. Trends in hormone use and ovarian cancer incidence in us white and australian women: Implications for the future. Cancer Causes Control. 2017;28(5):365-70.

30. Collaborative Group On Epidemiological Studies Of Ovarian C, Beral V, Gaitskell K, Hermon C, Moser K, Reeves G, et al. Menopausal hormone use and ovarian cancer risk: Individual participant metaanalysis of 52 epidemiological studies. Lancet. 2015;385(9980):1835-42.

31. Collaborative Group on Epidemiological Studies of Ovarian C, Beral V, Doll R, Hermon C, Peto R, Reeves G. Ovarian cancer and oral contraceptives: Collaborative reanalysis of data from 45 epidemiological studies including 23,257 women with ovarian cancer and 87,303 controls. Lancet. 2008;371(9609):303-14. 
32. Eggink FA, Mom CH, Kruitwagen RF, Reyners AK, Van Driel WJ, Massuger LF, et al. Improved outcomes due to changes in organization of care for patients with ovarian cancer in the netherlands. Gynecologic Oncology. 2016;141(3):524-30.

33. van der Sanden GA, Coebergh JW, Schouten LJ, Visser O, van Leeuwen FE. Cancer incidence in the netherlands in 1989 and 1990: First results of the nationwide netherlands cancer registry. Coordinating committee for regional cancer registries. Eur J Cancer. 1995;31A(11):1822-9.

34. Fritz AG. International classification of diseases for oncology : Icd-o. 3rd ed. Geneva: World Health Organization; 2000. vii, 240 p. p.

35. Sobin LH, Gospodarowicz MK, Wittekind C, International Union against Cancer. Tnm classification of malignant tumours. 7th ed. Chichester, West Sussex, UK ; Hoboken, NJ: Wiley-Blackwell; 2010. xx, 309 p. p.

36. Janssen-Heijnen ML, Houterman $S$, Lemmens VE, Louwman MW, Maas HA, Coebergh JW. Prognostic impact of increasing age and co-morbidity in cancer patients: A population-based approach. Crit Rev Oncol Hematol. 2005;55(3):231-40.

37. Pohar Perme M, Esteve J, Rachet B. Analysing population-based cancer survival - settling the controversies. BMC Cancer. 2016;16(1):933.

38. Meyer LA, Cronin AM, Sun CC, Bixel K, Bookman MA, Cristea MC, et al. Use and effectiveness of neoadjuvant chemotherapy for treatment of ovarian cancer. J Clin Oncol. 2016.

39. Chi DS, Bristow RE, Armstrong DK, Karlan BY. Is the easier way ever the better way? I Clin Oncol. 2011;29(31):4073-5.

40. Rosen B, Laframboise S, Ferguson S, Dodge J, Bernardini M, Murphy J, et al. The impacts of neoadjuvant chemotherapy and of debulking surgery on survival from advanced ovarian cancer. Gynecol Oncol. 2014;134(3):462-7.
41. Markauskas A, Mogensen O, dePont Christensen R, Jensen PT. Primary surgery or interval debulking for advanced epithelial ovarian cancer: Does it matter? Int J Gynecol Cancer. 2014;24(8):1420-8.

42. Vernooij F, Heintz P, Witteveen E, van der Graaf $Y$. The outcomes of ovarian cancer treatment are better when provided by gynecologic oncologists and in specialized hospitals: A systematic review. Gynecol Oncol. 2007;105(3):801-12.

43. Dahm-Kahler P, Palmqvist C, Staf C, Holmberg E, Johannesson L. Centralized primary care of advanced ovarian cancer improves complete cytoreduction and survival - a population-based cohort study. Gynecol Oncol. 2016.

44. Feinstein AR, Sosin DM, Wells CK. The will rogers phenomenon. Stage migration and new diagnostic techniques as a source of misleading statistics for survival in cancer. $\mathrm{N}$ Engl J Med. 1985;312(25):1604-8.

45. Coleman MP, Forman D, Bryant H, Butler J, Rachet B, Maringe $C$, et al. Cancer survival in australia, canada, denmark, norway, sweden, and the uk, 1995-2007 (the international cancer benchmarking partnership): An analysis of populationbased cancer registry data. Lancet. 2011;377(9760):127-38.

46. Grann AF, Norgaard M, Blaakaer J, SogaardAndersen E, Jacobsen JB. Survival of patients with ovarian cancer in central and northern denmark, 1998-2009. Clin Epidemiol. 2011;3 Suppl 1:59-64.

47. Sobin LH, Compton CC. Tnm seventh edition: What's new, what's changed: Communication from the international union against cancer and the american joint committee on cancer. Cancer. 2010;116(22):5336-9. 


\section{SUPPLEMENTARY MATERIAL}

S1: Treatment of early stage EOC patients diagnosed in the Netherlands between 1989-2014, by period of diagnosis $(N=7,248)$

\begin{tabular}{|c|c|c|c|c|c|c|}
\hline & $\begin{array}{r}1989-1993 \\
n(\%)\end{array}$ & $\begin{array}{r}1994-1998 \\
n(\%)\end{array}$ & $\begin{array}{r}1999-2003 \\
n(\%)\end{array}$ & $\begin{array}{r}2004-2008 \\
n(\%)\end{array}$ & $\begin{array}{r}2009-2014 \\
n(\%)\end{array}$ & $p$-value ${ }^{+}$ \\
\hline Surgery + chemotherapy & 487 (31.4) & $601(38.1)$ & $643(45.9)$ & $520(40.6)$ & $506(35.3)$ & 0.008 \\
\hline$<65$ & $343(34.0)$ & $434(41.4)$ & $449(49.0)$ & $361(41.2)$ & $317(35.3)$ & 0.485 \\
\hline$\geq 65$ & $144(26.6)$ & $167(31.6)$ & $194(40.0)$ & 159 (39.1) & $189(35.1)$ & $<0.001$ \\
\hline Surgery only & $1,036(66.8)$ & $951(60.3)$ & $725(51.7)$ & $750(58.5)$ & $904(63.0)$ & 0.012 \\
\hline$<65$ & $664(65.8)$ & $611(58.2)$ & $462(50.4)$ & $513(58.6)$ & $578(64.4)$ & 0.468 \\
\hline$\geq 65$ & $372(68.6)$ & $340(64.4)$ & $263(54.2)$ & $237(58.4)$ & $326(60.6)$ & 0.001 \\
\hline Chemotherapy only & $14(0.9)$ & $9(0.6)$ & $9(0.6)$ & $3(0.2)$ & $2(0.1)$ & 0.002 \\
\hline$<65$ & $2(0.2)$ & $1(0.1)$ & $2(0.2)$ & $1(0.1)$ & $1(0.1)$ & 0.705 \\
\hline$\geq 65$ & $12(2.2)$ & $8(0.5)$ & $7(1.5)$ & $2(0.5)$ & $1(0.2)$ & $<0.001$ \\
\hline No therapy & $14(0.9)$ & $16(1.0)$ & $25(1.8)$ & $9(0.7)$ & $24(1.6)$ & 0.146 \\
\hline$<65$ & $0(0.0)$ & $3(0.3)$ & $4(0.4)$ & $1(0.1)$ & $2(0.2)$ & 0.527 \\
\hline$\geq 65$ & $14(2.6)$ & $13(2.5)$ & $21(4.3)$ & $8(2.0)$ & $22(4.1)$ & 0.232 \\
\hline Lymph node dissection* & $58(3.8)$ & 293 (18.9) & $479(35.0)$ & $697(54.9)$ & $872(61.8)$ & $<0.001$ \\
\hline$<65$ & $42(4.2)$ & 229 (21.9) & $360(39.5)$ & $542(62.0)$ & $617(68.9)$ & $<0.001$ \\
\hline$\geq 65$ & $16(3.1)$ & $64(12.6)$ & $119(26.0)$ & $155(39.1)$ & $255(49.5)$ & $<0.001$ \\
\hline Second look surgery * & $13(0.9)$ & $64(4.1)$ & $110(8.0)$ & $207(16.3)$ & $244(17.3)$ & $<0.001$ \\
\hline$<65$ & $10(1.0)$ & $57(5.5)$ & $91(10.0)$ & $174(19.9)$ & $192(21.5)$ & $<0.001$ \\
\hline$\geq 65$ & $3(0.6)$ & $7(1.4)$ & $19(4.2)$ & $33(8.3)$ & $52(10.1)$ & $<0.001$ \\
\hline Total & 1,551 & 1,577 & 1,402 & 1,282 & 1,436 & \\
\hline
\end{tabular}

${ }^{*}$ As part of surgical treatment, with or without adjuvant chemotherapy, ${ }^{\dagger}$ Cochrane-Armitage trend test 
S2: Treatment of advanced stage EOC patients in the Netherlands between 1989 and 2014, by period of diagnosis and age at diagnosis $(N=22,047)$

\begin{tabular}{|c|c|c|c|c|c|c|}
\hline & $\begin{array}{r}1989-1993 \\
\text { n (\%) }\end{array}$ & $\begin{array}{r}1994-1998 \\
n(\%)\end{array}$ & $\begin{array}{r}1999-2003 \\
n(\%)\end{array}$ & $\begin{array}{r}2004-2008 \\
n(\%)\end{array}$ & $\begin{array}{r}2009-2014 \\
n(\%)\end{array}$ & p-value ${ }^{+}$ \\
\hline Surgery + chemotherapy & $2,205(54.5)$ & 2,384 (59.0) & 2,655 (67.7) & $2,864(70.1)$ & $3,990(67.1)$ & $<0.001$ \\
\hline$<65$ & $1,344(71.0)$ & $1,423(79.7)$ & $1,591(85.2)$ & $1,667(86.8)$ & 1,952 (84.3) & $<0.001$ \\
\hline$\geq 65$ & $861(40.0)$ & $961(42.6)$ & $1,064(51.7)$ & $1,197(55.3)$ & $2,038(56.2)$ & $<0.001$ \\
\hline Surgery only & $386(9.5)$ & $455(11.3)$ & $343(8.8)$ & $234(5.7)$ & $211(3.6)$ & $<0.001$ \\
\hline$<65$ & $119(6.3)$ & $101(5.6)$ & $85(4.6)$ & $67(3.5)$ & $57(2.5)$ & $<0.001$ \\
\hline$\geq 65$ & $267(12.4)$ & $354(15.7)$ & $258(12.5)$ & $167(7.7)$ & $154(4.2)$ & $<0.001$ \\
\hline Chemotherapy only & $923(22.8)$ & $663(16.4)$ & $480(12.2)$ & $475(11.6)$ & $900(15.1)$ & $<0.001$ \\
\hline$<65$ & $332(17.6)$ & $198(11.1)$ & $133(7.1)$ & $133(6.9)$ & $221(9.5)$ & $<0.001$ \\
\hline$\geq 65$ & $591(27.4)$ & $465(20.6)$ & 347 (16.9) & $342(15.8)$ & $679(18.7)$ & $<0.001$ \\
\hline Radiotherapy & $49(1.2)$ & $17(0.4)$ & $13(0.3)$ & $16(0.4)$ & $15(0.3)$ & $<0.001$ \\
\hline$<65$ & $31(1.6)$ & $9(0.5)$ & $8(0.4)$ & $9(0.5)$ & $4(0.2)$ & $<0.001$ \\
\hline$\geq 65$ & $18(0.8)$ & $8(0.4)$ & $5(0.3)$ & $7(0.3)$ & $11(0.3)$ & 0.014 \\
\hline No therapy & $486(12.0)$ & $523(12.9)$ & $433(11.0)$ & $498(12.2)$ & 829 (13.9) & 0.013 \\
\hline$<65$ & $67(3.5)$ & $55(3.1)$ & $50(2.7)$ & $45(2.3)$ & $81(3.5)$ & 0.630 \\
\hline$\geq 65$ & $419(19.4)$ & $468(20.7)$ & $383(18.6)$ & 453 (20.9) & $748(20.6)$ & 0.307 \\
\hline \multicolumn{7}{|l|}{ Timing chemotherapy } \\
\hline $\mathrm{PDS}^{\mathrm{a}}$ & N.A. ${ }^{*}$ & N.A.* & N.A.* & $1,789(65.2)$ & $1,576(40.0)$ & $<0.001$ \\
\hline NACT-IDS ${ }^{b}$ & N.A. ${ }^{*}$ & N.A.* & N.A. ${ }^{*}$ & 767 (27.9) & $2,250(57.2)$ & $<0.001$ \\
\hline PDS \& NACT-IDS & N.A. ${ }^{*}$ & N.A.* & N.A.* & $188(6.9)$ & $109(2.8)$ & $<0.001$ \\
\hline Total & 4,049 & 4,042 & 3,924 & 4,087 & 5,945 & \\
\hline
\end{tabular}

N.A. Not applicable (debulking surgery was not registered nationwide before 2004)

a PDS: primary debulking surgery, ${ }^{b}$ NACT-IDS: neoadjuvant chemotherapy and interval debulking surgery

${ }^{+}$Cochrane-Armitage trend test 
S3: Crude observed 5-year overall survival (OS) and adjusted hazard rates (HR) for advanced stage EOC patients diagnosed in the Netherlands between 1989 and 2014, by period of diagnosis and treatment protocol $(N=22,047)$

\begin{tabular}{|c|c|c|c|c|c|c|c|c|}
\hline & Model I & & Model II & & lodel III & & & \\
\hline & $\begin{array}{r}5 \text {-year } \\
\text { OS }^{\text {a }}\end{array}$ & $\begin{array}{r}H R \\
(95 \% \mathrm{Cl})^{+, a}\end{array}$ & $\begin{array}{r}5 \text {-year } \\
\text { OS }^{\text {b }}\end{array}$ & $\begin{array}{r}H R \\
(95 \% \mathrm{Cl})^{+, b} \\
\end{array}$ & $\begin{array}{r}5 \text {-year } \\
\text { OS }^{\text {b }}\end{array}$ & $\begin{array}{r}\text { HR } \\
(95 \% \mathrm{Cl})^{+, b}\end{array}$ & $\begin{array}{r}5 \text {-year } \\
\text { OS }\end{array}$ & $\begin{array}{r}H R \\
(95 \% \mathrm{Cl})^{+,}\end{array}$ \\
\hline 1989-1993 & 16.0 & reference & 24.2 & reference & 24.2 & reference & 6.2 & reference \\
\hline 1994-1998 & 18.1 & $\begin{array}{r}0.91 \\
(0.87-0.95)\end{array}$ & 27.3 & $\begin{array}{r}0.98 \\
(0.93-1.02)\end{array}$ & 27.3 & $\begin{array}{r}0.85 \\
(0.79-0.90)\end{array}$ & 4.9 & $\begin{array}{r}1.09 \\
(1.02-1.17)\end{array}$ \\
\hline 1999-2003 & 24.7 & $\begin{array}{r}0.73 \\
(0.70-0.77)\end{array}$ & 33.6 & $\begin{array}{r}0.84 \\
(0.80-0.88)\end{array}$ & 33.6 & $\begin{array}{r}0.68 \\
(0.64-0.72)\end{array}$ & 6.2 & $\begin{array}{r}1.03 \\
(0.96-1.11)\end{array}$ \\
\hline 2004-2008 & 24.7 & $\begin{array}{r}0.69 \\
(0.66-0.73)\end{array}$ & 33.0 & $\begin{array}{r}0.82 \\
(0.78-0.86)\end{array}$ & 33.0 & $\begin{array}{r}0.64 \\
(0.60-0.68)\end{array}$ & 5.2 & $\begin{array}{r}1.06 \\
(0.98-1.14)\end{array}$ \\
\hline 2009-2014 & 24.1 & $\begin{array}{r}0.62 \\
(0.59-0.65)\end{array}$ & 33.8 & $\begin{array}{r}0.74 \\
(0.71-0.78)\end{array}$ & 33.8 & $\begin{array}{r}0.57 \\
(0.53-0.61)\end{array}$ & 4.4 & $\begin{array}{r}0.96 \\
(0.89-1.03)\end{array}$ \\
\hline
\end{tabular}

${ }^{a}$ All advanced stage patients ${ }^{b}$ Patients who underwent surgery + chemotherapy ${ }^{c}$ Patients who did not underwent surgery + chemotherapy

${ }^{+}$Adjusted for age, stage at diagnosis, histologic type and differentiation grade

Model I: not adjusted for treatment, Model II: adjusted for surgery + chemotherapy, Model III: stratified by surgery + chemotherapy

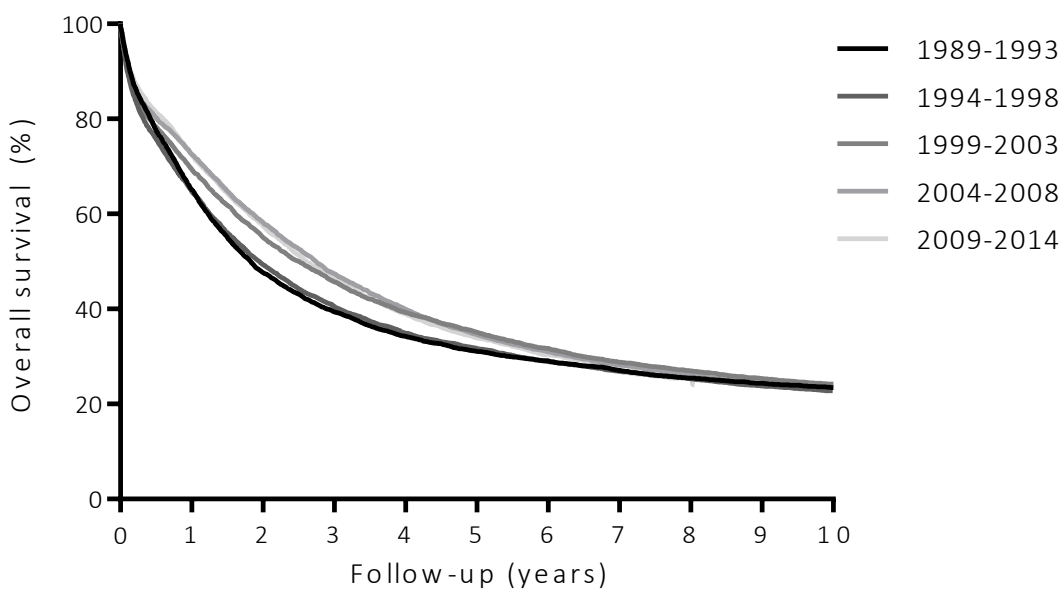

S4: Crude observed overall survival for all EOC patients diagnosed in the Netherlands between 1989 and 2014 , by period of diagnosis $(N=32,540)$ 
S5: Relative survival rates and adjusted relative excess risk (RER) of dying for all EOC patients diagnosed in the Netherlands between 1989 and 2014, by period of diagnosis and stage at diagnosis $(N=32,540)$

\begin{tabular}{|c|c|c|c|c|c|c|c|c|c|}
\hline & \multicolumn{3}{|c|}{ FIGO IA-IIA } & \multicolumn{3}{|c|}{ FIGO IIB-IV } & \multicolumn{3}{|c|}{ All patients combined } \\
\hline & $\begin{array}{r}5 \text {-year } \\
\text { RS } \\
\end{array}$ & $\begin{array}{r}\text { 10-year } \\
\text { RS }\end{array}$ & $\begin{array}{r}\text { RER } \\
(95 \% \mathrm{Cl})^{+} \\
\end{array}$ & $\begin{array}{r}\text { 5-year } \\
\text { RS } \\
\end{array}$ & $\begin{array}{r}10-y e a r \\
\text { RS }\end{array}$ & $\begin{array}{r}\text { RER } \\
(95 \% \mathrm{Cl})^{+} \\
\end{array}$ & $\begin{array}{r}\text { 5-year } \\
\text { RS } \\
\end{array}$ & $\begin{array}{r}\text { 10-year } \\
\text { RS }\end{array}$ & $\begin{array}{r}\text { RER } \\
(95 \% \mathrm{Cl})^{+} \\
\end{array}$ \\
\hline 1989-1993 & 80.8 & 77.1 & reference & 17.6 & 11.8 & reference & 34.0 & 28.8 & reference \\
\hline 1994-1998 & 80.9 & 78.4 & $\begin{array}{r}1.01 \\
(0.86-1.18)\end{array}$ & 20.0 & 12.1 & $\begin{array}{r}0.91 \\
(0.86-0.95)\end{array}$ & 34.5 & 28.3 & $\begin{array}{r}0.95 \\
(0.91-0.99)\end{array}$ \\
\hline 1999-2003 & 81.5 & 73.9 & $\begin{array}{r}0.87 \\
(0.74-1.04)\end{array}$ & 26.7 & 15.8 & $\begin{array}{r}0.72 \\
(0.69-0.76)\end{array}$ & 38.1 & 28.5 & $\begin{array}{r}0.79 \\
(0.76-0.83)\end{array}$ \\
\hline 2004-2008 & 83.9 & 77.7 & $\begin{array}{r}0.77 \\
(0.64-0.93)\end{array}$ & 26.8 & 15.3 & $\begin{array}{r}0.68 \\
(0.65-0.72)\end{array}$ & 37.2 & 27.2 & $\begin{array}{r}0.73 \\
(0.70-0.77)\end{array}$ \\
\hline $2009-2014$ & 84.3 & N.A. ${ }^{1}$ & $\begin{array}{r}0.73 \\
(0.60-0.89)\end{array}$ & 26.7 & N.A. ${ }^{1}$ & $\begin{array}{r}0.60 \\
(0.57-0.63)\end{array}$ & 36.6 & N.A. ${ }^{1}$ & $\begin{array}{r}0.63 \\
(0.61-0.67)\end{array}$ \\
\hline
\end{tabular}

${ }^{1}$ N.A.: not applicable, ${ }^{\dagger}$ Adjusted for age, stage at diagnosis, histologic type and differentiation grade

S6: Relative survival and adjusted RER of dying for advanced stage EOC patients diagnosed in the Netherlands between 1989 and 2014, by period of diagnosis and treatment protocol $(N=22,047)$

\begin{tabular}{|c|c|c|c|c|c|c|c|c|}
\hline & Model I & & Model II & & Model III & & & \\
\hline & $\begin{array}{r}\text { 5-year } \\
\mathrm{RS}^{\mathrm{a}} \\
\end{array}$ & $\begin{array}{r}\text { RER } \\
(95 \% \mathrm{Cl})^{+, a} \\
\end{array}$ & $\begin{array}{r}\text { 5-year } \\
\mathrm{RS}^{\mathrm{b}} \\
\end{array}$ & $\begin{array}{r}\text { RER } \\
(95 \% \mathrm{Cl})^{+, b} \\
\end{array}$ & $\begin{array}{r}\text { 5-year } \\
\mathrm{RS}^{\text {b }} \\
\end{array}$ & $\begin{array}{r}\text { RER } \\
(95 \% \mathrm{Cl})^{+, b} \\
\end{array}$ & $\begin{array}{r}\text { 5-year } \\
\text { RS }^{c} \\
\end{array}$ & $\begin{array}{r}\text { RER } \\
(95 \% \mathrm{Cl})^{+, c}\end{array}$ \\
\hline 1989-1993 & 17.6 & reference & 31.2 & reference & 31.2 & reference & 20.4 & reference \\
\hline 1994-1998 & 20.0 & $\begin{array}{r}0.91 \\
(0.86-0.95)\end{array}$ & 33.9 & $\begin{array}{r}0.99 \\
(0.94-1.03)\end{array}$ & 33.9 & $\begin{array}{r}0.85 \\
(0.79-0.90)\end{array}$ & 20.1 & $\begin{array}{r}1.12 \\
(1.04-1.20)\end{array}$ \\
\hline $1999-2003$ & 26.7 & $\begin{array}{r}0.72 \\
(0.69-0.76)\end{array}$ & 39.3 & $\begin{array}{r}0.84 \\
(0.80-0.89)\end{array}$ & 39.3 & $\begin{array}{r}0.67 \\
(0.63-0.72)\end{array}$ & 21.6 & $\begin{array}{r}1.05 \\
(0.98-1.14)\end{array}$ \\
\hline 2004-2008 & 26.8 & $\begin{array}{r}0.68 \\
(0.65-0.72)\end{array}$ & 38.7 & $\begin{array}{r}0.83 \\
(0.79-0.88)\end{array}$ & 38.7 & $\begin{array}{r}0.64 \\
(0.60-0.69)\end{array}$ & 21.1 & $\begin{array}{r}1.10 \\
(1.01-1.19)\end{array}$ \\
\hline 2009-2014 & 26.7 & $\begin{array}{r}0.60 \\
(0.57-0.63)\end{array}$ & 38.8 & $\begin{array}{r}0.74 \\
(0.71-0.78)\end{array}$ & 38.8 & $\begin{array}{r}0.56 \\
(0.53-0.60)\end{array}$ & 20.4 & $\begin{array}{r}0.97 \\
(0.90-1.05)\end{array}$ \\
\hline
\end{tabular}

${ }^{a}$ All advanced stage patients ${ }^{b}$ Patients who underwent surgery + chemotherapy ${ }^{c}$ Patients who did not underwent surgery + chemotherapy

${ }^{+}$Adjusted for age, stage at diagnosis, histologic type and differentiation grade

Model I: not adjusted for treatment, Model II: adjusted for surgery + chemotherapy, Model III: stratified by surgery

+ chemotherapy 


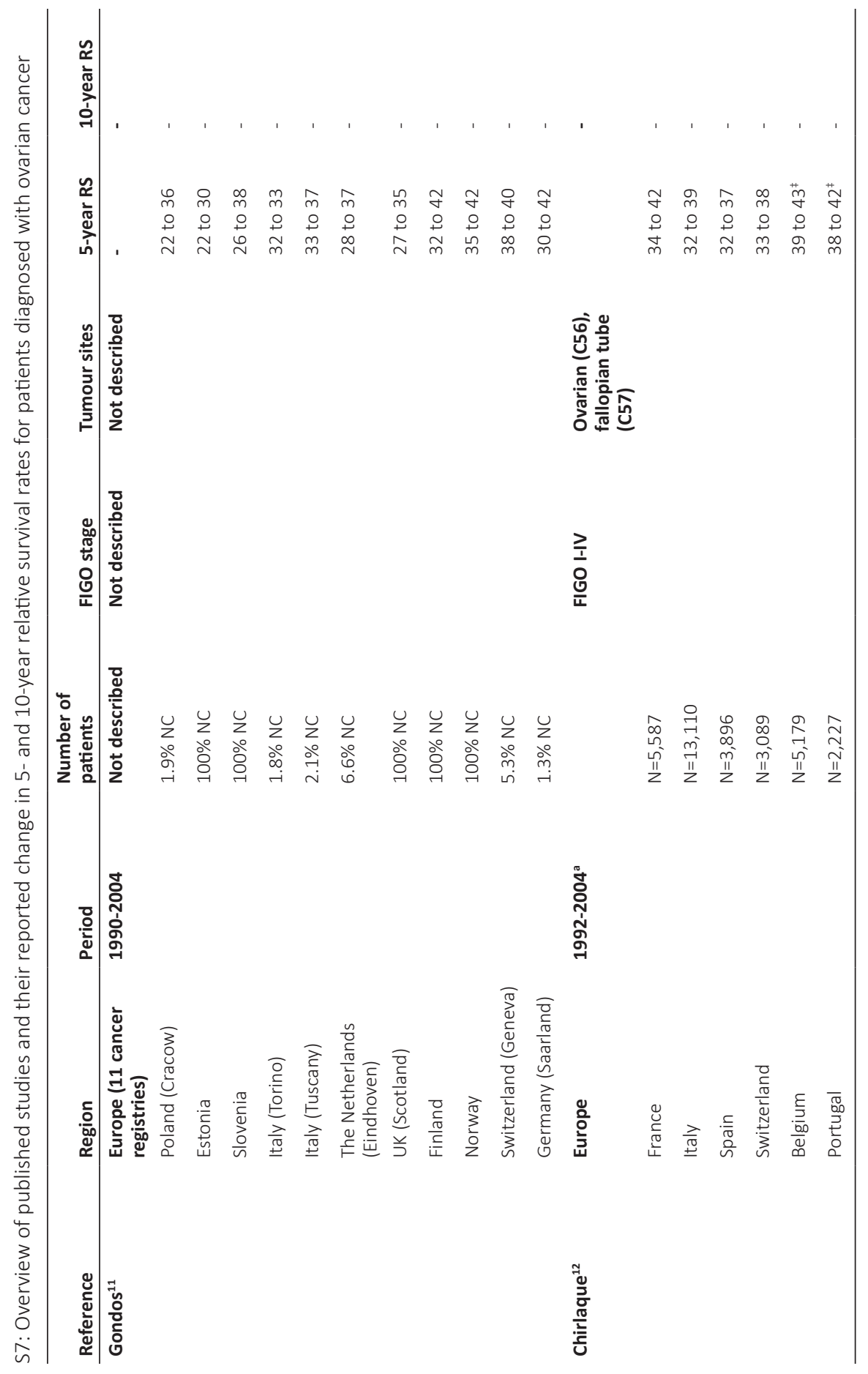




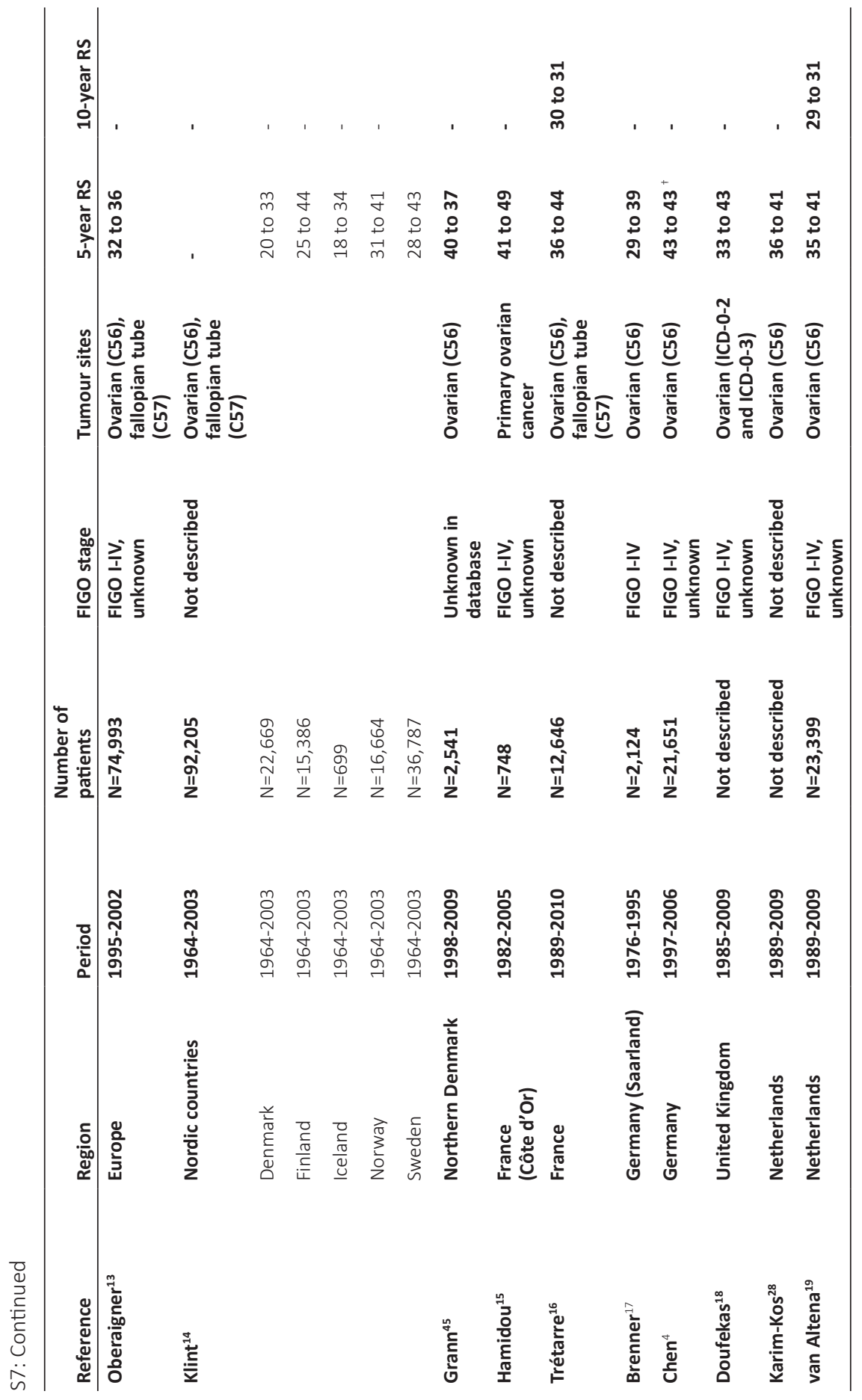




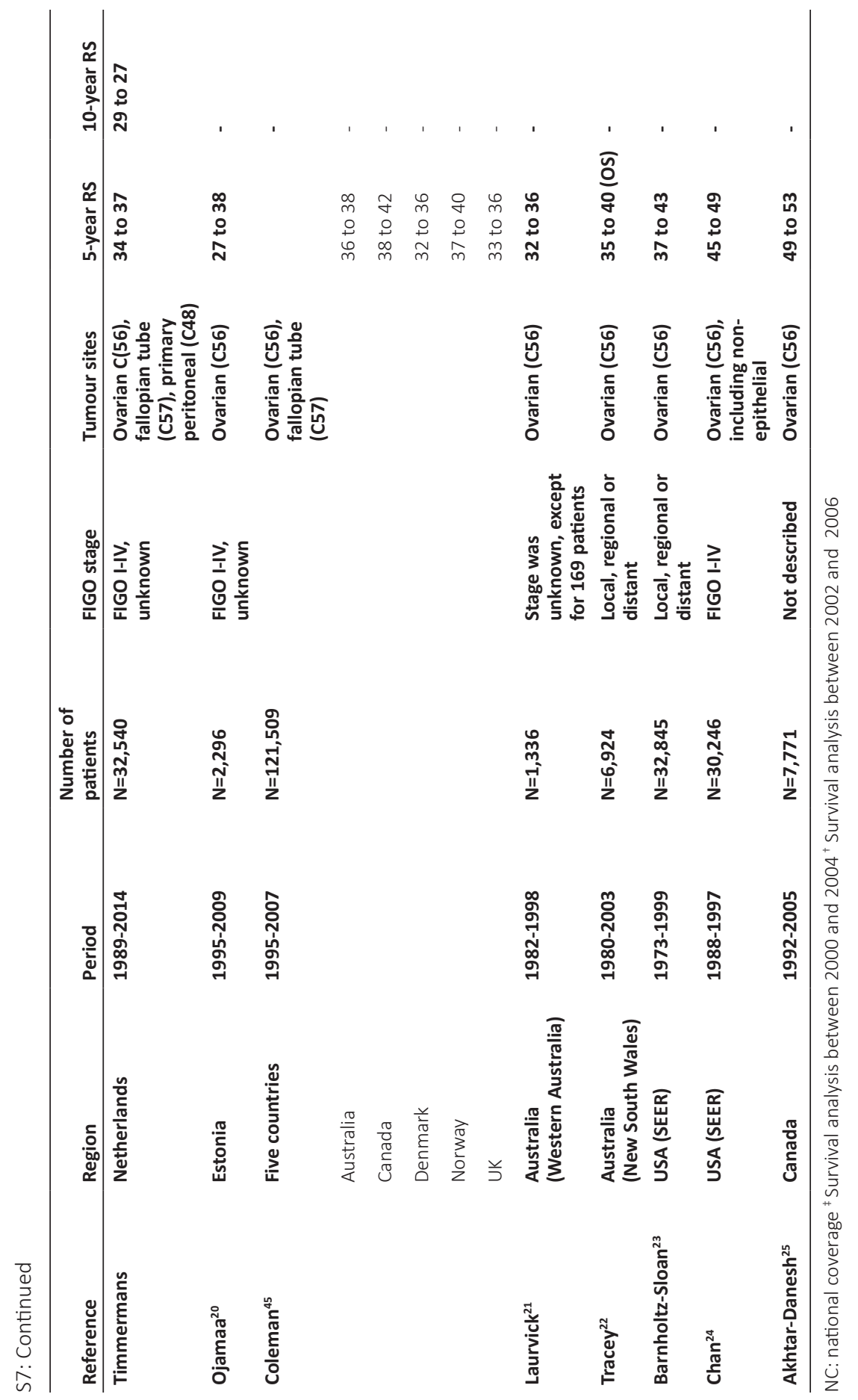






\section{3}

Centralisation of ovarian cancer in the Netherlands: hospital of diagnosis no longer determines patients' probability of undergoing surgery

M. Timmermans, M.S. Schuurman, V.K.Y. Ho, L.F. Massuger, H.W. Nijman, T. van Gorp, G.S. Sonke, R.F.P.M. Kruitwagen, M.A. van der Aa 


\section{ABSTRACT}

\section{Objective}

Surgical care for advanced stage epithelial ovarian cancer (EOC) patients has been centralised in the Netherlands since 2012. We evaluated whether the likelihood for patients to undergo surgery depends on the hospital of initial diagnosis before and after centralisation of surgical care.

\section{Methods}

Patients with EOC FIGO stage IIB-IV, diagnosed in the Netherlands between 2000 and 2015, were identified from the Netherlands Cancer Registry. Multilevel multivariate logistic regression was used to study the association between hospital of diagnosis and patients' likelihood of undergoing surgery in subsequent time periods. Furthermore, changes in overall survival were analysed by multivariable Cox regression models.

\section{Results}

15,314 EOC patients were selected from the NCR. Hospital of diagnosis was identified as a significant level for patients' likelihood of undergoing surgery in 2000-2005 (LR test $p<0.001$ ), as well as in 2006-2011 (LR test $p=0.002$ ) but not in 2012-2015 (LR test $p=0.127$ ). Patients who underwent surgery in 2012-2015 had a better survival when compared to 2006-2011 (HR 0.90(0.84-0.96)).

\section{Conclusion}

This study shows that centralisation of surgical care resolved the variation between hospitals in the probability to undergo cytoreductive surgery for patients with advanced EOC. Since centralisation was established in 2012, the decision to operate patients seems solely attributable to patient and tumour characteristics. This supports the growing evidence in favour of centralising (surgical) treatment for complex and heterogeneous diseases such as EOC. 


\section{INTRODUCTION}

Epithelial ovarian cancer (EOC) is the seventh most common cancer in women worldwide and the most lethal gynaecologic cancer ${ }^{1,2}$. Due to the non-specific symptoms of this malignancy the majority of patients are diagnosed with advanced staged disease. This results in poor prognosis with five-year survival rates of $25-35 \%^{3,4}$. The mainstay of therapeutic management consists of platinum based chemotherapy in addition to cytoreductive surgery. Patient survival depends (among others) on the ability to minimise residual disease during surgery ${ }^{5,6}$. This suggests an amendable role for cytoreductive surgery in the primary treatment for EOC.

The efforts to improve care for EOC patients should emphasise on minimising the amount of residual disease by extensive surgery. Research has shown that cytoreductive surgery performed in high-volume hospitals by experienced gynaecologic-oncologists leads to improved outcome rates ${ }^{7-15}$. In the Netherlands, EOC patients were traditionally staged and treated in all hospitals, regardless of patients- or tumour characteristics. Consequently the level of surgical expertise was suspected to differ considerably across hospitals. In the last decade, a gradual centralisation process was initiated in several stages. In the first stage, gynaecologists in smaller hospitals consulted registered gynaecological-oncologists to perform surgery together in these smaller hospitals. In 2012, a national consensus was reached to restrict the performance of surgery to hospitals which carried out a minimum of twenty cytoreductive surgeries on an annual basis. Furthermore, more emphasis was placed on regional multidisciplinary tumour board (MDT) meetings. All patients diagnosed with ovarian cancer are discussed with gynaecological-oncologists, medical oncologists, pathologists and radiotherapists, prior to treatment. Overall, these developments led to improved surgical outcomes and improved survival in the Netherlands 8,16 .

Although surgical care is increasingly centralised and outcomes improved for EOC patients, the initial diagnosis is made in virtually all Dutch hospitals. Most studies focus on the outcome rates of cytoreductive surgery and overall survival with respect to the success of centralisation. However, the diagnostic process and possible variation in treatment decisions between diagnosing hospitals is not a widely studied subject for ovarian cancer patients. In order to improve outcome rates for EOC patients, treatment decisions should be based on tumour- and patient characteristics and not be influenced by the hospital where patients are initially diagnosed. The present study examined whether the likelihood for EOC patients to undergo surgery depends on the hospital of initial diagnosis in an era of gradual centralisation of surgical care. 


\section{METHODS}

\section{Data collection}

Patients were identified from the Netherlands Cancer Registry (NCR). The NCR is a population-based registry based on notification by the automated nationwide network and registry of histo- and cytopathology in the Netherlands (PALGA) and the National Registry of Hospital Discharge Diagnosis (LMR). It covers all newly diagnosed malignancies in the Netherlands. Dedicated registration clerks routinely extract patient information from medical records within the hospitals.

The hospital and date of diagnosis is recorded for all patients in this study. In addition, hospitals and dates of provided treatments are recorded for patients from 2005 onwards. Treatment information includes the type of surgery (exploratory laparotomy, staging or cytoreductive surgery) and systemic treatment. Outcome of cytoreductive surgery was registered from 2004 onwards (optimal $(\leq 1 \mathrm{~cm})$ versus incomplete $(>1 \mathrm{~cm})$ ). Complete cytoreduction, defined as no macroscopic residual disease, is registered from 2010.

As for patient characteristics, data were obtained on patients' age at diagnosis and socioeconomic status. Information on vital status and date of death are obtained through linkage with the municipal demography registries. Regarding tumour characteristics, information is available on histological subtype according to the International Classification of Disease-Oncology (ICD-O), differentiation grade and both clinical and pathological TNM (tumour-node-metastasis) stage ${ }^{17,18}$. Staging according to the Fédération Internationale de Gynécologie et d'Obstétrique (FIGO) 2009 system was derived from the TNM.

\section{Study population}

All consecutive patients diagnosed with advanced stage EOC, including peritoneal and fallopian tube cancer (ICD-O codes C48.1, C48.2, C56.9 and C57.0), between 2000 and 2015 were selected from the NCR. Advanced stage EOC was defined as FIGO stage IIB or higher based on operative findings and final pathology. In case patients did not undergo surgery or when patients underwent interval cytoreductive surgery after neoadjuvant chemotherapy (NACT), clinical tumour stage was used to avoid down-staging. Patients with an unknown FIGO stage were included as well, but only if they were diagnosed with peritoneal EOC (C48.1 and C48.2) because TNM stage was not registered for these patients until 2010. 


\section{Hospital of diagnosis and surgery}

Diagnosis was assigned to the hospital that was visited first by each patient for her disease. If hospitals merged within one of the specific time periods, these hospitals were analysed as a single institution for that particular period. For calculating patient's probability of undergoing surgery, surgery was defined as any attempt to perform cytoreductive surgery, regardless of residual disease, timing of surgery and hospital of surgery. Thus, patients who underwent explorative surgery that did not result in tumour removal were regarded as patients who underwent surgery.

\section{Statistical analyses}

Multilevel statistical techniques have been developed to analyse data arranged in a natural hierarchy ${ }^{19,20}$. Hence, to assess whether hospital level influenced decision-making processes, multilevel logistic regression was performed, thereby adjusting for case mix factors $^{21,22}$. We included age, FIGO stage, histological type, differentiation grade and SES in the model, based on basic multivariable logistic regression models, and predicted the probability of undergoing surgery for each individual hospital expressed as an odds ratio (OR) accompanied by a $95 \%$ confidence interval (CI). The likelihood ratio test (LR test) was used to assess the influence of hospital level on the probability of undergoing surgery for the whole period. To study effects over time, a comparison was made between three time periods. The period before national consensus on centralisation took place was divided in two equal periods (2000-2005 and 2006-2011) and these were compared to the last period (2012-2015).

The impact of centralisation on overall survival was explored using multivariable Cox regression models for the three individual time periods. These periods were analysed for all patients combined and stratified by surgical treatment (yes or no). Overall survival time was defined as the date of diagnosis until death or if patients were still alive to the last followup date (1 February 2017). For all analyses a p-value <0.05 was considered statistically significant. Statistical analyses were performed using STATA/SE (version 14.1; STATA CORP., College Station, Texas, USA).

\section{RESULTS}

Between 2000 and 2015, 15,314 EOC patients were diagnosed with advanced stage disease. Mean age at diagnosis was 66.3 years (standard deviation (SD)) 12.4 years) and increased over time (from 65.1(12.5) in 2000-2005 to 67.8(12.0) in 2012-2015, p<0.001). Most patients were diagnosed with a high grade serous tumour and had FIGO stage III 
disease. The number of patients with an unknown FIGO stage decreased over time, while the number of patients with FIGO IV disease increased (table 1). A substantial number of our patients did not receive any therapy (12\%) or received single therapy only (19\%).

Table 1: Baseline characteristics of EOC patients diagnosed in the Netherlands by period of diagnosis $(n=15,314)$

\begin{tabular}{lrrrr}
\hline & $\mathbf{2 0 0 0 - 2 0 0 5} \mathbf{n}(\%)$ & $\mathbf{2 0 0 6 - 2 0 1 1} \mathbf{n}(\%)$ & $\mathbf{2 0 1 2 - 2 0 1 5} \mathbf{n}(\%)$ & p-value \\
\hline Age & & & & $<0.001^{+}$ \\
18-59 & $1,723(33.0)$ & $1,689(28.4)$ & $969(23.4)$ & \\
$60-74$ & $2,156(41.4)$ & $2,598(43.6)$ & $1,865(45.0)$ & \\
$>75$ & $1,335(25.6)$ & $1,669(28.0)$ & $1,310(31.6)$ & \\
Mean (SD) & $65.1(12.5)$ & $66.2(12.4)$ & $67.8(12.0)$ & $<0.001^{+}$ \\
FIGO stage & & & & $<0.001^{+}$ \\
IIB-IIC & $447(8.6)$ & $465(7.8)$ & $359(8.7)$ & \\
IIIA-IIIC & $3,085(59.2)$ & $3,387(56.9)$ & $2,477(59.8)$ & \\
IV & $1,163(22.3)$ & $1,515(25.4)$ & $1,303(31.4)$ & \\
Unknown & $519(9.9)$ & $589(9.9)$ & $5(0.1)$ & \\
Type of tumour & & & & \\
High grade serous & $4,044(77.6)$ & $4,782(80.3)$ & $3,356(81.0)$ & \\
Low grade serous & $143(2.7)$ & $170(2.9)$ & $121(2.9)$ & \\
Other & $1,027(19.7)$ & $1,004(16.8)$ & $667(16.1)$ & \\
Socioeconomic status & & & & \\
High & $1,562(29.9)$ & $1,776(29.8)$ & $1,262(30.4)$ & \\
Medium & $2,142(41.1)$ & $2,397(40.3)$ & $1,581(38.2)$ & \\
Low & $1,510(29.0)$ & $1,783(29.9)$ & $1,301(31.4)$ & \\
\hline Total & $\mathbf{5 , 2 1 4}$ & $\mathbf{5 , 9 5 6}$ & $\mathbf{4 , 1 4 4}$ & \\
\hline
\end{tabular}

${ }^{+}$Chi-square test, ${ }^{\ddagger}$ ANOVA test

\section{Hospital of diagnosis and hospital of surgery}

Due to merges, patients were diagnosed in 96 hospitals in 2000-2005, 92 hospitals in 20062011 and 90 hospitals in 2012-2015. Consequently, the mean annual number of diagnoses per hospital increased from 9 (interquartile range (IQR) 6-11) in 2000-2005 to 12 (IQR 7-15) in 2012-2015.

Within the study period the number of patients who underwent surgical treatment decreased from $77 \%$ in 2000-2005 to $73 \%$ in 2012-2015 ( $p<0.001$, table 2). The number of hospitals that performed cytoreductive surgery decreased from 77 in 2006-2011 to 39 
in 2012-2015 (unknown for 2000-2005 as hospital of surgery was not registered at that time). Despite of the overall decrease in surgical treatment, the mean annual number of cytoreductive surgeries per hospital increased from 9 (IQR 3-12) in 2006-2011 to 17 (IQR 5-20) in 2012-2015. More patients were referred to a specialised hospital to undergo cytoreductive surgery in the last period (35\% in 2006-2011 compared to $71 \%$ in 2012-2015, $p<0.001$ ). Furthermore, the number of hospitals that met the minimum requirement of 20 cytoreductive surgeries annually increased from 8\% in 2006-2011 to 26\% in 2012-2015. In addition, in 2015 69\% of the hospitals that performed cytoreductive surgery met this requirement.

Table 2: Hospital characterisations by period of diagnosis $(n=15,314)$

\begin{tabular}{|c|c|c|c|}
\hline & 2000-2005 n (\%) & 2006-2011 n (\%) & 2012-2015 n (\%) \\
\hline Diagnosing hospitals & 96 & 92 & 90 \\
\hline 1-10 annually & $66(68.7)$ & $46(50.0)$ & $43(47.8)$ \\
\hline$\geq 10$ annually & $28(29.2)$ & $42(45.7)$ & $39(43.3)$ \\
\hline$\geq 20$ annually & $2(2.1)$ & $4(4.3)$ & $8(8.9)$ \\
\hline Mean diagnosis annually (IQR) & $9.1(6.1-11.1)$ & $10.8(6.5-14.2)$ & $11.5(7.1-14.8)$ \\
\hline Debulking hospitals & N.A. & 77 & 39 \\
\hline 1-10 annually & N.A. & $52(67.5)$ & $18(46.2)$ \\
\hline$\geq 10$ annually & N.A. & $19(24.7)$ & $11(28.2)$ \\
\hline$\geq 20$ annually & N.A. & $6(7.8)$ & $10(25.6)$ \\
\hline Mean surgeries annually (IQR) & N.A. & $9.1(3.3-12.2)$ & $16.9(5.3-19.5)$ \\
\hline Surgical treatment & $4,022(77.1)$ & 4,622 (77.6) & $3,012(72.7)$ \\
\hline Referral for debulking surgery $^{+}$ & N.A. & $1,067(35.4)$ & $1,324(71.1)$ \\
\hline Total & 5,214 & 5,956 & 4,144 \\
\hline
\end{tabular}

+ Patients who were diagnosed in specialised centres were excluded from this analysis

The percentage of patients who underwent an incomplete cytoreduction, indicating macroscopic residual tumour of $>1$ centimetres, decreased from $23 \%$ in 2006-2011 to $13 \%$ in 2012-2015 ( $p<0.001)$. For patients treated with primary cytoreductive surgery or neoadjuvant chemotherapy these percentages decreased from $23 \%$ to $16 \%(p<0.001)$ and from $22 \%$ to $12 \%(p<0.001)$, respectively. Over the total study period, patients who were treated with primary cytoreductive surgery had a higher probability of an incomplete 
cytoreductive surgery compared to patients who received neoadjuvant chemotherapy (OR $1.37(1.23-1.52))$.

\section{Probability of undergoing surgery}

Prognostic factors for undergoing surgery are high socioeconomic status and younger age at diagnosis. Compared to those with FIGO III disease, patients with FIGO IV had a lower probability of undergoing surgery (OR 0.27(0.24-0.29)) and patients with FIGO IIB-IIC had a higher probability (OR 2.09(1.68-2.60)). Furthermore, patients with a low-grade serous tumour were more likely to undergo surgery compared to those with high-grade serous tumours (S1).

In addition to these patient-related factors, multilevel multivariate logistic regression identified the hospital of diagnosis as a significant level for patients' likelihood of undergoing surgery in 2000-2005 (LR test $p<0.001$, intra-class correlation (ICC) 6.1\%) as well as in 2006-2011 (LR test $p=0.002$, ICC 2.5\%) (figure 1a, 1b). This effect disappeared in the period 2012-2015, as no association between the hospital of initial diagnosis and probability of undergoing surgery was found in this timeframe (LR test $p=0.127, I C C 0.9 \%$, figure $1 c$ ).

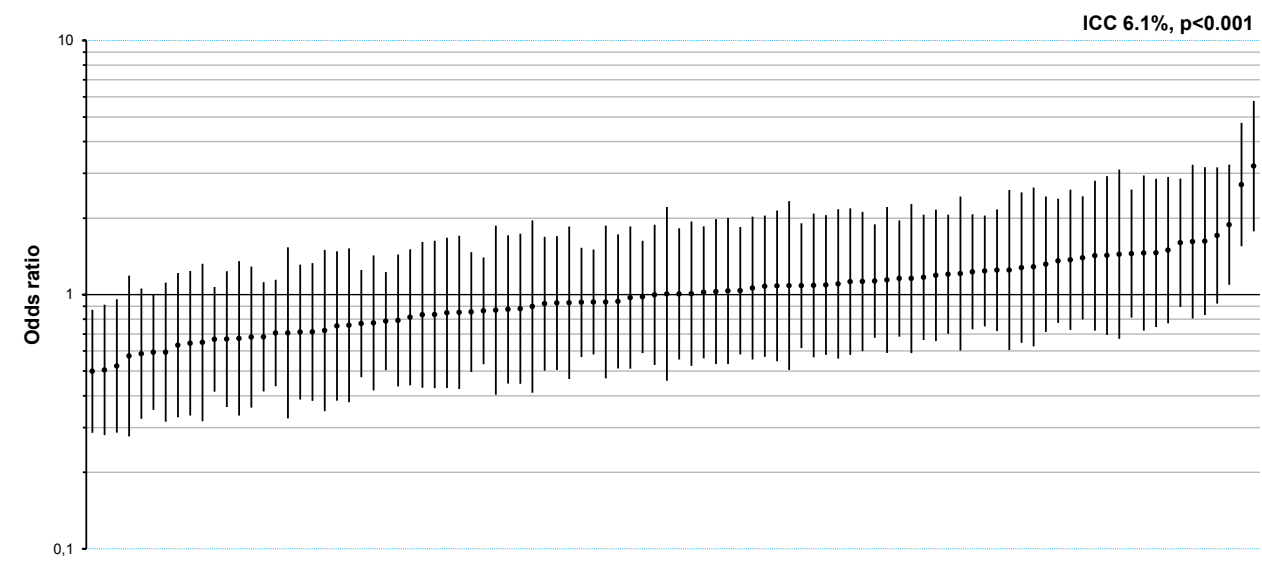

Hospital of diagnosis (2000-2005)

Figure 1a: Case-mix adjusted variation in the probability of undergoing surgery for each hospital of diagnosis in the period 2000-2005 expressed as an odds ratio and 95\% confidence interval on a log scale by a multilevel multivariate regression model. Patients diagnosed in hospitals with an odds ratio less than 1 had a lower likelihood to undergo surgery, hospitals are sorted by their adjusted OR. Adjustment was made for age, FIGO stage, histological type, differentiation grade and socioeconomic status $(n=5,214)$. 


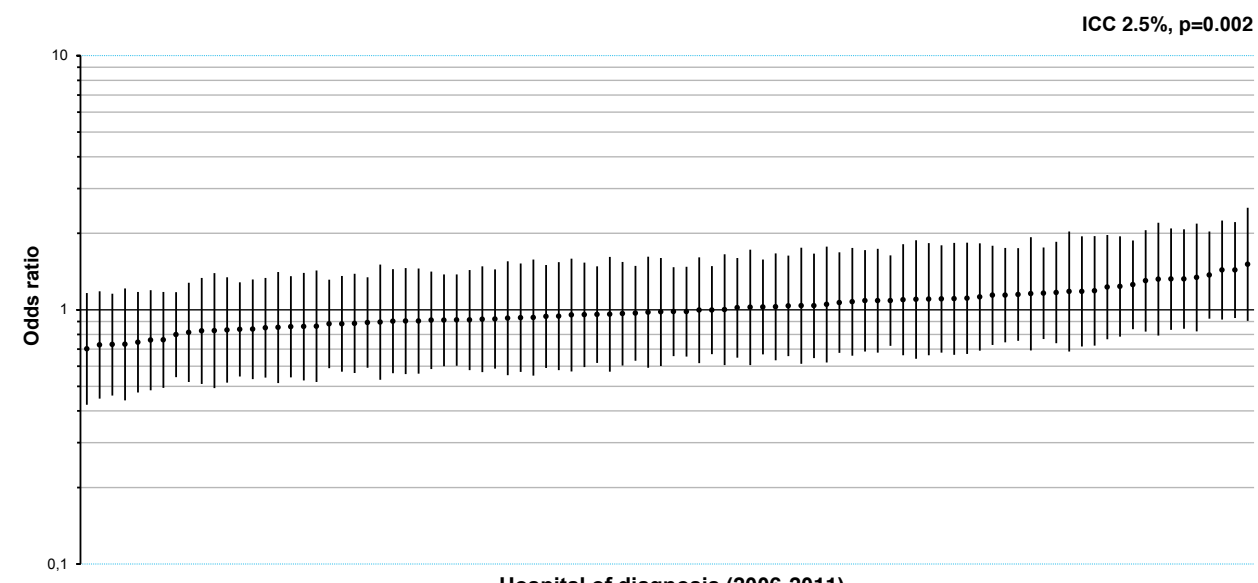

Hospital of diagnosis (2006-2011)

Figure 1b: Case-mix adjusted variation in the probability of undergoing surgery for each hospital of diagnosis in the period 2006-2011 expressed as an odds ratio and 95\% confidence interval on a log scale by a multilevel multivariate regression model. Patients diagnosed in hospitals with an odds ratio less than 1 had a lower likelihood to undergo surgery, hospitals are sorted by their adjusted OR. Adjustment was made for age, FIGO stage, histological type, differentiation grade and socioeconomic status $(n=5,956)$.

ICC $0.9 \%, p=0.127$

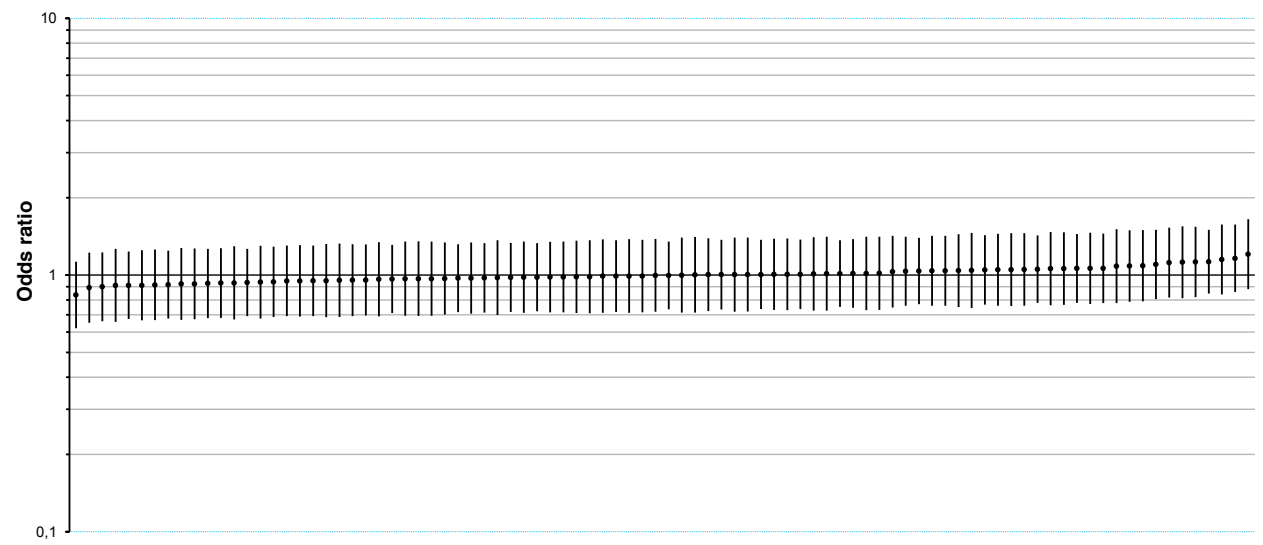

Hospital of diagnosis (2012-2015)

Figure 1c: Case-mix adjusted variation in the probability of undergoing surgery for each hospital of diagnosis in the period 2012-2015 expressed as an odds ratio and 95\% confidence interval on a log scale by a multilevel multivariate regression model. Patients diagnosed in hospitals with an odds ratio less than 1 had a lower likelihood to undergo surgery, hospitals are sorted by their adjusted OR. Adjustment was made for age, FIGO stage, histological type, differentiation grade and socioeconomic status $(n=4,144)$ 


\section{Survival}

Overall, crude five-year survival rates increased over time $(23.5 \%$ in $2000-2005,24.4 \%$ in 2006-2011 and 25.7\% in 2012-2015). When adjusted for patient and tumour characteristics, patients diagnosed in 2000-2005 experienced significant worse survival compared to those diagnosed in 2006-2011 (hazard ratio (HR) 1.15(1.10-1.20)) but there was no difference between patients diagnosed in 2006-2011 and in 2012-2015 (HR 0.98(0.93-1.03)). When stratified by surgical treatment we did see an increase in overall survival for patients who underwent surgery in the last period compared to 2006-2011 (HR 0.90(0.84-0.96), table 3).

Table 3: Multivariable Cox regression models by period of diagnosis $(n=15,314)$

\begin{tabular}{|c|c|c|c|c|c|c|}
\hline & Model I & & Model II & & Model III & \\
\hline & Crude OS ${ }^{a}$ & $\operatorname{HR}(95 \% \mathrm{Cl})^{+}$ & Crude OSa & $\operatorname{HR}(95 \% \mathrm{Cl})^{+}$ & Crude OSa & $\operatorname{HR}(95 \% \mathrm{Cl})^{+}$ \\
\hline 2000-2005 & 23.5 & $1.15(1.10-1.20)$ & 29.3 & $1.17(1.11-1.23)$ & 3.8 & $0.95(0.87-1.03)$ \\
\hline 2006-2011 & 24.4 & Reference & 30.6 & Reference & 2.7 & Reference \\
\hline 2012-2015 & 25.7 & $0.98(0.93-1.03)$ & 34.7 & $0.90(0.84-0.96)$ & N.A. & $0.97(0.89-1.05)$ \\
\hline
\end{tabular}

a-year crude overall survival (\%)

Model I: all patients ( $n=15,314)$, Model II: patient who underwent surgery $(n=11,656)$, Model III: patients who did not underwent surgery $(n=3,658)$

${ }^{+}$Adjusted for age, FIGO stage, histological type, differentiation grade and SES

\section{DISCUSSION}

In this study, we showed that for EOC patients, centralisation of surgical care resulted in more coherent treatment policies across Dutch hospitals. Following a number of initiatives, including the national consensus on a volume norm for cytoreductive surgeries, the decision whether or not to operate patients no longer depends on the hospitals of initial diagnosis. Instead, patients and tumour characteristics may now fully explain observed variations in treatment decisions.

Centralisation of (surgical) care aims to improve overall survival of EOC patients by, among others, improving the outcome of cytoreductive surgery. The percentage of cytoreductive surgeries that result in no macroscopic residual disease increase when they are performed in high volume hospitals by experienced gynaecological-oncologists ${ }^{14,15,23}$. In line with these studies, our study also showed that the percentage of patients with $>1$ centimetre of residual disease decreased after centralisation was established. Most importantly, our study confirmed the improved survival rates after centralisation for patients who underwent (an attempt to) surgical treatment as reported earlier by Eggink et $a l^{8}{ }^{8}$. In 
addition to these favourable outcomes, this study shows a decrease in treatment variation between diagnosing hospitals, suggesting improved awareness about the important role of cytoreductive surgery on patients' prognosis, also in non-surgical centres.

Overall survival rates of the whole study population remained fairly stable around $25 \%$, which is lower when compared to the results reported by the majority of studies ${ }^{24-26}$. However, most of these series concern single or multicentre studies that include a selective group of patients who had primary cytoreduction in combination with chemotherapy (PDS). In contrast, in our population-based study, we included unselected patients by using the NCR database. In this unselected nationwide population, a fair number of patients did not receive any treatment or underwent single therapy only, which translates into lower survival rates. Indeed, the subgroup of patients diagnosed between 2012-2015 who underwent PDS had a five-year survival of $53.7 \%$, which is comparable to the rates reported in other studies (data not shown).

Centralisation for EOC patients was implemented as anticipated; more patients were referred for surgical treatment and a decrease in surgical centres is noted over time. However, we showed that only $26 \%$ of the hospitals met the consensus requirement of performing a minimum of twenty cytoreductive surgeries on an annual basis within the last period. Centralisation was formally established in 2012 but implementation of new guidelines take time when covering multiple hospitals ${ }^{27}$. Regarding centralisation processes, some hospitals could be identified as 'early adopters' according to Roger's diffusion theory because the provided evidence convinces them. Other hospitals could be identified as 'late majority' or 'laggards' because of deviant beliefs ${ }^{28}$. This theory is exemplified by some hospital that still performed cytoreductive surgery in 2012-2013, and started referring their patients to specialised centres from 2014 onwards. So, in 2015, 69\% of the hospitals that performed cytoreductive surgery met the consensus requirement. Moreover, cytoreductive surgeries for recurrent disease are not registered within the NCR, so the annual number per hospital could be slightly higher.

In the second period, 2006-2011, surgical collaboration between registered gynaecologicaloncologist and general gynaecologists enabled smaller hospitals to continue performing cytoreductive surgeries rather than referring to specialised hospitals. These first initiatives to centralisation already resulted in a decrease in hospital variation, although the initial hospital of diagnosis still significantly influenced treatment decisions. In the last period, centralisation also covered the introduction of regional MDTs and a national consensus was reached, which may explain the non-significant association between the hospital of diagnosis and likelihood of undergoing surgery. 
The proportion of patients who underwent surgery decreased in the last period. We showed that important predictors for undergoing surgery were younger age, high SES and low FIGO stage, which is consistent with international literature ${ }^{21,29}$. In the last period patients became significantly older and were more often diagnosed with FIGO stage IV disease. This might have contributed to the decreased surgical rate in our population. The rise in FIGO IV disease could be explained by improved diagnostic workup in terms of extended pre-operative imaging and cytological examination of pleural fluid. Furthermore, the percentage of patients with an unknown FIGO stage decreased considerably in the last period as a result of nationwide registration of TNM stage for primary peritoneal cancers within the NCR. The distribution of stage III and IV patients in this group is comparable to primary ovarian cancers, so the rise in FIGO IV patients is probably not based on this registration artefact.

Besides changes in our population, the introduction of neoadjuvant chemotherapy as an alternative approach for advanced stage EOC patients may play a role in the decreased surgical rate 30,31 . The use of neoadjuvant chemotherapy increased in the Netherlands and the majority of advanced stage patients were treated with NACT-IDS in the last period ${ }^{8}$. After two or three cycles NACT, patients are evaluated whether they should undergo interval cytoreductive surgery. When NACT is prematurely stopped due to unacceptable side effects, or response to NACT is low and intraperitoneal tumour load is high, these patients might be considered ineligible for cytoreductive surgery. Consequently, the percentage of patients who undergo cytoreductive surgery decreased.

These alterations in treatment could also contribute to the improved surgical outcomes in the most recent period. The probability of gross residual disease is significantly lower after NACT. The selection of patients who undergo cytoreductive surgery thus altered over time. One could criticise this trend, if only patients with low intraperitoneal tumour load undergo cytoreductive surgery, outcomes will improve without actual improvement in quality of care. Consequently, if quality of care is getting worse, overall survival rates should drop in the most recent years. After all, cytoreductive surgery in combination with chemotherapy is the cornerstone of treatment in advanced ovarian cancer ${ }^{30}$. However, though surgical rates dropped in the last period, overall survival remained comparable and even improved for patients who had an attempt to cytoreductive surgery. This might imply that the selection process improved, and further improving patient selection is therefore of great importance.

The limitations of the study are mainly related to the lack of detailed information about comorbidity, which is regarded as an important factor for initiating surgical treatment ${ }^{32}$. However, the addition of comorbidity to a comparable multilevel model in two studies 
with gastric and oesophageal cancer patients did not reveal major differences in the analyses ${ }^{33,34}$. The initiation of surgery is not only based on the decision of physicians, but also on patients desires. This latter information is not available in our database and could possibly explain some variation between hospitals. Finally, we assumed that changes over time were associated with centralisation of surgical care and the introduction of MDTs. Although this sounds reasonable, and is supported by the decrease in surgical centres in the last period, we could not establish the cause-effect relationship of centralisation and improved outcome rates. Also we had no information about whether patients were truly discussed in MDTs.

\section{CONCLUSION}

This study shows that centralisation of surgical care resolved the variation between hospitals in the probability to undergo cytoreductive surgery for patients with advanced EOC. Since centralisation was established in 2012, the decision to operate patients seems solely attributable to patient and tumour characteristics. This supports the growing evidence in favour of centralising (surgical) treatment for complex and heterogeneous diseases such as EOC.

\section{Acknowledgements}

The authors thank the registration team of the Netherlands Comprehensive Cancer Organisation (IKNL) for the collection of data for the Netherlands Cancer Registry 


\section{REFERENCES}

1. Sankaranarayanan R, Ferlay J. Worldwide burden of gynaecological cancer: The size of the problem. Best Pract Res Clin Obstet Gynaecol. 2006;20(2):207-25.

2. Jemal A, Bray F, Center MM, Ferlay J, Ward E, Forman D. Global cancer statistics. CA Cancer J Clin. 2011;61(2):69-90.

3. Howlader N NA, Krapcho M, Miller D, Bishop K, Altekruse SF, Kosary CL, Yu M, Ruhl J, Tatalovich Z, Mariotto A, Lewis DR, Chen HS, Feuer EJ, Cronin KA (eds). . Seer cancer statistics review, 1975-2013, national cancer institute.

4. Sant M, Chirlaque Lopez MD, Agresti R, Sanchez Perez MJ, Holleczek B, BielskaLasota M, et al. Survival of women with cancers of breast and genital organs in europe 1999-2007: Results of the eurocare-5 study. Eur J Cancer. 2015.

5. Colombo PE, Labaki M, Fabbro M, Bertrand M, Mourregot A, Gutowski M, et al. Impact of neoadjuvant chemotherapy cycles prior to interval surgery in patients with advanced epithelial ovarian cancer. Gynecol Oncol. 2014;135(2):223-30.

6. Chang SJ, Hodeib M, Chang J, Bristow RE. Survival impact of complete cytoreduction to no gross residual disease for advancedstage ovarian cancer: A meta-analysis. Gynecol Oncol. 2013;130(3):493-8.

7. van Altena AM, van den Akker PA, de Hullu JA, Ottevanger PB, Aalders AL, Gerritse $\mathrm{R}$, et al. Efficacy of a regional network for ovarian cancer care. Obstet Gynecol. 2013;122(3):668-75.

8. Eggink FA, Mom $\mathrm{CH}$, Kruitwagen RF, Reyners AK, Van Driel WJ, Massuger LF, et al. Improved outcomes due to changes in organization of care for patients with ovarian cancer in the netherlands. Gynecol Oncol. 2016;141(3):524-30.
9. Vernooij F, Heintz $P$, Witteveen $E$, van der Graaf $Y$. The outcomes of ovarian cancer treatment are better when provided by gynecologic oncologists and in specialized hospitals: A systematic review. Gynecol Oncol. 2007;105(3):801-12

10. Vernooij F, Heintz AP, Coebergh JW, Massuger LF, Witteveen PO, van der Graaf Y. Specialized and high-volume care leads to better outcomes of ovarian cancer treatment in the netherlands. Gynecol Oncol. 2009;112(3):455-61.

11. Woo YL, Kyrgiou M, Bryant A, Everett $T$, Dickinson HO. Centralisation of services for gynaecological cancers - a cochrane systematic review. Gynecol Oncol. 2012;126(2):286-90.

12. van Vliet MM, Schreuder HW, Pasker-de Jong PC, Duk MJ. Centralisation of epithelial ovarian cancer surgery: Results on survival from a peripheral teaching hospital. Eur J Obstet Gynecol Reprod Biol. 2015;192:72-8.

13. Bristow RE, Chang J, Ziogas A, Randal LM, Anton-Culver H. High-volume ovarian cancer care: Survival impact and disparities in access for advanced-stage disease. Gynecol Oncol. 2014;132(2):403-10.

14. Dahm-Kahler P, Palmqvist C, Staf C, Holmberg E, Johannesson L. Centralized primary care of advanced ovarian cancer improves complete cytoreduction and survival - a population-based cohort study. Gynecol Oncol. 2016

15. Bristow RE, Palis BE, Chi DS, Cliby WA. The national cancer database report on advanced-stage epithelial ovarian cancer: Impact of hospital surgical case volume on overall survival and surgical treatment paradigm. Gynecol Oncol. 2010;118(3):2627. 
16. Querleu D, Planchamp F, Chiva L, Fotopoulou C, Barton D, Cibula D, et al. European society of gynaecologic oncology quality indicators for advanced ovarian cancer surgery. Int J Gynecol Cancer. 2016;26(7):1354-63.

17. Fritz AG. International classification of diseases for oncology : Icd-o. 3rd ed. Geneva: World Health Organization; 2000. vii, 240 p. p.

18. Sobin LH, Gospodarowicz MK, Wittekind C, International Union against Cancer. Tnm classification of malignant tumours. 7th ed. Chichester, West Sussex, UK ; Hoboken, NJ: Wiley-Blackwell; 2010. xx, 309 p. p.

19. Sanagou M, Wolfe R, Forbes A, Reid CM. Hospital-level associations with 30-day patient mortality after cardiac surgery: A tutorial on the application and interpretation of marginal and multilevel logistic regression. BMC Med Res Methodol. 2012;12:28.

20. Austin PC, Goel V, van Walraven C. An introduction to multilevel regression models. Can J Public Health. 2001;92(2):1504.

21. Bristow RE, Chang J, Ziogas A, Campos $B$, Chavez LR, Anton-Culver $H$. Sociodemographic disparities in advanced ovarian cancer survival and adherence to treatment guidelines. Obstet Gynecol. 2015;125(4):833-42.

22. Cowan RA, O'Cearbhaill RE, Gardner GJ, Levine DA, Roche KL, Sonoda $Y$, et al. Is it time to centralize ovarian cancer care in the united states? Ann Surg Oncol. 2016;23(3):989-93.

23. Aletti GD, Gostout BS, Podratz KC, Cliby WA. Ovarian cancer surgical resectability: Relative impact of disease, patient status, and surgeon. Gynecol Oncol. 2006;100(1):33-7.
24. Tate S, Kato K, Nishikimi K, Matsuoka A, Shozu M. Survival and safety associated with aggressive surgery for stage iii/iv epithelial ovarian cancer: A single institution observation study. Gynecol Oncol. 2017.

25. du Bois A, Reuss A, Pujade-Lauraine E, Harter P, Ray-Coquard I, Pfisterer J. Role of surgical outcome as prognostic factor in advanced epithelial ovarian cancer: A combined exploratory analysis of 3 prospectively randomized phase 3 multicenter trials: By the arbeitsgemeinschaft gynaekologische onkologie studiengruppe ovarialkarzinom (ago-ovar) and the groupe d'investigateurs nationaux pour les etudes des cancers de l'ovaire (gineco). Cancer. 2009;115(6):123444.

26. Mueller JJ, Zhou QC, lasonos A, O'Cearbhaill RE, Alvi FA, El Haraki A, et al. Neoadjuvant chemotherapy and primary debulking surgery utilization for advanced-stage ovarian cancer at a comprehensive cancer center. Gynecol Oncol. 2016;140(3):436-42.

27. Gagliardi AR, Alhabib $S$, members of Guidelines International Network Implementation Working G. Trends in guideline implementation: A scoping systematic review. Implement Sci. 2015;10:54.

28. Rogers EM. Diffusion of innovations. 5th ed. New York: Free Press; 2003. xxi, 551 p. p.

29. Fairfield KM, Lucas FL, Earle CC, Small L, Trimble EL, Warren JL. Regional variation in cancer-directed surgery and mortality among women with epithelial ovarian cancer in the medicare population. Cancer. 2010;116(20):4840-8.

30. Vergote I, Trope CG, Amant F, Kristensen $G B$, Ehlen T, Johnson N, et al. Neoadjuvant chemotherapy or primary surgery in stage iiic or iv ovarian cancer. N Engl J Med. 2010;363(10):943-53. 
31. Kehoe S, Hook J, Nankivell M, Jayson GC, Kitchener H, Lopes T, et al. Primary chemotherapy versus primary surgery for newly diagnosed advanced ovarian cancer (chorus): An open-label, randomised, controlled, non-inferiority trial. Lancet. 2015;386(9990):249-57.

32. Suidan RS, Leitao MM, Jr., Zivanovic O, Gardner GJ, Long Roche KC, Sonoda Y, et al. Predictive value of the age-adjusted charlson comorbidity index on perioperative complications and survival in patients undergoing primary debulking surgery for advanced epithelial ovarian cancer. Gynecol Oncol. 2015;138(2):246-51.

33. van Putten $M$, Verhoeven $R H$, van Sandick JW, Plukker JT, Lemmens VE, Wijnhoven BP, et al. Hospital of diagnosis and probability of having surgical treatment for resectable gastric cancer. Br J Surg. 2016;103(3):23341.

34. van Putten $M$, Koeter $M$, van Laarhoven HW, Lemmens VE, Siersema PD, Hulshof MC, et al. Hospital of diagnosis influences the probability of receiving curative treatment for esophageal cancer. Ann Surg. 2016. 


\section{SUPPLEMENTARY MATERIAL}

S1: Multivariable logistic regression to assess patient and tumour characteristics that predicts surgical treatment for the entire study period $(n=15,314)$

\begin{tabular}{|c|c|c|}
\hline & Surgical treatment (\%) & OR $(95 \% \mathrm{Cl})^{+}$ \\
\hline \multicolumn{3}{|l|}{ Age } \\
\hline $18-59$ & 91.2 & Reference \\
\hline $60-74$ & 83.3 & $0.50(0.44-0.57)$ \\
\hline$>75$ & 49.7 & $0.09(0.08-0.10)$ \\
\hline \multicolumn{3}{|l|}{ FIGO stage } \\
\hline$\|B-\| C$ & 91.6 & $2.09(1.68-2.60)$ \\
\hline$\||| A-\| \mid C$ & 82.0 & Reference \\
\hline IV & 58.8 & $0.27(0.24-0.29)$ \\
\hline Unknown & 73.1 & $0.57(0.49-0.67)$ \\
\hline \multicolumn{3}{|l|}{ Type of tumour } \\
\hline High grade serous & 73.9 & Reference \\
\hline Low grade serous & 88.9 & $1.98(1.42-2.75)$ \\
\hline Other & 84.1 & $1.43(1.26-1.62)$ \\
\hline \multicolumn{3}{|c|}{ Socioeconomic status } \\
\hline High & 78.7 & Reference \\
\hline Medium & 75.9 & $0.85(0.77-0.95)$ \\
\hline Low & 73.8 & $0.78(0.70-0.87)$ \\
\hline Total & 76.1 & \\
\hline
\end{tabular}

${ }^{+}$All OR's are adjusted for the listed variables 



\section{4}

Outcome of surgery in advanced ovarian cancer varies between geographical regions; opportunities for improvement in the Netherlands

M. Timmermans, G.S. Sonke, B.F.M. Slangen, A. Baalbergen, R.L.M. Bekkers, G. Fons, C.G. Gerestein, A.J. Kruse, E.M. Roes, P.L.M. Zusterzeel, K.K. Van de Vijver, R.F.P.M. Kruitwagen, M.A. van der Aa 


\section{ABSTRACT}

\section{Introduction}

The care for patients with epithelial ovarian cancer (EOC) is organised in eight different geographical regions in the Netherlands. This situation allows us to study differences in practice patterns and outcomes between geographical regions for patients with FIGO stage IIIC and IV.

\section{Methods}

We identified all EOC patients who were diagnosed with FIGO stage IIIC or IV between 01.01.2008 and 31.12.2015 from the Netherlands Cancer Registry. Descriptive statistics were used to summarise treatment and treatment sequence (primary cytoreductive surgery (PCS) or neoadjuvant chemotherapy and interval cytoreductive surgery (NACTICS)). Moreover, outcome of surgery was compared between geographical regions. Multilevel logistic regression was used to assess whether existing variation is explained by geographical region and case-mix factors.

\section{Results}

Overall, 6,741 patients were diagnosed with FIGO IIIC or IV disease. There were no differences in the percentage of patients that received any form of treatment between the geographical regions (range $80-86 \%, P=0.162$ ). In patients that received cytoreductive surgery and chemotherapy, a significant variation between the geographical regions was observed in the use of PCS and NACT-ICS (PCS: 24-48\%, $P<0.001$ ). The percentage of complete cytoreductive surgeries after PCS ranged from 10-59\% $(P<0.001)$ and after NACTICS from $37-70 \%(P<0.001)$. Moreover, geographical region was independently associated with the outcome of surgery, also when adjusted for treatment sequence $(P<0.001)$.

\section{Conclusion}

We observed a significant variation in treatment approach for advanced EOC between geographical regions in the Netherlands. Furthermore, the probability to achieve no residual disease differed significantly between regions, regardless of treatment sequence. This may suggest that surgical outcomes can be improved across geographical regions. 


\section{INTRODUCTION}

Epithelial ovarian cancer (EOC) is the most lethal gynaecological cancer worldwide, and long-term overall survival did not change over the last twenty years ${ }^{1,2}$. Most patients are diagnosed with advanced stage disease, which requires extensive treatment consisting of maximal cytoreductive surgery (CRS) and platinum-based chemotherapy.

The outcome of CRS is one of the few amendable factors in EOC patients, and is directly linked to survival rates ${ }^{3}$. Patients with no macroscopic residual disease after surgery (complete CRS) have the best survival ${ }^{4}$. Extensive surgical procedures, including bowel surgery and diaphragm stripping, are often required to obtain a complete CRS. It is suggested that surgical outcomes can be improved through several factors. First of all, neoadjuvant chemotherapy (NACT) may reduce intra-abdominal tumour load, which diminishes the complexity of the surgical procedure, in order to increase the likelihood to successful surgery ${ }^{5,6}$. Furthermore, centralizing surgical care, and thus increasing the surgical volume of hospitals and individual gynaecologic-oncologists, contributes to improved (surgical) outcomes $^{7-9}$. Finally, discussing all patients in (regional) multidisciplinary tumour board meetings, including adequate preoperative diagnostics (imaging, pathology review and in selected patient diagnostic laparoscopy), ensures that every patient undergoes the most optimal treatment strategy ${ }^{10,11}$.

The most optimal treatment strategy, however, is subject to a lively debate among experts. Over the last years, NACT followed by interval cytoreductive surgery (ICS) became an attractive treatment alternative with non-inferior long-term outcome in randomised studies and reduced morbidity in Fédération Internationale de Gynécologie et d'Obstétrique (FIGO) stage IIIC and IV patients ${ }^{5,6}$. However, since survival of patients after a complete primary cytoreductive surgery (PCS) is higher when compared to a complete ICS, variation between believers and non-believers exists in adopting NACT-ICS 5,12-14.

Patients with ovarian cancer are treated within different geographical regions in the Netherlands. In these regions, specialised gynaecologic-oncologic centres organise regional multidisciplinary tumour board meeting, in which patients from the whole region are discussed. Moreover, these meetings facilitate referral for CRS, as the performance of CRS is restricted to specialised gynaecologic-oncologic centres that perform a minimum of twenty cytoreductive surgeries annually. This situation allows us to study differences in practice patterns between geographical regions for all FIGO stage IIIC and IV patients, including those who undergo limited or no therapy at all. Therefore, the aim of our study is to describe variation between geographical regions in the Netherlands in primary treatment for advanced EOC patients, and its effect on patient outcome. 


\section{METHODS}

We identified all consecutive patients that were diagnosed with EOC, including fallopian tube and primary peritoneal cancer (International Classification of Diseases for Oncology (ICD-O) C56.9, C57.0, C48.2), from the Netherlands Cancer Registry (NCR) ${ }^{15}$. Thoroughly trained registration clerks routinely extract information on patient and tumour characteristics, diagnostic procedures and treatment from medical records. For this study, complementary data were obtained for patients who underwent chemotherapy and/or cytoreductive surgery. Follow-up is obtained by annual linkage with the municipal demography registries (GBA). The study design, data abstraction process and storage protocols were approved by the NCR review board.

\section{Study population}

We included all patients who were diagnosed with FIGO IIIC and IV disease between 01.01.2008 and 31.12.2015. Patients were divided into groups according to their treatment; either no therapy (i.e. neither chemotherapy nor cytoreductive surgery), chemotherapy only, or a combination of cytoreductive surgery and chemotherapy. Moreover, patients were categorised according to treatment sequence in PCS, NACT-ICS, or PCS+NACT-ICS. The latter category was used for patients who underwent an exploratory laparotomy followed by NACT and ICS, or when initial PCS resulted in a suboptimal cytoreduction and secondary ICS was performed.

\section{Geographical regions}

In the Netherlands, patients with ovarian cancer are treated within eight different geographical regions. Over time, the number of hospitals that perform cytoreductive surgery decreased as a result of formal surgical volume norms. Every region contains at least one academic/specialized referral centre. The treatment hospital defined the specific geographical region for patients. In case hospitals of surgery and chemotherapy differed, the hospital of surgery was chosen as treatment hospital. In addition, when patients did not undergo surgery or chemotherapy, the hospital of initial diagnosis was chosen.

\section{Definitions}

The outcome of cytoreductive surgery was defined as complete in case of no macroscopic residual disease, as optimal in case of residuals of $0-1 \mathrm{~cm}$ in maximal diameter, and as suboptimal in case of $>1 \mathrm{~cm}$ of residual disease. In case patients underwent multiple 
(attempts to) cytoreductions (PCS+NACT-ICS, the last cytoreductive surgery was used to determine the outcome of cytoreductive surgery.

For patients who underwent chemotherapy and/or cytoreductive surgery, CA125 at diagnosis, American Society of Anaesthesiologists (ASA) scores, and present comorbidities were extracted from medical records. The latter were used to calculate the Charlson Comorbidity Index $(\mathrm{CCl})^{16}$. In patients with limited or no therapy, socioeconomic status (SES) was used as proxy for comorbidity, since concomitant medical conditions are more common in patients with low SES ${ }^{17,18}$. SES was based on a patients postal area according to the Netherlands Institute for Social Research ${ }^{19}$.

\section{Statistical analyses}

Descriptive statistics were used to summarize treatment, treatment sequence (PCS, NACT-ICS or PCS+NACT-ICS) and outcomes of cytoreductive surgery in each geographical region and over the study period (in two-year intervals). In order to gain insight into crude differences between regions (i.e. not adjusted for patient- and tumour characteristics), chisquare tests were used. Multilevel logistic regression was used to account for differences in case mix between geographical regions. We adjusted our models for age, FIGO stage, histologic subtype, differentiation grade, year of diagnosis and SES. In patients who underwent cytoreductive surgery and/or chemotherapy multilevel models were adjusted for performance score and $\mathrm{CCl}$, rather than SES. In addition, CA125 at diagnosis $\left(\log _{\mathrm{e}}-\right.$ transformed) was also added in these models.

Kaplan-Meier survival curves and log-rank tests were used to analyse overall survival (OS) and event-free survival (EFS). OS was defined as the date from diagnosis until date of death or last follow-up date in case patients were still alive (01.02.2018), which was available for all included patients. EFS was only available for patients who underwent chemotherapy and/ or cytoreductive surgery. In these patients; EFS was defined as the date from last treatment until date of recurrence, progression or death (whichever occurred first). Progression was defined as clinical signs of tumour growth, i.e. increase in CA125 and/or visible lesions on imaging techniques (either regrowth of pre-existing lesions or new lesions), combined with the clinical judgment of the treating physician (medical oncologist or gynaecologists). In case patients had no signs of progression and were still alive, they were censored at their last hospital visit. For multivariable cox-regression models, we adjusted survival outcomes for age at diagnosis, FIGO stage, histologic subtype, differentiation grade, $\mathrm{CCl}, \mathrm{CA} 125$ at diagnosis and treatment sequence. A $P$-value $<0.05$ was considered statistically significant, and analyses were performed using STATA/SE (version 14.1; STATA CORP., College Station, Texas, USA). 


\section{RESULTS}

Overall, 6,741 patients were diagnosed with FIGO IIIC or IV disease between 01.01.2008 and 31.12.2015. We categorized patients into eight different geographical regions, which ranged in number of patients from 515 to 1,572 patients over the total study period. Baseline characteristics of all patients and stratified by region were presented in the appendix (S1).

\section{Variation in treatment over time and between geographical regions}

The number of patients that underwent CRS in combination with chemotherapy decreased over time in our total population (from 70\% in 2008-2009 to 62\% in 2014-2015). Simultaneously the number of patients that received solely chemotherapy increased, and the number of patients that received neither chemotherapy nor surgery increased as well (S2a). Changes over time were mainly observed in case of FIGO stage IIIC, while therapy did not significantly change in FIGO IV patients $(P=0.899)$. Over time, median age at diagnosis increased from 67 years (interquartile range (IQR) 59-76) to 69 years (IQR 61-77, $P<0.001$ ). Changes in therapy regimen were not observed in patients aged younger than $65(P=0.710)$, but did change significantly in patients over 65 years $(P=0.028)$.

We observed no difference in the number of patients that received no therapy between geographical regions (figure $1 a$, range $14-20 \%, P=0.134$ ). This did not change when we adjusted our analyses for patient- and tumour characteristics (LR test ICC 0.4\%, $P=0.162$ ). The number of patients that underwent cytoreductive surgery in combination with chemotherapy did differ between the geographical regions (range 61-71\%, $P<0.001$ ), also when adjusted for patient- and tumour characteristics (LR test ICC $1.4 \%, P<0.001$ ).

\section{Variation in the use of PCS and NACT-ICS over time and between geographical regions}

In patients that underwent the combination of cytoreductive surgery and chemotherapy, we observed a significant decrease in the use of PCS over time (41\% in 2008-2009 to 27\% in 2014-2015, $P<0.001$, S2b). Simultaneously, the number of patients that underwent PCS followed by NACT-ICS decreased over time as well (11\% in 2008-2009 to 6\% in 2014-2015, $P<0.001, \mathrm{~S} 2 \mathrm{~b})$. Furthermore, there was a significant variation in initial treatment sequence between the geographical regions (PCS: $24-48 \%$, NACT-ICS: $44-70 \%$ and PCS+NACT-ICS: $5-13 \%, P<0.001$, figure $1 b)$.

The variation in use of initial NACT-ICS could not be explained by differences in patient characteristics, while treatment region contributed to the variation in used treatment 
sequence (LR test ICC 5.7\%, $P<0.001$ ). Factors that were associated with a higher likelihood towards initial NACT-ICS were higher age, FIGO IV disease, poor performance score and a high CA125 at diagnosis (table 1 ).

Table 1: Prognostic factors that are associated with NACT-IDS in advanced EOC patients

\begin{tabular}{|c|c|}
\hline & OR $(95 \% \mathrm{Cl})^{+}$ \\
\hline \multicolumn{2}{|l|}{ Age } \\
\hline$<65$ & Reference \\
\hline $65-75$ & $1.27(1.07-1.49)$ \\
\hline$>75$ & $1.22(0.98-1.52)$ \\
\hline \multicolumn{2}{|l|}{ FIGO stage } \\
\hline IIIC & Reference \\
\hline IV & $2.93(2.44-3.52)$ \\
\hline \multicolumn{2}{|l|}{ Histologic subtype } \\
\hline Serous & Reference \\
\hline Mucinous & $0.37(0.22-0.63)$ \\
\hline Endometrioid & $0.61(0.40-0.92)$ \\
\hline Clear-cell & $0.23(0.15-0.36)$ \\
\hline Adenocarcinoma NOS & $2.25(1.66-3.04)$ \\
\hline Other & $0.41(0.22-0.76)$ \\
\hline \multicolumn{2}{|l|}{ Differentiation grade } \\
\hline 1 & Reference \\
\hline ॥ & $1.46(1.21-1.76)$ \\
\hline III & $1.71(1.60-2.84)$ \\
\hline \multicolumn{2}{|l|}{ ASA score } \\
\hline ASA I & Reference \\
\hline ASA ॥ & $1.46(1.21-1.76)$ \\
\hline$A S A \geq 3$ & $2.13(1.60-2.84)$ \\
\hline \multicolumn{2}{|l|}{ CCl score* } \\
\hline 0 & Reference \\
\hline 1 & $0.93(0.75-1.14)$ \\
\hline$\geq 2$ & $0.93(0.76-1.15)$ \\
\hline CA125 at diagnosis & $1.41(1.33-1.48)$ \\
\hline Year of diagnosis & $1.16(1.12-1.21)$ \\
\hline
\end{tabular}

${ }^{+}$All Odds Ratios (OR) are adjusted for the listed variables, all unknown variables were included in the model but not listed in this table 


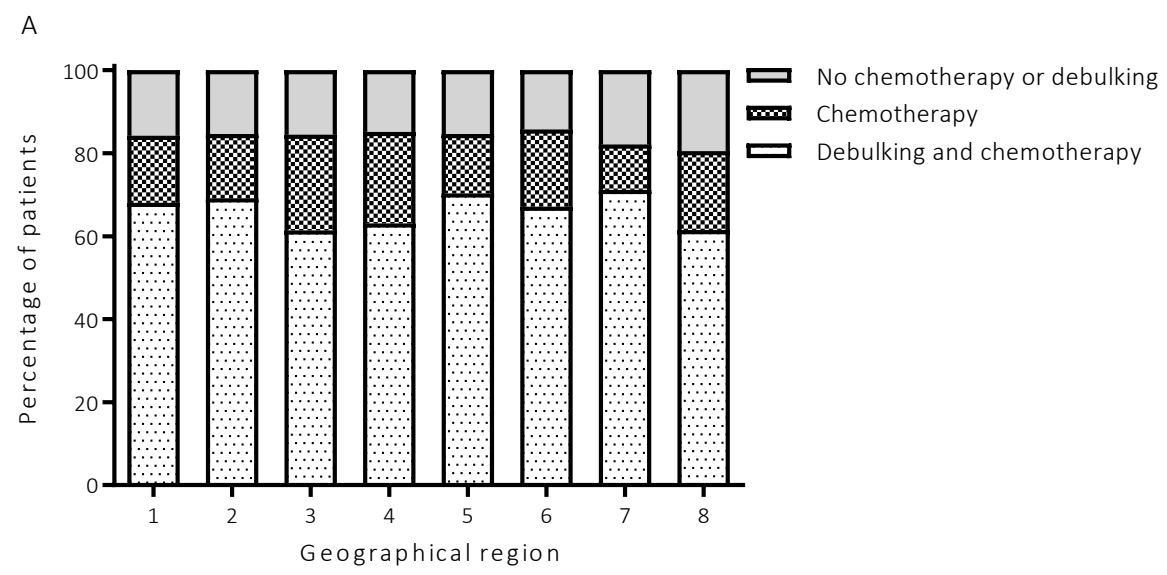

B

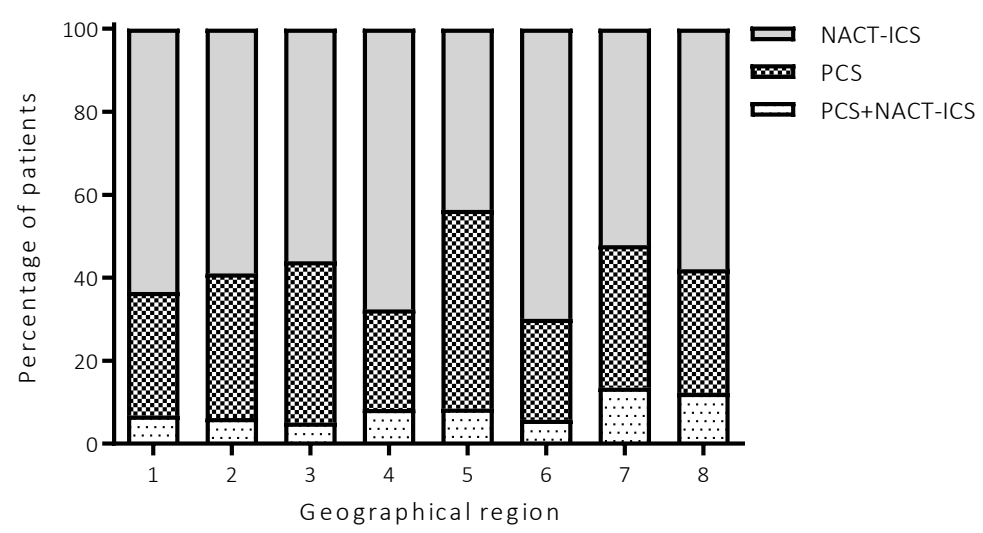

Figure 1: Treatment approach (A) and treatment sequence $(B)$ in advanced stage EOC patients by geographical region

\section{Variation in the outcome of surgery over time and between geographical regions}

The probability of a complete cytoreductive surgery was higher when patients were treated with NACT (41\% after PCS, 50\% after NACT-ICS), also when adjusted for patientand tumour characteristics $(O R$ 1.56, 95\% $\mathrm{Cl} 1.33-1.82)$. Therefore, the outcomes of surgery are presented stratified by the treatment sequence. Surgical outcomes improved over time, for both PCS and NACT-ICS patients (S3a and S3b, respectively). There was a significant variation, however, in surgical outcomes between geographical regions. For patients who underwent PCS, the percentage of complete surgery ranged between 1059\% $(P<0.001$, figure 2a). When adjusted for patient- and tumour characteristics, there was still a significant variation between geographical regions (LR test $P<0.001$, ICC 19.3\%). 
The same patterns were observed for patients who received NACT and ICS, but smaller variation existed between the geographical regions (37-70\%, LR test $P<0.001$, ICC 3.7\%, figure $2 b)$.

When treatment sequence was incorporated in our multilevel model, the probability of complete CRS was still influenced by the geographical region where patients were treated (24-67\%, LR test $P<0.001$, ICC 6.5\%).

A

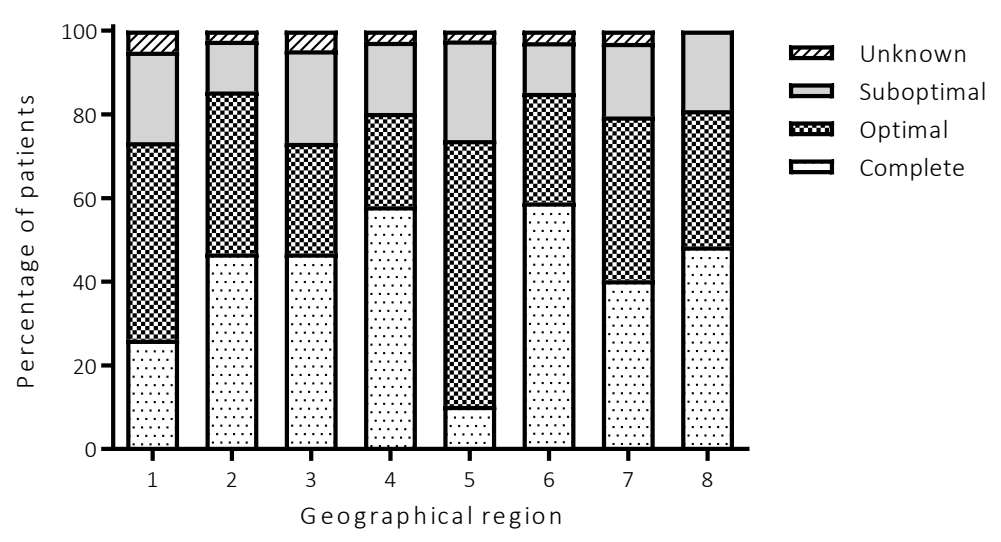

B

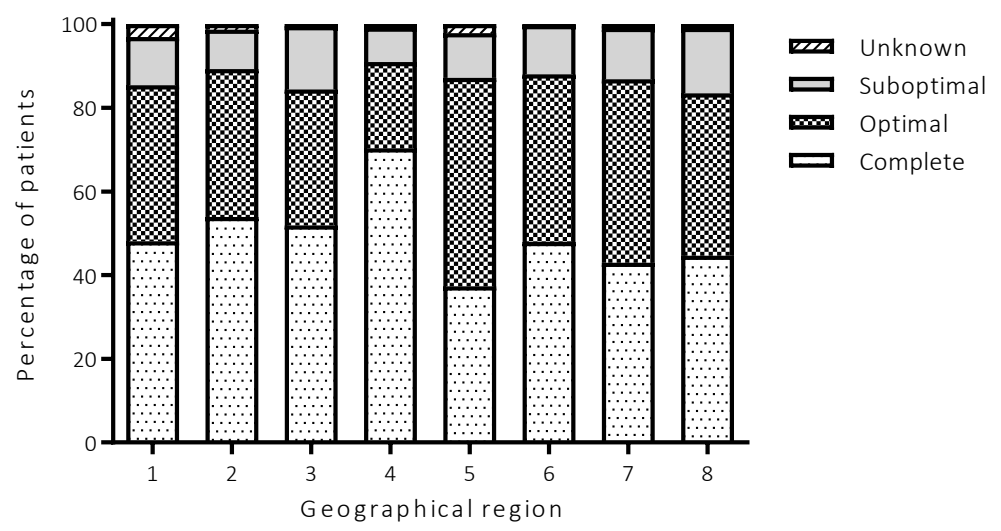

Figure 2: Surgical outcomes after PCS (a) and NACT-ICS (b) in advanced stage EOC patients by geographical region

\section{Survival outcomes}

OS was significantly influenced by treatment sequence and outcome of CRS. OS was the highest in patients with no residual disease after PCS (S4). Survival of patients who 
underwent PCS+NACT-ICS was similar to patients that underwent initial NACT-ICS (5-year survival both $23 \%, P=0.741$ ).
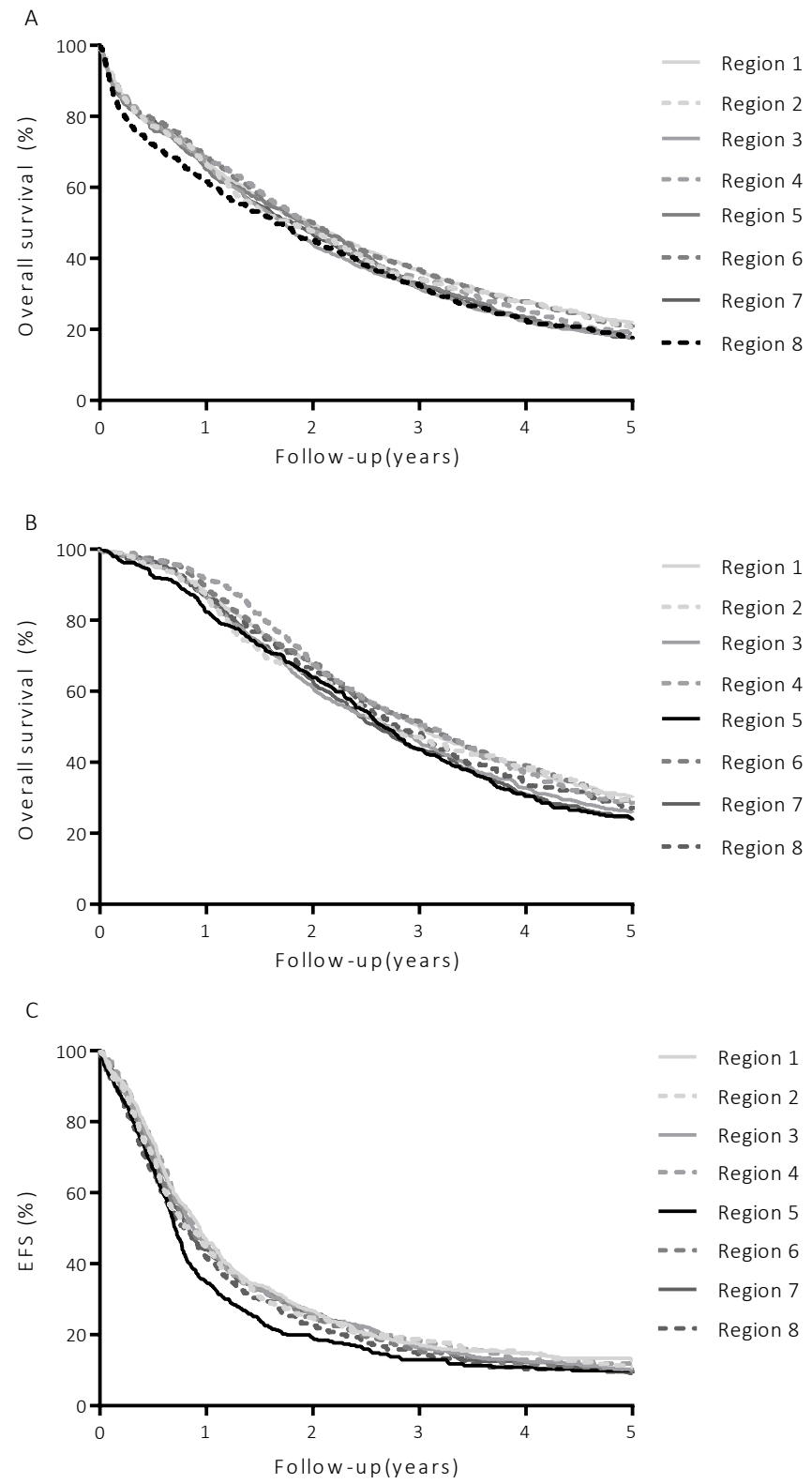

Figure 3: Kaplan-Meier survival curves stratified by geographical region. A) Overall survival for all patients B) Overall survival for patients who underwent cytoreductive surgery and chemotherapy C) Event-free survival for patients who underwent cytoreductive surgery and chemotherapy 
In all patients together, including those with no or limited therapy, there was no significant difference in OS between geographical regions (five-year OS range $17-22 \%, P=0.059$, figure 3a). In patients who underwent chemotherapy and cytoreductive surgery survival rates did differ significantly (five-year OS range $24-30 \%, P=0.030$, figure $3 \mathrm{~b}$ ). In addition, EFS (only known for patients undergoing cytoreductive surgery and chemotherapy) also differed significantly between regions (five-year EFS range $9-13 \%, P=0.030$, figure $3 c$ ). Patients who were treated in the region with the lowest number of complete cytoreductive surgeries (region 5), experienced significantly worse EFS and OS (adjusted $\mathrm{HR}_{\mathrm{EFS}}$ 1.28(1.14-1.44) and $H R_{\text {os }}$ 1.18(1.04-1.34) compared to all other regions). However, as stated above, the OS of all patients (including those with no or limited therapy) in this region was comparable to the other regions (adjusted $\mathrm{HR}_{\text {os }} 1.07(0.97-1.18)$ ).

\section{DISCUSSION}

In this large population-based study, we gained insight in the variation between geographical regions in the primary treatment for EOC patients. The use of PCS and NACT-ICS differed significantly between regions and could not be (fully) explained by differences in patient populations. Moreover, the probability of complete cytoreductive surgery differed among the regions, even when accounting for possible confounders (including treatment sequence).

A considerable number of patients did not undergo any treatment in our population (16\%), and this was not associated with geographical region. Over time, the number of patients that did not undergo any treatment increased, and was (partly) explained by an increasing age at diagnosis. Age is a strong predictor of receiving treatment ${ }^{20-23}$. This phenomenon could be explained by more comorbidity at higher age, and also by patients' wishes. Proper selection of patients who undergo treatment is of paramount importance, as some studies showed that the effect of age on survival disappears when standard treatment is applied ${ }^{22,24}$. A standardised geriatric assessment may help to identify those patients who benefit from surgery and platinum-based combination chemotherapy, and those who may not complete this aggressive therapy ${ }^{25-27}$. In the latter, (palliative) chemotherapy may increase survival in combination with symptom control and better quality of life. The effect of single-agent or standard combination chemotherapy should be studied in this fragile population as well, considering the increasing number of patients that is diagnosed at an older age.

In patients that underwent the combination of chemotherapy and cytoreductive surgery, the timing of surgery is based on (inter)national guidelines, in which a wide range of advices exists. The Dutch guideline (2012) and the NICE guideline (2011) both suggest that the 
aim of cytoreductive surgery should be complete resection, for which PCS and NACT-ICS can both be used ${ }^{28,29}$. The Belgian guideline (2016) prefers PCS when complete resection seems feasible, but NACT-ICS could be considered as alternative treatment approach (predominantly when lesions are larger than $5 \mathrm{~cm})^{30}$. The American guideline prefers PCS when complete cytoreductive surgery is deemed feasible, but prefers NACT-ICS over PCS in case of a high perioperative risk profile or a low likelihood to optimal cytoreduction $(<1 \mathrm{~cm})^{31}$. The German guideline (2013), however, states that patients obtain no benefit from NACT-ICS, and PCS is thus the preferred treatment option with no macroscopic residual disease as goal ${ }^{32}$. The discrepancy between guidelines reflects the ongoing debate about the subject, and the absence of clear advice in the Dutch guideline explains the observed variation between geographical regions.

A previously published meta-analysis concluded that NACT-ICS was inferior to PCS, and comprised retrospective data ${ }^{13}$. In our study, which is also based on retrospective data, patients with no residual disease after PCS experienced the best survival. Retrospective studies on PCS versus NACT-ICS are exposed to confounding by severity, which refers to the situation where physicians alter their treatment according to patient- and tumour characteristics $^{33}$. Especially in earlier years, where NACT-ICS was an exception in the treatment for advanced EOC, patients who underwent this treatment sequence were probably older and had a higher tumour load, which explains the inferior survival of NACTICS patients in these series. Two landmark randomized clinical trials found no differences in survival outcomes between PCS and NACT-ICS 5,6. The most important limitation of both studies is the low rate of complete cytoreductive surgeries, predominantly in the PCS group (19\% and $17 \%$ in the EORTC and CHORUS trial respectively), which may limit external validity. Upcoming RCTs try to overcome this limitation by setting surgical requirements, as it has been argued that surgical interventions can only be properly studied in RCTs with adequate surgical quality 34,35 .

It is agreed that the outcome of surgery is one of the most important prognostic factor for prolonged survival ${ }^{3,4}$. Our study showed that the geographical region influences the probability of leaving no macroscopic residual disease, independent of treatment approach (PCS vs. NACT-ICS). Patient related factors and tumour biology are known to affect surgical outcome, but are hardly amendable ${ }^{36-38}$. Centralisation of care, however, may improve surgical outcomes and survival in ovarian cancer patients ${ }^{7-9}$. A national consensus was reached in 2012 to restrict the performance of surgery to hospitals that carried out a minimum of twenty cytoreductive surgeries on an annual basis in the Netherlands. This consensus, in combination with increased use of NACT-ICS, resulted into more favourable surgical outcomes over time. The differences between geographical regions were, however, 
also present in the period after 2012 (data not shown). Previous studies already showed that a considerable number of hospitals involved in the surgical treatment of ovarian cancer patients, did not meet the minimal requirement of twenty cytoreductive surgeries annually

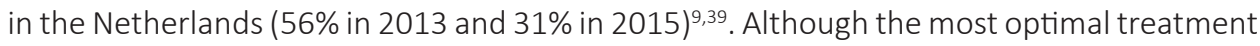
strategy is a subject of a lively debate, the goal of cytoreductive surgery should be no macroscopic residual disease. Further optimisation of surgical outcomes could be achieved through adequate patient selection, and adequate centralisation of surgical care to ensure the most optimal treatment regimen for all patients. These findings suggest opportunities for improvement to ensure that the likelihood towards no macroscopic residual disease is equal in patients with similar extent of disease.

In the present study, we observed variation in survival between geographical regions. This may be related to the variation in surgical outcomes, as OS and EFS were the lowest in the region with the lowest number of complete cytoreductive surgeries. However, when all patients were analysed together (including those with no or limited therapy), survival was comparable between all regions. Patient selection to those who benefit from cytoreductive surgery and chemotherapy may explain this discrepancy, and this may differ between regions. Moreover, the impact of the observed variation in clinical outcome is susceptible to a variety of biases. Earlier studies showed that initial disease burden at diagnosis influenced OS, while patients had the same amount of residual disease after surgery ${ }^{36,38}$. In addition, we observed that EFS was more affected than OS by the treatment region. This may be explained by other differences between geographical regions. Long-term overall survival is not only influenced by the primary treatment, but also by a patient's response to treatment for recurrent disease. Data about treatment after recurrence is lacking, however, in our database. Finally, the judgement of residual disease between geographical regions probably differs between gynaecologists, and may have influenced our results ${ }^{40,41}$.

Our study has some limitations. The amount of intra-abdominal disease at diagnosis (besides FIGO stage) as well as the location of the tumour bulk (upper or lower abdomen) were unknown in our database. These factors are inherently associated with successful surgery, and may explain (some) variation between regions. Moreover, a substantial number of patients did not undergo any treatment, but the rationale for omitting treatment in individual patients was not recorded. At last, our multivariable models were not adjusted for the use of (hyperthermic) intraperitoneal chemotherapy, and could have potentially biased our results since this is associated with improved survival in selected patient populations ${ }^{42,43}$. Strengths of our study are the population-based character, complete follow-up status, and additional data in treated patients (such as comorbidity, CA125 at diagnosis and performance status) for which we could adjust our models. 
In conclusion, we observed significant variation in the treatment approach between geographical regions, and in the probability to reach no macroscopic residual disease. This variation resulted in survival differences in the treated population, but not when all patients were analysed together. As the results of upcoming RCTs are eagerly awaited for the optimal treatment approach, stricter compliance to surgical guidelines may improve outcome of surgery.

\section{Acknowledgements}

The authors thank the registration team of the Netherlands Comprehensive Cancer Organisation (IKNL) for the collection of data for the Netherlands Cancer Registry.

\section{Funding}

This work was supported by Dutch Cancer Society [IKNL2014-6838]. 


\section{REFERENCES}

1. Torre LA, Bray F, Siegel RL, Ferlay J, LortetTieulent J, Jemal A. Global cancer statistics, 2012. CA Cancer J Clin. 2015;65(2):87-108.

2. Sant M, Chirlaque Lopez MD, Agresti R, Sanchez Perez MJ, Holleczek B, BielskaLasota $M$, et al. Survival of women with cancers of breast and genital organs in europe 1999-2007: Results of the eurocare-5 study. Eur J Cancer. 2015;51(15):2191-205.

3. du Bois A, Reuss A, Pujade-Lauraine E, Harter P, Ray-Coquard I, Pfisterer J. Role of surgical outcome as prognostic factor in advanced epithelial ovarian cancer: A combined exploratory analysis of 3 prospectively randomized phase 3 multicenter trials: By the arbeitsgemeinschaft gynaekologische onkologie studiengruppe ovarialkarzinom (ago-ovar) and the groupe d'investigateurs nationaux pour les etudes des cancers de l'ovaire (gineco). Cancer. 2009;115(6):123444.

4. Chang SJ, Hodeib M, Chang J, Bristow RE. Survival impact of complete cytoreduction to no gross residual disease for advancedstage ovarian cancer: A meta-analysis. Gynecol Oncol. 2013;130(3):493-8.

5. Vergote I, Trope CG, Amant F, Kristensen $\mathrm{GB}$, Ehlen $\mathrm{T}$, Johnson $\mathrm{N}$, et al. Neoadjuvant chemotherapy or primary surgery in stage iiic or iv ovarian cancer. N Engl J Med. 2010;363(10):943-53.

6. Kehoe S, Hook J, Nankivell M, Jayson GC, Kitchener H, Lopes $T$, et al. Primary chemotherapy versus primary surgery for newly diagnosed advanced ovarian cancer (chorus): An open-label, randomised, controlled, non-inferiority trial. Lancet. 2015;386(9990):249-57.
7. Woo YL, Kyrgiou M, Bryant A, Everett $T$, Dickinson HO. Centralisation of services for gynaecological cancers - a cochrane systematic review. Gynecol Oncol. 2012;126(2):286-90.

8. Dahm-Kahler P, Palmqvist C, Staf C, Holmberg E, Johannesson L. Centralized primary care of advanced ovarian cancer improves complete cytoreduction and survival - a population-based cohort study. Gynecol Oncol. 2016;142(2):211-6.

9. Eggink $\mathrm{FA}, \mathrm{Mom} \mathrm{CH}$, Kruitwagen RF, Reyners AK, Van Driel WJ, Massuger LF, et al. Improved outcomes due to changes in organization of care for patients with ovarian cancer in the netherlands. Gynecol Oncol. 2016.

10. Querleu D, Planchamp F, Chiva L, Fotopoulou C, Barton D, Cibula D, et al. European society of gynaecologic oncology quality indicators for advanced ovarian cancer surgery. Int J Gynecol Cancer. 2016;26(7):1354-63.

11. Rutten MJ, van Meurs HS, van de Vrie R, Gaarenstroom KN, Naaktgeboren CA, van Gorp T, et al. Laparoscopy to predict the result of primary cytoreductive surgery in patients with advanced ovarian cancer: A randomized controlled trial. J Clin Oncol. 2017;35(6):613-21.

12. Makar AP, Trope CG, Tummers P, Denys $H$, Vandecasteele K. Advanced ovarian cancer: Primary or interval debulking? Five categories of patients in view of the results of randomized trials and tumor biology: Primary debulking surgery and interval debulking surgery for advanced ovarian cancer. Oncologist. 2016;21(6):745-54. 
13. Bristow RE, Chi DS. Platinum-based neoadjuvant chemotherapy and interval surgical cytoreduction for advanced ovarian cancer: A meta-analysis. Gynecol Oncol. 2006;103(3):1070-6.

14. Meyer LA, Cronin AM, Sun CC, Bixel K, Bookman MA, Cristea MC, et al. Use and effectiveness of neoadjuvant chemotherapy for treatment of ovarian cancer. Journal of Clinical Oncology. 2016;34(32):3854-63.

15. Fritz AG. International classification of diseases for oncology : Icd-o. 3rd ed. Geneva: World Health Organization; 2000. vii, 240 p. p.

16. Charlson M, Szatrowski TP, Peterson J, Gold J. Validation of a combined comorbidity index. J Clin Epidemiol. 1994;47(11):1245-51.

17. Louwman WJ, Aarts MJ, Houterman S, van Lenthe FJ, Coebergh JW, JanssenHeijnen ML. A 50\% higher prevalence of life-shortening chronic conditions among cancer patients with low socioeconomic status. Br J Cancer. 2010;103(11):1742-8.

18. Aarts MJ, Koldewijn EL, Poortmans PM, Coebergh JW, Louwman M. The impact of socioeconomic status on prostate cancer treatment and survival in the southern netherlands. Urology. 2013;81(3):593-9.

19. van Duijn C, Keij I. Sociaal-economische status indicator op postcode niveau. [article in dutch]. Maandstatistiek van de bevolking. 2002;50:32-5.

20. Fourcadier E, Tretarre B, Gras-Aygon C, Ecarnot F, Daures JP, Bessaoud F. Undertreatment of elderly patients with ovarian cancer: A population based study. BMC Cancer. 2015;15:937.
21. Jordan S, Steer C, DeFazio A, Quinn M, Obermair A, Friedlander $\mathrm{M}$, et al. Patterns of chemotherapy treatment for women with invasive epithelial ovarian cancer--a population-based study. Gynecol Oncol. 2013;129(2):310-7.

22. Jorgensen $T L$, Teiblum $S$, Paludan $M$, Poulsen LO, Jorgensen AY, Bruun KH, et al. Significance of age and comorbidity on treatment modality, treatment adherence, and prognosis in elderly ovarian cancer patients. Gynecol Oncol. 2012;127(2):36774.

23. Schuurman MS, Kruitwagen R, Portielje JEA, Roes EM, Lemmens V, van der Aa MA. Treatment and outcome of elderly patients with advanced stage ovarian cancer: A nationwide analysis. Gynecol Oncol. 2018;149(2):270-4.

24. Eisenhauer EL, Tew WP, Levine DA, Lichtman SM, Brown CL, Aghajanian C, et al. Response and outcomes in elderly patients with stages iiic-iv ovarian cancer receiving platinum-taxane chemotherapy. Gynecol Oncol. 2007;106(2):381-7.

25. Tinquaut F, Freyer G, Chauvin F, Gane N, Pujade-Lauraine E, Falandry C. Prognostic factors for overall survival in elderly patients with advanced ovarian cancer treated with chemotherapy: Results of a pooled analysis of three gineco phase ii trials. Gynecol Oncol. 2016;143(1):22-6.

26. Fairfield KM, Murray K, Lucas FL, Wierman HR, Earle CC, Trimble EL, et al. Completion of adjuvant chemotherapy and use of health services for older women with epithelial ovarian cancer. J Clin Oncol. 2011;29(29):3921-6. 
27. Mohile SG, Dale W, Somerfield MR, Schonberg MA, Boyd CM, Burhenn PS, et al. Practical assessment and management of vulnerabilities in older patients receiving chemotherapy: Asco guideline for geriatric oncology. J Clin Oncol. 2018:JC O2018788687.

28. Integraal kanker centrum nederland - epitheliaal ovariumcarcinoom versie 2.0 (2012). Https://www.Oncoline.NI/ ovariumcarcinoom. Accessed september 2018.

29. National institute for health and clinical excellence - recognition and initial management of ovarian cancer (2011). Www.Nice.Org.Uk/cg122. Accessed september 2018.

30. Federaal kenniscentrum voor de gezondheidszorg- eierstokkanker: Diagnose, behandeling en follow-up (2016). Https:// kce.Fgov.Be/sites/default/files/atoms/files/ kce_268as_eierstokkanker_samevatting. Pdf. Accessed september 2018.

31. Wright AA, Bohlke $K$, Armstrong DK, Bookman MA, Cliby WA, Coleman RL, et al. Neoadjuvant chemotherapy for newly diagnosed, advanced ovarian cancer: Society of gynecologic oncology and american society of clinical oncology clinical practice guideline. J Clin Oncol. 2016;34(28):3460-73.

32. Wagner $U$, Harter $P$, Hilpert $F$, Mahner S, Reuss A, du Bois A, et al. S3-guideline on diagnostics, therapy and follow-up of malignant ovarian tumours: Short version 1.0- awmf registration number: 032/035ol, june 2013. Geburtshilfe Frauenheilkd. 2013;73(9):874-89.

33. Salas M, Hofman A, Stricker BH. Confounding by indication: An example of variation in the use of epidemiologic terminology. Am J Epidemiol. 1999;149(11):981-3.
34. Fotopoulou C, Sehouli J, Aletti G, Harter P, Mahner S, Querleu D, et al. Value of neoadjuvant chemotherapy for newly diagnosed advanced ovarian cancer: A european perspective. I Clin Oncol. 2017;35(6):587-90.

35. Fagotti A, Ferrandina G, Vizzielli G, Fanfani F, Gallotta V, Chiantera V, et al. Phase iii randomised clinical trial comparing primary surgery versus neoadjuvant chemotherapy in advanced epithelial ovarian cancer with high tumour load (scorpion trial): Final analysis of peri-operative outcome. Eur J Cancer. 2016;59:22-33.

36. Horowitz NS, Miller A, Rungruang B, Richard SD, Rodriguez N, Bookman MA, et al. Does aggressive surgery improve outcomes? Interaction between preoperative disease burden and complex surgery in patients with advanced-stage ovarian cancer: An analysis of gog 182. J Clin Oncol. 2015;33(8):937-43.

37. Bonome T, Levine DA, Shih J, Randonovich $M$, Pise-Masison CA, Bogomolniy $F$, et al. A gene signature predicting for survival in suboptimally debulked patients with ovarian cancer. Cancer Res. 2008;68(13):5478-86.

38. Rodriguez N, Miller A, Richard SD, Rungruang B, Hamilton CA, Bookman MA, et al. Upper abdominal procedures in advanced stage ovarian or primary peritoneal carcinoma patients with minimal or no gross residual disease: An analysis of gynecologic oncology group (gog) 182. Gynecol Oncol. 2013;130(3):487-92.

39. Timmermans M, Schuurman MS, Ho VKY, Massuger LF, Nijman HW, van Gorp T, et al. Centralization of ovarian cancer in the netherlands: Hospital of diagnosis no longer determines patients' probability of undergoing surgery. Gynecol Oncol. 2018;148(1):56-61. 
40. Eskander RN, Kauderer J, Tewari KS, Mannel RS, Bristow RE, O'Malley DM, et al. Correlation between surgeon's assessment and radiographic evaluation of residual disease in women with advanced stage ovarian cancer reported to have undergone optimal surgical cytoreduction: An nrg oncology/gynecologic oncology group study. Gynecol Oncol. 2018.

41. Prefontaine $M$, Gelfand AT, Donovan JT, Powell JL. Reproducibility of tumor measurements in ovarian cancer: A study of interobserver variability. Gynecol Oncol. 1994;55(1):87-90.

42. van Driel WJ, Koole SN, Sikorska K, Schagen van Leeuwen JH, Schreuder HWR, Hermans $\mathrm{RHM}$, et al. Hyperthermic intraperitoneal chemotherapy in ovarian cancer. N Engl J Med. 2018;378(3):230-40.

43. Jaaback K, Johnson N, Lawrie TA. Intraperitoneal chemotherapy for the initial management of primary epithelial ovarian cancer. Cochrane Database Syst Rev. 2016(1):CD005340. 


\section{SUPPLEMENTARY MATERIAL}

S1: Baseline characteristics of all patients stratified by oncological region

\begin{tabular}{|c|c|c|c|c|c|c|c|c|c|c|}
\hline & $\begin{array}{r}\text { Total } \\
\text { population } \\
(\%) \\
\end{array}$ & $\begin{array}{r}\text { Region } \\
1 \\
(\%) \\
\end{array}$ & $\begin{array}{r}\text { Region } \\
2 \\
(\%) \\
\end{array}$ & $\begin{array}{r}\text { Region } \\
3 \\
(\%) \\
\end{array}$ & $\begin{array}{r}\text { Region } \\
4 \\
(\%) \\
\end{array}$ & $\begin{array}{r}\text { Region } \\
5 \\
(\%) \\
\end{array}$ & $\begin{array}{r}\text { Region } \\
6 \\
(\%) \\
\end{array}$ & $\begin{array}{r}\text { Region } \\
7 \\
(\%) \\
\end{array}$ & $\begin{array}{r}\text { Region } \\
8 \\
(\%) \\
\end{array}$ & p-value \\
\hline Age & & & & & & & & & & $0.552+$ \\
\hline$<65$ & 37.2 & 40.2 & 37.9 & 36.7 & 34.6 & 37.1 & 37.9 & 38.1 & 33.3 & \\
\hline $65-75$ & 34.0 & 32.3 & 32.0 & 34.4 & 36.7 & 35.4 & 33.6 & 33.1 & 34.7 & \\
\hline$>75$ & 28.8 & 27.5 & 30.1 & 28.9 & 28.7 & 27.5 & 28.5 & 28.8 & 32.0 & \\
\hline Mean (SD) & $\begin{array}{r}67.8 \\
(12.1)\end{array}$ & $\begin{array}{r}67.0 \\
(12.3)\end{array}$ & $\begin{array}{r}68.0 \\
(12.4)\end{array}$ & $\begin{array}{r}68.2 \\
(11.5)\end{array}$ & $\begin{array}{r}68.0 \\
(11.6)\end{array}$ & $\begin{array}{r}67.5 \\
(12.2)\end{array}$ & $\begin{array}{r}67.5 \\
(12.6)\end{array}$ & $\begin{array}{r}67.7 \\
(11.9)\end{array}$ & $\begin{array}{r}68.9 \\
(11.3)\end{array}$ & $0.117^{\prime}$ \\
\hline FIGO stage & & & & & & & & & & 0.011 \\
\hline IIIC & 60.9 & 61.2 & 60.4 & 60.8 & 59.3 & 63.5 & 61.9 & 62.9 & 54.7 & \\
\hline IV & 34.7 & 34.9 & 34.2 & 34.5 & 34.5 & 32.6 & 35.2 & 32.8 & 39.1 & \\
\hline Unknown & 4.4 & 3.9 & 5.4 & 4.7 & 6.2 & 3.9 & 2.9 & 4.3 & 6.2 & \\
\hline SES & & & & & & & & & & $<0.001$ \\
\hline Low & 30.0 & 36.8 & 13.4 & 46.2 & 23.6 & 16.5 & 23.6 & 29.9 & 43.4 & \\
\hline Middle & 40.0 & 38.2 & 38.8 & 41.2 & 45.6 & 33.2 & 36.3 & 46.4 & 44.5 & \\
\hline High & 30.0 & 25.0 & 47.8 & 12.6 & 30.8 & 50.3 & 40.1 & 23.7 & 12.1 & \\
\hline Histologic subtype & & & & & & & & & & $<0.001$ \\
\hline Serous & 65.7 & 67.9 & 72.0 & 68.1 & 62.0 & 63.2 & 65.0 & 65.0 & 68.6 & \\
\hline Mucinous & 2.3 & 2.7 & 2.3 & 1.4 & 3.0 & 2.0 & 1.6 & 1.6 & 3.5 & \\
\hline Endometrioid & 2.7 & 3.5 & 2.5 & 2.1 & 1.5 & 3.1 & 2.0 & 2.0 & 1.9 & \\
\hline Clear-cell & 2.2 & 1.9 & 2.7 & 2.5 & 1.5 & 2.2 & 2.6 & 2.6 & 2.1 & \\
\hline Adenocarcinoma NOS & 25.0 & 21.3 & 18.7 & 24.7 & 28.9 & 26.8 & 26.2 & 26.2 & 22.7 & \\
\hline Other & 2.1 & 2.7 & 1.8 & 1.2 & 3.1 & 2.7 & 2.6 & 2.6 & 1.2 & \\
\hline Differentiation grade & & & & & & & & & & $<0.001$ \\
\hline । & 3.2 & 3.4 & 2.5 & 2.5 & 2.5 & 4.3 & 4.2 & 2.0 & 2.9 & \\
\hline$\|$ & 7.0 & 8.2 & 8.6 & 6.5 & 6.6 & 8.6 & 5.5 & 6.0 & 9.0 & \\
\hline III & 40.9 & 41.3 & 42.9 & 39.9 & 37.9 & 33.6 & 41.7 & 47.3 & 43.0 & \\
\hline Unknown & 48.9 & 47.1 & 46.0 & 51.1 & 53.0 & 53.5 & 48.6 & 44.7 & 45.1 & \\
\hline CCl score* & & & & & & & & & & $<0.001$ \\
\hline 0 & 65.1 & 62.6 & 62.9 & 64.6 & 64.4 & 67.5 & 65.8 & 67.4 & 65.2 & \\
\hline 1 & 16.6 & 17.0 & 13.8 & 19.3 & 16.1 & 17.7 & 15.5 & 16.9 & 16.0 & \\
\hline$\geq 2$ & 15.9 & 16.1 & 16.3 & 15.3 & 17.8 & 13.2 & 17.3 & 13.3 & 16.9 & \\
\hline Unknown & 2.4 & 4.3 & 7.0 & 0.8 & 1.7 & 1.6 & 1.4 & 2.4 & 1.9 & \\
\hline
\end{tabular}

* CCl score: Charlson Comorbidity Score ${ }^{+}$Chi-square test ${ }^{\ddagger}$ ANOVA test 


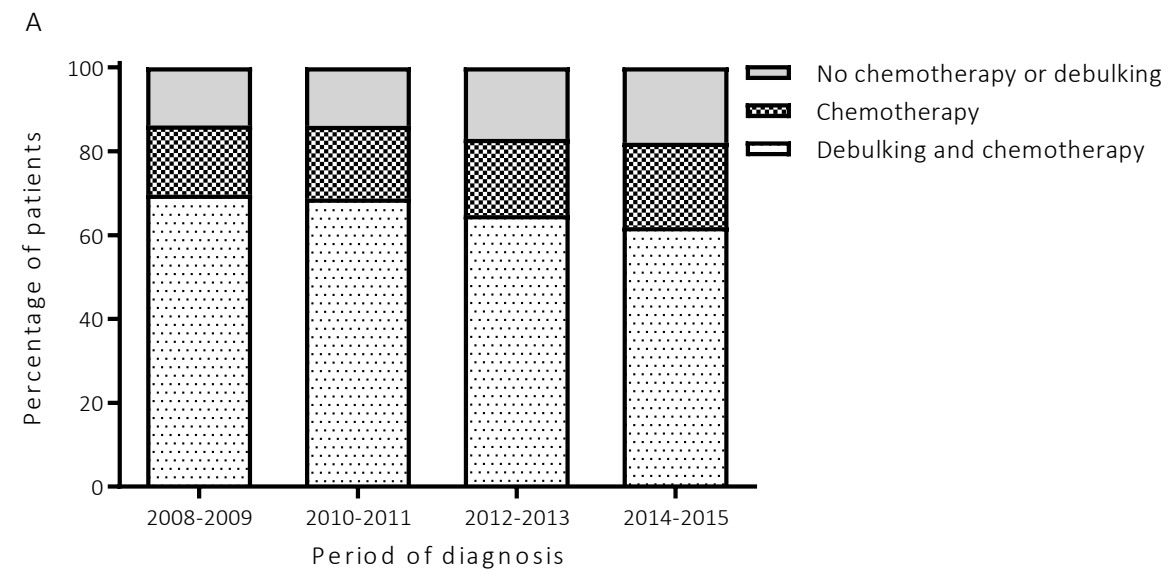

B

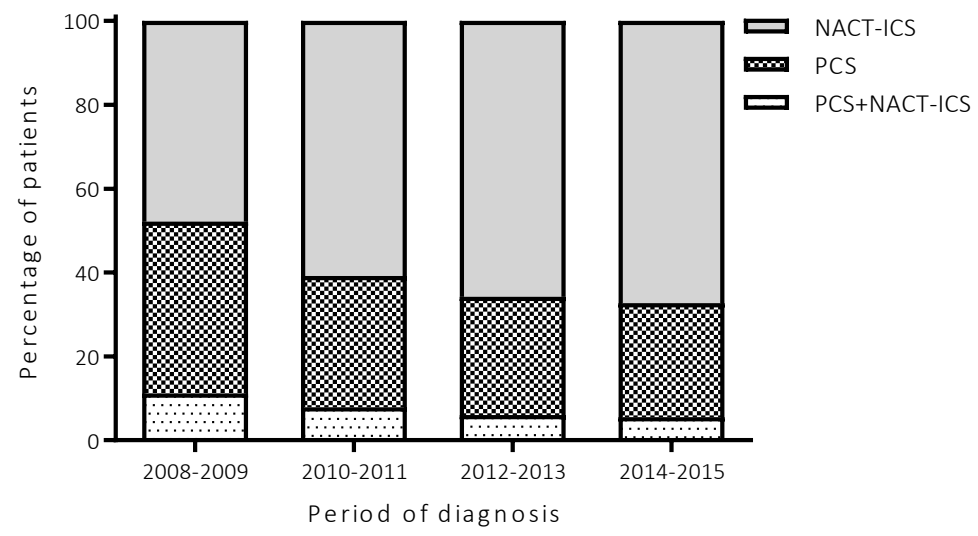

S2: Trends in treatment approach (A) and treatment sequence (B) in advanced stage EOC patients over time 
A

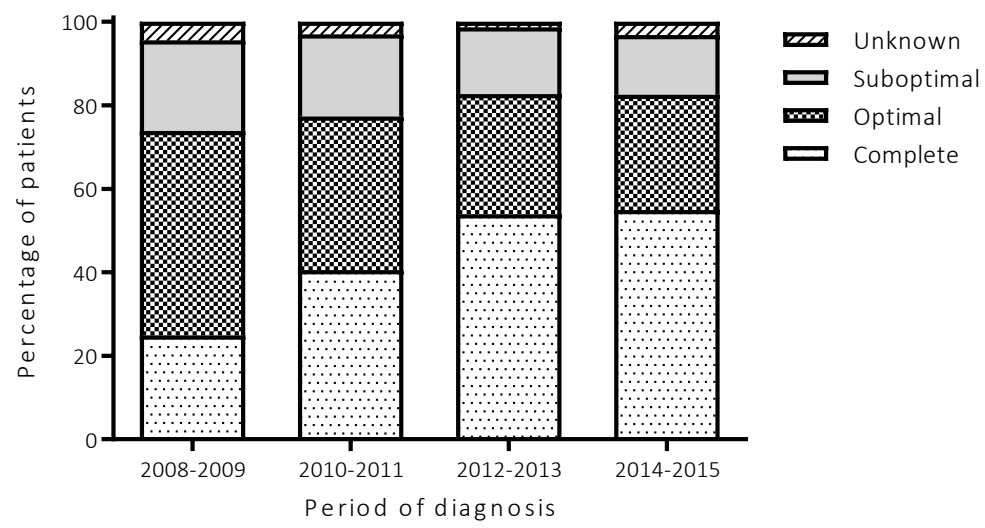

B

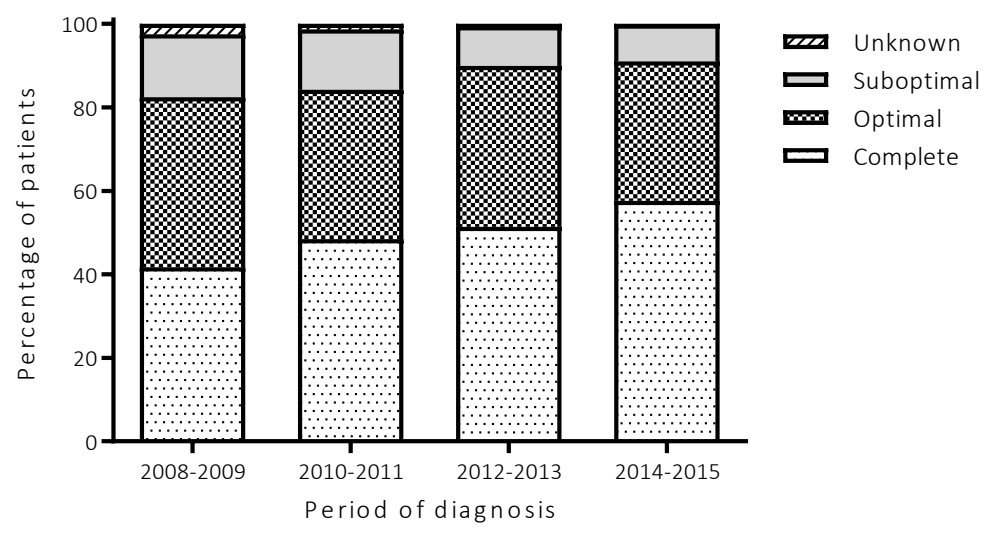

S3: Trends in surgical outcomes after PCS (A) and after NACT-ICS (B) in advanced stage EOC patients over time 
S4: Overall survival outcomes for FIGO stage IIIC and IV patients, stratified by treatment sequence and surgical outcome

\begin{tabular}{|c|c|c|c|c|}
\hline & $\begin{array}{r}\text { 5-year survival } \\
(\%)\end{array}$ & $\begin{array}{r}\text { Median survival } \\
\text { (months) }\end{array}$ & $\begin{array}{r}\text { Univariable HR } \\
(95 \% \mathrm{Cl})\end{array}$ & $\begin{array}{r}\text { Multivariable HR } \\
(95 \% \mathrm{Cl})^{+}\end{array}$ \\
\hline PCS, complete & 54.3 & 66.8 & reference & reference \\
\hline NACT-ICS, complete & 32.9 & 40.9 & 1.75 (1.53-1.99) & $1.63(1.41-1.88)$ \\
\hline PCS, optimal & 32.4 & 38.2 & $1.90(1.63-2.21)$ & $1.89(1.59-2.21)$ \\
\hline NACT-ICS, optimal & 14.6 & 27.3 & $3.02(2.64-3.45)$ & $2.74(2.36-3.18)$ \\
\hline PCS, suboptimal & 9.8 & 15.7 & $4.86(4.10-5.78)$ & $4.38(3.63-5.27)$ \\
\hline NACT-ICS, suboptimal & 6.4 & 19.2 & $4.73(4.03-5.55)$ & $4.35(3.66-5.17)$ \\
\hline
\end{tabular}

${ }^{+}$Adjusted for age (continuous), FIGO stage, histologic subtype, differentiation grade, performance score, $\mathrm{CCl}$ and CA125 at diagnosis 




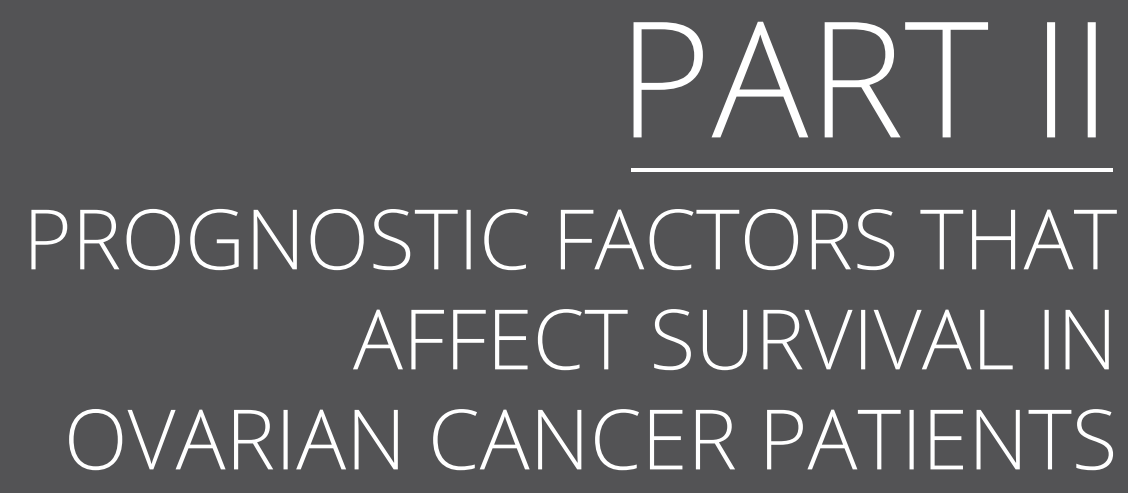



Perioperative change in CA125 is an independent prognostic factor for improved clinical outcome in advanced ovarian cancer

M. Timmermans, N. Zwakman, G.S. Sonke, K.K. Van de Vijver, M.J. Duk, M.A. van der Aa, R.F. Kruitwagen 


\section{ABSTRACT}

\section{Objective}

Despite being the most important prognostic factor for prolonged overall survival in epithelial ovarian cancer (EOC), the measurement of residual disease is hampered by its subjective character. Additional assessment tools are needed to establish the success of cytoreductive surgery in order to predict patients' prognosis more accurately. The aim of this study is to evaluate the independent prognostic value of perioperative CA125 change in advanced stage EOC patients.

\section{Study design}

We identified all patients who underwent primary cytoreductive surgery for advanced stage (FIGO IIB-IV) EOC between 2008 and 2015, from the Netherlands Cancer Registry. The relative perioperative change in CA125 was categorised into four groups; increase, $<50 \%$ decline, $50-79 \%$ decline and $\geq 80 \%$ decline. Overall survival (OS) was analysed using Kaplan-Meier survival curves and multivariable cox regression models.

\section{Results}

We included 1,232 eligible patients with known pre- and postoperative CA125 serum levels. Patients with a decline of $\geq 80 \%$ in CA125 levels experienced improved OS compared to those with a decline of $<50 \%$ (univariable Hazard Ratio (HR) $0.45,95 \% \mathrm{Cl} 0.36-0.57$ ). The prognostic effect of perioperative CA125 change was independent of patient- and treatment characteristics, such as the extent of residual disease after cytoreductive surgery (multivariable $\mathrm{HR}_{\geq 80 \%} 0.52(0.41-0.66)$ ).

\section{Conclusions}

This study shows that the perioperative change in CA125 is an independent prognostic factor for overall survival after primary surgery for EOC patients. This pleads for the use of a combined model, consisting of perioperative CA125 change and the outcome of residual disease, in order to predict the prognosis of EOC patients more accurately. 


\section{INTRODUCTION}

Epithelial ovarian cancer (EOC) is the leading cause of death from gynaecological tumours ${ }^{1}$. Since 1999, the five-year overall survival (OS) rates have hardly changed, resulting in an OS of $35 \%^{2-5}$. Management of advanced stage ovarian cancer consists of surgical cytoreduction and (neo)adjuvant platinum-based chemotherapy. The timing of surgery depends on patient characteristics and extensiveness of the tumour in relation to the ability of achieving maximal cytoreduction ${ }^{6,7}$.

Despite being the most important prognostic factor for prolonged OS in EOC patients, measurement of the extent of residual disease is hampered by several factors ${ }^{8-10}$. First, it is based on the surgeons' intraoperative assessment, and is therefore subject to interand intra-observer variability ${ }^{11,12}$. Second, it can be difficult to distinguish viable residual tumour from fibrotic lesions, particularly after neoadjuvant chemotherapy (NACT). Third, residual disease does not account for the number of lesions but only for the largest lesion in maximum diameter, and is therefore a crude measure of the residual cancer burden. Additional assessment tools are needed to establish the success of cytoreductive surgery in order to predict patients' prognosis more accurately ${ }^{12,13}$.

In search of new prognostic factors, it is suggested that initial disease burden influences the prognosis of patients, regardless of successful surgery ${ }^{14,15}$. This implies that disease presentation should be incorporated into new prognostic factors. The perioperative change in CA125 is an objective measurement which includes initial disease presentation, and may be a better marker for residual cancer burden after cytoreductive surgery (and therewith disease-specific survival), than the surgeons' estimation of residual tumour volume. Prior studies evaluating the prognostic value of perioperative CA125 decline were limited by a small sample size, precluding optimal multivariable adjustments ${ }^{16-18}$. Nevertheless, a decline in CA125 $<50 \%$ was associated with higher crude disease-specific mortality ${ }^{16,19-21}$.

The aim of this study is to establish the independent prognostic value of perioperative CA125 change in advanced EOC patients who underwent primary cytoreductive surgery. In addition, we aim to provide insight into the association between perioperative CA125 change and the outcome of cytoreductive surgery.

\section{METHODS}

Patients were identified from the Netherlands Cancer Registry (NCR), which is a nationwide cancer registry with coverage of all newly diagnosed malignancies in the Netherlands since 1989. Information on vital status and date of death were obtained from the municipal 
demography registries. The study design, data abstraction process and storage protocols were approved by the NCR review board.

\section{Study population}

For this study, we identified all consecutive patients diagnosed with EOC, including primary peritoneal and fallopian tube carcinoma (ICD-O codes C48.2, C56.9 and C57.0) 22, between 01.01.2008 and 31.12.2015 in the Netherlands. We selected all advanced stage patients (FIGO IIB-IV) who underwent primary cytoreductive surgery. FIGO stage (2014) was derived from the registered Tumour Nodal Metastasis (TNM) staging system ${ }^{23}$.

Dedicated registration clerks from the NCR reviewed all medical files of eligible patients to extract additional clinical data for this study. We collected all available CA125 values from date of diagnosis until the first CA125 value after the last treatment date. Furthermore, additional information about treatment protocol (details of chemotherapy and surgery), patient characteristics (i.e. Charlson Comorbidity Index and volume of ascites) and followup (disease progression) were collected ${ }^{24}$.

\section{Definitions}

Patients were eligible for analysis if CA125 values were recorded pre- and postoperatively, and if postoperative CA125 was determined before the initiation of adjuvant chemotherapy. If more than one preoperative value was documented $(n=260)$, the value closest to the date of cytoreductive surgery was used. For patients with more than one postoperative value before the initiation of adjuvant chemotherapy $(n=137)$, the lowest value was chosen as this probably reflects the effect of surgery best. Patients with normal preoperative CA125 values $(<35 \mathrm{U} / \mathrm{mL})$ were excluded $(\mathrm{S} 1)$.

In order to compare our results to previous studies, CA125 decline was categorised within the same groups; $<50 \%$ decline, $50-79 \%$ decline and $\geq 80 \%$ decline. Patients with an increase in CA125 levels were, however, analysed as a separate group in our study as it was expected that these patients may have a worse prognosis.

The outcome of cytoreductive surgery was defined as complete (no macroscopic residual disease), optimal (largest tumour nodule $\leq 1 \mathrm{~cm}$ in maximal diameter) or suboptimal (largest tumour nodule $>1 \mathrm{~cm}$ in maximal diameter). Patients with an unknown amount of residual disease were excluded (S1). 


\section{Statistical analyses}

Categorical variables were expressed as percentages, and chi-square tests were used to identify differences between groups. Continuous variables were expressed as the mean with a standard deviation if they were normally distributed, or as geometric mean with a confidence interval if skewed. Absolute CA125 levels showed a positively skewed distribution and were therefore $\log _{\mathrm{e}}$-transformed for further analyses in this study. Uniand multivariable linear regression analyses were used to compare perioperative change in CA125 levels by the outcome of cytoreductive surgery.

Progression-free survival (PFS) was defined as the time between date of diagnosis and progression or death, whichever occurred first. Progression was defined as clinical signs of tumour growth, i.e. increase in CA125 and/or visible lesions on imaging techniques (either regrowth of pre-existing lesions or new lesions), combined with the clinical judgment of the treating physician (medical oncologist or gynaecologist). Patients who were alive without record of progressive disease were censored at the date of their last hospital visit. OS was defined as the time between date of diagnosis and death or last follow-up for patients who were alive (01.02.2018). PFS and OS were analysed using Kaplan-Meier survival curves and multivariable cox regression models. A $P$-value $<0.05$ was considered statistically significant and statistical analyses were performed using STATA/SE (version 14.1; STATA CORP., College Station, Texas, USA).

\section{RESULTS}

We identified 2,113 eligible advanced stage EOC patients who underwent primary cytoreductive surgery of whom 881 patients were excluded (S1). Patients who were excluded were slightly older, more often had non-serous types of tumours and less often had an optimal debulking. The FIGO stage distribution was comparable between in- and excluded patients (S2). A total of 1,232 patients was included for analyses and baseline characteristics, stratified by the perioperative CA125 change, are listed in the supplementary material (S3). As can be appreciated from table S3, patients that had a decrease of $>80 \%$ were slightly younger, and were less often diagnosed in FIGO stage IV. The median time between the last preoperative CA125 value and cytoreductive surgery was 22 days (IQR 14-33), and the median time between cytoreductive surgery and the postoperative CA125 value was also 22 days (IQR 16-29). 


\section{Perioperative change in CA125 levels}

The preoperative CA125 values for patients with no macroscopic residual disease after cytoreductive surgery were significantly lower compared to patients with $\leq 1 \mathrm{~cm}$ residual disease $(P=0.001)$ or $>1 \mathrm{~cm}$ residual disease $(P=0.003$, table 1$))$. The preoperative CA125 values did not differ significantly between an optimal or suboptimal result during cytoreductive surgery ( $P=0.566$, figure 1$)$.

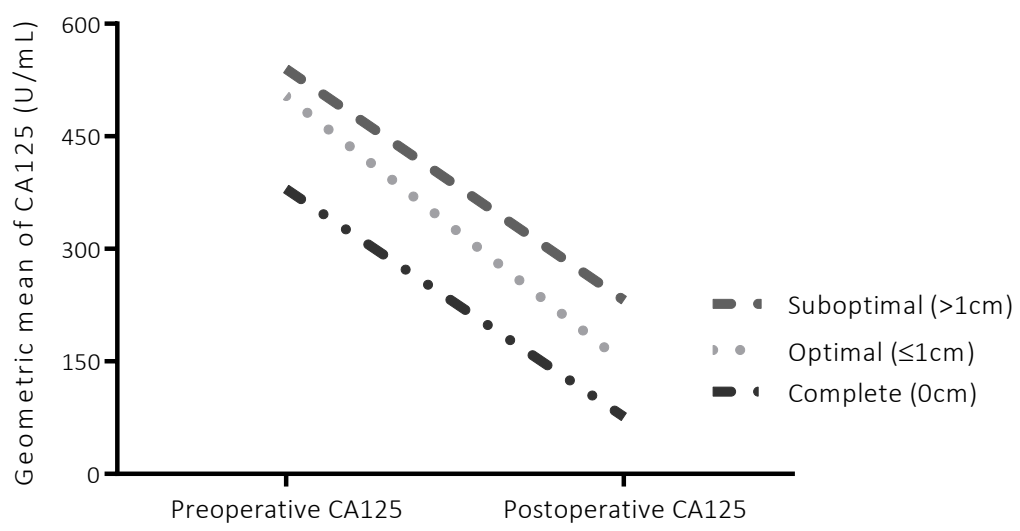

Figure 1: Perioperative CA125 decline stratified by the outcome of surgery

Moreover, after adjustment for age, FIGO stage, the amount of ascites and the time between CA125 measurement and surgery, preoperative CA125 levels did not differ between any of the groups ( $P=0.520$, table 1$)$.

The postoperative CA125 levels were significantly lower after complete cytoreductive surgery compared to patients with macroscopic residual disease, also after adjustment for the listed variables above (figure 1, table 1). In addition, postoperative CA125 levels after an optimal cytoreduction were also significantly lower when compared to patients with $>1$ $\mathrm{cm}$ of residual disease.

The absolute decline in CA125 was not associated with the outcome of cytoreductive surgery (table 2). The relative CA125 decline, however, differed significantly between patients with complete, optimal and incomplete cytoreductive surgery $(P<0.001)$. Patients with no residual disease experienced more often a decrease $\geq 80 \%$ compared to patients with any macroscopic residual disease (figure 2). 
Table 1: Association between CA125 levels and the outcome of surgery

\begin{tabular}{|c|c|c|c|c|c|c|}
\hline & $\begin{array}{l}\text { CA125 level } \\
(\mathrm{U} / \mathrm{mL})\end{array}$ & $\begin{array}{l}\text { CA125 level } \\
(\mathrm{U} / \mathrm{mL})\end{array}$ & Model I & & Model II & \\
\hline & $\begin{array}{l}\text { Geometric mean } \\
(95 \% \mathrm{Cl})\end{array}$ & $\begin{array}{l}\log _{e} \text { mean } \\
(\mathrm{SD})\end{array}$ & $\beta$-coefficient & $\mathrm{p}$-value $\mathrm{e}^{\mathrm{a}}$ & $\beta$-coefficient & $p$-value \\
\hline \multicolumn{7}{|c|}{ Preoperative CA125 } \\
\hline Suboptimal & $540(443-656)$ & $6.29(1.25)$ & Reference & & Reference & \\
\hline Optimal & $504(447-568)$ & $6.11(1.31)$ & $\begin{array}{l}-0.07 \\
(-0.30,0.17)\end{array}$ & 0.566 & $\begin{array}{l}0.01 \\
(-0.22,0.24)\end{array}$ & 0.960 \\
\hline \multirow[t]{2}{*}{ Complete } & $380(342-422)$ & $5.94(1.32)$ & $\begin{array}{l}-0.35 \\
(-0.58,-0.12)\end{array}$ & 0.003 & $\begin{array}{l}-0.06 \\
(-0.29,0.18)\end{array}$ & 0.645 \\
\hline & & & Linear trend & $<0.001$ & Linear trend & 0.520 \\
\hline \multicolumn{7}{|c|}{ Postoperative CA125 } \\
\hline Suboptimal & $232(186-288)$ & $5.45(1.40)$ & Reference & & Reference & \\
\hline Optimal & $148(132-166)$ & $5.00(1.26)$ & $\begin{array}{l}-0.45 \\
(-0.67,-0.23)\end{array}$ & $<0.001$ & $\begin{array}{l}-0.31 \\
(-0.51,-0.11)\end{array}$ & 0.002 \\
\hline \multirow[t]{2}{*}{ Complete } & $76(70-83)$ & $4.34(1.11)$ & $\begin{array}{l}-1.11 \\
(-1.32,-0.90)\end{array}$ & $<0.001$ & $\begin{array}{l}-0.68 \\
(-0.88,-0.47)\end{array}$ & $<0.001$ \\
\hline & & & Linear trend & $<0.001$ & Linear trend & $<0.001$ \\
\hline \multicolumn{7}{|c|}{ Decline (absolute) } \\
\hline Suboptimal & $293(225-383)$ & $5.68(1.54)$ & Reference & & Reference & \\
\hline Optimal & $340(291-397)$ & $5.83(1.60)$ & $\begin{array}{l}0.15 \\
(-0.17,0.46)\end{array}$ & 0.363 & $\begin{array}{l}0.21 \\
(-0.10,0.52)\end{array}$ & 0.186 \\
\hline \multirow[t]{2}{*}{ Complete } & $299(261-342)$ & $5.70(1.60)$ & $\begin{array}{l}0.02 \\
(-0.29,0.32)\end{array}$ & 0.912 & $\begin{array}{l}0.29 \\
(-0.03,0.61)\end{array}$ & 0.074 \\
\hline & & & Linear trend & 0.639 & Linear trend & 0.092 \\
\hline
\end{tabular}

${ }^{a}$ Model I: crude regression model ${ }^{\mathrm{b}}$ Model II: regression model with adjustment for age, FIGO stage, the amount of ascites and the time between CA125 and surgery (preoperative CA125) or surgery and CA125 (postoperative CA125)

\section{Prognostic effect of perioperative CA125 change}

The relative CA125 decline is a prognostic factor for OS $(P<0.001$, figure 3$)$. Patients with a decline of $\geq 80 \%$ in CA125 levels experienced improved crude OS compared to patients with a decline of 50-79\% (Hazard Rate (HR) 0.55, 95\% Cl 0.45-0.67) and to patients with a decline of $<50 \%$ (HR 0.45(0.36-0.57)), also when adjusted for patient- and tumour characteristics including the amount of residual disease and the histological subtype (adjusted HR's in table 2). In addition, patients with an increase in perioperative CA125 experienced worse OS compared to patients with a decline of $<50 \%$ (HR 1.49(1.15-1.93)). The prognosis of patients with a decline of $50-79 \%$ was comparable to those with a decline of $<50 \%$ (HR 0.94(0.76-1.17)). These effects were also observed for PFS (table 2). 


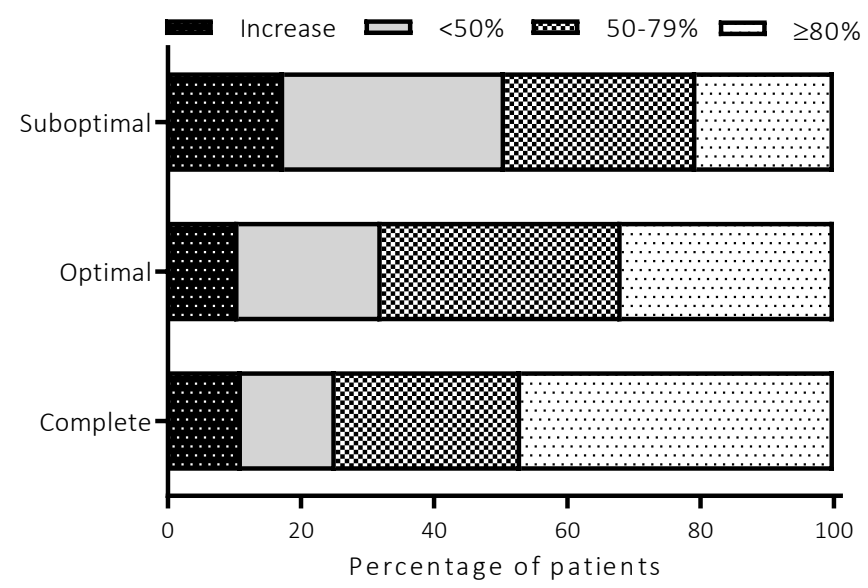

Figure 2: Categorised perioperative CA125 change stratified by the outcome of surgery

\section{Survival analyses stratified by the outcome of surgery}

In stratified analyses based on the outcome of surgery, the same patterns were observed. For example, when only patients with a complete cytoreduction were selected, the perioperative CA125 decline was still a prognostic factor for OS (S5). Again, the same patterns were observed for progression-free survival (table 2).

Table 2: Multivariable Cox regression models for overall- and progression-free survival

\begin{tabular}{|c|c|c|c|c|}
\hline & $\begin{array}{r}\text { All patients } \\
(\mathrm{HR}, 95 \% \mathrm{Cl})^{\mathrm{a}}\end{array}$ & $\begin{array}{r}\text { Complete debulking } \\
(\mathrm{HR}, 95 \% \mathrm{Cl})^{\mathrm{b}}\end{array}$ & $\begin{array}{r}\text { Optimal debulking } \\
(\mathrm{HR}, 95 \% \mathrm{Cl})^{\mathrm{b}}\end{array}$ & $\begin{array}{r}\text { Suboptimal debulking } \\
(\mathrm{HR}, 95 \% \mathrm{Cl})^{\mathrm{b}}\end{array}$ \\
\hline \multicolumn{5}{|l|}{ Overall survival } \\
\hline Increase & $1.49(1.15-1.93)$ & $1.85(1.18-2.89)$ & $1.38(0.90-2.11)$ & $1.00(0.56-1.80)$ \\
\hline$<50 \%$ decrease & Reference & Reference & Reference & Reference \\
\hline $50-79 \%$ decrease & $0.94(0.76-1.17)$ & $0.79(0.52-1.21)$ & $1.03(0.74-1.42)$ & $1.10(0.67-1.78)$ \\
\hline$\geq 80 \%$ decrease & $0.52(0.41-0.66)$ & $0.49(0.32-0.73)$ & $0.55(0.38-0.80)$ & $0.44(0.24-0.78)$ \\
\hline \multicolumn{5}{|c|}{ Progression-free survival } \\
\hline Increase & $1.24(1.00-1.57)$ & $1.71(1.16-2.52)$ & $1.02(0.70-1.50)$ & $0.97(0.57-1.68)$ \\
\hline$<50 \%$ decrease & Reference & Reference & Reference & Reference \\
\hline $50-79 \%$ decrease & $0.87(0.72-1.06)$ & $0.83(0.59-1.18)$ & $0.92(0.69-1.22)$ & $1.11(0.68-1.81)$ \\
\hline$\geq 80 \%$ decrease & $0.58(0.47-0.71)$ & $0.59(0.42-0.83)$ & $0.63(0.46-0.86)$ & $0.39(0.22-0.67)$ \\
\hline
\end{tabular}




\section{Sensitivity analyses}

Patients with a preoperative CA125 level between 35-160U/mL (lowest 25\% of our studied population), were less likely to experience a decline of $\geq 80 \%$ compared to those with higher baseline CA125 levels $(P<0.001)$. Therefore, we performed a sensitivity analysis in which we included the baseline CA125 level in our multivariable analyses. Trends in survival did not differ from our previous multivariable model $\left(H R_{\geq 80 \%-C A 125 \text { decline }} 0.50(0.39-0.64), H_{50-}\right.$ 79\%-CA125decline $0.92(0.74-1.15)$ and $H R_{\text {CA125increase }}$ 1.52(1.17-1.98) compared to a CA125 decline of $<50 \%)$.

\section{DISCUSSION}

In this population-based study, we observed that the relative perioperative change in serum CA125 is an independent prognostic factor for prolonged OS in advanced ovarian cancer. This prognostic effect was therefore also observed in patients with the same amount of residual disease, suggesting the need for a complementary model to predict clinical outcome more accurately in advanced ovarian cancer patients.

Both perioperative change in CA125 and the outcome of cytoreductive surgery were independent prognostic factors, so the association between the two factors needs to be addressed. Patients who underwent an optimal or suboptimal cytoreductive surgery had similar CA125 levels in the preoperative setting, while preoperative CA125 levels were significantly lower in the group of patients without macroscopic residual disease after surgery. However, after adjustment for FIGO stage and the presence of ascites, the height of the preoperative CA125 was similar in all groups despite differences in residual disease. These results suggest that FIGO stage and the presence of ascites are closely correlated to the serum level of CA125 preoperatively. CA125 is expressed on the ovarian tumour cell surface, and biological functions include, among others, the mesothelial cell adhesive interaction on peritoneal surfaces and modulation of tumour cell growth ${ }^{25-30}$. So, CA125 might play a role in the initial adhesion and subsequent implantation on the peritoneum, which enforces findings that the height of CA125 is associated with the tumour burden ${ }^{25,26}$. As the perioperative change in CA125 is closely associated with the outcome of cytoreductive surgery, it is not surprising that this decline is a prognostic factor for both PFS and OS ${ }^{16-18}$. But, even after adjustment for residual disease, the perioperative CA125 change remains an independent prognostic factor. A previous Dutch study showed that the perioperative CA125 change was a stronger predictor than postoperative residual disease ${ }^{16}$. In contrast, in the present study we found that both factors are important to establish the prognosis of patients. The discrepancy between the two studies is most likely caused by the larger 
cohort of this study. Moreover, it underlies the prognostic value of CA125 besides the outcome of residual disease.

Multiple studies confirmed that residual disease after surgery is the most important prognostic factor for prolonged $\mathrm{OS}^{8,10}$. The current method for determining residual disease after surgery relies on clinical intraoperative assessment. Several studies investigated the correlation between the surgeons' operative assessment and the amount of residual disease identified on postoperative computed tomography scans. These studies showed only a 46-60\% correlation between the two different methods, with a higher probability in underestimating the amount of residual disease than overestimating it ${ }^{12,31,32}$. Moreover, tumour measurements in individual patients by different surgeons are highly variable ${ }^{11}$. However, while searching for better prognostic factors to predict clinical outcomes in ovarian cancer, no factor seems to be more valuable than the amount of residual disease after surgery. We suggest designing a complementary model, which combines the outcome of surgery assessed by the surgeon and the perioperative CA125 change to make a more reliable prediction for both OS and PFS.

What pleads for such a combined prognostic model is the additional prognostic information of relative CA125 change besides the outcome of surgery. This could be explained by the abovementioned variability in the assessment of tumour residue by gynaecologists. But also by heterogeneity within the groups of patients with a certain amount of residual disease. The optimal group, for example, is defined by $\leq 1 \mathrm{~cm}$ of residual disease in maximum diameter, and therefore contains patients with only one tumour spot but also patients with hundreds of these spots as is the case in some patients with peritoneal carcinomatosis. Moreover, the outcome of surgery does not incorporate the initial disease burden, while this influences clinical outcome ${ }^{14,15}$. When using a combined model, a more specific prognosis could be made based on the outcome of surgery and CA125 levels.

Besides the perioperative decline, some patients experienced a postoperative increase in CA125 levels. The size of the present cohort enabled us to analyse this patient group separately, while most studies included these patients in their lowest group. Patients with an increase in CA125 experienced worse OS and PFS, especially those who had no residual disease after cytoreductive surgery. In studies on the physiological behaviour of CA125, it was shown that CA125 increases within the first two weeks after surgery, which is possibly caused by the surgery induced peritoneal damage ${ }^{33,34}$. Hereafter, it is expected to drop again. In our study, we found that the mean time between surgery and the postoperative CA125, was shorter in the group with a postoperative increased CA125 compared to those with a decline ( 21 versus 28 days, $P=0.005$ ). Even though time may explain the increase, it cannot explain the worse OS of these patients. Moreover, we found that patients with 
a postoperative increase had a lower CA125 at diagnosis. This could not be explained by differences in FIGO stage, tumour grade or histologic subtype, but we found that patients with an increase in CA125 were less often diagnosed with a large amount of ascites $(\geq 500 \mathrm{~mL})$. However, the presence of ascites is an unfavourable prognostic factor ${ }^{35,36}$. Therefore, it remains unclear why these patients experience worse OS. Nevertheless, the abovementioned results seem to confirm the added value of the perioperative change in CA125 as prognostic factor.

The present study has several limitations, of which its retrospective nature is the most important. Therefore, a substantial number of patients was excluded from analyses due to missing CA125 values. Another limitation may be the inclusion of different histological subtypes of EOC, such as endometrioid and clear-cell EOC. As known from earlier studies, CA125 is most highly expressed in serous ovarian cancers, and predominantly in high grade serous ovarian cancer ${ }^{37-39}$. This may raise the question if our results are applicable to other histologic subtypes. We observed, however, the same prognostic effects in these tumour types as well (data not shown). In addition, serum CA125 levels were measured on different moments after surgery. We adjusted for the time between surgery and CA125 levels in our multivariable models, however this may have influenced the rate of postoperative decline. Moreover, the prognostic effect was based on chosen thresholds based on earlier studies, this threshold could potentially be optimized. And finally, the amount of residual disease is judged by several gynaecologists, which could have led to suboptimal interpretation of actual residual disease and may biased our results.

In conclusion, this study confirmed that the perioperative CA125 change is a prognostic factor for improved clinical outcomes in EOC patients. Newly found are the prognostic differences between the CA125 groups in patients with the same outcome of cytoreductive surgery. This pleads for the use of a combined model, consisting of perioperative CA125 change and the outcome of residual disease, in order to predict the prognosis of EOC patients more accurately.

\section{Acknowledgements}

The authors thank the registration team of the Netherlands Comprehensive Cancer Organisation (IKNL) for the collection of data for the Netherlands Cancer Registry.

\section{Funding}

This work was supported by Dutch Cancer Society [IKNL2014-6838]. 


\section{REFERENCES}

1. Sant $M$, Chirlaque Lopez MD, Agresti $R$, Sanchez Perez MJ, Holleczek B, BielskaLasota $M$, et al. Survival of women with cancers of breast and genital organs in europe 1999-2007: Results of the eurocare-5 study. Eur J Cancer. 2015;51(15):2191-205.

2. Timmermans $M$, Sonke GS, Van de Vijver KK, van der Aa MA, Kruitwagen R. No improvement in long-term survival for epithelial ovarian cancer patients: A population-based study between 1989 and 2014 in the netherlands. Eur J Cancer. 2017;88:31-7.

3. van Altena AM, Karim-Kos HE, de Vries E, Kruitwagen RF, Massuger LF, Kiemeney LA. Trends in therapy and survival of advanced stage epithelial ovarian cancer patients in the netherlands. Gynecol Oncol. 2012;125(3):649-54.

4. Chen T, Jansen L, Gondos A, Emrich K, Holleczek B, Katalinic A, et al. Survival of ovarian cancer patients in germany in the early 21st century: A period analysis by age, histology, laterality, and stage. Eur J Cancer Prev. 2013;22(1):59-67.

5. Grann AF, Norgaard M, Blaakaer J, SogaardAndersen $E$, Jacobsen JB. Survival of patients with ovarian cancer in central and northern denmark, 1998-2009. Clin Epidemiol. 2011;3 Suppl 1:59-64.

6. Vergote I, Trope CG, Amant F, Kristensen $\mathrm{GB}$, Ehlen $\mathrm{T}$, Johnson N, et al. Neoadjuvant chemotherapy or primary surgery in stage iiic or iv ovarian cancer. N Engl J Med. 2010;363(10):943-53.

7. Kehoe S, Hook J, Nankivell M, Jayson GC, Kitchener $H$, Lopes $T$, et al. Primary chemotherapy versus primary surgery for newly diagnosed advanced ovarian cancer (chorus): An open-label, randomised, controlled, non-inferiority trial. Lancet. 2015;386(9990):249-57.
8. Elattar A, Bryant A, Winter-Roach BA Hatem M, Naik R. Optimal primary surgical treatment for advanced epithelial ovarian cancer. Cochrane Database Syst Rev. 2011(8):CD007565.

9. Chang SJ, Bristow RE. Evolution of surgical treatment paradigms for advanced-stage ovarian cancer: Redefining 'optimal' residual disease. Gynecol Oncol. 2012;125(2):48392.

10. Chang SJ, Hodeib M, Chang J, Bristow RE. Survival impact of complete cytoreduction to no gross residual disease for advancedstage ovarian cancer: A meta-analysis. Gynecol Oncol. 2013;130(3):493-8.

11. Prefontaine $M$, Gelfand AT, Donovan JT, Powell JL. Reproducibility of tumor measurements in ovarian cancer: A study of interobserver variability. Gynecol Oncol. 1994;55(1):87-90.

12. Eskander RN, Kauderer J, Tewari KS, Mannel RS, Bristow RE, O'Malley DM, et al. Correlation between surgeon's assessment and radiographic evaluation of residual disease in women with advanced stage ovarian cancer reported to have undergone optimal surgical cytoreduction: An $\mathrm{nrg}$ oncology/gynecologic oncology group study. Gynecol Oncol. 2018.

13. Kang S. Do we need a better marker for successful ovarian cancer surgery? J Gynecol Oncol. 2017;28(1):e21.

14. Rodriguez N, Miller A, Richard SD, Rungruang B, Hamilton CA, Bookman MA, et al. Upper abdominal procedures in advanced stage ovarian or primary peritoneal carcinoma patients with minimal or no gross residual disease: An analysis of gynecologic oncology group (gog) 182. Gynecol Oncol. 2013;130(3):487-92. 
15. Horowitz NS, Miller A, Rungruang B, Richard SD, Rodriguez N, Bookman MA, et al. Does aggressive surgery improve outcomes? Interaction between preoperative disease burden and complex surgery in patients with advanced-stage ovarian cancer: An analysis of gog 182. J Clin Oncol. 2015;33(8):937-43.

16. Zwakman N, van de Laar R, Van Gorp T, Zusterzeel PL, Snijders MP, Ferreira I, et al. Perioperative changes in serum ca125 levels: A prognostic factor for diseasespecific survival in patients with ovarian cancer. J Gynecol Oncol. 2017;28(1):e7.

17. Yoo SC, Yoon JH, Lyu MO, Kim WY, Chang SJ, Chang KH, et al. Significance of postoperative ca-125 decline after cytoreductive surgery in stage iiic/iv ovarian cancer. J Gynecol Oncol. 2008;19(3):169-72.

18. Zivanovic O, Sima CS, lasonos A, BellMcGuinn KM, Sabbatini PJ, Leitao MM, et al. Exploratory analysis of serum ca- 125 response to surgery and the risk of relapse in patients with figo stage iiic ovarian cancer. Gynecol Oncol. 2009;115(2):209-14.

19. Rosen A, Sevelda P, Klein M, Spona J, Beck A. A ca125 score as a prognostic index in patients with ovarian cancer. Arch Gynecol Obstet. 1990;247(3):125-9.

20. Brand $E$, Lidor $Y$. The decline of ca 125 level after surgery reflects the size of residual ovarian cancer. Obstet Gynecol. 1993;81(1):29-32.

21. Gadducci A, Landoni F, Maggino T, Sartori E, Zola P, Fanucchi A. The relationship between postoperative decline of serum ca 125 levels and size of residual disease after initial surgery in patients with advanced ovarian cancer: A ctf study. Gynecol Oncol. 1996;63(2):234-7.

22. Fritz AG. International classification of diseases for oncology : Icd-o. 3rd ed. Geneva: World Health Organization; 2000. vii, 240 p. p.
23. Sobin LH, Compton CC. Tnm seventh edition: What's new, what's changed: Communication from the international union against cancer and the american joint committee on cancer. Cancer. 2010;116(22):5336-9.

24. Charlson M, Szatrowski TP, Peterson J, Gold J. Validation of a combined comorbidity index. J Clin Epidemiol. 1994;47(11):124551.

25. Bruney L, Conley KC, Moss NM, Liu Y, Stack MS. Membrane-type i matrix metalloproteinase-dependent ectodomain shedding of mucin16/ ca-125 on ovarian cancer cells modulates adhesion and invasion of peritoneal mesothelium. Biol Chem. 2014;395(10):1221-31.

26. Gubbels JA, Belisle J, Onda M, Rancourt C, Migneault $M, H o ~ M$, et al. Mesothelinmuc16 binding is a high affinity, $\mathrm{n}$-glycan dependent interaction that facilitates peritoneal metastasis of ovarian tumors. Mol Cancer. 2006;5(1):50.

27. Patankar MS, Jing $Y$, Morrison JC, Belisle JA, Lattanzio FA, Deng $Y$, et al. Potent suppression of natural killer cell response mediated by the ovarian tumor marker ca125. Gynecol Oncol. 2005;99(3):704-13.

28. Rump A, Morikawa $Y$, Tanaka M, Minami $S$, Umesaki N, Takeuchi $M$, et al. Binding of ovarian cancer antigen ca125/muc16 to mesothelin mediates cell adhesion. J Biol Chem. 2004;279(10):9190-8.

29. Theriault $C$, Pinard $M$, Comamala $M$, Migneault M, Beaudin J, Matte I, etal. Muc16 (ca125) regulates epithelial ovarian cancer cell growth, tumorigenesis and metastasis. Gynecol Oncol. 2011;121(3):434-43.

30. Zeillemaker AM, Verbrugh HA, Hoynck van Papendrecht AA, Leguit P. Ca 125 secretion by peritoneal mesothelial cells. J Clin Pathol. 1994;47(3):263-5. 
31. Chi DS, Ramirez PT, Teitcher JB, Mironov $\mathrm{S}$, Sarasohn DM, Iyer RB, et al. Prospective study of the correlation between postoperative computed tomography scan and primary surgeon assessment in patients with advanced ovarian, tubal, and peritoneal carcinoma reported to have undergone primary surgical cytoreduction to residual disease $1 \mathrm{~cm}$ or less. J Clin Oncol. 2007;25(31):4946-51.

32. Lakhman $Y$, Akin $O$, Sohn MJ, Zheng J, Moskowitz CS, lyer RB, et al. Early postoperative ct as a prognostic biomarker in patients with advanced ovarian, tubal, and primary peritoneal cancer deemed optimally debulked at primary cytoreductive surgery. AJR Am J Roentgenol. 2012;198(6):1453-9.

33. van der Zee AG, Duk JM, Aalders JG, Boontje AH, ten Hoor KA, de Bruijn HW. The effect of abdominal surgery on the serum concentration of the tumour-associated antigen ca 125. Br J Obstet Gynaecol. 1990;97(10):934-8.

34. Redman CW, Jones SR, Luesley DM, Nicholl SE, Kelly K, Buxton EJ, et al. Peritoneal trauma releases ca125? $\mathrm{Br} J$ Cancer. 1988;58(4):502-4.

35. Szender JB, Emmons T, Belliotti S, Dickson D, Khan A, Morrell K, et al. Impact of ascites volume on clinical outcomes in ovarian cancer: A cohort study. Gynecol Oncol. 2017;146(3):491-7.

36. Huang $H$, Li YJ, Lan $C Y$, Huang $Q D$, Feng $Y L$, Huang $Y W$, et al. Clinical significance of ascites in epithelial ovarian cancer. Neoplasma. 2013;60(5):546-52.

37. May T, Stewart JM, Bernardini MQ, Ferguson SE, Laframboise $\mathrm{S}$, Jiang $\mathrm{H}$, et al. The prognostic value of perioperative, presystemic therapy ca125 levels in patients with high-grade serous ovarian cancer. Int J Gynaecol Obstet. 2018;140(2):247-52.
38. Hogdall EV, Christensen L, Kjaer SK, Blaakaer J, Kjaerbye-Thygesen A, Gayther S, et al. Ca125 expression pattern, prognosis and correlation with serum ca125 in ovarian tumor patients. From the danish "malova" ovarian cancer study. Gynecol Oncol. 2007;104(3):508-15.

39. Shih le M, Kurman RJ. Ovarian tumorigenesis: A proposed model based on morphological and molecular genetic analysis. Am J Pathol. 2004;164(5):1511-8. 


\section{SUPPLEMENTARY MATERIAL}

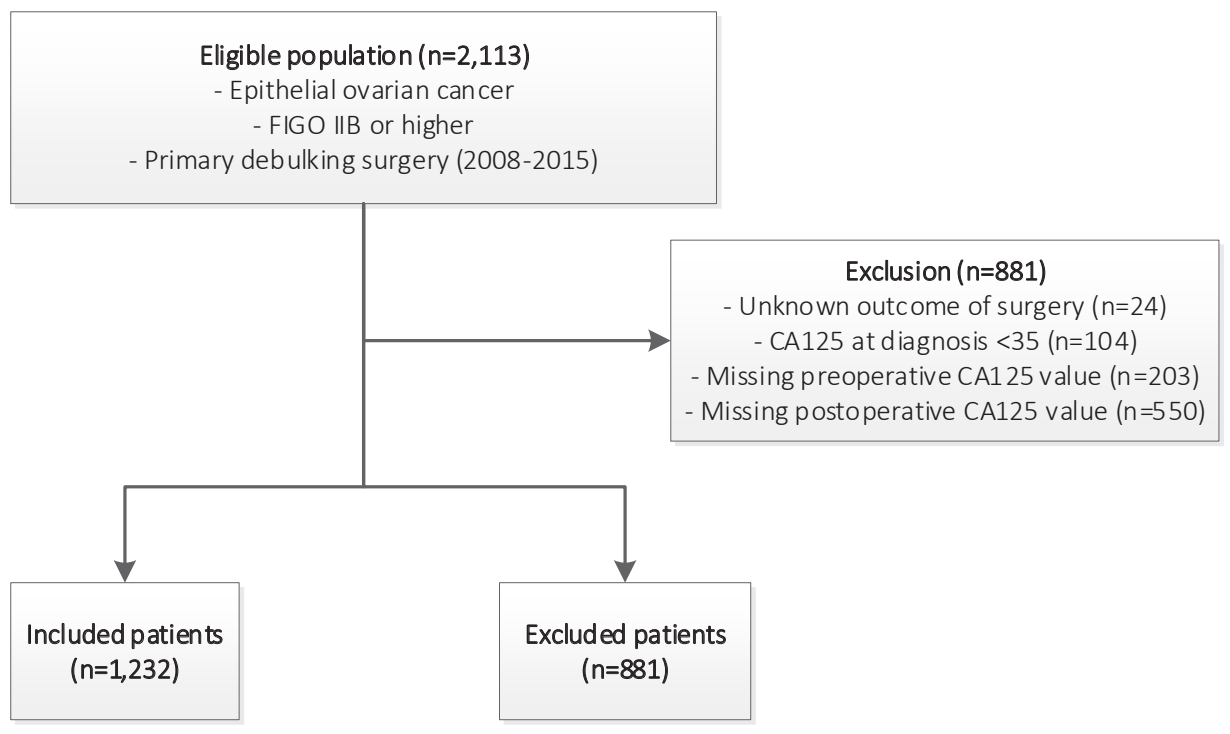

S1: In- and exclusion criteria 
S2: Baseline characteristics of in- and excluded patients

\begin{tabular}{|c|c|c|c|}
\hline & $\begin{array}{r}\text { Patients included } \\
(\mathrm{n}, \%)\end{array}$ & $\begin{array}{r}\text { Patients excluded } \\
(n, \%)\end{array}$ & p-value \\
\hline Age & & & $0.023^{+}$ \\
\hline$<65$ & $652(52.9)$ & $422(47.9)$ & \\
\hline$\geq 65$ & $580(47.1)$ & $459(52.1)$ & \\
\hline Mean (SD) & $62.9(11.4)$ & 64 (11.9) & $0.039^{\ddagger}$ \\
\hline FIGO stage & & & $0.276^{+}$ \\
\hline IIB & $231(18.8)$ & $187(21.2)$ & \\
\hline$\| C$ & $68(5.5)$ & $60(6.8)$ & \\
\hline IIIA & $36(2.9)$ & $30(3.4)$ & \\
\hline IIIB & $154(12.5)$ & 96 (10.9) & \\
\hline IIIC & $578(46.9)$ & $406(46.1)$ & \\
\hline IV & $128(10.4)$ & $72(8.2)$ & \\
\hline Unknown & $37(3.0)$ & $30(3.4)$ & \\
\hline Type of tumour & & & $<0.001^{+}$ \\
\hline Serous & 935 (75.9) & $592(67.2)$ & \\
\hline Mucinous & $38(3.1)$ & $64(7.3)$ & \\
\hline Endometrioid & $108(8.8)$ & $98(11.1)$ & \\
\hline Clear-cell & $77(6.2)$ & $66(7.5)$ & \\
\hline Adenocarcinoma NOSa & 48 (3.9) & $37(4.2)$ & \\
\hline Other & $26(2.1)$ & $24(2.7)$ & \\
\hline Grade & & & $0.002^{+}$ \\
\hline I & 98 (7.9) & $88(10.0)$ & \\
\hline ॥ & $212(17.2)$ & $125(14.2)$ & \\
\hline III & $734(59.6)$ & $488(55.4)$ & \\
\hline Unknown & $188(15.3)$ & $180(20.4)$ & \\
\hline Outcome of surgery & & & $<0.001^{+}$ \\
\hline Complete & $611(49.6)$ & $432(49.0)$ & \\
\hline Optimal & $461(37.4)$ & $242(27.4)$ & \\
\hline Suboptimal & $160(13.0)$ & 139 (15.9) & \\
\hline Unknown & $0(0.0)$ & $68(7.7)$ & \\
\hline Total & 1232 (58.3) & 881 (41.7) & \\
\hline
\end{tabular}

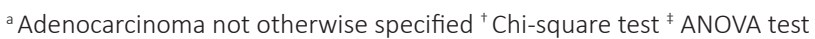


S3: Baseline characteristics of included patients stratified by the perioperative change in CA125

\begin{tabular}{|c|c|c|c|c|c|}
\hline & $\begin{array}{r}\text { Increase } \\
\text { in CA-125 } \\
(n, \%)\end{array}$ & $\begin{array}{r}<50 \% \\
\text { decrease } \\
\text { in CA125 } \\
(n, \%)\end{array}$ & $\begin{array}{r}50-79 \% \\
\text { decrease } \\
\text { in CA125 } \\
(n, \%)\end{array}$ & $\begin{array}{r}\geq 80 \% \\
\text { decrease } \\
\text { in CA125 } \\
(n, \%)\end{array}$ & p-value \\
\hline Age & & & & & $0.050^{+}$ \\
\hline$<65$ & $64(44.1)$ & $119(50.0)$ & $205(53.7)$ & $264(56.5)$ & \\
\hline$\geq 65$ & $81(55.9)$ & $119(50.0)$ & $177(46.3)$ & $203(43.5)$ & \\
\hline Mean (SD) & $64.5(11.1)$ & $63.7(12.3)$ & $63.1(10.8)$ & $61.9(11.6)$ & $0.049^{\ddagger}$ \\
\hline FIGO stage & & & & & $<0.001^{+}$ \\
\hline$\| B / I I C$ & $16(11.0)$ & 33 (13.9) & $71(18.6)$ & $111(23.8)$ & \\
\hline IIIA1 & $13(9.0)$ & $9(3.8)$ & $14(3.7)$ & $32(6.8)$ & \\
\hline IIIA2 & $4(2.8)$ & $4(1.7)$ & $12(3.1)$ & $16(3.4)$ & \\
\hline IIIB & $15(10.4)$ & $24(10.1)$ & $48(12.6)$ & $67(14.3)$ & \\
\hline IIIC & $74(51.0)$ & $117(49.1)$ & $178(46.6)$ & $209(44.8)$ & \\
\hline IV & $15(10.3)$ & $41(17.2)$ & $47(12.3)$ & $25(5.4)$ & \\
\hline Unknown & $8(5.5)$ & $10(4.2)$ & $12(3.1)$ & $7(1.5)$ & \\
\hline Type of tumour & & & & & $0.157^{\dagger}$ \\
\hline Serous & 110 (75.9) & $186(78.2)$ & $295(77.2)$ & $344(73.7)$ & \\
\hline Mucinous & $7(4.8)$ & $7(2.9)$ & $10(2.6)$ & $14(3.0)$ & \\
\hline Endometrioid & $7(4.8)$ & $17(7.1)$ & $28(7.3)$ & $56(12.0)$ & \\
\hline Clear-cell & $11(7.6)$ & $17(7.1)$ & $29(7.6)$ & $20(4.3)$ & \\
\hline Adenocarcinoma NOS & $6(4.1)$ & $8(3.4)$ & $11(2.9)$ & $23(4.9)$ & \\
\hline Other & $4(2.8)$ & $3(1.3)$ & $9(2.4)$ & $10(2.1)$ & \\
\hline Grade & & & & & $0.071^{+}$ \\
\hline । & $11(7.6)$ & $18(7.6)$ & $23(6.0)$ & $46(9.9)$ & \\
\hline II & $17(11.7)$ & 45 (18.9) & $71(18.6)$ & 79 (16.9) & \\
\hline III & $85(58.6)$ & $138(58.0)$ & $225(58.9)$ & $286(61.2)$ & \\
\hline Unknown & $32(22.1)$ & $37(15.5)$ & $63(16.5)$ & $56(12.0)$ & \\
\hline Ascites & & & & & $0.019^{\dagger}$ \\
\hline$<500 \mathrm{~mL}$ & $117(80.7)$ & $159(66.8)$ & $264(69.1)$ & 317 (67.9) & \\
\hline$\geq 500 \mathrm{~mL}$ & $28(19.3)$ & $79(33.2)$ & $118(30.9)$ & $150(32.1)$ & \\
\hline Chemotherapy alterations & & & & & $0.239^{+}$ \\
\hline Yes & $93(64.1)$ & $139(58.4)$ & $236(61.8)$ & $296(63.4)$ & \\
\hline No & $42(29.0)$ & $90(37.8)$ & $127(33.2)$ & $141(30.2)$ & \\
\hline No chemotherapy & $10(6.9)$ & $9(3.8)$ & $19(5.0)$ & $30(6.4)$ & \\
\hline Total & $145(11.8)$ & $238(19.3)$ & $382(31.0)$ & $467(37.9)$ & \\
\hline
\end{tabular}

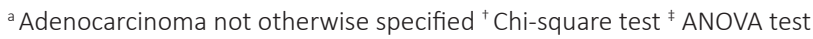



Interval between debulking surgery and adjuvant chemotherapy is associated with overall survival in patients with advanced ovarian cancer

M. Timmermans, M.A. van der Aa, R.I. Lalisang, P.O. Witteveen, K.K. Van de Vijver, R.F.P.M. Kruitwagen, G.S. Sonke 


\section{ABSTRACT}

\section{Objective}

Treatment for advanced epithelial ovarian cancer (EOC) consists of debulking surgery and (neo)adjuvant platinum-based chemotherapy. The aim of this study was to evaluate whether the time from surgery to adjuvant chemotherapy (TTC) was associated with clinical outcome.

\section{Methods}

We identified all Dutch patients who received optimal or complete debulking surgery for primary EOC (FIGO IIB-IV) between 2008 and 2015 from the Netherlands Cancer Registry. TTC was divided into three groups based on the interquartile range (IQR). Early ( $<25 \%$ ) and prolonged (>75\%) TTC were compared to intermediate TTC (25-75\%). Logistic regression was used to identify factors associated with a prolonged TTC and multivariable Cox regression to evaluate the independent effect of treatment interval on overall survival (OS). Patients receiving primary debulking surgery (PDS) and patients receiving interval debulking surgery (IDS) were analysed separately.

\section{Results}

4,097 patients were included, 1,612 underwent PDS and 2,485 IDS. Median TTC was 29 days (IQR 24-37). Age $\geq 65$, complete debulking surgery, postoperative complications, and hospitalisation $\geq 10$ days were independently associated with a longer TTC for both PDS and IDS. TTC in the longest quartile was associated with poor OS after both PDS (Hazard rate (HR) 1.43, 95\% CI 1.09-1.88) and NACT-IDS (HR 1.22(1.02-1.47)) when compared to the intermediate TTC, but only in patients with no macroscopic residual disease after surgery.

\section{Conclusions}

Our study provides evidence that delayed initiation of adjuvant chemotherapy is an independent prognostic factor for worse overall survival after complete (interval)debulking surgery. We advise to start adjuvant chemotherapy within five to six weeks after debulking surgery. 


\section{INTRODUCTION}

Treatment for advanced ovarian cancer consists of debulking surgery and (neo)adjuvant platinum based chemotherapy ${ }^{1}$. The goal of debulking surgery is to leave no residual disease $^{2}$. When the likelihood of gross residual disease after primary debulking surgery (PDS) is high, neoadjuvant chemotherapy (NACT) can reduce tumour load and is an alternative treatment approach to reach complete debulking surgery ${ }^{1,3,4}$. Regardless of treatment approach, adjuvant chemotherapy is a prerequisite to improve clinical outcomes.

Despite the generally accepted use of adjuvant chemotherapy, there is no guideline on the optimal interval between debulking surgery and the start of adjuvant chemotherapy. It is assumed that commencement of adjuvant chemotherapy should be initiated as soon as possible, as this may prevent early tumour growth within the before mentioned time interval $\left.\right|^{5-7}$. Studies in breast and colorectal cancer indeed suggested that delayed initiation of adjuvant chemotherapy impairs overall survival| ${ }^{5,8-11}$. Studies in ovarian cancer, however, report conflicting results ${ }^{5,12}$. Some studies failed to show an association between the 'Time To start adjuvant Chemotherapy' (TTC) and overall survival ${ }^{6,13-19}$, while others indicated that

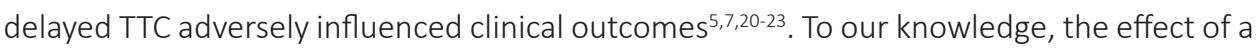
prolonged TTC was not previously studied after interval debulking surgery (IDS) in ovarian cancer, although this treatment sequence is increasingly applied.

Various patient-, tumour-, and surgery-related characteristics may cause a delay in adjuvant chemotherapy administration, such as comorbidity and the extent of surgery ${ }^{23,24}$. Analyses of the interplay between these factors, preferably using unbiased population-based studies, may provide insight into possible modifiable characteristics and can help to minimise the time interval between surgery and adjuvant chemotherapy.

The aim of this study was to identify factors that are associated with prolonged TTC and whether the timing of adjuvant chemotherapy is independently associated with clinical outcomes in patients treated with either PDS or NACT-IDS.

\section{METHODS}

All consecutive patients who were diagnosed with epithelial ovarian cancer (EOC), including primary peritoneal and fallopian tube carcinoma (International Classification of Diseases for Oncology (ICD-O) C48.2, C56.9 and C57.0), between 01.01.2008 and 31.12.2015 were identified from the Netherlands Cancer Registry (NCR) ${ }^{25}$. The NCR is a population-based cancer registry with coverage of all newly diagnosed malignancies in the Netherlands. Information on vital status and date of death are obtained by yearly linkage of the NCR with the municipal demography registries. For the purpose of this study, dedicated registration 
clerks collected additional medical information from medical files, including the Charlson Comorbidity Index $(\mathrm{CCl})^{26}$, treatment details (surgery and chemotherapy) and the date of disease recurrence.

\section{Study population}

Patients were eligible for inclusion if they were diagnosed with advanced stage disease, underwent debulking surgery and received at least one course of adjuvant chemotherapy. Patients were excluded if they underwent more than one debulking surgery, had an unknown time interval between surgery and chemotherapy or had $>1 \mathrm{~cm}$ of residual disease after debulking surgery (figure 1).

\section{Definitions of clinical outcomes}

Advanced stage disease was defined by Fédération Internationale de Gynécologie et d'Obstétrique (FIGO) stage IIB or higher. FIGO stage (2014) was derived from the TumourNode-Metastasis (TNM) staging system and based on postoperative findings. In case patients underwent NACT-IDS clinical TNM stage was used ${ }^{27}$.

The TTC was defined as the period between debulking surgery and the start of subsequent chemotherapy. In case patients underwent IDS, the treatment-free interval between NACT and IDS was also determined for adjustment in multivariable analysis. Six cycles of carboplatin plus paclitaxel was considered regular care. Actual chemotherapy regimen was recorded for each patient including dose modifications and delays, all survival models were adjusted for these chemotherapy alterations.

Outcome of debulking surgery was defined as complete in case of no macroscopic residual disease and as optimal if the largest diameter of residual disease was $\leq 1 \mathrm{~cm}$. Debulking surgery was defined as extended if one of the following procedures was executed during surgery; (retroperitoneal) lymphadenectomy, bowel resection, peritoneum stripping (including diaphragm), splenectomy, pancreatectomy, liver resections and/or bladder resections, or if the duration of the operation was longer than 240 minutes.

Postoperative complications were recorded if they occurred within 30 days after debulking surgery and included infectious complications, surgical site complications, thromboembolic events, reoperations, bowel complications (anastomotic leakage or abscess) and functional complications (such as urinary retention or ileus). Postoperative recovery was regarded as complicated if any complications occurred or if patients were admitted to the intensive care unit (in case of more than 1 day). Furthermore, readmissions were recorded if they occurred within thirty days postoperative and were added to the total admission time. 


\section{Statistical analyses}

The TTC was summarised and categorised in three groups based on the inter quartile range (IQR); lowest 25\% (<23 days), 25-75\% (24-37 days) and highest 75\% (>37 days). Baseline characteristics of these groups were compared using Chi-square tests for categorical variables and ANOVA or Mann-Whitney-U tests for continuous variables. Associations with prolonged TTC (time> 75\% quartile, i.e. >37 days) were explored with uni- and multivariable logistic regression models.

Overall survival (OS) was defined as the interval between date of first treatment (surgery for PDS patients and chemotherapy for NACT-IDS patients) and death or between date of first treatment and last follow-up for patients who were alive at data cut-off (1 February 2017). Progression-free survival (PFS) was defined as the date of first treatment until progression or death, whichever occurred first. Progression was defined as clinical signs of tumour growth, i.e. increase in CA125 and/or visible lesions on imaging techniques (either regrowth of pre-existing lesions or new lesions), combined with the clinical judgment of the treating physician (medical oncologist or gynaecologist). In case patients were still alive and had no progressive disease, patients were censored at the date of their last hospital visit. PFS and OS were analysed by Kaplan-Meier survival curves and multivariable Cox regression models. All statistical analyses were performed using STATA/SE (version 14.1; STATA CORP., College Station, Texas, USA) and a p-value<0.05 was considered statistically significant.

\section{RESULTS}

We identified 4,097 eligible patients from the NCR who were diagnosed between 2008 and 2015. Of them 1,612 (39.3\%) underwent PDS and 2,485 (60.7\%) underwent NACT-IDS (figure 1). The median time between surgery and the start of adjuvant chemotherapy was 29 days (IQR 24-37), and slightly differed between patients undergoing PDS (31 days (IQR 26-40) and NACT-IDS (28 days (IQR 23-36)). Both treatment sequences were evaluated separately and baseline characteristics of both groups are listed in the supplementary material (S1, S2). 


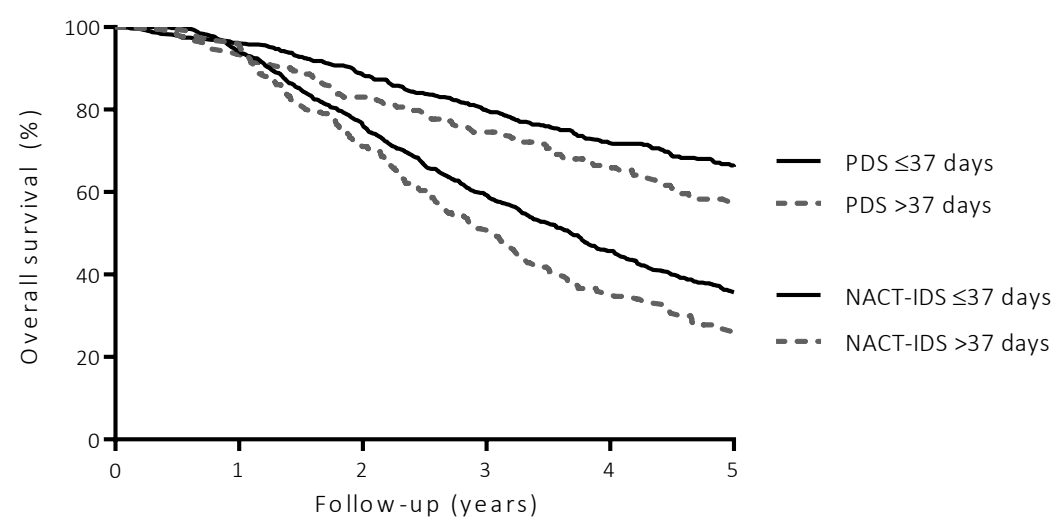

Figure 1: Overall survival for patients with no residual disease after surgery stratified by treatment sequence

\section{Associations with prolonged TTC}

Age ( $\geq 65$ years), postoperative complications, prolonged hospitalisation and complete debulking surgery were independently associated with delayed initiation of adjuvant chemotherapy after both PDS and NACT-IDS in a multivariable logistic regression model (table 1). In addition, a $\mathrm{CCl}$ of 1-2 was also predictive of a delay in chemotherapy when compared to a $\mathrm{CCl}$ of 0 , but a score of 3 or higher was not an independent prognostic factor. In univariable analysis, extensive surgery was associated with prolonged TTC, both in patients receiving PDS (odds ratio (OR) 1.27, 95\%Cl 1.02-1.58) and patients receiving NACTIDS (OR 1.84(1.51-2.24)). In multivariable analyses, however, extensive surgery was only associated with a prolonged TTC in patients who underwent NACT-IDS (table 1). FIGO stage and the presence of ascites were not associated with a delay in chemotherapy (table 1 ).

\section{Influence of TTC on prognosis in patients who underwent PDS}

For patients treated with PDS, crude median OS did not differ significantly between TTC intervals (TTC ${ }_{<24}: 67.6$ months, TTC $_{24-37}: 66.5$ months, TTC $_{>37}: 60.9$ months, $P=0.173$ ). When adjusted for patient- and tumour characteristics, including postoperative complications and chemotherapy alterations, there was no association between delayed chemotherapy and overall survival in patients with macroscopic residual disease after surgery (Hazard Rate $\left(\mathrm{HR}_{>37}: 0.89(0.68-1.16)\right.$ vs 24-37 days, table 2$)$. However, patients with no residual disease after debulking surgery and a prolonged TTC experienced worse OS ( $\mathrm{HR}_{>37}: 1.43(1.09-1.88)$ vs 24-37 days, figure 2). In addition, patients with TTC $<24$ days had comparable survival with TTC of 24-37 days in both models (table 2). These trends in OS were comparable in a 
sensitivity analysis, where we used the specific TTC interval for PDS (i.e. <26 days vs. 2640 days vs. $>40$ days) instead of the TTC intervals of the whole study population (data not shown). Moreover, progression-free survival did not differ between TTC intervals (data not shown).

Table 1: Multivariable logistic regression to determine prognostic factors for prolonged TTC (>37 days) stratified by treatment sequence

\begin{tabular}{|c|c|c|}
\hline & PDS $(\mathrm{OR}, 95 \% \mathrm{Cl})^{+}$ & NACT-IDS $(\mathrm{OR}, 95 \% \mathrm{Cl})^{\dagger}$ \\
\hline \multicolumn{3}{|l|}{ Age } \\
\hline$<65$ years & Reference & Reference \\
\hline$\geq 65$ years & 1.35 (1.07-1.69) & $1.74(1.40-2.17)$ \\
\hline \multicolumn{3}{|l|}{ FIGO stage } \\
\hline FIGO II & $1.08(0.81-1.45)$ & $0.88(0.28-2.75)$ \\
\hline FIGO III & Reference & Reference \\
\hline FIGO IV & $1.17(0.77-1.77)$ & $0.86(0.69-1.09)$ \\
\hline \multicolumn{3}{|l|}{ Charlson Comorbidity Index } \\
\hline 0 & Reference & Reference \\
\hline $1-2$ & $1.28(1.00-1.67)$ & $1.29(1.02-1.62)$ \\
\hline$\geq 3$ & $1.45(0.68-3.09)$ & $1.51(0.83-2.72)$ \\
\hline \multicolumn{3}{|l|}{ Ascites } \\
\hline$<500 \mathrm{~mL}$ & Reference & Reference \\
\hline$\geq 500 \mathrm{~mL}$ & $0.89(0.68-1.17)$ & $0.97(0.75-1.24)$ \\
\hline \multicolumn{3}{|l|}{ Extensive surgery } \\
\hline No & Reference & Reference \\
\hline Yes & $1.18(0.93-1.49)$ & $1.39(1.11-1.73)$ \\
\hline \multicolumn{3}{|l|}{ Postoperative complications } \\
\hline No & Reference & Reference \\
\hline Yes & $1.59(1.24-2.04)$ & $1.89(1.50-2.38)$ \\
\hline \multicolumn{3}{|l|}{ Hospitalisation } \\
\hline$<10$ days & Reference & Reference \\
\hline$\geq 10$ days & $2.22(1.70-2.90)$ & $3.69(2.92-4.66)$ \\
\hline \multicolumn{3}{|l|}{ Outcome of surgery } \\
\hline Optimal ( $\leq 1 \mathrm{~cm} \mathrm{RD)}$ & Reference & Reference \\
\hline Complete (no macroscopic RD) & $1.40(1.09-1.80)$ & $1.30(1.04-1.61)$ \\
\hline
\end{tabular}

RD: Residual disease ${ }^{\dagger}$ All OR's are adjusted for the listed variables, FIGO unknown and CCl unknown were included in the model but not listed in this table 
Table 2: Influence of TTC interval on overall survival stratified by the amount of residual disease

Model I (HR, 95\% Cl)

Model II (HR, 95\% Cl) ${ }^{\dagger}$

\section{PDS}

$<24$ days

24-37 days

$>37$ days

NACT-IDS

$<24$ days

24-37 days

$>37$ days
1.09 (0.78-1.54)

Reference

1.43 (1.09-1.88)

1.07 (0.89-1.28)

Reference

1.22 (1.02-1.47)
0.94 (0.72-1.23)

Reference

0.89 (0.68-1.16)

${ }^{+}$Adjusted for age, stage at diagnosis, histologic type, differentiation grade, performance score, postoperative complications, prolonged hospitalisation and chemotherapy alterations. For patients undergoing NACT-IDS, additional adjustment was made for the duration of the treatment free interval between NACT and IDS.

Model I: only patients with no residual disease, Model II: only patients with macroscopic residual disease $(\leq 1 \mathrm{~cm})$

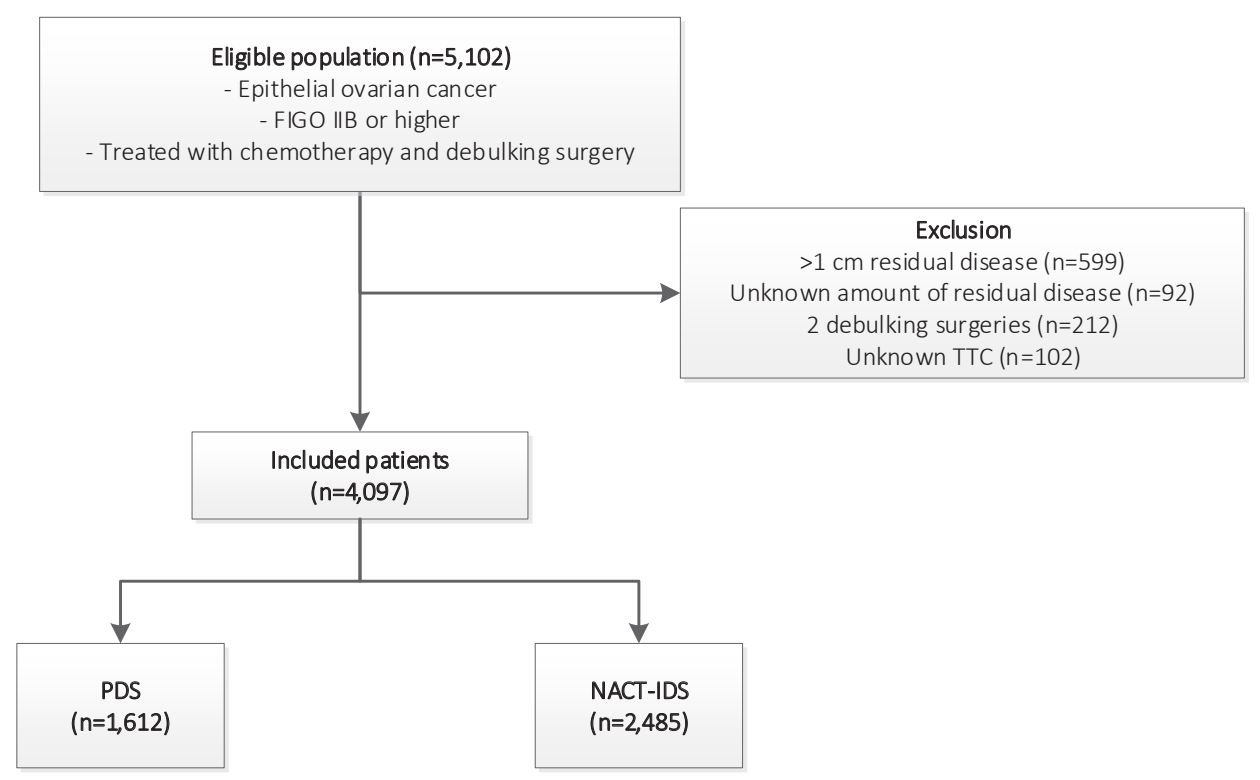

Figure 2: In- and exclusion criteria for the studied population

\section{Influence of TTC on prognosis in patients who underwent NACT-IDS}

In patients undergoing NACT-IDS, crude median OS differed significantly between TTC intervals ( $\mathrm{TTC}_{<24}: 33.8$ months, $\mathrm{TTC}_{24-37}: 37.1$ months, $\mathrm{TTC}_{>37}: 31.0$ months, $P=0.007$ ). In a multivariable cox regression model, including adjustment for treatment free interval 
between NACT and IDS, there was no association between delayed adjuvant chemotherapy and overall survival in patients with macroscopic residual disease after surgery $\left(\mathrm{HR}>_{37}\right.$ : $1.10(0.90-1.33)$ vs 24-37 days). But similar to PDS patients, this was objectified in patients with no residual disease $\left(\mathrm{HR}_{>37}: 1.22(1.02-1.47)\right.$, figure 2$)$. Again, trends in OS did not alter when the specific NACT-IDS TTC intervals were used and PFS did not differ between groups.

\section{DISCUSSION}

In our large-scale population-based study we evaluated factors that are associated with delayed initiation of adjuvant chemotherapy and its influence on clinical outcomes in both patients undergoing PDS and NACT-IDS. In patients with no macroscopic residual disease after debulking surgery, delayed initiation of adjuvant chemotherapy was associated with impaired OS. However, we did not observe this effect in patients with macroscopic residual disease after surgery. Moreover, the observed associations with TTC and overall survival were not seen in progression-free survival.

In this study we gained insight into prognostic factors that are related to a prolonged TTC. As reported in earlier studies, prolonged hospitalisation and occurrence of postoperative complications were the strongest prognostic factors for delayed initiation of chemotherapy ${ }^{15,20}$. A complicated postoperative recovery often leads to prolonged hospitalisation due to additional medical interventions, and therefore may result in delayed chemotherapy administration ${ }^{23}$. Higher age and a higher $\mathrm{CCl}$ were also independent predictive factors for a delay in chemotherapy and this is confirmed in other studies ${ }^{24,28}$. Furthermore, patients with no residual disease were more prone to delayed initiation of chemotherapy, probably because they require more often extensive surgery ${ }^{29}$. This was most pronounced in NACT-IDS patients, who suffered significantly more often from postoperative complications after equal levels of extensive surgery compared to PDS patients (data not shown). In addition, the higher tendency of clinicians to start chemotherapy as soon as possible in patients with residual disease may also play a role $e^{5-7}$.

A substantial number of studies investigated the time interval between debulking surgery and chemotherapy. The results of these studies are difficult to compare since the median time between surgery and the commencement of adjuvant chemotherapy ranged from 17 to 42 days in the listed studies. These differences illustrate the heterogeneity of studied populations and therefore may explain the inconsistent outcomes. In addition, TTC intervals were based on either IQR ${ }^{13-15}$, median $\operatorname{TTC}^{6,7,18,20}$, or various weeks ${ }^{16,17,19,21-23}$, which also contributes to the conflicting results. In our study, we chose for IQR and compared the outliers (lowest and highest IQR groups) with the intermediate group (mean IQR) as 
we were interested if either early or late start influenced clinical outcomes. By using the median, or a number of weeks as a cut-off this association could not be studied.

Several studies have indicated that the early start of chemotherapy might be associated with worse clinical outcomes. The studies of Flynn et al. and Rosa et al. demonstrated worse OS when patients started before 22 and 28 days respectively ${ }^{6,17}$. In both studies, however, patients with gross macroscopic residual disease were overrepresented in the early groups. Consequently, there was no effect on clinical outcomes when they adjusted their models for residual disease. By only including patients with $\leq 1 \mathrm{~cm}$ residual disease, this trend in overall survival was not seen in our study. In addition, patients with an early initiation of chemotherapy neither experience a survival benefit compared to the intermediate group, indicating that earlier start of adjuvant chemotherapy does not contribute to improved clinical outcomes ${ }^{22}$.

We did find an independent association between delayed initiation of chemotherapy and impaired clinical outcomes. In patients treated with either PDS or NACT-IDS, the strongest influence was demonstrated in patients with no residual disease after debulking surgery. This is in concordance with earlier published studies ${ }^{7,22,23}$. A hypothesis for our findings might be that the prolonged interval after surgery attenuates the good prognosis of a complete debulking surgery, as it allows the tumour to regrow again. Even though macroscopic residual disease is absent in patients after a complete debulking, microscopic residual disease might be forced into accelerated proliferation and tumour regrowth due to the surgical intervention, as suggested by mouse models ${ }^{30,31}$. In addition, oophorectomy may induce tumour angiogenesis leading to rapid growth of (microscopic) residual tumour cells in ovarian cancer patients ${ }^{32}$.

Our findings are in contrast with a study of Hofstetter et al., who demonstrated a negative effect of prolonged TTC on overall survival only in patients with residual disease after debulking surgery ${ }^{20}$. They suggested that larger tumour masses tend to be less perfused than smaller tumour masses, and are therefore less responsive to chemotherapy ${ }^{20}$. Still, by including patients with $\leq 1 \mathrm{~cm}$ of residual disease we cannot speak of 'large tumour masses' in our series. But it remains unclear why patients with an optimal debulking do not benefit from early initiation of chemotherapy.

Patients are more prone to a delay in chemotherapy after very extensive surgery, which may raise the question whether we always should pursue complete debulking surgery if it is associated with a high probability to postoperative complications, and therefore delay in treatment continuation. Even though this is a valid argument, the prognosis of patients with no residual disease and a prolonged TTC is still superior to patients with macroscopic residual disease and an intermediate TTC (data not shown). So our results should not be 
used to justify spending less effort in the operating room as a concern of prolonged TTC, which is confirmed in the study of Aletti ${ }^{15}$.

This study has a number of strengths. The population-based character enabled us to include all consecutive Dutch patients who underwent surgery and chemotherapy for advanced ovarian cancer in an era of platinum-based chemotherapy and the aim to no residual disease after surgery. Furthermore, we were able to adjust our clinical outcomes for chemotherapy alterations, extended surgery and postoperative complications. Both extended surgery and postoperative complications were associated with the time interval, and influenced our survival models, but did not undo the effect of chemotherapy delays. Finally, we also included patients who underwent interval debulking surgery, which actually is a more common alternative treatment approach in ovarian cancer patients.

Besides these strengths, there are also some limitations. We had to exclude 102 patients from our analyses because time intervals were not known. We assumed that these missing time intervals were at random, and case-mix did not vary between the in- and excluded patients, but some bias cannot be excluded. In addition, we could not distinguish patients with an exploratory laparotomy from patients with a real effort to debulking surgery but a non-optimal outcome (>1 cm residual disease). Therefore, we excluded these patients and this limits the usability as these patients are also part of clinical daily practice. Furthermore, reasons for late start of adjuvant chemotherapy were not recorded. We adjusted our models for postoperative complications, comorbidity and prolonged hospitalisation, assuming to be the most common reasons for delaying adjuvant treatment.

In conclusion, our study provides evidence that delayed initiation of adjuvant chemotherapy is an independent prognostic factor for worse overall survival after complete (interval) debulking surgery. Consequently, we advise to start adjuvant chemotherapy within the first five to six weeks after debulking surgery.

\section{Acknowledgements}

The authors thank the registration team of the Netherlands Comprehensive Cancer Organisation (IKNL) for the collection of data for the Netherlands Cancer Registry.

\section{Funding}

This work was supported by Dutch Cancer Society [IKNL2014-6838]. 


\section{REFERENCES}

1. Wright AA, Bohlke $\mathrm{K}$, Armstrong $\mathrm{DK}$, Bookman MA, Cliby WA, Coleman RL, et al. Neoadjuvant chemotherapy for newly diagnosed, advanced ovarian cancer: Society of gynecologic oncology and american society of clinical oncology clinical practice guideline. J Clin Oncol. 2016;34(28):3460-73.

2. Chang SJ, Hodeib M, Chang J, Bristow RE. Survival impact of complete cytoreduction to no gross residual disease for advancedstage ovarian cancer: A meta-analysis. Gynecol Oncol. 2013;130(3):493-8.

3. Kehoe S, Hook J, Nankivell M, Jayson GC, Kitchener H, Lopes T, et al. Primary chemotherapy versus primary surgery for newly diagnosed advanced ovarian cancer (chorus): An open-label, randomised, controlled, non-inferiority trial. Lancet. 2015;386(9990):249-57.

4. Vergote I, Trope CG, Amant F, Kristensen $\mathrm{GB}$, Ehlen $\mathrm{T}$, Johnson N, et al. Neoadjuvant chemotherapy or primary surgery in stage iiic or iv ovarian cancer. N Engl J Med. 2010;363(10):943-53.

5. Alexander $M$, Blum $R$, Burbury $K$, Coutsouvelis J, Dooley M, Fazil O, et al. Timely initiation of chemotherapy: A systematic literature review of six priority cancers results and recommendations for clinical practice. Intern Med J. 2017;47(1):16-34.

6. Flynn PM, Paul J, Cruickshank DJ, Scottish Gynaecological Cancer Trials G. Does the interval from primary surgery to chemotherapy influence progression-free survival in ovarian cancer? Gynecol Oncol. 2002;86(3):354-7.

7. Mahner S, Eulenburg C, Staehle A, Wegscheider K, Reuss A, Pujade-Lauraine E, et al. Prognostic impact of the time interval between surgery and chemotherapy in advanced ovarian cancer: Analysis of prospective randomised phase iii trials. Eur J Cancer. 2013;49(1):142-9.
8. Gagliato Dde M, Gonzalez-Angulo AM, Lei X, Theriault RL, Giordano SH, Valero V, et al. Clinical impact of delaying initiation of adjuvant chemotherapy in patients with breast cancer. J Clin Oncol. 2014;32(8):73544.

9. Alkis N, Durnali AG, Arslan UY, Kocer M, Onder FO, Tokluoglu S, et al. Optimal timing of adjuvant treatment in patients with early breast cancer. Med Oncol. 2011;28(4):12559.

10. Des Guetz G, Nicolas P, Perret GY, Morere $J F$, Uzzan B. Does delaying adjuvant chemotherapy after curative surgery for colorectal cancer impair survival? A metaanalysis. Eur J Cancer. 2010;46(6):1049-55.

11. Bos $A C$, van Erning $F N$, van Gestel $Y R$, Creemers GJ, Punt CJ, van Oijen MG, et al. Timing of adjuvant chemotherapy and its relation to survival among patients with stage iii colon cancer. Eur J Cancer. 2015;51(17):2553-61.

12. Larsen E, Blaakaer J. Epithelial ovarian cancer: Does the time interval between primary surgery and postoperative chemotherapy have any prognostic importance? Acta Obstet Gynecol Scand. 2009;88(4):373-7.

13. Gadducci A, Sartori E, Landoni F, Zola P, Maggino T, Maggioni A, et al. Relationship between time interval from primary surgery to the start of taxane- plus platinumbased chemotherapy and clinical outcome of patients with advanced epithelial ovarian cancer: Results of a multicenter retrospective italian study. J Clin Oncol. 2005;23(4):751-8.

14. Paulsen T, Kaern J, Kjaerheim K, Haldorsen $T$, Trope C. Influence of interval between primary surgery and chemotherapy on short-term survival of patients with advanced ovarian, tubal or peritoneal cancer. Gynecol Oncol. 2006;102(3):447-52. 
15. Aletti GD, Long HJ, Podratz KC, Cliby WA. Is time to chemotherapy a determinant of prognosis in advanced-stage ovarian cancer? Gynecol Oncol. 2007;104(1):212-6.

16. Anuradha S, Donovan PJ, Webb PM, Brand $\mathrm{AH}$, Goh J, Friedlander $\mathrm{M}$, et al. Variations in adjuvant chemotherapy and survival in women with epithelial ovarian cancer - a population-based study. Acta Oncol. 2016;55(2):226-33.

17. Rosa DD, Clamp A, Mullamitha S, Ton NC, Lau S, Byrd L, et al. The interval from surgery to chemotherapy in the treatment of advanced epithelial ovarian carcinoma. Eur J Surg Oncol. 2006;32(5):588-91.

18. Lydiksen L, Jensen-Fangel S, Blaakaer J. Is it possible to define an optimal time for chemotherapy after surgery for ovarian cancer? Gynecol Oncol. 2014;133(3):454-9.

19. Sorbe B. Prognostic importance of the time interval from surgery to chemotherapy in treatment of ovarian carcinoma. Int J Gynecol Cancer. 2004;14(5):788-93.

20. Hofstetter G, Concin N, Braicu I, Chekerov R, Sehouli J, Cadron I, et al. The time interval from surgery to start of chemotherapy significantly impacts prognosis in patients with advanced serous ovarian carcinoma - analysis of patient data in the prospective ovcad study. Gynecol Oncol. 2013;131(1):15-20.

21. Wright J, Doan T, McBride R, Jacobson J, Hershman D. Variability in chemotherapy delivery for elderly women with advanced stage ovarian cancer and its impact on survival. Br J Cancer. 2008;98(7):1197-203.

22. Tewari KS, Java JJ, Eskander RN, Monk BJ, Burger RA. Early initiation of chemotherapy following complete resection of advanced ovarian cancer associated with improved survival: Nrg oncology/gynecologic oncology group study. Ann Oncol. 2016;27(1):114-21.
23. Wright JD, Herzog TJ, Neugut Al, Burke WM, Lu YS, Lewin SN, et al. Effect of radical cytoreductive surgery on omission and delay of chemotherapy for advancedstage ovarian cancer. Obstet Gynecol. 2012;120(4):871-81.

24. Singh S, Guetzko M, Resnick K. Preoperative predictors of delay in initiation of adjuvant chemotherapy in patients undergoing primary debulking surgery for ovarian cancer. Gynecol Oncol. 2016;143(2):241-5.

25. Fritz AG. International classification of diseases for oncology: Icd-o. 3rd ed. Geneva: World Health Organization; 2000. vii, 240 p. p.

26. Charlson M, Szatrowski TP, Peterson J, Gold J. Validation of a combined comorbidity index. J Clin Epidemiol. 1994;47(11):124551.

27. Sobin LH, Compton CC. Tnm seventh edition: What's new, what's changed: Communication from the international union against cancer and the american joint committee on cancer. Cancer. 2010;116(22):5336-9.

28. Noer MC, Sperling CD, Ottesen B, Antonsen SL, Christensen IJ, Hogdall C. Ovarian cancer and comorbidity: Is poor survival explained by choice of primary treatment or system delay? Int J Gynecol Cancer. 2017;27(6):1123-33.

29. Suidan RS, Leitao MM, Jr., Zivanovic O, Gardner GJ, Long Roche KC, Sonoda Y, et al. Predictive value of the age-adjusted charlson comorbidity index on perioperative complications and survival in patients undergoing primary debulking surgery for advanced epithelial ovarian cancer. Gynecol Oncol. 2015;138(2):246-51.

30. Fisher B, Gunduz N, Saffer EA. Influence of the interval between primary tumor removal and chemotherapy on kinetics and growth of metastases. Cancer Res. 1983;43(4):1488-92. 
31. Gunduz N, Fisher B, Saffer EA. Effect of surgical removal on the growth and kinetics of residual tumor. Cancer Res. 1979;39(10):3861-5.

32. Schiffenbauer YS, Abramovitch R, Meir G, Nevo N, Holzinger M, Itin A, et al. Loss of ovarian function promotes angiogenesis in human ovarian carcinoma. Proc Natl Acad Sci U S A. 1997;94(24):13203-8. 


\section{SUPPLEMENTARY MATERIAL}

S1: Baseline characteristics of patients undergoing PDS stratified by TTC interval

\begin{tabular}{|c|c|c|c|c|}
\hline & $<24$ days $(n, \%)$ & 24-37 days $(n, \%)$ & $>37$ days $(n, \%)$ & p-value \\
\hline Age & & & & $0.001^{\dagger}$ \\
\hline$<65$ & $198(61.9)$ & $461(56.2)$ & 231 (48.9) & \\
\hline$\geq 65$ & $122(38.1)$ & $359(43.8)$ & $241(51.1)$ & \\
\hline Mean (SD) & $60.1(10.6)$ & $61.6(10.9)$ & $64.3(10.8)$ & $<0.001^{\ddagger}$ \\
\hline FIGO stage & & & & $0.620^{\dagger}$ \\
\hline II & 59 (18.5) & $184(22.5)$ & $109(23.1)$ & \\
\hline III & $225(70.3)$ & $555(67.7)$ & $309(65.5)$ & \\
\hline IV & $26(8.1)$ & $61(7.4)$ & $43(9.1)$ & \\
\hline Unknown & $10(3.1)$ & $20(2.4)$ & $11(2.3)$ & \\
\hline Type of tumour & & & & $0.335^{+}$ \\
\hline Serous & $232(72.5)$ & $624(76.1)$ & $330(69.9)$ & \\
\hline Mucinous & $13(4.1)$ & $32(3.9)$ & $23(4.9)$ & \\
\hline Endometrioid & $41(12.8)$ & $66(8.0)$ & $57(12.1)$ & \\
\hline Clear-cell & $20(6.2)$ & $54(6.6)$ & $36(7.6)$ & \\
\hline Adenocarcinoma NOS & $8(2.5)$ & $27(3.3)$ & $17(3.6)$ & \\
\hline Other & $6(1.9)$ & $17(2.1)$ & $9(1.9)$ & \\
\hline Differentiation grade & & & & $0.758^{+}$ \\
\hline । & $30(9.3)$ & $68(8.3)$ & $51(10.8)$ & \\
\hline II & $54(16.9)$ & $125(15.2)$ & $77(16.3)$ & \\
\hline III & $182(56.9)$ & $487(59.4)$ & $271(57.4)$ & \\
\hline Unknown & $54(16.9)$ & $140(17.1)$ & $73(15.5)$ & \\
\hline Charlson Comorbidity Index & & & & $0.092^{+}$ \\
\hline 0 & $249(77.8)$ & $604(73.7)$ & $322(68.2)$ & \\
\hline $1-2$ & $61(19.1)$ & $181(22.1)$ & $123(26.1)$ & \\
\hline$\geq 3$ & $6(1.9)$ & $14(1.7)$ & $12(2.5)$ & \\
\hline Unknown & $4(1.2)$ & $21(2.5)$ & $15(3.2)$ & \\
\hline Extensive surgery & & & & $0.036^{+}$ \\
\hline No & $180(56.3)$ & $424(51.7)$ & $222(47.0)$ & \\
\hline Yes & $140(43.7)$ & $396(48.3)$ & $250(53.0)$ & \\
\hline Postoperative complications & & & & $<0.001^{+}$ \\
\hline No & $262(81.9)$ & $585(71.3)$ & $278(58.9)$ & \\
\hline Yes & $58(18.1)$ & $235(28.7)$ & $194(41.1)$ & \\
\hline Hospitalisation & & & & $<0.001^{+}$ \\
\hline$<10$ days & $262(81.9)$ & $669(81.6)$ & $301(63.8)$ & \\
\hline$\geq 10$ days & $57(17.8)$ & $149(18.2)$ & $167(35.4)$ & \\
\hline Unknown & $1(0.3)$ & $2(0.2)$ & $4(0.8)$ & \\
\hline Median (IQR) & $6(5-8)$ & $7(5-8)$ & $8(6-12)$ & $<0.001^{\|}$ \\
\hline
\end{tabular}

adenocarcinoma NOS: Adenocarcinoma not otherwise specified, ${ }^{+}$Chi-square test, ${ }^{\ddagger}$ ANOVA test, "MannWhitney-U test 
S2: Baseline characteristics of patients undergoing NACT-IDS stratified by TTC interval

\begin{tabular}{|c|c|c|c|c|}
\hline & $<24$ days $(n, \%)$ & 24-37 days $(n, \%)$ & $>37$ days $(n, \%)$ & p-value \\
\hline Age & & & & $<0.001^{\dagger}$ \\
\hline$<65$ & $352(52.9)$ & $589(45.2)$ & $184(35.6)$ & \\
\hline$\geq 65$ & $313(47.1)$ & $714(54.8)$ & $333(64.4)$ & \\
\hline Mean (SD) & $63.2(9.8)$ & $64.7(10.2)$ & $67(9.7)$ & $<0.001^{\ddagger}$ \\
\hline FIGO stage & & & & $<0.001^{\dagger}$ \\
\hline II & $4(0.6)$ & $19(1.5)$ & $4(0.8)$ & \\
\hline III & $390(58.6)$ & $808(62.0)$ & $344(66.5)$ & \\
\hline IV & $228(34.3)$ & $438(33.6)$ & $157(30.4)$ & \\
\hline Unknown & $43(6.5)$ & $38(2.9)$ & $12(2.3)$ & \\
\hline Type of tumour & & & & $0.002^{+}$ \\
\hline Serous & $554(83.3)$ & 1038 (79.7) & $440(85.1)$ & \\
\hline Mucinous & $9(1.3)$ & $10(0.8)$ & $5(1.0)$ & \\
\hline Endometrioid & $8(1.2)$ & $35(2.7)$ & $8(1.5)$ & \\
\hline Clear-cell & $17(2.6)$ & $22(1.7)$ & $4(0.8)$ & \\
\hline Adenocarcinoma NOS & $65(9.8)$ & $187(14.3)$ & $56(10.8)$ & \\
\hline Other & $12(1.8)$ & $11(0.8)$ & $4(0.8)$ & \\
\hline Differentiation grade & & & & $0.871^{\dagger}$ \\
\hline 1 & $14(2.1)$ & $22(1.7)$ & $13(2.5)$ & \\
\hline II & $45(6.8)$ & $86(6.6)$ & $31(6.0)$ & \\
\hline III & 305 (45.9) & $601(46.1)$ & $227(43.9)$ & \\
\hline Unknown & $301(45.2)$ & $594(45.6)$ & $246(47.6)$ & \\
\hline Charlson Comorbidity Index & & & & $0.010^{+}$ \\
\hline 0 & $479(72.0)$ & $894(68.6)$ & $323(62.5)$ & \\
\hline $1-2$ & $163(24.5)$ & $347(26.6)$ & $162(31.3)$ & \\
\hline$\geq 3$ & $9(1.4)$ & $38(2.9)$ & $20(3.9)$ & \\
\hline Unknown & $14(2.1)$ & $24(1.8)$ & $12(2.3)$ & \\
\hline Extensive surgery & & & & $<0.001^{+}$ \\
\hline No & $441(66.3)$ & $801(61.5)$ & $256(49.5)$ & \\
\hline Yes & $224(33.7)$ & $502(38.5)$ & $261(50.5)$ & \\
\hline Postoperative complications & & & & $<0.001^{+}$ \\
\hline No & $533(80.2)$ & $950(72.9)$ & $267(51.6)$ & \\
\hline Yes & $132(19.8)$ & $353(27.1)$ & $250(48.4)$ & \\
\hline Hospitalisation & & & & $<0.001^{\dagger}$ \\
\hline$<10$ days & $612(92.0)$ & $1066(81.8)$ & $284(54.9)$ & \\
\hline$\geq 10$ days & $46(6.9)$ & $233(17.9)$ & $231(44.7)$ & \\
\hline Unknown & $7(1.1)$ & $4(0.3)$ & $2(0.4)$ & \\
\hline Median (IQR) & $6(5-7)$ & $7(5-9)$ & $9(7-14)$ & $<0.001$ \\
\hline
\end{tabular}

${ }^{a}$ Adenocarcinoma NOS: Adenocarcinoma not otherwise specified, ${ }^{+}$Chi-square test, ${ }^{\ddagger}$ ANOVA test, "MannWhitney-U test 




\section{Localisation of distant metastases} defines prognosis and treatment efficacy in patients with FIGO stage IV ovarian cancer

M. Timmermans, G.S. Sonke, K.K. Van de Vijver, P.B. Ottevanger, H.W. Nijman, M.A. van der Aa, R.F.P.M. Kruitwagen 


\section{ABSTRACT}

\section{Introduction}

Ovarian cancer patients who are diagnosed with FIGO stage IV disease represent a highly heterogeneous group with possible survival differences. The FIGO staging system was therefore updated in 2014. The aim of our study was to evaluate the 2014 changes to FIGO stage IV ovarian cancer on overall survival (OS).

\section{Methods}

We identified all patients diagnosed with FIGO stage IV disease between 01.01.2008 and 31.12.2015 from the Netherlands Cancer Registry. We analysed the prognostic effect of FIGO IVa versus IVb. In addition, patients with extra-abdominal lymph node involvement as only site of distant disease were analysed separately. OS was analysed by Kaplan-Meier curves and multivariable Cox regression models.

\section{Results}

We identified 2,436 FIGO IV patients, of which 35\% was diagnosed with FIGO IVa disease. Five-year OS of FIGO IVa and IVb patients (including those with no or limited therapy) was $8.9 \%$ and $13.0 \%$ respectively $(P=0.508)$. Patients with only extra-abdominal lymph node involvement had a significant better OS than all other FIGO IV patients (5-year OS 25.9\%, Hazard Rate 0.77(0.62-0.95)).

\section{Conclusion}

Our study shows that the FIGO IV sub-classification into FIGO IVa and IVB does not provide additional prognostic information. Patients with extra-abdominal lymph node metastases as only site of FIGO IV disease, however, have a better prognosis compared to all other FIGO IV patients. These results warrant a critical appraisal of the current FIGO IV subclassification. 


\section{INTRODUCTION}

The vast majority of epithelial ovarian cancer (EOC) patients is diagnosed with advanced stage disease, and about 12-33\% have International Federation of Gynaecology and Obstetrics (FIGO) stage IV disease at initial presentation ${ }^{1,2}$. In the majority of these patients, stage IV disease is based on the presence of malignant pleural effusion (30-60\%), parenchymal liver metastases (10-25\%) or extra-abdominal lymph node metastases $(5-40 \%)^{1,3-5}$.

Following the recognition that patients with FIGO stage IV represent a highly heterogeneous group with possible survival differences, the FIGO staging system was updated in 2014. The new classification distinguishes between patients with malignant pleural effusion (FIGO IVa), and patients with either abdominal parenchymal invasion or extra-abdominal metastases (FIGO IVb) ${ }^{6,7}$. Multiple studies evaluated the prognostic value of the new subclassification, albeit with conflicting results ${ }^{1,8-15}$. Most studies reported similar survival results for FIGO IVa and IVb patients, while some studies found a prognostic favourable effect of extra-abdominal lymph node metastases as only site of distant disease ${ }^{1,8-10}$. Most of the analyses were, however, often hampered by limited patient numbers and missing clinical information.

The mainstay of primary treatment of FIGO IV patients consists of debulking surgery in combination with (neo)adjuvant chemotherapy. Two landmark randomised clinical trials (RCTs) studied the timing of surgery in EOC patients, i.e. primary debulking surgery (PDS) versus interval debulking surgery (IDS), and found similar survival rates in both FIGO IIIC and IV patients ${ }^{16,17}$. However, it is clear that patients with no residual disease after surgery have the best prognosis. Therefore, the decision to schedule patients for either PDS or neoadjuvant chemotherapy (NACT) and IDS, is nowadays mainly based on the ability to achieve a maximal (intra-abdominal) cytoreduction with acceptable surgical morbidity. In case of extra-abdominal disease, it is suggested that NACT may indicate whether a complete cytoreduction could be achieved. In case of no response or progression during NACT, surgery might be omitted.

The aim of our study was to evaluate the renewed FIGO sub-classification into stage IVa and IVb on clinical outcome in a large population-based cohort. In addition, we studied the effect of treatment in these groups to offer clinical guidance on the preferred treatment in FIGO IV patients. 


\section{METHODS}

We identified all consecutive patients who were diagnosed with EOC, including fallopian tube and primary peritoneal cancer (International Classification of Diseases for Oncology (ICD-O) C56.9, C57.0, C48.2), from the Netherlands Cancer Registry (NCR). The NCR is a nationwide cancer registry and covers all Dutch cancer patients since 1989. Thoroughly trained registration clerks routinely extracted information on patient and tumour characteristics (including the localisation of metastases), diagnostic procedures and treatment. Follow-up status is obtained by annual linkage with the municipal demography registries (GBA). The study design, data abstraction process and storage protocols were approved by the NCR review board.

\section{Study population}

We included all FIGO IV patients who were diagnosed between 01.01.2008 and 31.12.2015, including patients with clinically suspicious metastases (but not histologically proven). Malignant pleural effusion was cytologically confirmed in $99 \%$ of patients, as this is required for FIGO stage IV disease in the Tumour-Node-Metastasis (TNM) system. FIGO stage 2009 was derived from the TNM 7 staging system ${ }^{18}$, which means that inguinal lymph node metastases were not included within the FIGO IV group, as they were regarded as regional lymph nodes (N1) at that time.

\section{Definitions}

Patients were categorised as FIGO IVa if they were diagnosed with malignant pleural effusion without other extra-abdominal or parenchymal spread, and as FIGO IVb in all other cases. In separate analysis, we divided patients according to the localisation of distant disease; 1) pleural malignant effusion, 2) parenchymal metastases (either intraabdominal or extra-abdominal), 3) extra-abdominal lymph node metastases or 4) other. Patients were categorised as 'other' if they were diagnosed with metastases in more than one of the before mentioned categories, e.g. malignant pleural effusion and parenchymal liver metastasis.

The outcome of cytoreductive surgery (debulking) was defined as complete in case of no macroscopic abdominal residual disease, as optimal when the largest diameter was $\leq 1 \mathrm{~cm}$, and as suboptimal in case of residuals $>1 \mathrm{~cm}$ in maximal diameter.

For patients undergoing surgery and chemotherapy, additional medical information was collected. As a result, all present co-morbidities were registered in our database, and the Charlson-Comorbidity Index (CCl) was modelled based on these registered comorbidities, 
which was categorised 0,1 , and $\geq 2$ points ${ }^{19}$. Chemotherapeutic agents, the number of cycles and alterations to the chemotherapeutic scheme were registered. Our models were adjusted for chemotherapy modifications, where six cycles of carboplatin and paclitaxel without dose-reductions was considered regular care.

\section{Statistical analyses}

Overall survival (OS) was defined as the interval between the date of diagnosis and death, or last follow-up date for patients who were still alive (1 February 2018). Kaplan Meier survival curves, log-rank tests and, if applicable, uni- and multivariable cox regression models were used to analyse OS. The proportional hazards assumption was tested for all survival analyses. If the hazards were not constant over time, i.e. the proportional hazards assumption was violated, we used time-varying effects in our cox regression model to adjust our results for non-proportionality ${ }^{20}$. When comparing PDS and NACT-IDS, an additional matching criterion was used as a sensitivity analysis to overcome the introduction of immortal time bias ${ }^{21}$. Immortal time bias refers to a time interval in the follow-up period where the event of interest could not have occurred because of exposure definition, i.e. patients who underwent debulking surgery after NACT could not have died during NACT22. Our matching criterion implied that patients were excluded if they died or were lost to follow-up during the median time that NACT lasted in our population (103 days). Moreover, regular Kaplan-Meier curves were added to the supplementary material (S5). Statistical analyses were performed using STATA/SE, version 14.1 (Stata-Corp, College Station, Texas, USA) and a p-value <0.05 was considered statistically significant.

\section{RESULTS}

Between 2008 and 2015, 1,884 out of 2,436 FIGO IV patients were treated with surgery and/or chemotherapy (77\%), and the rate was stable over time ( $P=0.524$, figure 1$)$. Median age of patients was 69 years at diagnosis (interquartile range (IQR) 61-78). Most patients were diagnosed with malignant pleural effusion (35\%) or parenchymal metastases (37\%). Most parenchymal metastases were localised in the liver (56\%), and other localisations were the gastro-intestinal tract (9\%), and lungs (16\%). A minority of patients had solely extra-abdominal lymph node involvement (12\%). The most common sites for extraabdominal lymph node involvement were intrathoracic lymph nodes (38\%) and lymph nodes of the head, face and neck (21\%, such as supraclavicular lymph nodes) or multiple locations (15\%). Other baseline characteristics are displayed in the supplementary material (S1). 


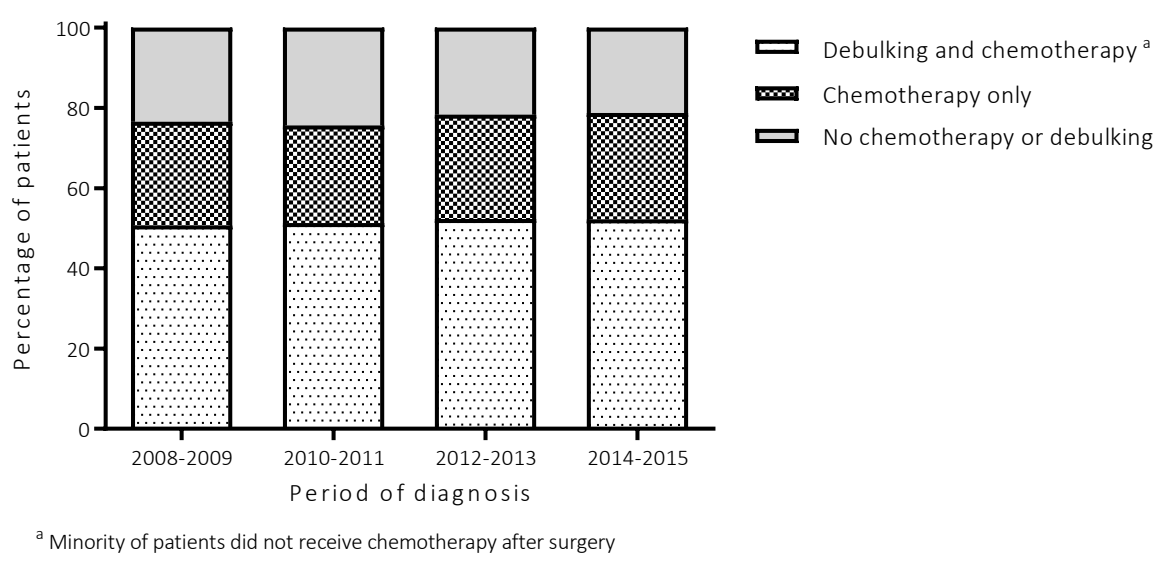

Figure 1: Treatment of all FIGO IV EOC patients over time $(n=2,436)$

\section{Clinical outcome of the renewed FIGO IV sub-classification}

In our total population (i.e. including those with no or limited therapy), five-year OS was 8.9\% for FIGO IVa and $13.0 \%$ for FIGO IVb patients. We found no prognostic effect of the renewed sub-classification in our total population (Hazard Rate (HR) 1.03, 95\% Cl 0.94-1.13), $P=0.508)$. Survival rates were higher in patients who were treated with the combination of debulking surgery and chemotherapy (five-year OS FIGO IVa: 14.6\%, FIGO IVb: 23.6\%, $\mathrm{HR}_{\mathrm{FIGO} \mathrm{IVb}}$ 0.82(0.72-0.94), $\left.P=0.004\right)$. Moreover, when adjusted for age, $\mathrm{CCl}$, histologic subtype, treatment sequence, chemotherapy alterations and the outcome of debulking surgery, FIGO IVb patients experienced better survival compared to FIGO IVa patients (adjusted HR 0.75(0.65-0.87))

\section{Clinical outcome stratified by the localisation of metastases}

In our total population (i.e. including those with no or limited therapy), stratification by localisation of metastasis, revealed that patients with solely extra-abdominal lymph node metastases experienced higher OS when compared to the other groups of FIGO IV patients (five-year OS was 25.9\% for lymph node metastases and 9.8\% for other metastases, $P<0.001$, figure 2). In addition, this effect was also observed in our treated population (i.e. combination of chemotherapy and debulking surgery). In these patients, even after adjustment for age, $\mathrm{CCl}$, histologic subtype, treatment sequence, chemotherapy alterations and the outcome of debulking surgery, the improved prognosis for patients with lymph node metastases remained statistically significant (adjusted HR 0.77(0.62-0.95) compared to all other metastases). Sensitivity analysis showed that there was no difference in OS 
between histologically confirmed malignant lymph node involvement and those who were clinically suspicious $(P=0.618)$.

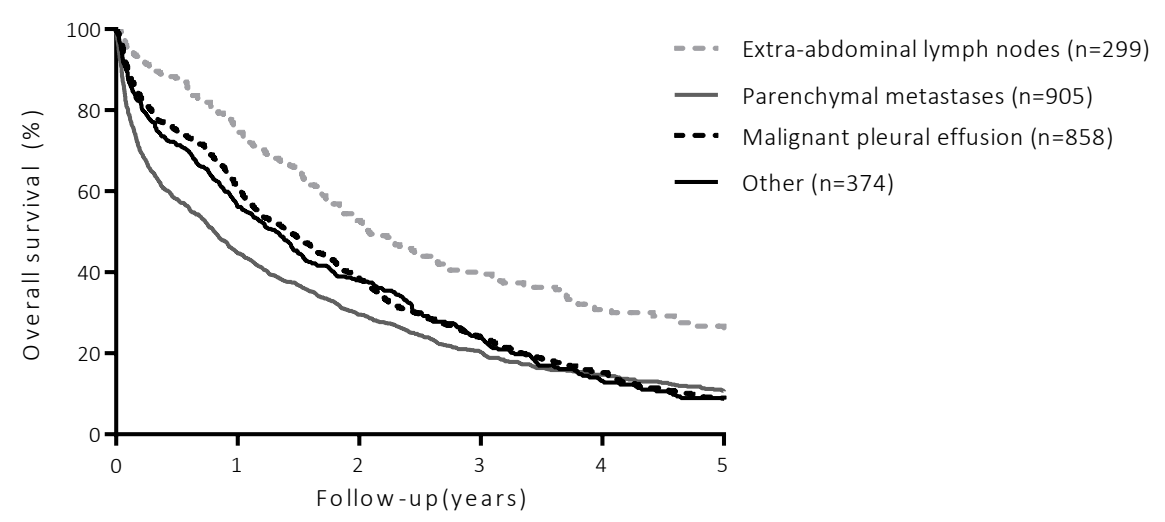

Figure 2: Overall survival of all FIGO IV patients by localisation of their metastases $(n=2,436)$

\section{Clinical outcomes stratified by therapy}

The number of patients who were treated with PDS decreased over time from $27 \%$ in 2008 2009 to $10 \%$ in 2014-2015 ( $P<0.001$, S2). Simultaneously, the outcome of surgery improved in both groups $(\mathrm{S} 3, \mathrm{~S} 4)$. NACT-IDS was associated with a higher rate of complete or optimal surgeries when compared to PDS (adjusted OR 2.27(1.54-3.34)).

The effect of treatment sequence (PDS or NACT-IDS) seems to conflict over time in FIGO IVa patients, where survival lines are crossing at 18 months (S5 panel A). In FIGO IVb patients, treatment sequence did not influence survival (adjusted $H R_{\text {NACT-IDS }} 0.97(0.76-1.24)$ ). No difference in OS between the two treatment sequences was also observed in patients with extra-abdominal lymph node metastases only or other metastases (S5 panel C $P=0.990$, and $D P=0.784$ respectively). In patients with parenchymal metastases, however, NACT-IDS

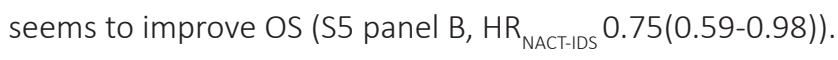

In the subsequent sensitivity analysis including a matching criterion to account for immortal time bias, 9/62 patients who died within three months after PDS were excluded. Of these nine patients, 4 died shortly after PDS, and 5 received at least one cycle of chemotherapy. The sensitivity analysis then showed a survival benefit for the remaining PDS patients with malignant pleural effusion compared to NACT-IDS ( $P=0.003$, figure 3 panel $A$ ). After adjustment for age, $\mathrm{CCl}$, histologic subtype, treatment sequence, chemotherapy alterations and the outcome of debulking surgery, this survival benefit remains significant $\left(H_{\text {NACT-IDS }} 1.96(1.33-2.88)\right)$. In patients with parenchymal metastases, where 14 out of 102 PDS patients were excluded, NACT-IDS is comparable to PDS ( $P=0.554)$. 

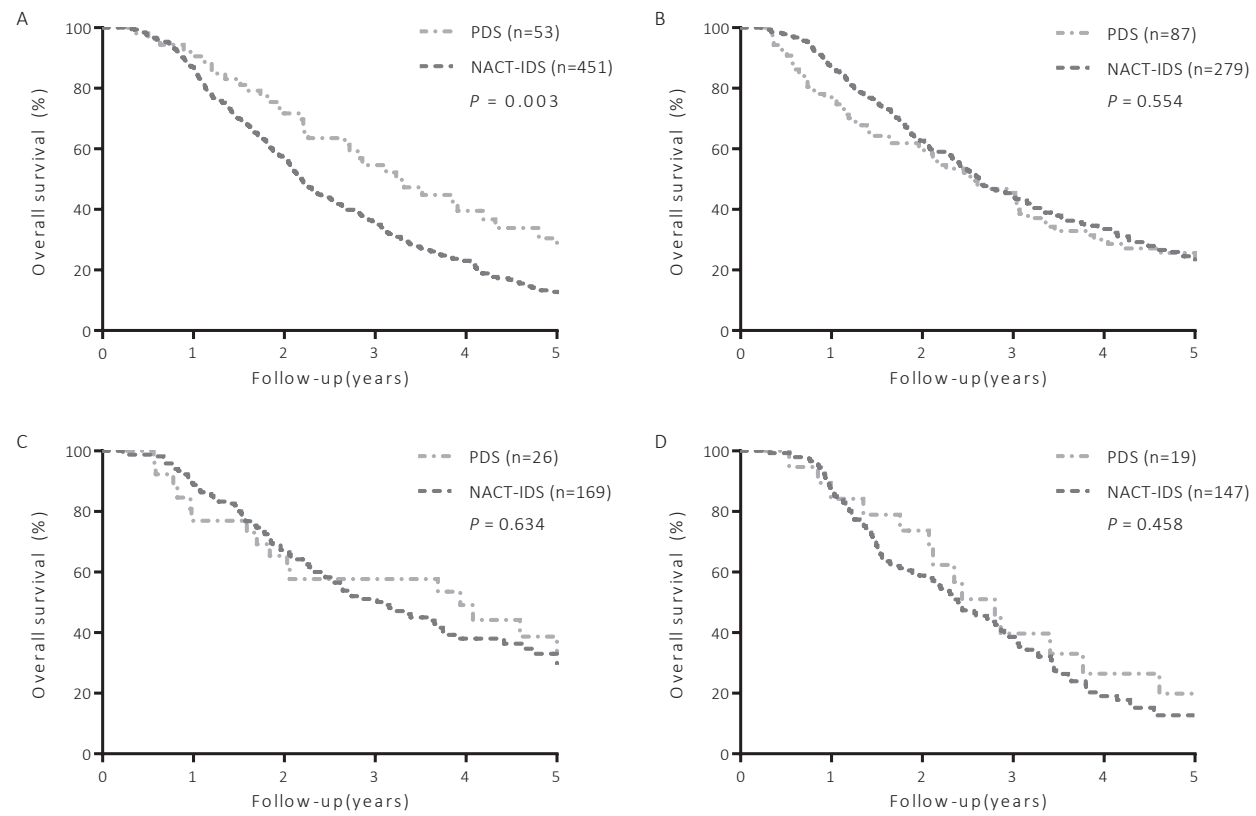

Figure 3: Sensitivity analysis for overall survival by the localisation of metastases, by using the matching criterion. Every panel contains overall survival with a follow-up of five years, the dark grey lines depict NACT-IDS patients and het light grey lines PDS patients. The $P$-values represent a Log-rank test. A) pleural malignant effusion, B) parenchymal metastases, C) extra-abdominal metastases, D) other metastases

\section{DISCUSSION}

Our population-based study showed that the renewed FIGO IV sub-classification did not provide additional prognostic information. However, patients with extra-abdominal lymph node metastases as only site of distant disease experienced a significantly higher OS than other groups of FIGO IV patients. In addition, we showed that PDS may be an alternative to NACT-IDS in selected FIGO IV patients with malignant pleural effusion as only site of distant disease.

Multiple studies investigated the additional distinction in FIGO IV patients. Most of them did not find any significant differences in OS, while others indicated that FIGO IVb patients, counterintuitively, might have a better prognosis ${ }^{8,11-15}$. In our study, we confirmed in a population-based setting, that there was no difference between FIGO IVa and FIGO $\mathrm{IVb}$ patients. In patients who were treated with the combination of chemotherapy and debulking surgery, however, FIGO IVb patients might experience improved OS. This is probably explained by the percentage of patients that does not undergo the combined 
treatment, which differs significantly between FIGO IVa and FIGO IVb patients (40\% vs. 59\% respectively, $P<0.001)$. As a minority of patients with FIGO IVb disease is treated with the advised treatment, this selection probably contributes to the differences between both analyses.

Patients with FIGO stage IV based on only extra-abdominal lymph node metastases have the most favourable prognosis, and this particular finding is in accordance with other studies ${ }^{8-10}$. The beneficial effect on clinical outcome is in concordance with the renewed distinction in FIGO III patients. In the current FIGO staging classification, patients with regional lymph node metastases only are now classified as FIGO IIla1 instead of FIGO IIIc. The latter adjustment to the FIGO staging system is proven to be more accurate for prognosis, while the revised FIGO IV stage does not provide any prognostic information, ${ }^{7,923-25}$. A limitation of our current research is that patients with inguinal lymph node metastases were not included in the analyses, as they could not be identified from our cancer registry. Following TNM7 and FIGO 2009, these patients were still classified as FIGO IIIc disease and the localisation of regional lymph node metastases is not registered ${ }^{18}$. However, the number of FIGO IV patients with solely inguinal lymph node metastases appears to be low (2-5\%), and the survival of these patients may be similar to FIGO III patients with solitary pelvic or para-aortic nodal involvement ${ }^{1,9,26}$. Consequently, this supports our findings that patients with extra-abdominal lymph node metastases show the most favourable prognosis in the FIGO IV group. The prognostic role of only extra-abdominal lymph nodes in EOC patients should be investigated in future prospective studies, and it remains questionable whether these patients should even be classified as FIGO IV patients ${ }^{9,10}$.

Over time, the percentage of patients that received no treatment in our population (i.e. no chemotherapy and no debulking surgery) was $20-25 \%$. Moreover, another $25 \%$ of all patients received chemotherapy without debulking surgery. The decision to schedule patients for cancer-directed treatment or palliative care is based on a multidisciplinary team meeting, including medical oncologists, gynaecologic-oncologists, radiologists and pathologists. Reasons for abstaining treatment are not routinely collected within our database, and are therefore unknown. The inclusion of patients without cancer-directed treatment explains the low survival rates in our total population when compared to other studies, as the combination of platinum-based chemotherapy and maximal debulking surgery is essential to improve patients' prognosis s,8,9,13. $^{2}$.

Our study showed that debulking surgery contributes to the prognosis of selected patients that eventually underwent surgery in our population, as the survival rates of this group are higher when compared to patients with limited therapy. In addition, the amount of residual disease is a strong prognostic factor for OS (data not shown). This implies that at least a 
selection of patients with FIGO IV disease is comparable to other advanced stage patients in clinical decision making, with no residual disease after surgery as ultimate goal ${ }^{27-30}$. This finding is supported by the distribution of recurrences in FIGO IV patients. Several studies showed that most recurrences occur intra-abdominal, which underscores the importance of controlling intra-abdominal disease $\mathrm{e}^{11,31,32}$. However, as shown in other studies, if debulking surgery results in $>1 \mathrm{~cm}$ of residual disease, it is questionable if this treatment approach is superior to chemotherapy alone ${ }^{2,3}$. The presence of initially unresectable disease $(>1 \mathrm{~cm})$ could therefore be challenged with NACT, and surgery might be omitted in case of poor response. This emphasises that patient selection to those who will benefit from surgery is crucial to avoid surgical morbidity and even mortality.

The preference for timing of surgery changed over time, with an increase in the use of NACT-IDS in FIGO IV patients, which contributed to the more favourable outcomes of surgery in the whole population. NACT-IDS seems to be beneficial in FIGO IV patients, as we showed that survival was comparable between PDS and NACT-IDS, and multiple studies reported reduced morbidity after NACT-IDS ${ }^{16,17,33,34}$. In our retrospective study, confounding by severity plays a role in the selection of patients for either NACT-IDS or PDS. Patients that undergo PDS are probably diagnosed with a lower tumour burden and a higher probability towards complete debulking surgery. As this favourable prognosis does not translate into better survival rates, PDS might not be the preferred treatment for these patients. Moreover, a recent sensitivity analysis on FIGO IV patients of the EORTC study confirmed the beneficial effect of NACT-IDS, and the authors conclude that NACT-IDS might be the preferred treatment in FIGO IVb patients ${ }^{8,16}$. However, other studies indicate that PDS remains the preferred treatment, also for FIGO IV patients ${ }^{1,2}$.

We identified a subgroup of selected patients that may benefit from PDS over NACT-IDS. In a sensitivity analysis that excluded patients that died shortly after PDS in order to overcome immortal time bias, a more favourable outcome was observed in patients with malignant pleural effusion ${ }^{22}$. Immortal time bias refers to those patients who did not respond or died during NACT and thus could not have undergone IDS. These patients are represented in our chemotherapy only group, and therefore do not compromise clinical outcome in the NACT-IDS group ${ }^{22}$. It makes sense that a selection of patients may be better served by PDS. Pleural effusion can be the result of trans-diaphragmatic migration of malignant cells through pleuroperitoneal communications, which usually responds well to adjuvant chemotherapy ${ }^{35}$. Unfortunately, the number of FIGO IVa patients who underwent PDS is limited in our series and this finding needs to be confirmed in future prospective studies. Moreover, PDS can only be beneficial if patients that die shortly after this extensive procedure could be identified pre-operatively. 
Our study is hampered by its retrospective character, and the definition of the amount of residual disease in FIGO IV patients. Should the presence of extra-abdominal disease, in case of an intra-abdominal complete debulking surgery, alter the outcome of the surgery? This issue is not often addressed in other studies, neither does there exist a clear definition in international literature. Therefore, it is possible that gynaecologists interpreted the outcome of residual disease differently and this might have introduced bias in our analyses as our registration clerks register the judgment of the gynaecologists. Strengths of our study are the population-based character (including those patients with no or limited therapy), complete follow-up records, and the number of patients, as most studies were underpowered to identify the prognostic effect of certain metastases on clinical outcome. In conclusion, we showed that the renewed FIGO IV classification into FIGO IVa and IVB does not provide meaningful prognostic information. Patients with extra-abdominal lymph node metastases as only site of FIGO IV disease, however, do have a better prognosis compared to all other FIGO IV patients. These findings warrant a critical evaluation of the current FIGO IV sub-classification.

\section{Acknowledgements}

The authors thank the registration team of the Netherlands Comprehensive Cancer Organisation (IKNL) for the collection of data for the Netherlands Cancer Registry.

\section{Funding}

This work was supported by Dutch Cancer Society [IKNL2014-6838]. 


\section{REFERENCES}

1. Ataseven B, Chiva LM, Harter P, GonzalezMartin A, du Bois A. Figo stage iv epithelial ovarian, fallopian tube and peritoneal cancer revisited. Gynecol Oncol. 2016;142(3):597607.

2. Ataseven B, Grimm C, Harter P, Heitz F, Traut A, Prader $S$, et al. Prognostic impact of debulking surgery and residual tumor in patients with epithelial ovarian cancer figo stage iv. Gynecol Oncol. 2016;140(2):21520.

3. Aletti GD, Dowdy SC, Podratz KC, Cliby WA. Analysis of factors impacting operability in stage iv ovarian cancer: Rationale use of a triage system. Gynecol Oncol. 2007;105(1):84-9.

4. Cormio G, Rossi C, Cazzolla A, Resta L, Loverro G, Greco P, et al. Distant metastases in ovarian carcinoma. Int J Gynecol Cancer. 2003;13(2):125-9.

5. Ogawa K, Yoshii Y, Aoki Y, Nagai Y, Tsuchida $\mathrm{Y}$, Toita $\mathrm{T}$, et al. Treatment and prognosis of brain metastases from gynecological cancers. Neurol Med Chir (Tokyo). 2008;48(2):57-62; discussion-3.

6. Prat J, Oncology FCoG. Staging classification for cancer of the ovary, fallopian tube, and peritoneum. Int J Gynaecol Obstet. 2014;124(1):1-5.

7. Mutch DG, Prat J. 2014 figo staging for ovarian, fallopian tube and peritoneal cancer. Gynecol Oncol. 2014;133(3):401-4.

8. Tajik $\mathrm{P}$, van de Vrie R, Zafarmand $\mathrm{MH}$, Coens $C$, Buist MR, Vergote I, et al. The figo stage iva versus ivb of ovarian cancer: Prognostic value and predictive value for neoadjuvant chemotherapy. Int J Gynecol Cancer. 2018.

9. Nasioudis D, Chapman-Davis E, Frey MK, Caputo TA, Witkin SS, Holcomb K. Should epithelial ovarian carcinoma metastatic to the inguinal lymph nodes be assigned stage ivb? Gynecol Oncol. 2017;147(1):81-4.
10. Hjerpe E, Staf C, Dahm-Kahler P, Stalberg $\mathrm{K}$, Bjurberg $\mathrm{M}$, Holmberg $\mathrm{E}$, et al. Lymph node metastases as only qualifier for stage iv serous ovarian cancer confers longer survival than other sites of distant disease- a swedish gynecologic cancer group (swegcg) study. Acta Oncol. 2017:1-7.

11. Jamieson A, Sykes P, Eva L, Bergzoll C, Simcock B. Subtypes of stage iv ovarian cancer; response to treatment and patterns of disease recurrence. Gynecol Oncol. 2017;146(2):273-8.

12. Rosendahl M, Hogdall CK, Mosgaard BJ. Restaging and survival analysis of 4036 ovarian cancer patients according to the 2013 figo classification for ovarian, fallopian tube, and primary peritoneal cancer. Int J Gynecol Cancer. 2016;26(4):680-7.

13. Ataseven B, Harter P, Grimm C, Heitz F, Heikaus S, Traut A, et al. The revised 2014 figo staging system for epithelial ovarian cancer: Is a subclassification into figo stage iva and ivb justified? Gynecol Oncol. 2016;142(2):243-7.

14. Toptas T, Pestereli E, Erol O, Bozkurt S, Erdogan $G$, Simsek $T$. Validation of revised figo staging classification for cancer of the ovary, fallopian tube, and peritoneum based on a single histological type. Int J Gynecol Cancer. 2016;26(6):1012-9.

15. Paik ES, Lee YY, Lee EJ, Choi CH, Kim TJ, Lee JW, et al. Survival analysis of revised 2013 figo staging classification of epithelial ovarian cancer and comparison with previous figo staging classification. Obstet Gynecol Sci. 2015;58(2):124-34.

16. Vergote I, Trope CG, Amant F, Kristensen $\mathrm{GB}$, Ehlen $\mathrm{T}$, Johnson $\mathrm{N}$, et al. Neoadjuvant chemotherapy or primary surgery in stage iiic or iv ovarian cancer. N Engl J Med. 2010;363(10):943-53. 
17. Kehoe S, Hook J, Nankivell M, Jayson GC, Kitchener H, Lopes $T$, et al. Primary chemotherapy versus primary surgery for newly diagnosed advanced ovarian cancer (chorus): An open-label, randomised, controlled, non-inferiority trial. Lancet. 2015;386(9990):249-57.

18. Sobin LH, Compton CC. Tnm seventh edition: What's new, what's changed: Communication from the international union against cancer and the american joint committee on cancer. Cancer. 2010;116(22):5336-9.

19. Charlson M, Szatrowski TP, Peterson J, Gold J. Validation of a combined comorbidity index. J Clin Epidemiol. 1994;47(11):124551.

20. Bellera CA, MacGrogan $G$, Debled $M$, de Lara CT, Brouste V, Mathoulin-Pelissier S. Variables with time-varying effects and the cox model: Some statistical concepts illustrated with a prognostic factor study in breast cancer. BMC Med Res Methodol. 2010;10:20.

21. Shariff SZ, Cuerden MS, Jain AK, Garg $A X$. The secret of immortal time bias in epidemiologic studies. J Am Soc Nephrol. 2008;19(5):841-3.

22. Lai TY, Hu YW. Neoadjuvant therapy in resectable pancreatic cancer: Immortal time bias and its correction. J Clin Oncol. 2017;35(14):1623.

23. Cliby WA, Aletti GD, Wilson TO, Podratz KC. Is it justified to classify patients to stage iiic epithelial ovarian cancer based on nodal involvement only? Gynecol Oncol. 2006;103(3):797-801.

24. Onda T, Yoshikawa H, Yasugi T, Mishima M, Nakagawa S, Yamada M, et al. Patients with ovarian carcinoma upstaged to stage iii after systematic lymphadenctomy have similar survival to stage i/ii patients and superior survival to other stage iii patients. Cancer. 1998;83(8):1555-60.
25. Ferrandina G, Scambia G, Legge F, Petrillo $M$, Salutari V. Ovarian cancer patients with "node-positive-only" stage iiic disease have a more favorable outcome than stage iiia/b. Gynecol Oncol. 2007;107(1):154-6.

26. Yang $X J$, Zheng FY, Xu YS, Ou RY. Ovarian cancer initially presenting with isolated ipsilateral superficial inguinal lymph node metastasis: A case study and review of the literature. J Ovarian Res. 2014;7:20.

27. Bristow RE, Montz FJ, Lagasse LD, Leuchter RS, Karlan BY. Survival impact of surgical cytoreduction in stage iv epithelial ovarian cancer. Gynecol Oncol. 1999;72(3):278-87.

28. Curtin JP, Malik R, Venkatraman ES, Barakat RR, Hoskins WJ. Stage iv ovarian cancer: Impact of surgical debulking. Gynecol Oncol. 1997;64(1):9-12.

29. Wimberger $P$, Wehling $M$, Lehmann $N$, Kimmig R, Schmalfeldt B, Burges $A$, et al. Influence of residual tumor on outcome in ovarian cancer patients with figo stage iv disease: An exploratory analysis of the agoovar (arbeitsgemeinschaft gynaekologische onkologie ovarian cancer study group). Ann Surg Oncol. 2010;17(6):1642-8.

30. Winter WE, 3rd, Maxwell GL, Tian C, Sundborg MJ, Rose GS, Rose PG, et al. Tumor residual after surgical cytoreduction in prediction of clinical outcome in stage iv epithelial ovarian cancer: A gynecologic oncology group study. I Clin Oncol. 2008;26(1):83-9.

31. Perri T, Ben-Baruch $G$, Kalfon $S$, Beiner ME, Helpman L, Hogen LB, et al. Abdominopelvic cytoreduction rates and recurrence sites in stage iv ovarian cancer: Is there a case for thoracic cytoreduction? Gynecol Oncol. 2013;131(1):27-31.

32. Aletti GD, Podratz KC, Cliby WA, Gostout BS. Stage iv ovarian cancer: Disease site-specific rationale for postoperative treatment. Gynecol Oncol. 2009;112(1):22-7. 
33. Yang $L$, Zhang $B$, Xing $G$, Du J, Yang $B$, Yuan $Q$, et al. Neoadjuvant chemotherapy versus primary debulking surgery in advanced epithelial ovarian cancer: A meta-analysis of peri-operative outcome. PLoS One. 2017;12(10):e0186725.

34. Fagotti A, Ferrandina G, Vizzielli G, Fanfani F, Gallotta V, Chiantera V, et al. Phase iii randomised clinical trial comparing primary surgery versus neoadjuvant chemotherapy in advanced epithelial ovarian cancer with high tumour load (scorpion trial): Final analysis of peri-operative outcome. Eur J Cancer. 2016;59:22-33.

35. Porcel JM, Diaz JP, Chi DS. Clinical implications of pleural effusions in ovarian cancer. Respirology. 2012;17(7):1060-7. 


\section{SUPPLEMENTARY MATERIAL}

S1: Baseline characteristics of all FIGO IV ovarian cancer patients $(n=2,436)$

Number of patients (\%)

\begin{tabular}{|c|c|}
\hline \multicolumn{2}{|l|}{ Age } \\
\hline$<65$ & $866(35.6)$ \\
\hline $65-75$ & $822(33.7)$ \\
\hline$>75$ & $748(30.7)$ \\
\hline Mean (SD) & $68.4(12.1)$ \\
\hline \multicolumn{2}{|l|}{ Charlson Comorbidity Score* } \\
\hline 0 & $1,129(59.9)$ \\
\hline $1-2$ & $311(16.5)$ \\
\hline$\geq 3$ & $311(16.5)$ \\
\hline Unknown & $133(7.1)$ \\
\hline \multicolumn{2}{|l|}{ Type of tumour } \\
\hline Serous & $1,392(57.1)$ \\
\hline Mucinous & 45 (1.9) \\
\hline Endometrioid & $44(1.8)$ \\
\hline Clear-cell & 45 (1.9) \\
\hline Adenocarcinoma NOS & $849(34.8)$ \\
\hline Other & $61(2.5)$ \\
\hline \multicolumn{2}{|l|}{ Differentiation grade } \\
\hline I & $52(2.1)$ \\
\hline II & $108(4.4)$ \\
\hline III & $833(34.2)$ \\
\hline Unknown & $1,443(59.3)$ \\
\hline \multicolumn{2}{|l|}{ Localisation of metastasis } \\
\hline Pleural malignant effusion & $858(35.2)$ \\
\hline Intra-abdominal & 905 (37.2) \\
\hline Lymph node metastases & $299(12.3)$ \\
\hline Other & $374(15.3)$ \\
\hline \multicolumn{2}{|l|}{ Treatment approach } \\
\hline No chemotherapy or debulking & $552(22.7)$ \\
\hline Chemotherapy only & $626(25.7)$ \\
\hline Debulking surgery and/or chemotherapy & $1258(51.6)$ \\
\hline
\end{tabular}

* Charlson-Comorbidity score was only known for patients who were treated with surgery and/or chemotherapy $(n=1,884)$ 


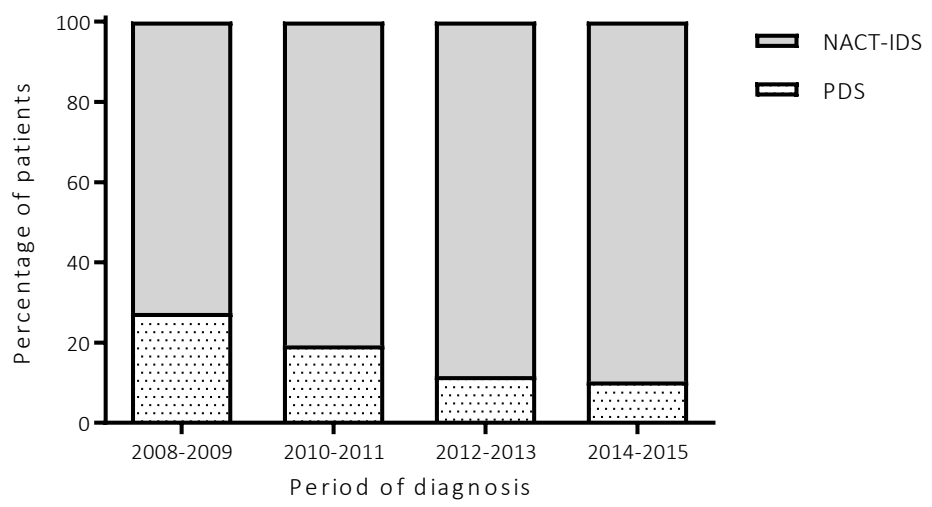

S2: Treatment sequence of FIGO IV EOC patients over time $(n=1,258)$

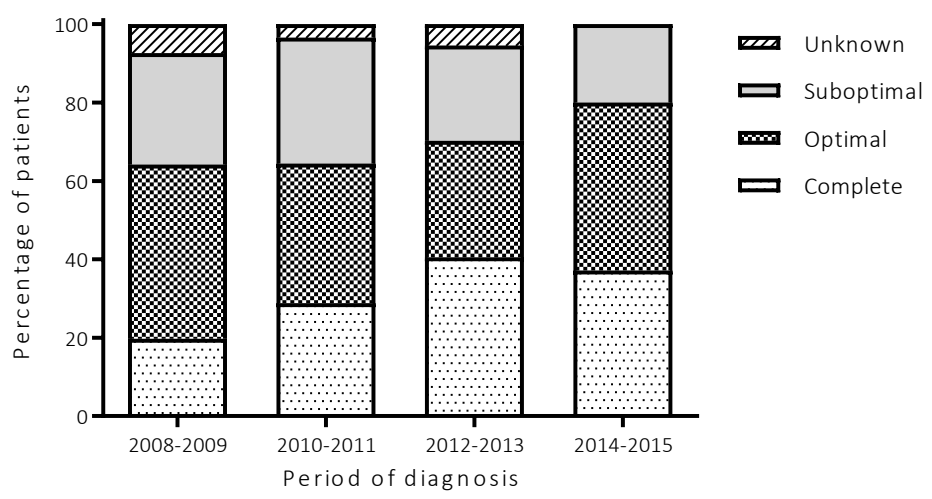

S3: Outcome of debulking surgery of PDS patients $(n=212)$

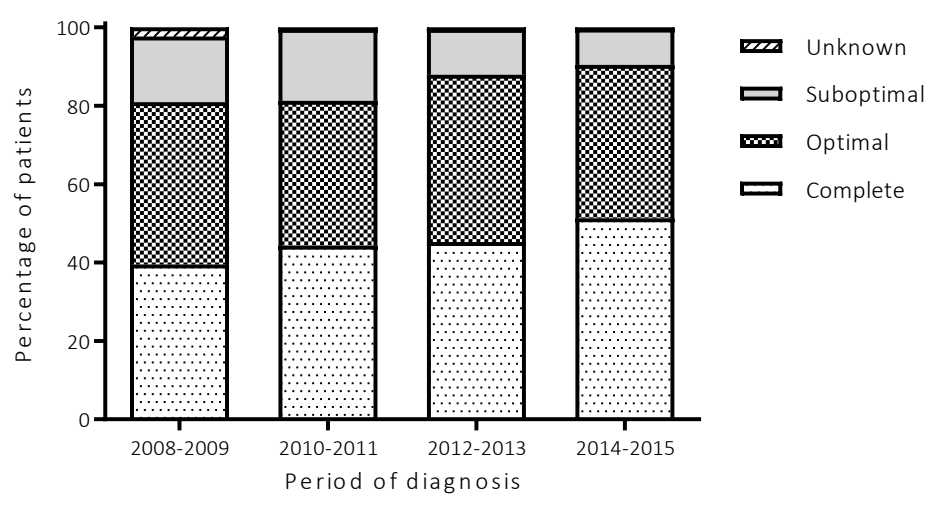

S4: Outcome of debulking surgery of NACT-IDS patients $(n=1,046)$ 
A
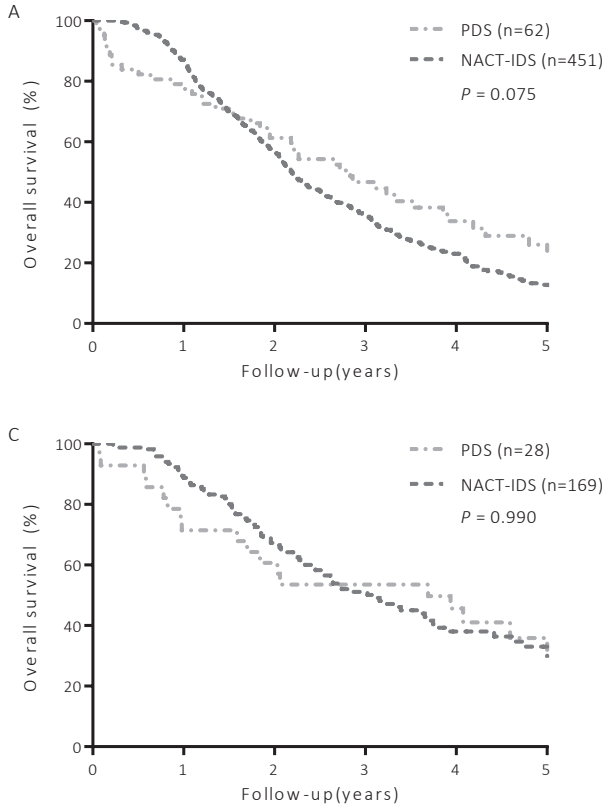
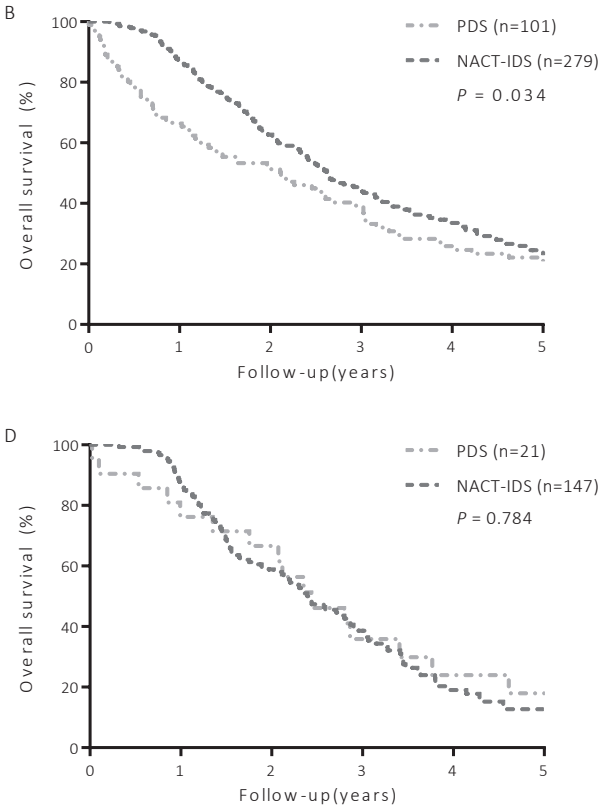

S5: Overall survival stratified by the localisation of metastases. Every panel contains overall survival with a follow-up of five years, the dark grey lines depict NACT-IDS patients and the light grey lines PDS patients. The P-values represent a Log-rank test. A) pleural malignant effusion, B) parenchymal metastases, C) extra-abdominal lymph node metastases and D) other metastases 



\section{PART III}

OPTIMISING PATIENT SELECTION

FOR PRIMARY SURGERY OR CHEMOTHERAPY 



\section{8}

Neoadjuvant chemotherapy or primary debulking surgery in FIGO IIIC and IV patients; results from a survey study in the Netherlands

M. Timmermans, G.S. Sonke, W.J. van Driel, R.I. Lalisang, P.B. Ottevanger, C.D. de Kroon, K.K. Van de Vijver, M.A. van der Aa, R.F. Kruitwagen

European Journal of Obstetrics \& Gynecology and Reproductive Biology 2018; 


\section{ABSTRACT}

\section{Objective}

Primary debulking surgery (PDS) followed by adjuvant chemotherapy is historically recommended as first line treatment for advanced stage ovarian cancer. Two randomised controlled trials, however, showed similar efficacy and reduced toxicity with neoadjuvant chemotherapy followed by interval debulking surgery (NACT-IDS). Nevertheless, uptake of NACT-IDS varies widely between hospitals, which cannot be explained by difference in patient populations. In this survey, we therefore aimed to evaluate the views on NACTIDS among all Dutch gynaecologists and medical oncologists involved in the treatment of ovarian cancer.

\section{Study design}

An e-mail link to the online questionnaire was sent to all medical oncologists and gynaecologists in the Netherlands, regardless of their (sub)specialisations. The data was analysed using descriptive statistics and chi-square tests were used to analyse differences between groups.

\section{Results}

Three-hundred-forty physicians were invited to fill out the questionnaire. After two reminders, 167 of them responded (49\%). Among the responders, 82\% of the gynaecologists versus $93 \%$ of the medical oncologists considered the available evidence sufficiently convincing to treat advanced stage ovarian cancer patients with NACT-IDS ( $p=0.076)$. Moreover, $33 \%$ of gynaecologists and $62 \%$ of medical oncologists preferred NACT-IDS to PDS as first line treatment ( $p=0.001)$. While most responders (86\%) indicated that selecting the right patients for NACT-IDS is difficult, those with bulky disease, FIGO stage IV or metastases near the porta hepatica were most likely to undergo NACT-IDS.

\section{Conclusion}

The majority of Dutch gynaecologists and medical oncologists adopted NACT-IDS as an alternative treatment approach for advanced stage primary ovarian cancer. About twothirds of medical oncologists and one-third of gynaecologists prefer NACT-IDS to PDS as first line treatment in this setting. Improving patient selection is considered of paramount importance. 


\section{INTRODUCTION}

The outcome for patients with advanced stage epithelial ovarian cancer (EOC) is generally poor, with five-year survival rates of $25 \%-35 \%{ }^{1}$. There is a lively debate about the most optimal treatment for these patients. The mainstay of therapeutic regimens consists of debulking surgery combined with platinum-based combination chemotherapy. Historically, primary debulking surgery followed by adjuvant chemotherapy (PDS) is recommended as first line treatment. Over the last two decades, an alternative regiment consisting of neoadjuvant chemotherapy followed by interval debulking surgery and adjuvant chemotherapy (NACT-IDS) emerged².

In 2010, the randomised controlled trial of Vergote et al. compared the use of NACT-IDS versus PDS in patients with bulky FIGO IIIC and IV EOC. This study demonstrated that overall survival and progression free survival after NACT-IDS were similar compared to PDS ${ }^{3}$, while perioperative morbidity and mortality were reduced after NACT-IDS. Just before publication of the results of this trial the opinion of gynaecologists and medical oncologists among the American Society of Gynaecologic Oncology (SGO) with respect to the preferred treatment was evaluated. It was concluded that most members did not treat their patients with NACTIDS and did not consider the available evidence sufficient for this treatment sequence ${ }^{4}$. In 2011, the opinion of the European Society of Gynaecological Oncology (ESGO) members was evaluated, and a majority believed there was sufficient evidence to treat FIGO IIIC and IV patients with NACT-IDS. However, there was a large variation between countries (e.g. $16 \%$ in Germany versus 100\% in Belgium $)^{5}$.

More recently, the CHORUS trial of Kehoe et. al. confirmed the non-inferiority of NACTIDS $^{6}$. In addition, multiple international retrospective studies also demonstrated less perioperative morbidity and mortality after interval debulking surgery ${ }^{7-9}$. Nevertheless, the use of NACT-IDS remains a topic of debate, partly because findings from observational studies indicate that patients with no residual disease after PDS might have a better survival than those with no residual disease after $\operatorname{IDS}^{7,8,10}$. Furthermore, it is argued that the choice of treatment (PDS versus NACT-IDS), and the amount of residual disease after (interval) debulking surgery, is strongly related to the expertise of the surgical team.

Dutch hospitals are classified according to their level of specialisation as general, semispecialised, or specialised hospitals (including all University hospitals) ${ }^{11}$. Since 2012, surgical care for ovarian cancer is centralised in the Netherlands and debulking surgery is solely executed in hospitals that perform a minimum of twenty debulking surgeries annually. These are semi-specialised or specialised hospitals, and the distinction between the two types of hospitals is defined by the employment of gynaecological oncologists. 
After a regular training in gynaecology and following an additional two-year fellowship in gynaecologic oncology, the Dutch Society of Gynaecologic Oncology can certify members as gynaecological oncologists. In semi-specialised hospitals, gynaecological oncologists participate in each debulking surgery together with semi-specialised gynaecologists. Medical oncologists administer (neo)adjuvant chemotherapy in practically all hospitals, regardless of their specialisation. The initial diagnosis of ovarian cancer can be made in all Dutch hospitals, by either gynaecologists or medical oncologists. Subsequently, but before the initiation of treatment, all patients are discussed in a multidisciplinary tumour board meeting by gynaecological oncologists, medical oncologists, pathologists, radiologists and radiation oncologists for the optimal treatment strategy, as recommended by the ESGO ${ }^{12}$. The use of NACT-IDS increased over the last years in the Netherlands, but the uptake of NACT-IDS varies widely between hospitals which cannot be explained by differences in patient populations ${ }^{13}$. In this survey, we aimed to evaluate the views on NACT-IDS among all Dutch gynaecologists and medical oncologists involved in the treatment of ovarian cancer.

\section{METHODS}

\section{Questionnaire}

A digital questionnaire was used to perform this survey in the Netherlands. It was send to gynaecologists and medical oncologists in all Dutch hospitals, regardless of their (sub) specialisation. A link to the survey was send by e-mail. Responders received their first e-mail, which explained the purpose of the study and a link to the survey program in January 2016. To increase the response rate, all non-responders received a reminder after three and six weeks. Not all responders filled in a complete questionnaire, and these responders also received a reminder to complete their questionnaire after eight weeks.

Questions were based on the two previous survey studies ${ }^{4,5}$. Responders were asked about demographics, experience, diagnostic techniques, definitions of the outcome of debulking surgery, chemotherapy protocols and their use and believe in NACT-IDS. The questionnaire is provided as a supplementary file together with the CHERRY checklist to establish the validity of this questionnaire $(\mathrm{S} 1, \mathrm{~S} 2)^{14}$.

\section{Statistical analysis}

The answers were summarised using descriptive statistics. Not all questions had to be answered, therefore the number of responses varies between questions. Percentages were calculated based on the number of answers to each questions. Respondents from 
specialised and semi-specialised hospitals were categorised as one group, and compared to responders from general hospitals. Chi-square tests were used to analyse differences between groups. A p-value $<0.05$ was considered statistically significant for all analyses. Statistical analyses were performed using STATA/SE (version 14.1; STATA CORP., College Station, Texas, USA).

\section{RESULTS}

Three-hundred-forty physicians were invited to fill out the questionnaire, 167 physicians responded $(167 / 340=49 \%)$. Most responders were gynaecologists (table 1 ). Of all respondents, $28 \%$ of gynaecologists and $12 \%$ of medical oncologists were employed at (semi-)specialised hospitals. The vast majority had more than five years of experience with the treatment of ovarian cancer patients (84\%) and treated 5 to 20 newly diagnosed patients a year $(60 \%$, table 1$)$.

Table 1: Demographics of respondents on the online survey in the Netherlands

\section{Specialisation}

Gynaecologists

\section{Type of hospital}

Specialised

Semi-specialised

General

\section{Experience}

$<5$ years

5-10 years

37 (23.4)

11-15 years

$>15$ years

$58(36.7)$

\section{Number of EOC patients a year}




\section{Evidence for NACT-IDS}

Most responders considered the available evidence as sufficient to treat advanced stage EOC patients with NACT-IDS (82\% of gynaecologists and $93 \%$ of medical oncologists, $\mathrm{p}=0.076)$. In addition, there was no difference between responders from specialised, semispecialised and general hospitals ( $84 \%, 88 \%$ and $88 \%$ respectively, $p=0.836)$. Patients with FIGO stage IV, bulky disease in the upper abdomen or metastasis near the porta hepatica were most prone to undergo neoadjuvant chemotherapy, but patients with an extremely high CA125 or spleen involvement had a higher probability to undergo primary debulking surgery (table 2).

Table 2: Scores of patients and tumour characteristics that benefit from NACT-IDS

\begin{tabular}{lr}
\hline & Score $^{\text {a }}$ \\
\hline FIGO IV & 2.56 \\
Bulky disease upper abdomen & 2.44 \\
Metastasis porta hepatica & 2.40 \\
Serious comorbidity & 2.22 \\
Inevitable bowel resection & 2.22 \\
FIGO IIIC & 2.07 \\
Large amount of ascites & 2.05 \\
Diaphragm involvement & 2.03 \\
Spleen metastasis & 1.93 \\
Extreme high CA-125 values & 1.50 \\
\hline
\end{tabular}

a Respondents could answer on a Likert scale (0-4); the number of responses on every specific number of the Likert scale were multiplied by this value and the total sum was divided by the number of responses $(n=167)$

Before the publication of the EORTC trial, already $15 \%$ of gynaecologists and $55 \%$ of medical oncologists considered NACT-IDS as a treatment option ( $p<0.001)$. In general hospitals, this percentage was higher for both gynaecologists and medical oncologists (table 3). After the publication of the EORTC and CHORUS trials, the adoption of NACT-IDS increased within all groups to a comparable adoption rate (table 3 ).

Opinions about whether NACT-IDS should be the preferred treatment for all FIGO IIIC and IV patients were diverse. Whereas a minority of gynaecologists (33\%) thought that NACT-IDS should be first choice of treatment in this selected group of patients, most medical oncologists believed that it should be first choice (62\%, table 3$)$. In addition, $16 \%$ of gynaecological oncologists and $46 \%$ of medical-oncologists from specialised hospitals preferred NACT-IDS. 
Table 3: Use and adoption of NACT-IDS by gynaecologists and medical-oncologists, stratified by type of hospital

\begin{tabular}{|c|c|c|c|c|c|}
\hline & $\begin{array}{r}\text { (Semi-) } \\
\text { specialised } \\
\text { gynaecologists }^{\text {a }} \\
\end{array}$ & $\begin{array}{r}\text { General } \\
\text { gynaecologists }\end{array}$ & $\begin{array}{r}\text { (Semi-) } \\
\text { specialised } \\
\text { medical } \\
\text { oncologists }{ }^{{ }^{3}} \\
\end{array}$ & $\begin{array}{r}\text { General } \\
\text { medical } \\
\text { oncologists } \\
\end{array}$ & $p$-value ${ }^{b}$ \\
\hline \multicolumn{6}{|l|}{ Sufficient evidence for NACT-IDS } \\
\hline Before Vergote trial & $2(4.8)$ & $10(27.0)$ & $6(46.2)$ & $22(57.9)$ & $<0.001$ \\
\hline Present & $38(86.4)$ & $31(77.5)$ & $12(80.0)$ & $39(97.5)$ & 0.061 \\
\hline NACT-IDS as preferred treatment & & & & & 0.001 \\
\hline Yes & $10(22.7)$ & $18(45.0)$ & $8(53.3)$ & $26(65.0)$ & \\
\hline No & $34(77.3)$ & $22(55.0)$ & $7(46.7)$ & $14(35.0)$ & \\
\hline
\end{tabular}

a Responders from semi-specialised and specialised hospitals were categorised as one group and depicted under a ${ }^{b}$ Chi-square test

\section{Diagnostic process}

Most physicians based their decision to schedule patients for primary debulking surgery or neoadjuvant chemotherapy on preoperative imaging (94\%). Computed tomography (CT) scans (79\%), transvaginal or transabdominal ultrasounds (46\%) and diagnostic laparoscopy (46\%) were reported as most useful techniques. Diagnostic laparoscopy was not used as standard diagnostic work-up, although some physicians performed this technique to establish the probability to achieve a complete or optimal primary debulking surgery. Positron emission tomography-CT (PET-CT) (2\%), magnetic resonance imaging (MRI) scans (5\%) and thoracoscopy (1\%) were rarely used. In addition to preoperative imaging, a majority of responders (56\%) stated that age and performance status also influenced the choice between PDS and NACT-IDS. Nevertheless, most responders (86\%) indicated that prediction of the outcome of debulking surgery based on pre-operative imaging was unreliable. This estimation did not differ between gynaecologist and medical oncologists (90\% and $80 \%$ respectively, $p=0.073)$, or between types of hospitals $(p=0.863)$.

\section{Surgery}

The definitions of complete and optimal debulking surgery are known by the majority of responders, $91 \%$ of responders defined a complete debulking surgery as no macroscopic residual disease and $81 \%$ of responders defined an optimal debulking as $\leq 1 \mathrm{~cm}$ residual disease in maximal diameter. Medical oncologists more often than gynaecologist thought that optimal debulking was defined by less than $0.5 \mathrm{~cm}$ residual disease $(21 \%$ 
and $6 \%$ respectively), or as no macroscopic residual disease (13\% and $3 \%$ respectively). Gynaecological oncologists and medical oncologists from specialised hospitals defined it adequately in $94 \%$ and $71 \%$ respectively.

Most responders estimated the number of patients treated with PDS as first line therapy within their hospitals between $11 \%$ and $40 \%$ (48.2\%) and only 5.6\% estimated that more than $90 \%$ of their patients were treated with PDS. A substantial number of responders did not know the percentage of complete or optimal debulking surgeries in their hospital (57$60 \%)$.

\section{Chemotherapy}

There was a large overlap for chemotherapy regimens in both neoadjuvant chemotherapy and adjuvant chemotherapy. Most responders chose for the combination of three-weekly carboplatin and paclitaxel for both PDS and NACT-IDS ( $87 \%$ and $84 \%$ respectively). General gynaecologists more often answered 'I do not know' compared to (semi)-specialised gynaecologists and all medical oncologists for first line chemotherapy protocol (PDS: 16\% vs. $2 \%$ vs. $0 \%$, NACT: $26 \%$ vs. $4 \%$ vs. $2 \%$ respectively). For patients treated with NACT-IDS, the preferred number of neoadjuvant cycles is three (88\%), only $3 \%$ varied the number of neoadjuvant cycles based on chemotherapy response. After optimal and suboptimal debulking surgery, most responders chose for three adjuvant cycles (91\% and 88\% respectively) and a minority chose for more than three cycles (4\% and $7 \%$ respectively). Other chemotherapy regimens that were used in daily practice were weekly carboplatin and weekly paclitaxel (42\% PDS and 37\% NACT-IDS), carboplatin monotherapy (43\% PDS and 36\% NACT-IDS) and intraperitoneal chemotherapy (18\% PDS and 3\% NACT-IDS).

\section{DISCUSSION}

In this survey study, we evaluated the views of Dutch gynaecologists and medical oncologists on NACT-IDS for advanced stage primary ovarian cancer. The study was executed as an update of two earlier survey studies among the SGO and ESGO members. Our results show that a substantial number of responders consider NACT-IDS as an alternative treatment approach for patients with FIGO IIIC or IV disease. In addition, the majority of medical oncologists prefer NACT-IDS to PDS in this group, whereas gynaecologists still more often opt for PDS as first line treatment.

The decision to schedule patients for PDS or NACT-IDS is mainly based on pre-operative imaging in relation to the probability of a successful debulking surgery $(\leq 1 \mathrm{~cm}$ of residual disease in maximal diameter). In concordance with the previous survey studies, however, 
the majority of physicians indicated that the outcome of debulking surgery could not reliably be predicted ${ }^{4,5}$. Bulky disease in the upper abdomen, FIGO stage IV disease, metastases near the porta hepatica, poor performance status, and an inevitable bowel resection were the most commonly mentioned additional reasons to choose NACT-IDS.

A prior survey among SGO members, conducted in 2009 before the publication of the EORTC trial, concluded that responders considered the available evidence in favour of NACT-IDS as insufficient (82\%). In a second survey conducted shortly after publication of the EORTC trial, the ESGO members were more convinced of the available evidence, with $70 \%$ accepting NACT-IDS as an alternative treatment option. This latter study, however, reported large variation between European countries in their use of NACT-IDS (e.g. 16\% in Germany versus $100 \%$ in Belgium) ${ }^{5}$. At present, our results are in line with the results of the ESGO survey, with an adoption rate of $86 \%$. In addition, most responders started to use NACT-IDS after the publication of the EORTC trial. This is supported by the increase in the use of NACT-IDS over the last years in the Netherlands ${ }^{13}$.

The CHORUS trial and the EORTC trial showed similar overall- and progression- free survival for patients after PDS and NACT-IDS, but postoperative morbidity was lower after NACTIDS $^{3,6}$. This raises the question why NACT-IDS is not considered the preferred treatment for all FIGO IIIC and IV patients. Among the SGO members in 2009, 74\% thought PDS should be the preferred treatment, unfortunately this was not evaluated among the ESGO members. Our results show more diversion. Still, 55\% of all responders were convinced of PDS as first line treatment, although there was a significant difference between gynaecologists and medical oncologists ( $67 \%$ and $33 \%$ respectively, $p=0.001$ ).

The diversity in uptake of NACT-IDS may reflect the ongoing discussion regarding the results of the clinical trials. These studies are critically evaluated as the non-inferiority outcome might be caused by the rather low percentages of patients with no macroscopic residual disease after debulking surgery. Consequently, survival rates in these studies were lower when compared to international non-randomised studies ${ }^{15-17}$. These outcomes may suggests that NACT-IDS could be an alternative approach in patients with extended tumour burden and a low probability to complete PDS, as the amount of residual disease after debulking surgery is the most prognostic factor for prolonged overall survival ${ }^{2,3,6}$. However, if the likelihood to no macroscopic residual disease is high, NACT-IDS should not be the first choice of treatment for these patients, which is supported by the majority of gynaecologists and medical oncologists from specialised hospitals. Besides evidence-based rationale, logistic reasons may also play a role in the use of NACT-IDS in the Netherlands. As the surgical treatment is centralised, extended wait lists for surgery or reduced intensive care capacity might be reasons to start with NACT in general hospitals. 
The addition of intraperitoneal chemotherapy to the primary treatment improves overall survival in patients who underwent PDS with minimal residual disease ${ }^{18-21}$. This treatment is accompanied with an increase in side effects ${ }^{21}$, so optimal patient selection and adequate experience with intraperitoneal chemotherapy are crucial. In our study, $18 \%$ of responders used intraperitoneal chemotherapy after primary surgery in Dutch daily practice. The possibility of intraperitoneal chemotherapy after successful PDS may persuade physicians to pursue PDS in order to improve outcomes for EOC patients. Furthermore there are several trials that investigate the efficacy and safety of hyperthermic intraperitoneal chemotherapy (HIPEC) during interval debulking surgery, such as the CHORINE trial (NCT01628380) and the OVIHIPEC trial (NCT00426257) 22,23. In our study only 3\% of responders used intraperitoneal chemotherapy during interval debulking surgery in daily practice, probably related to the OVIHIPEC trial. This was lower compared to the SGO members (42-49\% depending on the outcome of surgery), but comparable to the ESGO members (2.6\%). The addition of HIPEC during interval debulking surgery may be a valuable treatment opportunity in patients who cannot be optimally debulked in a primary setting ${ }^{23}$.

Our study has some limitations. We used the same questionnaire as the two prior surveys, which has not been validated however, and added some non-validated questions. As a result, we cannot be certain that the results reliably reflect daily practice ${ }^{24}$. Furthermore, our overall response rate was only 49\% (167/340). Since we could not identify the opinions of the non-responders, the results of this survey may not be generalisable. In addition, we included gynaecologists and medical oncologist from all Dutch hospitals. While increasing the sample size and reflecting the views of physicians in the entire country, experience and knowledge about the most recent developments in ovarian cancer treatment may be lacking in responders from general hospitals. This is reflected by the percentage of gynaecologists and medical oncologists from general hospitals that were not aware of the key RCTs for advanced ovarian cancer patients (data not shown) (3,6. $^{3}$.

This survey study contributes to the debate about the timing of surgery in advanced ovarian cancer. The adoption rate of neoadjuvant chemotherapy is high for advanced ovarian cancer patients in the Netherlands, and even first choice of treatment in FIGO IIIC and IV patients according to a majority of medical oncologists. Semi-specialised gynaecologists, however, still more often opt for PDS as first line treatment, and this choice seems to depend on the probability of successful surgery in the primary setting. This emphasises the

great importance of our selection processes to ensure that every patient undergoes the most optimal treatment.

\section{Funding}

This work was supported by Dutch Cancer Society [IKNL2014-6838]. 


\section{REFERENCES}

1. Sant M, Chirlaque Lopez MD, Agresti R, Sanchez Perez MJ, Holleczek B, BielskaLasota $M$, et al. Survival of women with cancers of breast and genital organs in europe 1999-2007: Results of the eurocare-5 study. Eur J Cancer. 2015.

2. Chang SJ, Hodeib M, Chang J, Bristow RE. Survival impact of complete cytoreduction to no gross residual disease for advancedstage ovarian cancer: A meta-analysis. Gynecol Oncol. 2013;130(3):493-8.

3. Vergote I, Trope CG, Amant F, Kristensen $\mathrm{GB}$, Ehlen T, Johnson N, et al. Neoadjuvant chemotherapy or primary surgery in stage iiic or iv ovarian cancer. N Engl J Med. 2010;363(10):943-53.

4. Dewdney SB, Rimel BJ, Reinhart AJ, Kizer NT, Brooks RA, Massad LS, et al. The role of neoadjuvant chemotherapy in the management of patients with advanced stage ovarian cancer: Survey results from members of the society of gynecologic oncologists. Gynecol Oncol. 2010;119(1):1821.

5. Cornelis S, Van Calster B, Amant F, Leunen K, van der Zee AG, Vergote I. Role of neoadjuvant chemotherapy in the management of stage iiic-iv ovarian cancer: Survey results from the members of the european society of gynecological oncology. Int J Gynecol Cancer. 2012;22(3):407-16.

6. Kehoe S, Hook J, Nankivell M, Jayson GC, Kitchener H, Lopes $T$, et al. Primary chemotherapy versus primary surgery for newly diagnosed advanced ovarian cancer (chorus): An open-label, randomised, controlled, non-inferiority trial. Lancet. 2015;386(9990):249-57.

7. Wright AA, Bohlke K, Armstrong DK, Bookman MA, Cliby WA, Coleman RL, et al. Neoadjuvant chemotherapy for newly diagnosed, advanced ovarian cancer: Society of gynecologic oncology and american society of clinical oncology clinical practice guideline. J Clin Oncol. 2016;34(28):3460-73.
8. Mueller JJ, Zhou QC, lasonos A, O'Cearbhaill RE, Alvi FA, El Haraki A, et al. Neoadjuvant chemotherapy and primary debulking surgery utilization for advanced-stage ovarian cancer at a comprehensive cancer center. Gynecol Oncol. 2016;140(3):436-42.

9. Glasgow MA, Yu H, Rutherford TJ, Azodi $M$, Silasi DA, Santin AD, et al. Neoadjuvant chemotherapy (nact) is an effective way of managing elderly women with advanced stage ovarian cancer (figo stage iiic and iv). J Surg Oncol. 2013;107(2):195-200.

10. Meyer LA, Cronin AM, Sun CC, Bixel K, Bookman MA, Cristea MC, et al. Use and effectiveness of neoadjuvant chemotherapy for treatment of ovarian cancer. J Clin Oncol. 2016.

11. Vernooij F, Heintz AP, Witteveen PO, van der Heiden-van der Loo M, Coebergh JW, van der Graaf Y. Specialized care and survival of ovarian cancer patients in the netherlands: Nationwide cohort study. J Natl Cancer Inst. 2008;100(6):399-406.

12. Querleu D, Planchamp F, Chiva L, Fotopoulou C, Barton D, Cibula D, et al. European society of gynaecologic oncology quality indicators for advanced ovarian cancer surgery. Int J Gynecol Cancer. 2016;26(7):1354-63.

13. Eggink FA, Mom CH, Kruitwagen RF, Reyners AK, Van Driel WJ, Massuger LF, et al. Improved outcomes due to changes in organization of care for patients with ovarian cancer in the netherlands. Gynecol Oncol. 2016.

14. Eysenbach G. Improving the quality of web surveys: The checklist for reporting results of internet e-surveys (cherries). I Med Internet Res. 2004;6(3):e34.

15. Rauh-Hain JA, Rodriguez N, Growdon WB, Goodman AK, Boruta DM, 2nd, Horowitz NS, et al. Primary debulking surgery versus neoadjuvant chemotherapy in stage iv ovarian cancer. Ann Surg Oncol. 2012;19(3):959-65. 
16. Chi DS, Musa F, Dao F, Zivanovic O, Sonoda Y, Leitao MM, et al. An analysis of patients with bulky advanced stage ovarian, tubal, and peritoneal carcinoma treated with primary debulking surgery (pds) during an identical time period as the randomized eortc-ncic trial of pds vs neoadjuvant chemotherapy (nact). Gynecol Oncol. 2012;124(1):10-4.

17. Aletti GD, Dowdy SC, Gostout BS, Jones MB, Stanhope CR, Wilson TO, et al. Aggressive surgical effort and improved survival in advanced-stage ovarian cancer. Obstet Gynecol. 2006;107(1):77-85.

18. Alberts DS, Liu PY, Hannigan EV, O'Toole R, Williams SD, Young JA, et al. Intraperitoneal cisplatin plus intravenous cyclophosphamide versus intravenous cisplatin plus intravenous cyclophosphamide for stage iii ovarian cancer. N Engl J Med. 1996;335(26):1950-5.

19. Armstrong DK, Bundy $B$, Wenzel L, Huang $\mathrm{HQ}$, Baergen R, Lele S, et al. Intraperitoneal cisplatin and paclitaxel in ovarian cancer. $\mathrm{N}$ Engl J Med. 2006;354(1):34-43.

20. Markman M, Bundy BN, Alberts DS, Fowler JM, Clark-Pearson DL, Carson LF, et al. Phase iii trial of standard-dose intravenous cisplatin plus paclitaxel versus moderately highdose carboplatin followed by intravenous paclitaxel and intraperitoneal cisplatin in small-volume stage iii ovarian carcinoma: An intergroup study of the gynecologic oncology group, southwestern oncology group, and eastern cooperative oncology group. J Clin Oncol. 2001;19(4):1001-7.

21. Jaaback K, Johnson N, Lawrie TA. Intraperitoneal chemotherapy for the initial management of primary epithelial ovarian cancer. Cochrane Database of Systematic Reviews. 2016;2016(2).

22. Lim MC, Kang S, Choi J, Song YJ, Park S, Seo SS, et al. Hyperthermic intraperitoneal chemotherapy after extensive cytoreductive surgery in patients with primary advanced epithelial ovarian cancer: Interim analysis of a phase ii study. Ann Surg Oncol. 2009;16(4):993-1000.
23. van Driel WJ, Koole SN, Sikorska K, Schagen van Leeuwen JH, Schreuder HWR, Hermans RHM, et al. Hyperthermic intraperitoneal chemotherapy in ovarian cancer. N Engl J Med. 2018;378(3):230-40.

24. Boynton PM, Greenhalgh T. Selecting, designing, and developing your questionnaire. BMJ. 2004;328(7451):13125. 


\section{SUPPLEMENTARY MATERIAL}

S1: Survey questions to evaluate views on PDS versus NACT-IDS for FIGO IIIC and IV patients

1. What is your sex?

Male

$\bigcirc$ Female

2. What is your specialisation?

Gynaecological-oncologist

Semi-specialised gynaecologist

General gynaecologist

Fellow gynaecological-oncologist

Medical oncologist

Fellow medical oncologist

3. How would you define your current practice type?

Specialised

Semi-specialised

General

4. Do you treat patients with ovarian cancer?
$\bigcirc$ Yes
No, but I did in the past
No
Other

5. What is your experience in treating patients with ovarian cancer?
$\bigcirc<5$ years
5-10 years
11-15 years
$>15$ years
Other

6. How many patients do you treat annually (mean over the last five years)?
$0<5$ patients
5-10 patients
11-20 patients
21-35 patients
36-50 patients
51-70 patients
71-100 patients
101-150 patients
Other 
7. What is the definition used in your institution for optimal debulking in ovarian cancer?
$\bigcirc$ No residual tumour
Residual tumour $<0.5$ centimetre
$\bigcirc$ Residual tumour $<1.0$ centimetre
Residual tumour $<2.0$ centimetre
Other

8. What is the definition used in your institution of complete debulking in ovarian cancer?
$\bigcirc$ No residual tumour
Residual tumour $<0.5$ centimetre
$\bigcirc$ Residual tumour $<1.0$ centimetre
Residual tumour $<2.0$ centimetre
Other

9. Do you think you can accurately determine preoperatively the outcome of debulking surgery (complete/optimal or suboptimal)?
$\bigcirc$ Yes
No
$\bigcirc$ I do not know

10. Does pre-operative imaging play a role in your decision to schedule a patients for primary debulking surgery?
$\bigcirc$ Yes
$\bigcirc$ No

11. (If question 10 is yes) --> How does preoperative imaging play a role in your decision to schedule patients for a primary debulking surgery?
$\bigcirc$ I only schedule patients for a primary debulking if there is a chance on a complete debulking (no residual disease)
$\bigcirc$ I only schedule patients for a primary debulking if there is a chance on an optimal debulking $(<1 \mathrm{~cm}$ residual disease)
Other

12. (If question 10 is yes) --> Which of the modalities do you use in daily practice to establish whether a patient can or cannot be optimally debulked?
Transvaginal and/or abdominal echography
CT scan
PET-CT scan
MRI scan
PET-MRI scan
Diagnostic laparoscopy
Diagnostic thoracoscopy
Other 
13. Does diagnostic laparoscopy play a role in your decision to schedule a patient for primary debulking surgery?
Yes
No

14. (If question 13 is yes) How does diagnostic laparoscopy play a role in your decision to schedule a patient for primary debulking surgery (in daily practice and/or in clinical trial situations)?

I always use diagnostic laparoscopy

If there is doubt (based on i.e. pre-operative imaging) if a complete debulking can be achieved

If there is doubt (based on i.e. pre-operative imaging) if an optimal debulking can be achieved

$\bigcirc$ Other

15. Does CA-125 play a role in your decision to schedule a patient for primary debulking surgery?
No
Yes
Other

16. Does age and performance status play a role in your decision to schedule a patient for primary debulking surgery?
$\bigcirc$ Yes, only age plays a role
Yes, only performance status plays a role
$\bigcirc$ Yes, both age and performance status play a role
No, neither age nor performance status plays a role
Other

17. Of all FIGO IIIC and IV patients, how many patients undergo primary debulking surgery in your institution?
None
$1-10 \%$
○ $11-25 \%$
$26-40 \%$
$41-60 \%$
$61-75 \%$
O $6-90 \%$
$>90 \%$
I do not know

18. How many patients undergo a complete primary debulking surgery in your institution?
None
$<20 \%$
- $20-40 \%$
- $41-60 \%$ 

- $61-80 \%$
O $>80 \%$
I do not know

19. How many patients undergo an optimal primary debulking surgery in your institution?
None
○ $<20 \%$
$20-40 \%$
$41-60 \%$
61-80\%
$>>80 \%$
$\bigcirc$ I do not know

20. What is the standard chemotherapy protocol after primary debulking surgery?
$\bigcirc$ Three weekly carboplatin and weekly paclitaxel
Three weekly carboplatin and three weekly paclitaxel
I do not know
Other

21. Which other chemotherapy regimens do you use in daily practice for patients after primary debulking surgery?
Weekly carboplatin and weekly paclitaxel
Three weekly cisplatin and weekly paclitaxel
IP cisplatin and IV paclitaxel at day 1 , and IP cisplatin at day 8 and three weekly IV paclitaxel
Carboplatin monotherapy
$\bigcirc$ Cisplatin monotherapy
I do not use other chemotherapy regimens
I do not know
Other

22. How many patients undergo a complete interval debulking surgery in your institution?
None
○ $<20 \%$
$20-40 \%$
- $41-60 \%$
61-80\%
$>>80 \%$
I do not know

23. How many patients undergo an optimal interval debulking surgery in your institution?
None
$<<20 \%$
○ $20-40 \%$ 


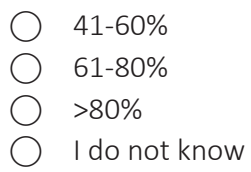

24. What is the standard chemotherapy protocol before and after interval debulking surgery?

Three weekly carboplatin and weekly paclitaxel

Three weekly carboplatin and three weekly paclitaxel

I do not know

Other

25. Which other chemotherapy regimens do you use in daily practice for patients before and after interval debulking surgery?

$\bigcirc$ Weekly carboplatin and weekly paclitaxel

Three weekly cisplatin and weekly paclitaxel

IP cisplatin and IV paclitaxel at day 1 , and IP cisplatin at day 8 and three weekly IV paclitaxel

Carboplatin monotherapy

$\bigcirc$ Cisplatin monotherapy

I do not use other chemotherapy regimens

I do not know

Other

26. How many cycles do you usually give before the patient undergoes an interval debulking surgery?

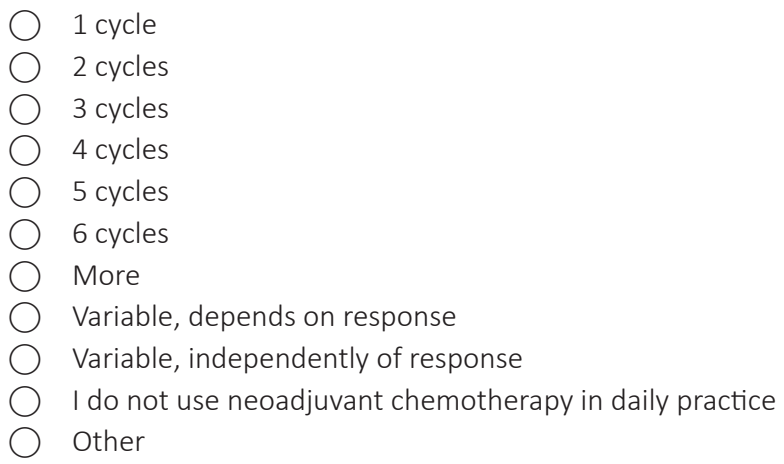

27. How many cycles do you usually give after optimal interval debulking surgery?
3 cycles
> $>3$ cycles
Intra-peritoneal chemotherapy
Other 
28. How many cycles do you usually give after suboptimal interval debulking surgery?
3 cycles
> $>3$ cycles
Intra-peritoneal chemotherapy
Other

29. Which patients do you feel benefit the most from neoadjuvant chemotherapy followed by interval debulking surgery (Likert scale 1-4)
FIGO IIIC
FIGO IV
Bulky disease in the upper abdomen
Bowel obstruction or involvement, for which bowel resection is inevitable
Metastasis at the porta hepatic
Diaphragmatic metastasis
Spleen metastasis
A large volume of ascites
Extreme values of $\mathrm{Ca}-125$
Serious co-morbidity
Other

30. Do you think that sufficient evidence is provided to use neoadjuvant chemotherapy followed by interval debulking surgery in daily practice?
$\bigcirc$ Yes
$\bigcirc$ No

31. Did your opinion about neoadjuvant chemotherapy change after the publication of the EORTC trial (Vergote, 2010)?
Yes
No, I already thought there was sufficient evidence to use NACT-IDS
No, I still think there is not enough evidence to use NACT-IDS in daily practice
$\bigcirc$ I do not know the EORTC trial or its results
Other

32. Did your opinion about neoadjuvant chemotherapy change after the publication of the CHORUS trial (Kehoe, 2015)?
Yes
No, I already thought there was sufficient evidence to use NACT-IDS
No, I still think there is not enough evidence to use NACT-IDS in daily practice
I do not know the EORTC trial or its results
$\bigcirc$ Other 
33. Do you think that NACT-IDS should be the preferred treatment for patients with FIGO IIIC or IV ovarian cancer instead of PDS?
Yes
$\bigcirc$ No
Other 


\section{S2: Checklist for Reporting Results of Internet E-Surveys (CHERRIES)}

\begin{tabular}{|c|c|}
\hline Design & Survey design \\
\hline IRB (Institutional Review & IRB approval \\
\hline $\begin{array}{l}\text { Board) approval and } \\
\text { informed consent process }\end{array}$ & Informed consent \\
\hline
\end{tabular}

Development and pretesting

Recruitment process and description of the sample having access to the questionnaire

Data protection

Development and testing closed survey
A non-validated questionnaire was used to perform this non-validated survey study in the Netherlands. A personal link to the survey was sent by e-mail to all gynaecological oncologists, semi-specialised gynaecologists and medical oncologists with special interest in gynaecologic oncology in the Netherlands. There was no list that covered all these specialists, therefore we contacted all 86 hospitals to identify them.

IRB approval was not needed.

The participants were informed about the purpose of the study, the duration to complete the survey, who the investigators were and were ensured that all data was handled anonymously.

The following commercial web survey provider was used: surveymonkey.com. All data were hosted by SurveyMonkey. A personal e-mail with a link was created to ensure that respondents could not respond multiple times.

The questions were based on the two previous survey studies to establish comparison between the three studies. These questions were evaluated and adjusted by expert physicians in the field. The web survey was tested before the start of the study by multiple colleagues.

Open survey versus It was a closed survey. The only way to access the survey was by the personal link respondents received in their e-mail. There was no option to fill in the questionnaire on an open site.

Contact mode

The target population received an email explaining the goals and purposes of the survey and asked for their participation. This email included the link to the online survey. In order to enlarge the response rate, a second and third invitation was sent three and six weeks later. Furthermore respondents that not completed their survey after eight weeks received a reminder as well.

Advertising the survey 
Survey administration

Web/E-mail

Context

Mandatory/voluntary

Incentives

Time/Date

Randomisation

of items or

questionnaires

Adaptive questioning

Number of Items

Number of screens (pages)

Completeness check

Review step
Adaptive questioning was mostly used. Based on the answer, respondents were directed to an additional question or to the next question.

The link to the survey was provided in an email. Respondents could only get access to the web based survey by clicking on the link. The data were collected automatically after their submission and could be altered within the study period.

Not applicable; there was no web site in which the survey was posted.

Responding to the survey was voluntary.

There were no incentives offered if respondents completed the questionnaire.

The survey was conducted between January and February 2016.

No items or questionnaires were randomised.

The survey consisted of 33 questions maximum; because of adaptive questioning some respondents could have answered less questions.

The survey consisted of 15 pages maximum; because of adaptive questioning some respondents could have seen less pages.

All questions were multiple choice, and for some questions there was a possibility to make a remark. Not all questions were obligated to answer, but if respondents did not fulfil the whole questionnaire, they received a reminder after eight weeks.

Respondents were able to go back to previous pages and update existing answers at every moment in the process until the survey was closed by the investigators. 


\begin{tabular}{|c|c|c|}
\hline \multirow[t]{5}{*}{ Response rates } & Unique site visitor & $\begin{array}{l}\text { Every respondent received a link to their } \\
\text { personal e-mail address. This made it possible } \\
\text { (in theory) to respond to the questionnaire } \\
\text { multiple times if the person in question had } \\
\text { access to the e-mail addresses of their peers. }\end{array}$ \\
\hline & $\begin{array}{l}\text { View rate (Ratio } \\
\text { of unique survey } \\
\text { visitors/unique site } \\
\text { visitors) }\end{array}$ & $\begin{array}{l}\text { Of the } 340 \text { physicians who were invited; } 233 \\
\text { opened their e-mail to read the invitation } \\
(233 / 340=68.5 \%) \text { and } 107 \text { did not open their } \\
\text { e-mail }(107 / 340=31.5 \%)\end{array}$ \\
\hline & $\begin{array}{l}\text { Participation rate } \\
\text { (Ratio of unique } \\
\text { visitors who agreed } \\
\text { to participate/unique } \\
\text { first survey page } \\
\text { visitors) }\end{array}$ & $\begin{array}{l}\text { In total } 172 \text { respondents saw the first page } \\
\text { of the survey within SurveyMonkey after } \\
\text { opening their e-mail }(172 / 233=73.8 \%) \text {. }\end{array}$ \\
\hline & $\begin{array}{l}\text { Completion rate } \\
\text { (Ratio of users who } \\
\text { finished the survey/ } \\
\text { users who agreed to } \\
\text { participate) }\end{array}$ & $\begin{array}{l}\text { In total } 167 \text { of } 172 \text { respondents partially } \\
\text { replied to the survey }(97.1 \%) \text { and } 139 \\
\text { completely filed in the questionnaire } \\
(139 / 172=80.8 \%) \text {. }\end{array}$ \\
\hline & & The total response rate was $49.1 \%(167 / 340)$ \\
\hline \multirow{4}{*}{$\begin{array}{l}\text { Preventing multiple entries } \\
\text { from the same individual }\end{array}$} & Cookies used & Not used \\
\hline & IP check & Not used \\
\hline & Log file analysis & Not used \\
\hline & Registration & $\begin{array}{l}\text { Every respondent received a link to their } \\
\text { personal e-mail address, no registration with } \\
\text { login was required. This made it possible } \\
\text { (in theory) to respond to the questionnaire } \\
\text { multiple times if the person in question had } \\
\text { access to the e-mail addresses of their peers. }\end{array}$ \\
\hline \multirow[t]{3}{*}{ Analysis } & $\begin{array}{l}\text { Handling of } \\
\text { incomplete } \\
\text { questionnaires }\end{array}$ & $\begin{array}{l}\text { All questions were analysed separately and } \\
\text { not based on complete/partial completion. } \\
\text { Not all questions were obligated to answer, } \\
\text { therefore the number of responses could } \\
\text { variate between questions. Percentages were } \\
\text { calculated based on the number of answers } \\
\text { to each question }\end{array}$ \\
\hline & $\begin{array}{l}\text { Questionnaires } \\
\text { submitted with an } \\
\text { atypical timestamp }\end{array}$ & Not applicable \\
\hline & Statistical correction & Not applicable \\
\hline
\end{tabular}



A preoperative clinical model to assess the probability of complete primary cytoreductive surgery for advanced stage ovarian cancer patients

M. Timmermans, S.M.J. van Kuijk, G.S. Sonke, C.G. Gerestein, K.K. Van de Vijver, M.A. van der Aa, R.F.P.M. Kruitwagen 


\section{ABSTRACT}

\section{Introduction}

Patient selection is critical to optimise outcome and prevent morbidity of primary surgery in epithelial ovarian cancer patients. Therefore, the aim of our study is to develop a clinically relevant prediction model in order to improve patient selection for upfront successful cytoreductive surgery defined as no macroscopic residual disease.

\section{Methods}

We identified all patients with advanced epithelial ovarian cancer (FIGO III-IV) who underwent an attempt to primary cytoreductive surgery between 01.01.2008 and 31.12.2015 from the Netherlands cancer registry. All potential predictors for successful surgical outcome were entered in a logistic regression model. Using backward stepwise elimination, we selected the most important predictors. The discriminative ability of our model was assessed by the area under the receiving operating characteristic curve (AUC). Internal validation was performed using bootstrap techniques.

\section{Results}

We included 2,215 advanced stage ovarian cancer patients. Our final model consisted of age at diagnosis, FIGO stage, omental cake, ascites, CA125 at diagnosis, and the presence of a gynaecological oncologist during cytoreductive surgery. The AUC was 0.75 (95\% confidence interval 0.72-0.77).

\section{Conclusion}

We developed and internally validated a good discriminative model that predicts the probability to complete cytoreductive surgery as primary treatment in advanced epithelial ovarian cancer patients. After external validation, this model may improve patient selection towards those that may actually benefit from successful primary surgery. 


\section{INTRODUCTION}

Survival outcomes of advanced stage ovarian cancer patients largely depend on the ability to minimise residual disease during cytoreductive surgery ${ }^{1}$. Consequently, maximal cytoreduction is the cornerstone in the treatment of epithelial ovarian cancer (EOC).

Since the introduction of neoadjuvant chemotherapy followed by interval cytoreductive surgery (NACT-ICS), it has been shown that patients with no residual disease after cytoreductive surgery (either upfront or interval surgery) have the best survival rates ${ }^{2,3}$. This led to a change in paradigm, where no macroscopic residual disease is nowadays the goal of cytoreductive surgery, instead of optimal surgery with residual disease of $\leq 1 \mathrm{~cm}$ in maximal diameter. Primary cytoreductive surgery (PCS) is still the preferred treatment if complete cytoreductive surgery seems feasible, predominantly in FIGO stage III disease. When complete PCS is considered impossible, due to high intraperitoneal tumour load or because of a high likelihood towards surgical complications, NACT-ICS is an attractive treatment approach with non-inferior survival rates and decreased perioperative morbidity-4.

Patients are scheduled for either PCS or NACT-ICS based on clinical characteristics, physical examination and imaging techniques. However, it is well known that predicting the outcome of surgery is inaccurate ${ }^{5}$. The use of diagnostic laparoscopy may decrease the amount of futile laparotomies ( $>1 \mathrm{~cm}$ of residual disease at the end of PCS) and has been shown to be cost-effective $e^{6,7}$. However, it requires invasive diagnostic procedures with possible morbidity after initial diagnostic laparoscopy or during subsequent cytoreductive surgery ${ }^{8,9}$. Therefore, multiple studies tried to predict the outcome of surgery based on computed tomography (CT) scans ${ }^{10-21}$. However, the vast majority of CT based models are not internally or externally validated or lack sufficient discriminative ability in an external independent population ${ }^{22-26}$.

In order to prevent unnecessary morbidity from futile primary laparotomies, and to improve success rates of performed surgeries, a clinical model to predict the outcome of cytoreductive surgery is of paramount importance for optimal patient selection. A number of recent models could not be validated externally by our group, as specific predictors of those models are not routinely collected ${ }^{27-31}$. In addition, most of the models are developed on small samples derived from single centres, which are known to be less generalisable into new populations. Therefore, the aim of our study was to develop a prediction model based on a large population-based dataset to improve patient selection for upfront successful cytoreductive surgery defined as no macroscopic residual disease. 


\section{METHODS}

We identified all patients who were diagnosed with epithelial ovarian cancer (EOC), including fallopian tube and primary peritoneal cancer (International Classification of Diseases for Oncology (ICD-O) C56.9, C57.0, C48.2), in the Netherlands between 01.01.2008 and 31.12.2015 from the Netherlands Cancer Registry (NCR) ${ }^{32}$. Information on patient and tumour characteristics, diagnosis, and treatment was routinely extracted from medical records by thoroughly trained registration clerks. Additionally, the registration team obtained complementary patient (e.g. performance score and comorbidity) and diagnostic characteristics (e.g. presence of omental cake on imaging) after training for this project.

\section{Study population}

Patients were eligible for this study if they were diagnosed with advanced EOC, FIGO stage III-IV, and underwent an attempt at primary cytoreductive surgery. If this attempt resulted in exploratory surgery only, they were still included in this study. The amount of residual disease was registered as complete in case of no macroscopic residual disease, incomplete in case of macroscopic residual disease (regardless of the largest diameter). If surgery resulted in no, or limited, resection (i.e. salpingo-oophorectomy for diagnostic purposes) they were included in the group with macroscopic residual disease.

Patients with FIGO stage III-IV EOC who underwent NACT-ICS without an attempt to PCS were also identified from the NCR, and were used for baseline comparisons between both groups. Moreover, this group was used to study the natural selection for either PCS or NACT-ICS over time. Patients without an initial attempt to PCS were excluded for the model development as outcome of cytoreductive surgery in the primary setting is unknown for this group.

\section{Model development}

We imputed missing values using multiple imputation to prevent a loss of precision and a high likelihood of biased coefficients, which is associated with decreased external validity ${ }^{33}$. The number of imputations was set to 20, resulting in 20 imputed datasets. A sensitivity analysis was performed by comparing the imputed data to a complete case analysis, to determine whether our conclusions would be dependent on the method to handle missing data. Sensitivity analyses showed similar results for all imputed datasets (data not shown). Potential predictors for macroscopic residual disease after cytoreductive surgery were based on previously published studies and expert opinion. This results in higher external validity compared to selecting predictors only based on observed statistically significant 
associations in the data used for the model development. Potential predictors that were entered in a logistic regression model were age at diagnosis, FIGO stage (based on imaging techniques, and pre-operative cytologic/histologic confirmation of metastases), localisation of metastases in case of FIGO IV disease, histologic subtype, differentiation grade, presence of ascites (based on pre-operative imaging), omental cake (based on pre-operative imaging), CA125 at diagnosis ( $\log _{\mathrm{e}}$-transformed), American Society of Anaesthesiologists (ASA) score, Charlson Comorbidity Index score (CCI) and the presence of a gynaecological oncologist during surgery. All potential predictors were entered in a logistic regression model. We used backward stepwise elimination based on the Wald test to select the most important predictors. A less strict alpha was selected to prevent too early exclusion of potentially important predictors (alpha $=0.20)$, as per prediction modelling guidelines ${ }^{34}$. Predictors that were selected in at least half of the 20 imputed datasets were selected. After selection, the initial prediction model was estimated.

\section{Model performance}

The ability of the model to predict the patients' probability of having no macroscopic residual disease after cytoreductive surgery was based on the area under the receiver operating characteristic curve (AUC). Higher AUC indicates a higher discriminative capacity, i.e. the model can better separate those with a complete cytoreductive surgery from those with macroscopic residual disease. In addition, calibration was tested using the HosmerLemeshow ( $\mathrm{H}-\mathrm{L})$ goodness-of-fit. A non-significant $\mathrm{H}$ - L test indicates no significant deviation from good model fit. Moreover, we plotted the difference between observed and predicted probabilities to assess the calibration of the model visually.

\section{Interval validation}

Internal validation was performed using bootstrap techniques. This method yields a shrinkage factor that can be used to correct for overfitting of the model (i.e. the model performs well for the population it was designed for, but not for future patients) by shrinking the regression coefficients towards zero. The model intercept was re-estimated after shrinkage. In addition, the bootstrap internal validation yields measures of optimism in the performance of the model in the development data, which can subsequently be used to compute optimism-corrected indices of performance. The number of bootstrap samples was set to 1000 .

All statistical analyses were performed using STATA/SE, version 14.1 (Stata Corp, College Station, Texas, USA) and R, version 3.2.1.(http://www.r-project.org). 


\section{RESULTS}

We identified 5,038 patients with FIGO stage III-IV EOC who underwent PCS or NACT-ICS between 2008 and 2015 in the Netherlands. Of them, 2,215 patients underwent an initial attempt to PCS (44\%) and this percentage decreased over time (56\% in 2008-2009 to 37\% in 2014-2015, $P<0.001)$. Simultaneously, the number of complete cytoreductive surgeries gradually increased from 31\% in 2008-2009 to 56\% in 2014-2015 ( $P<0.001)$. Moreover, the presence of a gynaecological oncologist was more common in the most recent years (78\% in 2008-2009 to 95\% in 2014-2015, $P<0.001$ ).

Baseline characteristics were significantly different for patients who were treated with NACT-ICS and an initial attempt to PCS (table 1). Patients who underwent NACT-ICS were significantly older, and were more often diagnosed with an ASA score of II or higher. The extent of disease was higher in NACT-ICS patients, as FIGO stage IV disease was more common, CA125 was higher at diagnosis and an omental cake was more often present on pre-operative imaging.

\section{Associations between clinical characteristics and outcome of surgery}

Histological subtype, differentiation grade, localisation of metastases in case of FIGO IV, performance score and $\mathrm{CCl}$-score were not independently associated with the outcome of cytoreductive surgery, nor did they improve the model performance. Therefore, these variables were eliminated from our final model. Our final model consisted of age at diagnosis, FIGO stage, omental cake on pre-operative imaging, presence of ascites on pre-operative imaging, CA125 at diagnosis ( $\log _{\mathrm{e}}$-transformed), and the presence of a gynaecological oncologist during cytoreductive surgery. All final ORs are listed in table 2.

\section{Model development and internal validation}

The AUC of our final model was 0.75 (confidence interval (CI) 0.72-0.77), which indicates good discriminative ability (figure 1 ). In addition, the $\mathrm{H}$ - L test was non-significant $(P=0.916)$, indicating good model fit, and our calibration plot showed that our model was well calibrated (S1). Internal validation by bootstrapping 1000 times revealed a shrinkage factor of 0.99 of our model. The shrinkage factor was used to adjust the regression coefficient estimates for over-optimism, so that future predictions will be better.

The performance of our currently developed model in daily clinical practice is highly dependent on the chosen threshold for a positive test (table 3). In figure 2, we illustrated how the currently developed prediction model could be implemented in daily clinical practice. Moreover, we tested our model on patients that received initial NACT-ICS in the 
Table 1: Baseline characteristics of advanced EOC patients stratified by initial treatment sequence

\begin{tabular}{|c|c|c|c|}
\hline & PCS (\%) & NACT-ICS (\%) & p-value \\
\hline Age & & & $<0.001$ \\
\hline$<65$ & $1146(51.7)$ & $1250(44.3)$ & \\
\hline $65-75$ & $743(33.6)$ & 1125 (39.8) & \\
\hline$>75$ & $326(14.7)$ & $448(15.9)$ & \\
\hline Median (IQR) & $64(55-72)$ & $66(59-73)$ & $<0.001$ \\
\hline \multicolumn{4}{|l|}{ FIGO stage } \\
\hline FIGO IIIA-IIIB & $536(24.2)$ & $102(3.6)$ & \\
\hline FIGO IIIC & $1317(59.5)$ & $1651(58.5)$ & \\
\hline FIGO IV & $282(12.7)$ & $981(34.8)$ & \\
\hline Unknown & $80(3.6)$ & $89(3.1)$ & \\
\hline Localization of metastases & & & $<0.001$ \\
\hline No metastases & $1933(87.3)$ & $1842(65.2)$ & \\
\hline Malignant pleural effusion & $103(4.6)$ & $428(15.2)$ & \\
\hline Other metastases & $179(8.1)$ & $553(19.6)$ & \\
\hline Histologic subtype & & & $<0.001$ \\
\hline High grade serous & $1650(25.5)$ & $2403(85.1)$ & \\
\hline Other & $565(74.5)$ & $420(14.9)$ & \\
\hline Omental cake & & & $<0.001$ \\
\hline No & $1263(57)$ & $783(27.7)$ & \\
\hline Yes & $650(29.4)$ & $1901(67.4)$ & \\
\hline Unknown & $302(13.6)$ & 139 (4.9) & \\
\hline \multicolumn{4}{|l|}{ CA125 at diagnosis* } \\
\hline Mean (SD) & $5.9(1.5)$ & $6.9(1.3)$ & $<0.001$ \\
\hline Ascites & & & $<0.001$ \\
\hline No ascites & $385(17.4)$ & $780(27.6)$ & \\
\hline Ascites & 1239 (55.9) & $1500(53.2)$ & \\
\hline Unknown & $591(26.7)$ & $543(19.2)$ & \\
\hline ASA score & & & $<0.001$ \\
\hline ASA I & $594(26.8)$ & $577(20.4)$ & \\
\hline ASA II or higher & $1174(53)$ & 1915 (67.9) & \\
\hline Unknown & $447(20.2)$ & $331(11.7)$ & \\
\hline Charlson Comorbidity Index & & & 0.170 \\
\hline $0-1$ & 1795 (81.1) & $2306(81.7)$ & \\
\hline$\geq 2$ & $353(15.9)$ & $466(16.5)$ & \\
\hline Unknown & $67(3)$ & $51(1.8)$ & \\
\hline Gynaecologic-oncologist & & & $<0.001$ \\
\hline No & $404(18.2)$ & $246(8.7)$ & \\
\hline Yes & $1523(68.8)$ & 2511 (89) & \\
\hline Unknown & $288(13)$ & $66(2.3)$ & \\
\hline
\end{tabular}

* CA125 values were $\log _{\mathrm{e}}$-transformed 
Dutch study population that was excluded for the model development. This sensitivity analysis showed that $5.2 \%$ of all patients that underwent NACT-ICS were selected for upfront PCS based on the currently developed model.

Table 2: Odds ratios and estimates for complete cytoreductive surgery based on the internally validated prediction model

\begin{tabular}{|c|c|c|c|c|}
\hline & & OR $(95 \% \mathrm{Cl})$ & & Shrunk coefficient \\
\hline Age & & $0.99(0.98-0.99)$ & & -0.014 \\
\hline \multicolumn{5}{|l|}{ FIGO stage } \\
\hline FIGO IIIA-IIIB & \multicolumn{4}{|c|}{ reference } \\
\hline FIGO IIIC & \multicolumn{3}{|c|}{$0.35(0.24-0.51)$} & -1.036 \\
\hline FIGO IV & \multicolumn{3}{|c|}{$0.22(0.14-0.24)$} & -1.499 \\
\hline \multicolumn{5}{|l|}{ Omental cake } \\
\hline No & \multicolumn{4}{|c|}{ reference } \\
\hline Yes & \multicolumn{3}{|c|}{$0.41(0.21-0.82)$} & -0.867 \\
\hline CA-125 at diagnosis* & \multicolumn{3}{|c|}{$0.91(0.78-0.96)$} & -0.099 \\
\hline \multicolumn{5}{|l|}{ Ascites } \\
\hline No ascites & \multicolumn{4}{|c|}{ reference } \\
\hline Ascites & \multicolumn{3}{|c|}{$0.57(0.41-0.79)$} & -0.557 \\
\hline \multicolumn{5}{|l|}{ Gynaecologic-oncologist } \\
\hline No & \multicolumn{4}{|c|}{ reference } \\
\hline Yes & \multicolumn{3}{|c|}{$2.35(1.50-3.68)$} & 0.839 \\
\hline \multicolumn{5}{|c|}{$\begin{array}{l}\text { Table 3: Model performance at different thresholds in the prediction of residual disease after upfront } \\
\text { cytoreductive surgery }\end{array}$} \\
\hline Cut-off for a positive test & Sensitivity (\%) & Specificity (\%) & PPV (\%) & NPV (\%) \\
\hline $10 \%$ & 98.7 & 7.3 & 38.4 & 90.8 \\
\hline $20 \%$ & 89.8 & 36.5 & 45.3 & 86.0 \\
\hline $30 \%$ & 78.1 & 58.2 & 52.2 & 82.0 \\
\hline $40 \%$ & 61.5 & 76.5 & 60.4 & 77.2 \\
\hline $50 \%$ & 46.9 & 87.8 & 69.2 & 73.9 \\
\hline $60 \%$ & 37.7 & 92.6 & 75.0 & 71.8 \\
\hline $70 \%$ & 19.7 & 97.4 & 81.3 & 67.5 \\
\hline $80 \%$ & 3.4 & 99.2 & 71.1 & 63.7 \\
\hline
\end{tabular}

PPV: positive predictive value, NPV: negative predictive value 


\section{Score calculator}

In addition to the prediction model, we developed an online score calculator, and an example for an individual patient is provided in the supplementary material (S2). This score calculator was based on the internally validated estimates of our model.

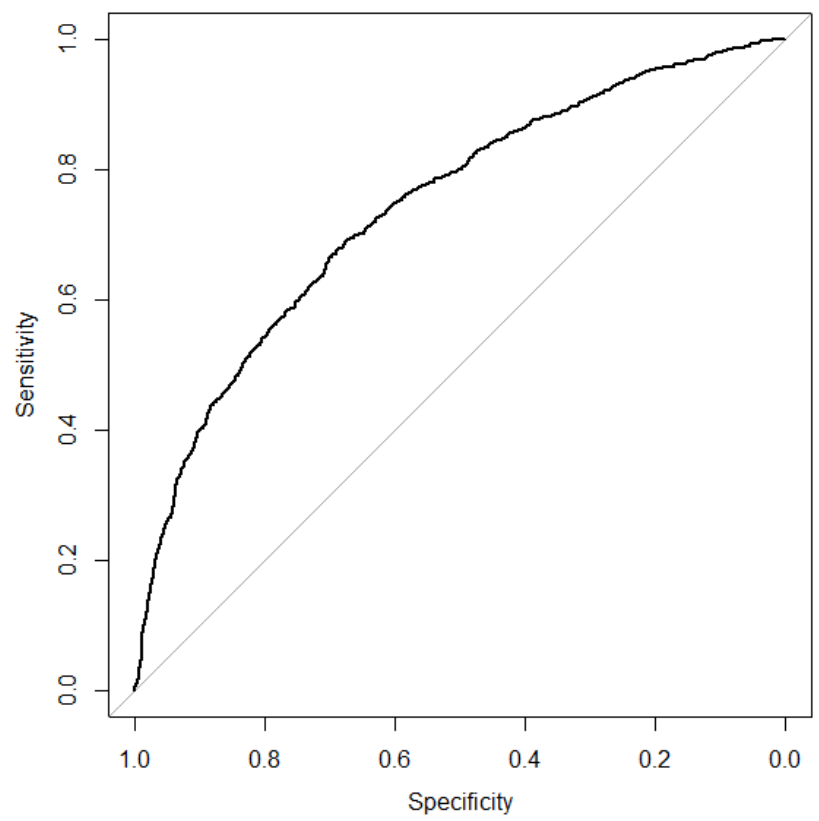

Figure 1: Area under the receiver operating characteristic curve (AUC) on the probability towards no macroscopic residual disease after upfront cytoreductive surgery

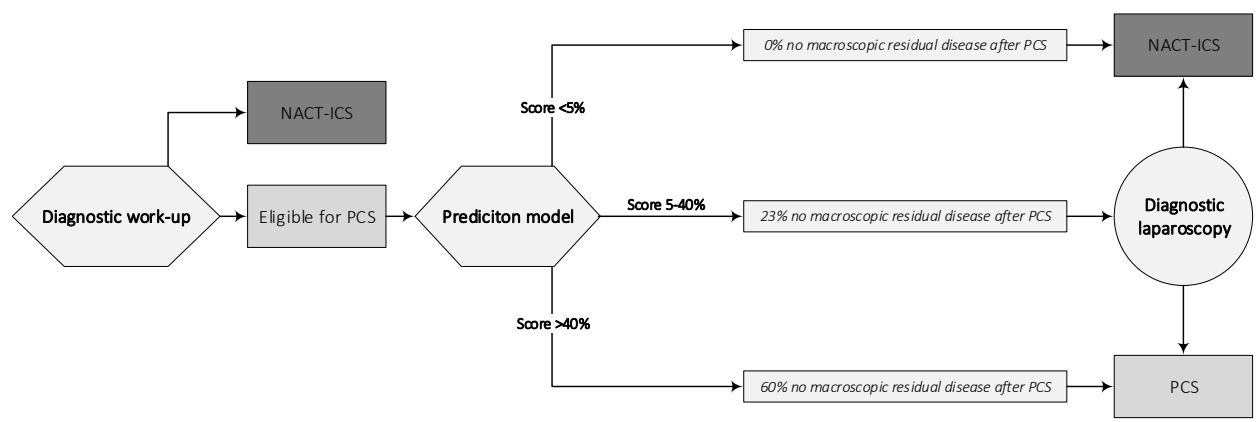

Figure 2: Illustration how the prediction model could be implemented in clinical daily practice, the percentages in the grey boxes represent the current data of the used population 


\section{DISCUSSION}

The decision to schedule EOC patients for either PCS or NACT-ICS depends, among others, on the ability to reach a complete cytoreductive surgery. In this large population-based, multicentred study we developed and internally validated a prediction model, based on simple baseline characteristics, that estimates the probability to successful PCS. The implementation of this model may offer clinical guidance in this heterogenous patient population.

The ability to reach a complete cytoreductive surgery is most often based on imaging techniques, predominantly CT scans, which resulted in numerous CT based prediction models ${ }^{10-21}$. Extensive research has been done to the accuracy of these models, but all of them failed to show enough discriminative ability in new populations ${ }^{22-26}$. One of the reasons that may cause the lack of external validity of these models is that expertise of radiologists greatly differs between centres. This results in interobserver variability between radiologists in the assessment of radiographic features. Moreover, the interaction between radiologists and gynaecological oncologists influences clinical decision-making, as some surgeons are more aggressive in their approach to reach a complete cytoreductive surgery ${ }^{22,35,36}$. This underscores why these models are prone to individual interpretation, and lack generalisability in other populations. The currently developed model is based on a large population-based, multi-centre dataset, which may result into a better prediction in other populations as well, since multiple radiologists and gynaecologists were included. Moreover, the presence of ascites and an omental cake are simple radiographic features for expert radiologists in gynaecologic oncology.

Previously developed prediction models mainly focussed on the probability of suboptimal $(>1 \mathrm{~cm})$ cytoreductive surgery, but did not distinct complete from optimal surgery ${ }^{11,17,28-31}$. The usability of those models is currently limited, since optimal surgery has been abandoned as the appropriate goal of PCS. As a result, PCS should only be considered in case of a high probability towards no macroscopic residual disease and previously developed models are therefore not accurate enough. Moreover, the vast majority of these models is hampered by a small sample size and a patient population from a single-institution, which has proven to decrease accuracy in other populations.

Other models show promising results in their own study population, but could not be externally validated by our group due to missing variables in our dataset. Serum human epididymis protein 4 (HE4) may be a useful predictor for successful surgery, and the height is associated with initial tumour burden. AUCs for complete surgery ranged between 0.63 and $0.79^{27,37}$. Moreover, when combined with CA125 and performance status, this 
increased to an AUC of $0.85^{27}$. Our model may improve when the serum HE4 is added as potential predictor, but this requires implementation of HE4 in the diagnostic work-up for advanced ovarian cancer patients.

A recently developed and validated model based on the GOG-182 study shows promising results, with a highest $A \cup C$ of 0.87 in the training set and 0.83 in the validation $\operatorname{set}^{38}$. The GOG-182 study randomized patients for varying adjuvant platinum-based chemotherapy protocols, while all patients underwent primary cytoreduction ${ }^{39}$. The training set was used to develop the model and included patients that were randomized within the first 2.5 years $(n=1,007)$, subsequently all other patients were categorized in the validation set and this was used to externally validate the model $(n=473)$. One of the potential predictors in their study was disease score, which categorized patients according to the extent of initial tumour burden. The AUCs of 0.87 and 0.83 were reached by including the intra-operative disease score, which is not accessible in a preoperative setting. Therefore, AUCs were lower when this predictor was excluded from the model (training set AUC 0.78 and validation set 0.73 ). It did, however, show that intra-abdominal disease is an important predictor for successful surgery.

The extent and localisation of intra-abdominal disease could be well established by diagnostic laparoscopy prior to cytoreductive surgery. In a randomised setting, it has been shown that the number of futile laparotomies decreases when diagnostic laparoscopy is used to assess the resectability of advanced stage ovarian cancer ${ }^{7}$. Moreover, the use of standardised laparoscopic scoring systems increases perioperative accuracy in the estimation of subsequent successful PCS ${ }^{40,41}$. This raises the question why we need a pre-operative prediction model. The use of diagnostic laparoscopy is unfortunately not without its downsides, and they should be taken into consideration as well. The most important disadvantage of diagnostic laparoscopy is the development of port-sitemetastases, varying from $16-47 \%{ }^{42}$. Although these metastases are not directly associated with impaired survival rates, they are responsible for additional perioperative morbidity and more complex subsequent cytoreductive surgery ${ }^{9,43}$. In addition, the use of diagnostic laparoscopy and accompanied scoring systems does not ensure successful PCS, as the false negative result of laparoscopy ranges between $4-30 \%{ }^{44}$. The implementation of diagnostic laparoscopy should therefore be limited to those patients in whom successful PCS seems feasible. In this patient group, the currently developed prediction model may be of additional use.

Despite the good performance of our model in this manuscript, a prediction model is only beneficial in daily clinical practice if it is more accurate in the prediction of the desired outcome compared to the assessment of the clinician. In the Dutch LAPOVCA trial, patients 
were eligible for inclusion if optimal PCS with $\leq 1 \mathrm{~cm}$ residual disease was deemed feasible. Out of the 201 included patients, 107 (53\%) patients achieved optimal surgery at the initial attempt (regardless of the performance of diagnostic laparoscopy), while only $36 \%$ $(73 / 201)$ had no residual disease after the initial attempt ${ }^{7}$. Moreover, this is probably an overestimation to real clinical practice, as patients with specific disease features (large pelvic masses, diaphragmatic peritonitis or peri-aortic lymphadenectomy $>1 \mathrm{~cm}$ ) were already excluded from this trial. This stresses the urge to optimise the preoperative selection for successful PCS.

Based on a large population-based dataset, our model provides an estimation on the probability of a complete PCS. The clinical utility of our model depends on the chosen threshold for a positive test. In case the cut-off point for a positive test is $40 \%$ or higher, $60 \%$ of advanced ovarian cancer patients have no residual disease after upfront PCS. Although not perfect, it is still 1.7 times higher when compared to regular clinical assessment (based on the LAPOVCA trial). In case of a higher threshold, the specificity of the model increases, and the number of futile laparotomies decreases as a result. The chosen threshold for a positive test may vary between advocates of PCS and NACT-ICS, as advocates of NACT-ICS may accept less futile laparotomies at the expense of more patients undergoing NACTICS while they were candidates for successful upfront PCS. The implementation of a preoperative prediction model could be helpful in the process of shared-decision making, where risks and benefits are more quantifiable for both physicians and patients. Moreover, after the initial estimation and the use of a prediction model, diagnostic laparoscopy could be of additional value in a more specific selection of patients.

Despite the good discriminative ability of our model, and the fact that internal validation was a part of the model development, there are some limitations. We excluded all patients that received initial NACT-ICS for the development of the model, as they were targeted as not suitable for primary surgery. We showed that the number of patients that could be selected for PCS, based on the currently developed model, was rather low in the initial NACT-ICS group (5\%), which may be an indication that the model can also be used in other populations. We could, however, not externally validate our currently developed model on this patient population as the outcome of PCS could not be established in that cohort (as they did not undergo an attempt to primary surgery). The number of patients that was treated with NACT-ICS increased over the last year in the Netherlands, and this is a potential source of bias for our estimates. In addition, while the population-based setting with multicentre inclusion is a benefit of our study since estimates are more generalisable, the performance of the model may differ between centres due to differences in surgical capacities. However, the model could be adjusted for specific centres in external validation 
processes. Most importantly, our model is not externally validated, which is warranted before implementation is possible in clinical daily practice.

In conclusion, we developed and internally validated a model that estimates the probability to complete cytoreductive surgery as primary treatment in advanced ovarian cancer patients. After external validation, this model may improve patient selection towards those that may actually benefit from successful primary surgery.

\section{Acknowledgements}

The authors thank the registration team of the Netherlands Comprehensive Cancer Organisation (IKNL) for the collection of data for the Netherlands Cancer Registry.

\section{Funding}

This work was supported by Dutch Cancer Society [IKNL2014-6838]. 


\section{REFERENCES}

1. Chang SJ, Hodeib M, Chang J, Bristow RE. Survival impact of complete cytoreduction to no gross residual disease for advancedstage ovarian cancer: A meta-analysis. Gynecol Oncol. 2013;130(3):493-8.

2. Vergote I, Trope CG, Amant F, Kristensen $G B$, Ehlen T, Johnson N, et al. Neoadjuvant chemotherapy or primary surgery in stage iiic or iv ovarian cancer. N Engl J Med. 2010;363(10):943-53.

3. Kehoe S, Hook J, Nankivell M, Jayson GC, Kitchener $H$, Lopes $T$, et al. Primary chemotherapy versus primary surgery for newly diagnosed advanced ovarian cancer (chorus): An open-label, randomised, controlled, non-inferiority trial. Lancet. 2015;386(9990):249-57.

4. Fagotti A, Ferrandina G, Vizzielli G, Fanfani F, Gallotta V, Chiantera V, et al. Phase iii randomised clinical trial comparing primary surgery versus neoadjuvant chemotherapy in advanced epithelial ovarian cancer with high tumour load (scorpion trial): Final analysis of peri-operative outcome. European Journal of Cancer. 2016;59:22-33.

5. Gerestein CG, van der Spek DW, Eijkemans MJ, BakkerJ, KooiGS, BurgerCW. Prediction of residual disease after primary cytoreductive surgery for advanced-stage ovarian cancer: Accuracy of clinical judgment. Int J Gynecol Cancer. 2009;19(9):1511-5.

6. van de Vrie $R$, van Meurs HS, Rutten MJ, Naaktgeboren CA, Opmeer BC, Gaarenstroom KN, et al. Cost-effectiveness of laparoscopy as diagnostic tool before primary cytoreductive surgery in ovarian cancer. Gynecologic Oncology. 2017;146(3):449-56.

7. Rutten MJ, van Meurs HS, van de Vrie R, Gaarenstroom KN, Naaktgeboren CA, van Gorp T, et al. Laparoscopy to predict the result of primary cytoreductive surgery in patients with advanced ovarian cancer: A randomized controlled trial. J Clin Oncol. 2017;35(6):613-21.
8. Ataseven B, Grimm C, Harter P, Heikaus S, Heitz F, Traut A, et al. Prognostic impact of port-site metastasis after diagnostic laparoscopy for epithelial ovarian cancer. Annals of Surgical Oncology. 2016;23:83440.

9. Heitz F, Ognjenovic D, Harter P, Kommoss $\mathrm{S}$, Ewald-Riegler $\mathrm{N}$, Haberstroh $\mathrm{M}$, et al. Abdominal wall metastases in patients with ovarian cancer after laparoscopic surgery: Incidence, risk factors, and complications. Int J Gynecol Cancer. 2010;20(1):41-6.

10. Byrom J, Widjaja E, Redman CW, Jones PW, Tebby S. Can pre-operative computed tomography predict resectability of ovarian carcinoma at primary laparotomy? BJOG. 2002;109(4):369-75.

11. Gerestein CG, Eijkemans MJ, Bakker J, Elgersma OE, van der Burg ME, Kooi GS, et al. Nomogram for suboptimal cytoreduction at primary surgery for advanced stage ovarian cancer. Anticancer Res. 2011;31(11):40439.

12. Janco JM, Glaser G, Kim B, McGree ME, Weaver AL, Cliby WA, et al. Development of a prediction model for residual disease in newly diagnosed advanced ovarian cancer. Gynecol Oncol. 2015;138(1):70-7.

13. Jung DC, Kang S, Kim SC, Kim JW, Nam $J H$, Ryu SY, et al. Use of complex surgical procedures, patterns of tumor spread, and ca-125 predicts a risk of incomplete cytoreduction: A korean gynecologic oncology group study (kgog-3022). Gynecol Oncol. 2013;131(2):336-40.

14. Nelson BE, Rosenfield AT, Schwartz PE. Preoperative abdominopelvic computed tomographic prediction of optimal cytoreduction in epithelial ovarian carcinoma. J Clin Oncol. 1993;11(1):166-72. 
15. Risum S, Hogdall C, Loft A, Berthelsen AK, Hogdall E, Nedergaard L, et al. Prediction of suboptimal primary cytoreduction in primary ovarian cancer with combined positron emission tomography/computed tomography--a prospective study. Gynecol Oncol. 2008;108(2):265-70.

16. Son HM, Kim SH, Kwon BR, Kim MJ, Kim $\mathrm{CS}$, Cho SH. Preoperative prediction of suboptimal resection in advanced ovarian cancer based on clinical and ct parameters. Acta Radiol. 2017;58(4):498-504.

17. Stashwick C, Post MD, Arruda JS, Spillman MA, Behbakht K, Davidson SA, et al. Surgical risk score predicts suboptimal debulking or a major perioperative complication in patients with advanced epithelial ovarian, fallopian tube, or primary peritoneal cancer. Int J Gynecol Cancer. 2011;21(8):1422-7.

18. Suidan RS, Ramirez PT, Sarasohn DM, Teitcher JB, Mironov S, Iyer RB, et al. A multicenter prospective trial evaluating the ability of preoperative computed tomography scan and serum ca-125 to predict suboptimal cytoreduction at primary debulking surgery for advanced ovarian, fallopian tube, and peritoneal cancer. Gynecol Oncol. 2014;134(3):455-61.

19. Ferrandina G, Sallustio G, Fagotti A, Vizzielli G, Paglia A, Cucci E, et al. Role of ct scan-based and clinical evaluation in the preoperative prediction of optimal cytoreduction in advanced ovarian cancer: A prospective trial. $\mathrm{Br} J$ Cancer. 2009;101(7):1066-73.

20. Bristow RE, Duska LR, Lambrou NC, Fishman EK, O'Neill MJ, Trimble EL, et al. A model for predicting surgical outcome in patients with advanced ovarian carcinoma using computed tomography. Cancer. 2000;89(7):1532-40.
21. Dowdy SC, Mullany SA, Brandt KR, Huppert BJ, Cliby WA. The utility of computed tomography scans in predicting suboptimal cytoreductive surgery in women with advanced ovarian carcinoma. Cancer. 2004;101(2):346-52.

22. Rutten IJ, van de Laar R, Kruitwagen RF, Bakers FC, Ploegmakers MJ, Pappot TW, et al. Prediction of incomplete primary debulking surgery in patients with advanced ovarian cancer: An external validation study of three models using computed tomography. Gynecol Oncol. 2016;140(1):22-8.

23. Ibeanu OA, Bristow RE. Predicting the outcome of cytoreductive surgery for advanced ovarian cancer: A review. Int J Gynecol Cancer. 2010;20 Suppl 1:S1-11.

24. Axtell $A E$, Lee $M H$, Bristow RE, Dowdy SC, Cliby WA, Raman S, et al. Multi-institutional reciprocal validation study of computed tomography predictors of suboptimal primary cytoreduction in patients with advanced ovarian cancer. J Clin Oncol. 2007;25(4):384-9.

25. Gemer O, Gdalevich M, Ravid M, Piura B, Rabinovich A, Gasper T, et al. A multicenter validation of computerized tomography models as predictors of non- optimal primary cytoreduction of advanced epithelial ovarian cancer. Eur J Surg Oncol. 2009;35(10):1109-12.

26. Rutten $M J$, van de Vrie $R$, Bruining $A$, Spijkerboer AM, Mol BW, Kenter GG, et al. Predicting surgical outcome in patients with international federation of gynecology and obstetrics stage iii or iv ovarian cancer using computed tomography: A systematic review of prediction models. Int J Gynecol Cancer. 2015;25(3):407-15. 
27. Karlsen MA, Fago-Olsen C, Hogdall E, Schnack TH, Christensen IJ, Nedergaard $L$, et al. A novel index for preoperative, non-invasive prediction of macro-radical primary surgery in patients with stage iiic-iv ovarian cancer-a part of the danish prospective pelvic mass study. Tumour Biol. 2016;37(9):12619-26.

28. Ashrafganjoei $T, \quad$ Mohamadianamiri M, Farzaneh F, Hosseini MS, Arab M. Investigating preoperative hematologic markers for prediction of ovarian cancer surgical outcome. Asian Pac J Cancer Prev. 2016;17(3):1445-8

29. de Jong $D$, Eijkemans MJ, Lie Fong $S$, Gerestein CG, Kooi GS, Baalbergen A, et al. Preoperative predictors for residual tumor after surgery in patients with ovarian carcinoma. ONCOLOGY. 2007;72(5-6):293301.

30. Vorgias G, lavazzo C, Savvopoulos P, Myriokefalitaki E, Katsoulis M, Kalinoglou $\mathrm{N}$, et al. Can the preoperative ca-125 level predict optimal cytoreduction in patients with advanced ovarian carcinoma? A single institution cohort study. Gynecol Oncol. 2009;112(1):11-5.

31. Angioli R, Plotti F, Capriglione S, Aloisi A, Montera R, Luvero D, et al. Can the preoperative he4 level predict optimal cytoreduction in patients with advanced ovarian carcinoma? Gynecol Oncol. 2013;128(3):579-83.

32. Fritz AG. International classification of diseases for oncology : Icd-o. 3rd ed. Geneva: World Health Organization; 2000. vii, 240 p. p.

33. Hayati Rezvan P, Lee KJ, Simpson JA. The rise of multiple imputation: A review of the reporting and implementation of the method in medical research. BMC Med Res Methodol. 2015;15:30.

34. Harrell FE, Jr., Lee KL, Califf RM, Pryor DB, Rosati RA. Regression modelling strategies for improved prognostic prediction. Stat Med. 1984;3(2):143-52.
35. MacKintosh ML, Rahim R, Rajashanker B, Swindell R, Kirmani BH, Hunt J, et al. Ct scan does not predict optimal debulking in stage iii-iv epithelial ovarian cancer: A multicentre validation study. J Obstet Gynaecol. 2014;34(5):424-8.

36. Horowitz NS, Miller A, Rungruang B, Richard $\mathrm{SD}$, Rodriguez N, Bookman MA, et al. Does aggressive surgery improve outcomes? Interaction between preoperative disease burden and complex surgery in patients with advanced-stage ovarian cancer: An analysis of gog 182. J Clin Oncol. 2015;33(8):937-43.

37. Braicu El, Fotopoulou C, Van Gorp T, Richter R, Chekerov R, Hall C, et al. Preoperative he4 expression in plasma predicts surgical outcome in primary ovarian cancer patients: Results from the ovcad study. Gynecol Oncol. 2013;128(2):245-51.

38. Horowitz NS, Larry Maxwell G, Miller A, Hamilton CA, Rungruang $B$, Rodriguez $N$, et al. Predictive modeling for determination of microscopic residual disease at primary cytoreduction: An nrg oncology/gynecologic oncology group 182 study. Gynecol Oncol. 2018;148(1):49-55.

39. Bookman MA, Brady MF, McGuire WP, Harper PG, Alberts DS, Friedlander M, et al. Evaluation of new platinum-based treatment regimens in advanced-stage ovarian cancer: A phase iii trial of the gynecologic cancer intergroup. J Clin Oncol. 2009;27(9):1419-25.

40. Petrillo M, Vizzielli G, Fanfani F, Gallotta V, Cosentino F, Chiantera $V$, et al. Definition of a dynamic laparoscopic model for the prediction of incomplete cytoreduction in advanced epithelial ovarian cancer: Proof of a concept. Gynecol Oncol. 2015;139(1):5-9.

41. Fagotti A, Ferrandina $G$, Fanfani $F$, Garganese G, Vizzielli G, Carone V, et al. Prospective validation of a laparoscopic predictive model for optimal cytoreduction in advanced ovarian carcinoma. Am J Obstet Gynecol. 2008;199(6):642 e1-6. 
42. Ataseven B, Grimm C, Harter P, Heitz F, Traut A, Prader $S$, et al. Prognostic impact of debulking surgery and residual tumor in patients with epithelial ovarian cancer figo stage iv. Gynecol Oncol. 2016;140(2):21520.

43. Ataseven B, Grimm C, Harter P, Heikaus S, Heitz F, Traut A, et al. Prognostic impact of port-site metastasis after diagnostic laparoscopy for epithelial ovarian cancer. Ann Surg Oncol. 2016;23(Suppl 5):834-40.

44. Rutten MJ, Leeflang MM, Kenter GG, Mol BW, Buist M. Laparoscopy for diagnosing resectability of disease in patients with advanced ovarian cancer. Cochrane Database Syst Rev. 2014(2):CD009786. 


\section{SUPPLEMENTARY MATERIAL}

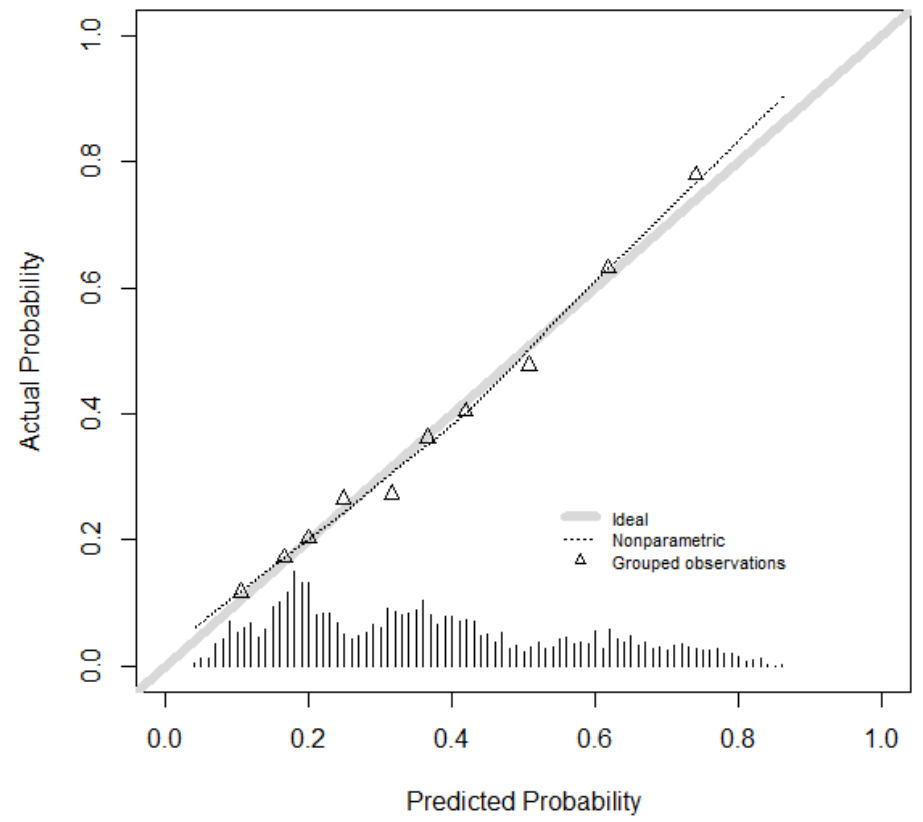

S1: Calibration plot of the logistic regression model to predict complete cytoreductive surgery

\section{Probability towards upfront complete cytoreductive surgery $59 \%$}

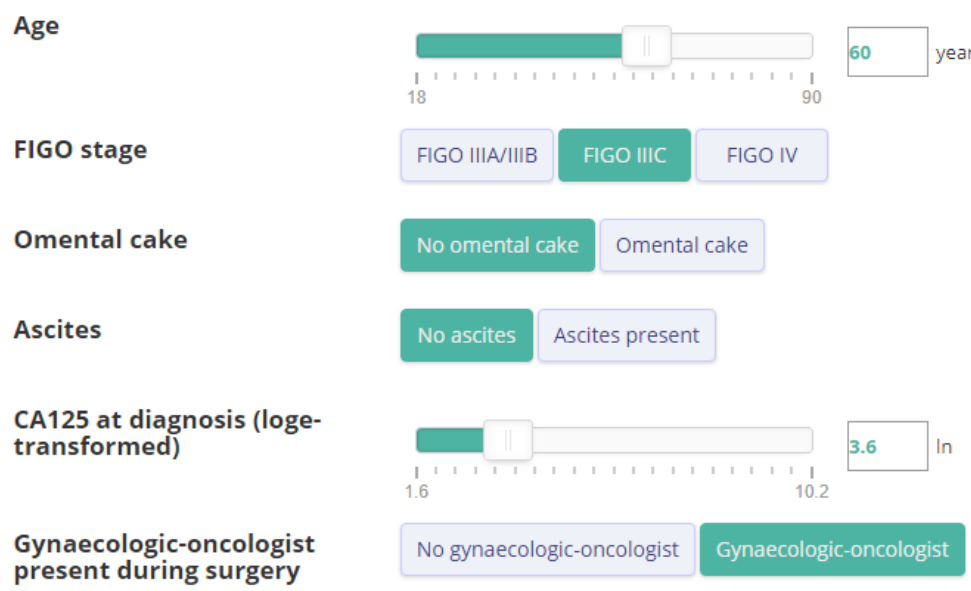

S2: Example of the online score calculator based on the internally validated estimates of the developed prediction model 




\section{0}

The prognostic value of residual disease after neoadjuvant chemotherapy in advanced ovarian cancer; a systematic review

M. Timmermans, O. van der Hel, G.S. Sonke, K.K. Van de Vijver, M.A. van der Aa, R.F.P.M. Kruitwagen 


\section{ABSTRACT}

\section{Introduction}

The ability to minimize residual disease during primary cytoreductive surgery is the strongest predictor for improved overall survival in advanced ovarian cancer. But while the probability to achieve a macroscopic complete resection increases if surgery is preceded by neoadjuvant chemotherapy (NACT), survival rates after NACT are similar to those observed after primary surgery. This may suggest that the prognostic effect of residual disease is altered after NACT. More specifically, randomized data suggest that there is no difference between optimal $(0.1-1 \mathrm{~cm})$ and suboptimal $(>1 \mathrm{~cm})$ cytoreductive surgery after NACT. Therefore, the aim of the current review is to establish the prognostic effect of the amount of residual disease after interval cytoreductive surgery (ICS) on overall survival.

\section{Methods}

Potential articles for inclusion in the current review were systematically searched through Medline, Embase and Cochrane in September 2017. Median overall survival (mOS) was summarized by the outcome of ICS per study. In addition, mOS was summarized for all studies together stratified by the outcome of ICS, based on the principle of a weighted average.

\section{Results}

In total, 3,677 unique manuscripts were individually screened on title and abstract, which resulted in 11 individual studies that comprised a total of 2,178 patients. MOS was 41 months for patients with no residual disease (range 33-54 months), 27 months for patients with $0.1-1 \mathrm{~cm}$ of residual disease (range 19-38 months) and 21 months with $>1 \mathrm{~cm}$ of residual disease (range 14-27 months). Six studies showed significant differences between optimal and suboptimal ICS, while five studies showed no differences.

\section{Conclusion}

The summary of the currently available literature showed that after NACT, patients with optimal cytoreductive surgery experience lengthened survival compared to patients with suboptimal cytoreductive surgery. Patients with no macroscopic residual disease, however, have the most favorable survival outcomes, similar to what is seen after primary cytoreductive surgery. 


\section{INTRODUCTION}

The vast majority of epithelial ovarian cancer patients is diagnosed with advanced stage disease, which is associated with poor clinical outcome ${ }^{1,2}$. Standard therapy comprises a combination of platinum-based chemotherapy and cytoreductive surgery. Patients survival strongly depends on the sensitivity to first-line chemotherapy and the ability to minimize residual disease during primary cytoreductive surgery (PCS), where patients with no macroscopic residual disease have the best prognosis ${ }^{3,4}$.

Traditionally, patients underwent PCS followed by six cycles of adjuvant chemotherapy. Initial disease burden is a limiting factor in achieving an optimal surgical result. Neoadjuvant chemotherapy (NACT) was introduced to diminish intra-abdominal tumor load and, hence, increase the likelihood towards successful interval cytoreductive surgery (ICS). Two landmark randomized clinical trials (RCTs) compared clinical outcomes between PCS and NACT-ICS in International Federation of Gynecology and Obstetrics (FIGO) IIIC and IV patients, and showed similar survival rates between both groups ${ }^{5,6}$, with reduced morbidity after NACT-ICS ${ }^{7,8}$. The percentage of patients with $\leq 1 \mathrm{~cm}$ of residual disease, however, was higher in the NACT-ICS group. The higher probability towards successful surgery after NACT was confirmed in the meta-analysis by Kang et al. ${ }^{9}$ The discrepancy between improved surgical outcome after NACT without improvement in long-term outcome raises the question why the prognostic value of surgical outcome differs for patients who receive PCS versus those that receive NACT-ICS.

A recent study by Meyer et al. showed that survival after PCS and NACT-ICS was similar in case of complete cytoreductive surgery (i.e. no macroscopic residual disease), while survival of PCS patients was significantly better after optimal cytoreductive surgery (0.1$1 \mathrm{~cm}$ of residual disease) when compared to NACT-ICS patients ${ }^{10}$. This suggests that any macroscopic residual disease after NACT is an unfavorable prognostic factor for survival. Moreover, randomized data suggest that there is no difference in survival between optimal $(0.1-1 \mathrm{~cm})$ and suboptimal $(>1 \mathrm{~cm})$ cytoreductive surgery after $\mathrm{NACT}^{5}$. The aim of the current review is therefore to establish the prognostic effect of the amount of residual disease after NACT-ICS on overall survival, in order to support clinical decision making for patients who benefit from ICS after NACT. More specifically, we aim to investigate if survival differences are present between suboptimal and optimal cytoreductive surgery.

\section{METHODS}

The definition of residual disease after surgery has evolved over time. Successful cytoreductive surgery was previously defined as tumor residuals $\leq 2 \mathrm{~cm}$, while nowadays it is 
defined as no macroscopic residual disease ${ }^{4,11-13}$. As our review aims to define the prognostic effect of residual disease in the current platinum-based era, we focused on studies that adopted current definitions for residual disease and categorized patients into complete (i.e. no macroscopic residual disease), optimal (i.e. largest diameter $0.1-1 \mathrm{~cm}$ ) and suboptimal (i.e. largest diameter $>1 \mathrm{~cm}$ of residual disease) surgery. The Preferred Reporting Items for Systematic Reviews and Meta-Analyses (PRISMA) tool was used to ensure transparent reporting and is added to our supplementary material $(S 1)^{14,15}$. Moreover, the protocol for the current review is registered in the international prospective register of systematic reviews (PROSPERO) with the following registration number CRD42018083656 and can be accessed through the following website https://www.crd.york.ac.uk/PROSPERO/.

\section{Search}

Potential articles for inclusion in the current study were systematically searched through Medline, Embase and Cochrane (Cochrane Database of Systematic Reviews (CDSR) and Central) databases at September 2017. The systematic search is provided in the supplementary material for the Medline search (S2). After merging the results of the three searches, all records were individually screened on title and abstract by two authors (MT and $\mathrm{OvdH}$ ). Discrepancies were discussed and resolved by consensus, resulting in either in- or exclusion for full text screen.

\section{Inclusion and exclusion criteria}

Study inclusion criteria were as follows: 1) primary epithelial ovarian, fallopian tube, or peritoneal carcinoma, 2) patients treated with NACT-ICS, 3) FIGO stages IIB to IV, 4) residual disease categorized as complete (i.e. no macroscopic residual disease), optimal (i.e. largest diameter $0.1-1 \mathrm{~cm}$ ) and suboptimal (i.e. largest diameter $>1 \mathrm{~cm}$ ) and 5) overall survival (OS) outcomes reported by the before mentioned categories of residual disease in patients that underwent NACT-ICS.

\section{Data extraction}

In case of multiple publications based on the same study cohort, the most relevant study (according to our inclusion criteria) was included. We extracted the following information for each eligible study; study design, year of publication, number of patients, \% FIGO IIIC and IV patients, chemotherapy protocols, residual disease, median overall survival (mOS), 5-year survival rates, and hazard ratio's (HR) between complete, optimal and suboptimal cytoreductive surgery. Median survival and five-year survival rates were estimated from 
Kaplan-Meier curves if they were not mentioned in the text. In case data were unavailable in the manuscript or supplementary files, we contacted the corresponding author of the study for additional data.

\section{Statistical analysis}

mOS of patients from all studies was summarized based on the principle of a weighted average, where the number of patients of the study was leading in the weight of the analysis. Moreover, in most cox-regression analyses complete cytoreductive was selected as reference category. Since we were predominantly interested in the differences between optimal and suboptimal cytoreductive surgery, HR's were recalculated with suboptimal surgery as new reference category. This was based on the following formula: $\left(\left(1 / \mathrm{HR}_{\text {suboptimal vs. complete }}\right) * H \mathrm{R}_{\text {optimal vs. complete }}\right)=H \mathrm{R}_{\text {optimal vs, suboptimal }}$. Confidence intervals could not be calculated, so statistical significance could not be determined.

\section{Quality appraisal}

Both reviewers (MT and OvdH) performed an independent assessment of the quality of all included studies. Retrospective cohort studies were assessed by the Newcastle Ottawa Scale (NOS) and RCTs were assessed by the Cochrane Risk of Bias Assessment tool ${ }^{16,17}$. Discrepancies were discussed and resolved by consensus.

\section{RESULTS}

In total, 3,677 unique manuscripts were individually screened on title and abstract. Hereafter, we selected 83 studies for a full-text review, and 11 studies were eventually identified as eligible and were included in the present study (figure 1) 5,6,18-26. We included two RCTs, and nine observational studies. Included patient numbers ranged from 61 to 460, and resulted in a total of 2,178 included patients.

\section{Quality appraisal of retrospective studies}

Based on the NOS scale, the quality of included retrospective cohort studies was high. The risk of selection bias was low in all studies, as consecutive patients were included in all studies. Comparability between groups differed among studies, and only two studies adjusted their survival analyses for both age and FIGO stage, being important prognostic factors for overall survival22,26. The assessment of outcome and length of follow-up was adequate in all studies, although only two of them reported on the loss to follow-up and 
whether it was equal between groups ${ }^{18,20}$. Overall 7 out of 9 studies had a score of 7 or higher, and two studies had an overall score of 6 (S3).

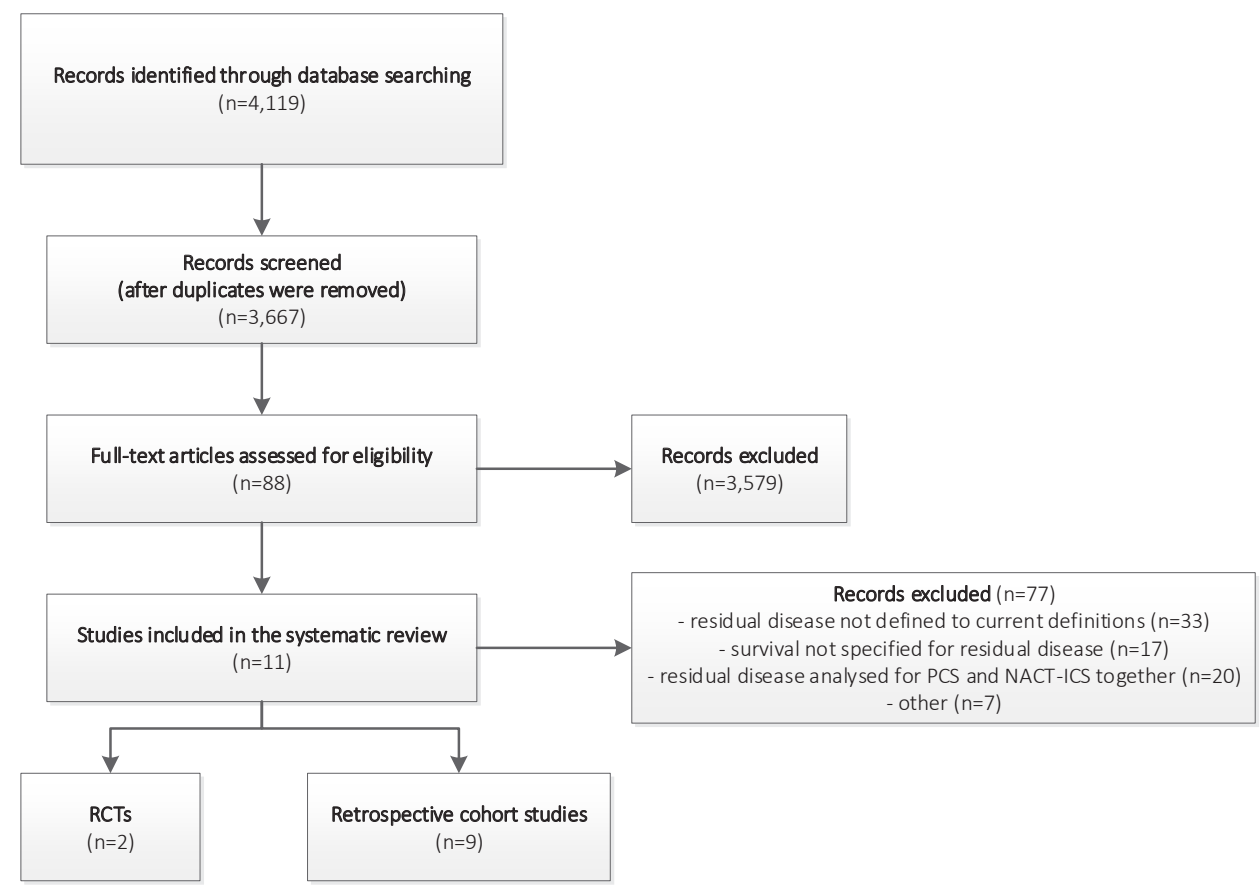

Figure 1: Systematic search of the current review

\section{Quality appraisal of randomized studies}

Based on the Cochrane Risk of Bias Tool, the quality of the two included RCTs was good. Both studies had a high risk of performance bias; as both patients and physicians were obviously aware of the chosen treatment (PCS or NACT-ICS) and blinding was impossible in both studies. This risk, however, did not influence the research question for this review as we only included patients of the NACT-ICS group. Risks of biases were scored as low (S4, S5).

\section{Study populations}

Study characteristics are summarized in table 1. The vast majority of studies consisted of patients that were treated by either PCS or NACT-ICS, while two studies only included NACTICS patients. The percentages of included NACT-ICS patients ranged from $20 \%$ to $67 \%$. All studies included FIGO IIIC and IV patients, and the percentages of FIGO IV patients ranged 


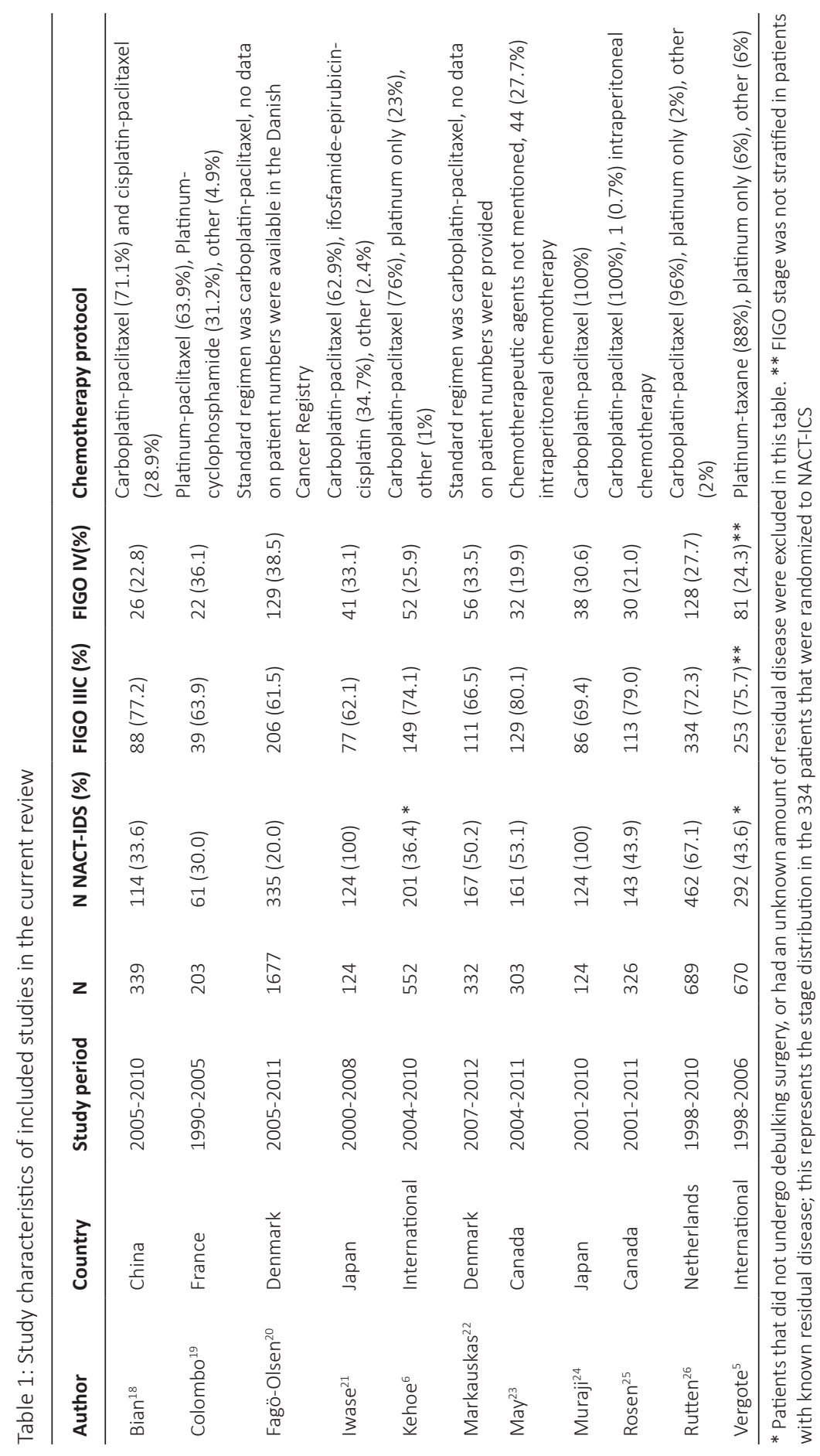


from $21 \%$ to $39 \%$. Standard chemotherapeutic protocols consisted of a combination of carboplatin and paclitaxel. A total of $73 \%$ to $100 \%$ of patient populations was treated with this combination. Intraperitoneal chemotherapy was rarely used, but one study reported that $28 \%$ of their NACT-ICS patients received intraperitoneal chemotherapy, which was associated with improved survival in this study ${ }^{23}$.

\section{Survival outcomes after NACT stratified by the amount of residual disease}

mOS was summarized for all studies in figure 2 and table 2. Patients with no macroscopic residual disease had the most favorable survival in all studies. mOS after complete cytoreduction ranged from 33 to 54 months, and based on all studies the weighted average was 41 months. mOS of patients with an optimal cytoreduction ranged from 19 to 38 months, and mOS of patients with a suboptimal result ranged from 14 months to 27 months. The weighted average of mOS was 27 months for patients with $0.1-1 \mathrm{~cm}$ of residual disease and 21 months with $>1 \mathrm{~cm}$ of residual disease.

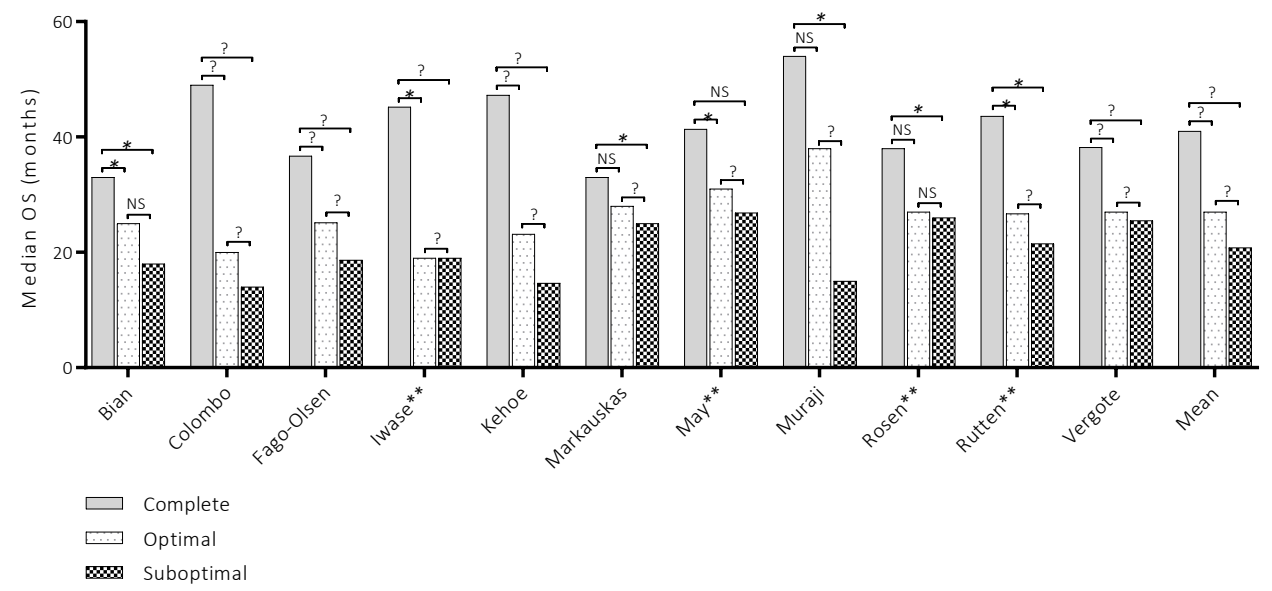

Figure 2: Median overall survival of all studies included in the systematic review stratified by outcome of cytoreductive surgery. ${ }^{*} P<0.05$, NS non-significant, ? significance not mentioned in the paper, ${ }^{* *}$ Median overall survival based on Kaplan-Meier curve

Six studies showed significant, or likely significant, differences between optimal and suboptimal cytoreductive surgery ${ }^{6,19,20,22,24,26}$, while five studies showed no differences ${ }^{5,18,}$ 21,23,25. Two studies directly compared survival between optimal and suboptimal outcomes after ICS and both found no significant differences between patients with $0.1-1 \mathrm{~cm}$ and $>1 \mathrm{~cm}$ of residual disease ${ }^{18,25}$. Other studies did not compare suboptimal and optimal 
outcomes, but chose patients with no macroscopic residual disease as reference category. Based on the effect of the recalculated hazard ratios (without confidence intervals), two additional studies probably found no differences between suboptimal and optimal surgery $\left(\mathrm{HR}_{\text {optimal }} 1.10 \text { and } 1.01 \text { compared to suboptimal ICS, table } 2\right)^{5,23}$. Other studies probably found survival differences between suboptimal and optimal surgery, with recalculated HRs ranging from 0.37 to $0.58^{22,24,26}$. Two of the latter studies adjusted their survival models for age and FIGO stage with similar results 22,26 . For the remaining studies, HRs could not be recalculated due to missing data in the original manuscript $t^{6,18-21}$.

Table 2: Median overall survival and hazard ratios by outcome of cytoreductive surgery

\begin{tabular}{|c|c|c|c|c|c|c|}
\hline & \multicolumn{3}{|c|}{ Median overall survival (months) } & \multicolumn{3}{|c|}{ Hazard ratio } \\
\hline & Complete & Optimal & Suboptimal & Complete & Optimal & Suboptimal \\
\hline $\operatorname{Bian}^{18}$ & 33 & 25 & 18 & - & - & - \\
\hline Colombo ${ }^{19}$ & 49 & 20 & 14 & - & - & - \\
\hline Fagö-Olsen ${ }^{20}$ & 37 & 25 & 19 & - & - & - \\
\hline Iwase ${ }^{21 *}$ & 45 & 19 & 19 & - & - & - \\
\hline Kehoe $^{6}$ & 47 & 23 & 15 & - & - & - \\
\hline Markauskas 22 & 33 & 28 & 25 & 0.53 & 0.48 & reference \\
\hline $\operatorname{May}^{23} *$ & 41 & 31 & 27 & 0.70 & 1.10 & reference \\
\hline Muraji ${ }^{24}$ & 54 & 38 & 15 & 0.26 & 0.37 & reference \\
\hline Rosen $25 *$ & 38 & 27 & 26 & 0.56 & 0.79 & reference \\
\hline Rutten ${ }^{26}$ & 44 & 27 & 22 & 0.32 & 0.58 & reference \\
\hline Vergote ${ }^{5 \neq}$ & 38 & 27 & 26 & 0.65 & 1.01 & reference \\
\hline Mean & 41 & 27 & 21 & & & \\
\hline
\end{tabular}

* Median overall survival based on Kaplan-Meier curve ${ }^{\ddagger}$ Hazard ratio from univariable model, all others multivariable

\section{DISCUSSION}

In the current systematic review, we aimed to establish the prognostic effect of residual disease after NACT in advanced stage ovarian cancer patients. More specifically, we were interested if patients with $\leq 1 \mathrm{~cm}$ of residual disease had a survival benefit over patients with $>1 \mathrm{~cm}$ of residual disease. The included studies showed variable results, although mOS seems to be lengthened by optimal cytoreduction compared to suboptimal cytoreduction. Nevertheless, it is clear that complete cytoreductive surgery results in the most favorable survival outcomes. 
In an era of evidence-based medicine, it is remarkable that the therapeutic effect of surgical cytoreduction has never been studied in a RCT. The importance of cytoreduction to no macroscopic residual disease, however, has become widely accepted despite the lack of robust evidence from RCT's. The landmark studies of Griffiths et al. and Hoskins et al., who showed that improved survival outcomes were obtained after minimizing the amount of residual disease, contributed to the key role of cytoreduction in the primary treatment of ovarian cancer patients ${ }^{4,13,27-29}$. Again, in the current review of the literature, patients who underwent a complete cytoreductive surgery had the most favorable prognosis.

It is suggested that initial disease burden at diagnosis may be a more powerful determinant in the survival of ovarian cancer patients than the amount of residual disease after cytoreductive surgery ${ }^{30-32}$. This may be a reason to abandon radical surgical procedures such as diaphragmatic surgery and upper-abdominal organ resections, since extensive surgery may induce more severe morbidity and perhaps even mortality ${ }^{7,8}$. A large retrospective analysis of the GOG-182 study investigated the independent prognostic effect of disease scores in FIGO III and IV patients with no residual disease after cytoreductive surgery. This study confirmed that a high disease score at diagnosis, compared to patients with a low disease score at diagnosis, resulted in impaired survival, although both groups had no residual disease after surgical cytoreduction. The authors concluded that the amount of residual disease alone does not undo the survival impact of initial disease burden ${ }^{31}$. Another analysis of the same study population, however, showed that in patients with a high disease score, survival improved if complete cytoreduction was reached when compared to optimal surgical results ${ }^{33}$. So, although extent of the disease at diagnosis is an important prognostic factor for overall survival, it is not a valid argument to limit the efforts of achieving a complete surgical result.

Other studies have questioned whether the outcome of surgical cytoreduction primarily reflects surgical skills or tumor biology $\mathrm{y}^{30,32,34}$. A systematic review summarized the existing data of the relationship between biomarkers (such as protein expression, gene expression, copy-number alterations) and surgical outcomes ${ }^{35}$. There are some indications that tumor infiltrating lymphocytes, and specific gene profiles can predict surgical outcome ${ }^{35-37}$. The authors of the review, however, observed that the vast majority of studies used univariable statistical analysis, and if multivariable analysis was applied, most associations disappeared when incorporating confounders such as FIGO stage and histological subtype into their model. Moreover, even homogenous studies, consisting of advanced stage high-grade serous ovarian cancers, were unable to accurately predict surgical outcome ${ }^{38}$. So, although extensive disease and the possible interaction with tumor biology play a prognostic role in survival outcomes, it is not a definite predictor for successful surgery ${ }^{35,39}$. This finding 
is confirmed in studies that showed improved outcomes improve if surgery was executed by expert gynecologic-oncologists in high-volume hospitals ${ }^{40,41}$. Moreover, hospitals that incorporated systematic performance of radical upper abdominal surgery into their institutions obtained even better surgical- and survival outcomes ${ }^{42-46}$. This suggests that surgical skill can partly compensate for initial disease burden and it pleads for radical aggressive surgery in advanced ovarian cancer, although surgical morbidity should be incorporated in treatment decisions.

Earlier studies established that if complete cytoreductive surgery cannot be obtained, patients with $\leq 1 \mathrm{~cm}$ of residual disease had a favorable prognosis over patients with $>1 \mathrm{~cm}$ of residual disease after PCS ${ }^{47-50}$. In the current study, we showed that the prognostic effect of optimal over suboptimal surgery is variable between the included studies after NACT. Based on the weighted average analysis, patients with an optimal surgical result experienced a median survival advantage of six months over suboptimal debulked patients. Although this finding suggests that optimal ICS may be a surgical goal, we propose that surgical resection of all residual lesions should be pursued to establish the most optimal prognosis, especially as there is no convincing evidence that optimal cytoreductive surgery actually establishes an independent improvement for overall survival.

One of the possible explanations for the variable results may be the lack of initial surgical effort in patients with $>1 \mathrm{~cm}$ of residual disease, for example because gynecologists estimated that successful surgery was not feasible. It is likely that patients with no real effort to cytoreductive surgery experience decreased survival. The prognostic effect of initial effort has been demonstrated in randomized studies concerning second-look cytoreductive surgery (SCS). The study by van der Burg et al. randomized patients to SCS or no SCS after initial suboptimal PCS and three courses of subsequent chemotherapy. They found that the performance of SCS resulted in a median overall survival advantage of six months when compared to no $\mathrm{SCS}^{51}$. The consecutive randomized study of Rose, however, showed that SCS does not lengthen survival ${ }^{52}$. The main difference between the studies was the amount of residual disease present after the initial attempt to cytoreductive surgery ( $>5 \mathrm{~cm}$ residual disease in $77 \%$ versus $43 \%$ of all patients), and reflects the initial attempt towards no residual disease $\mathrm{e}^{51,52}$. It is unfortunately unknown if the selected studies in the current review included patients with an inadequate effort to cytoreductive surgery.

Another possible explanation may be that the amount of residual disease has been interpreted variably between studies. The amount of residual disease is hampered by its subjective character, and it has been shown that gynecologists easily underestimate the amount of residual disease ${ }^{53-55}$. In particular, chemotherapy-induced fibrosis may increase the variability, since lesions that appear to be benign may still contain vital 
tumor elements ${ }^{22,56}$. This results in insufficient surgery, and leads to an overestimation of patients who are successfully operated after NACT. The study of May et al. showed that intraperitoneal chemotherapy, most profound in case of no macroscopic residual disease, can improve overall survival when compared to standard intravenous chemotherapy ${ }^{23}$. This is in accordance to the recently published randomized study on the beneficial effect of hyperthermic intraperitoneal chemotherapy after NACT in the Netherlands ${ }^{57}$. The addition of intraoperative chemotherapy may eliminate microscopic disease, and therefore improve survival.

In most other tumor types, such as colorectal or breast cancer, the success of surgery is based on radical or irradical resections. From a biological point of view, radicality as prognostic factor seems to be more argumentative than the amount of residual disease as it is currently defined for ovarian cancer. An optimal surgical result, defined as $\leq 1 \mathrm{~cm}$ of residual disease in maximum diameter, comprises a variety of patients with possible differences in survival outcomes. An example is that patients with peritonitis carcinomatosis, and hence hundreds of minimal tumor spots, are categorized in the same group as patients with one spot of half a centimeter after surgical cytoreduction. The tumor volume of residual disease is therefore highly variable and the current definition may not represent true prognostic effects.

Following the recognition that an increasing amount of residual disease limits survival, it seems reasonable that a cut-off in the amount of macroscopic residual disease for the entire population may be prognostically relevant, but it should not set goals for surgical outcomes in advanced ovarian cancer. The aim should be to remove as much of the tumor as possible. In order to adjust survival models for possible confounders, macroscopic residual disease (yes or no), response to NACT, surgical aggressiveness, initial disease burden, and tumor volume could be integrated into these models to predict survival outcomes more accurately. These aspects should therefore be incorporated in future studies to compare outcomes more easily.

The observation that survival outcomes after complete cytoreductive surgery are comparable between PCS and NACT-ICS, while they are different between optimal PCS and NACT-ICS, may be related to induced platinum resistance after $\mathrm{NACT}^{10}$. It is possible that an interruption in chemotherapy administration may give the remaining, still vital, tumor cells the chance to protect themselves against subsequent adjuvant platinum-based chemotherapy. The administration of six cycles of NACT followed by cytoreductive surgery with no subsequent post-operative chemotherapy, comparable to gastro-intestinal and breast cancer, might be one of the options to increase chemotherapy dose before surgery and to avoid an additional delay in chemotherapy administration. 
There are a number of limitations in the current summary of the literature. Some studies were rather small, especially in their numbers of optimal and suboptimal cytoreductive surgeries, which limits their influence in the mOS rates for all studies combined. Moreover the natural selection for either PCS or NACT-ICS inherently influences survival, as the number of patients who were included in the studies and underwent NACT ranged between $20 \%$ and $67 \%$. And finally, the surgical skills of gynecologists-oncologist plays a prominent factor in achieving the best surgical result, and this varies between studies which makes the comparison more complex.

Despite these limitations, we showed that patients with no residual disease after ICS experience the most favorable survival compared to patients with macroscopic residual disease. The additional prognostic effect of optimal versus suboptimal cytoreductive surgery probably lengthens survival but macroscopic residual disease of any diameter should not be the goal for cytoreductive surgery. Future prospective studies should include initial disease burden and extent of surgery to establish the prognostic effect of surgical outcome.

\section{Funding}

This work was supported by Dutch Cancer Society [IKNL2014-6838]. 


\section{REFERENCES}

1. Sant $M$, Chirlaque Lopez MD, Agresti R, Sanchez Perez MJ, Holleczek B, Bielska-Lasota $M$, et al. Survival of women with cancers of breast and genital organs in europe 19992007: Results of the eurocare- 5 study. Eur J Cancer. 2015;51(15):2191-205.

2. Torre LA, Trabert B, DeSantis CE, Miller KD, Samimi G, Runowicz CD, et al. Ovarian cancer statistics, 2018. CA Cancer J Clin. 2018.

3. Bristow RE, Tomacruz RS, Armstrong DK, Trimble EL, Montz FJ. Survival effect of maximal cytoreductive surgery for advanced ovarian carcinoma during the platinum era: A meta-analysis. J Clin Oncol. 2002;20(5):1248-59.

4. Chang SJ, Hodeib M, Chang J, Bristow RE. Survival impact of complete cytoreduction to no gross residual disease for advancedstage ovarian cancer: A meta-analysis. Gynecol Oncol. 2013;130(3):493-8.

5. Vergote I, Trope CG, Amant F, Kristensen $\mathrm{GB}$, Ehlen $\mathrm{T}$, Johnson $\mathrm{N}$, et al. Neoadjuvant chemotherapy or primary surgery in stage iiic or iv ovarian cancer. N Engl J Med. 2010;363(10):943-53.

6. Kehoe S, Hook J, Nankivell M, Jayson GC, Kitchener $H$, Lopes $T$, et al. Primary chemotherapy versus primary surgery for newly diagnosed advanced ovarian cancer (chorus): An open-label, randomised, controlled, non-inferiority trial. Lancet. 2015;386(9990):249-57.

7. Fagotti A, Ferrandina G, Vizzielli G, Fanfani F, Gallotta V, Chiantera V, et al. Phase iii randomised clinical trial comparing primary surgery versus neoadjuvant chemotherapy in advanced epithelial ovarian cancer with high tumour load (scorpion trial): Final analysis of peri-operative outcome. Eur J Cancer. 2016;59:22-33.
8. Yang $L$, Zhang $B$, Xing $G$, Du J, Yang B, Yuan $Q$, et al. Neoadjuvant chemotherapy versus primary debulking surgery in advanced epithelial ovarian cancer: A meta-analysis of peri-operative outcome. PLoS One. 2017;12(10):e0186725.

9. Kang $\mathrm{S}$, Nam BH. Does neoadjuvant chemotherapy increase optimal cytoreduction rate in advanced ovarian cancer? Meta-analysis of 21 studies. Ann Surg Oncol. 2009;16(8):2315-20.

10. Meyer LA, Cronin AM, Sun CC, Bixel K, Bookman MA, Cristea MC, et al. Use and effectiveness of neoadjuvant chemotherapy for treatment of ovarian cancer. Journal of Clinical Oncology. 2016;34(32):3854-63.

11. Chi DS, Eisenhauer EL, Lang J, Huh J, Haddad $L$, Abu-Rustum NR, et al. What is the optimal goal of primary cytoreductive surgery for bulky stage iiic epithelial ovarian carcinoma (eoc)? Gynecol Oncol. 2006;103(2):559-64.

12. Eisenkop SM, Spirtos NM. What are the current surgical objectives, strategies, and technical capabilities of gynecologic oncologists treating advanced epithelial ovarian cancer? Gynecol Oncol. 2001;82(3):489-97.

13. Hoskins WJ, McGuire WP, Brady MF, Homesley HD, Creasman WT, Berman $M$, et al. The effect of diameter of largest residual disease on survival after primary cytoreductive surgery in patients with suboptimal residual epithelial ovarian carcinoma. Am J Obstet Gynecol. 1994;170(4):974-9; discussion 9-80.

14. Moher D, Liberati A, Tetzlaff J, Altman DG, Group P. Preferred reporting items for systematic reviews and meta-analyses: The prisma statement. PLoS Med. 2009;6(7):e1000097. 
15. Liberati A, Altman DG, Tetzlaff J, Mulrow C, Gotzsche PC, loannidis JP, et al. The prisma statement for reporting systematic reviews and meta-analyses of studies that evaluate health care interventions: Explanation and elaboration. PLoS Med. 2009;6(7):e1000100.

16. Wells GA, Shea B, O'Connell D, Peterson J, Welch $\mathrm{V}$, Losos $\mathrm{M}$, et al. The newcastleottawa scale (nos) for assessing the quality of nonrandomised studies in meta-analyses (2018). Http://www.Ohri.Ca/programs/ clinical_epidemiology/oxford.Asp.

17. Collaboration TC. The cochrane risk of bias tool (2018). Https://methods.Cochrane. Org/bias/assessing-risk-bias-includedstudies\#the $\% 20$ cochrane $\% 20$ risk $\% 20$ of\%20bias\%20tool.

18. Bian C, Yao K, Li L, Yi T, Zhao X. Primary debulking surgery vs. Neoadjuvant chemotherapy followed by interval debulking surgery for patients with advanced ovarian cancer. Archives of Gynecology and Obstetrics. 2016;293(1):163-8.

19. Colombo PE, Mourregot A, Fabbro M, Gutowski M, Saint-Aubert B, Quenet F, et al. Aggressive surgical strategies in advanced ovarian cancer: A monocentric study of 203 stage iiic and iv patients. European Journal of Surgical Oncology. 2009;35(2):135-43.

20. Fago-Olsen $\mathrm{CL}$, Ottesen $\mathrm{B}$, Kehlet $\mathrm{H}$, Antonsen SL, Christensen IJ, Markauskas $A$, et al. Does neoadjuvant chemotherapy impair long-term survival for ovarian cancer patients? A nationwide danish study. 2014;132(2):292-8.

21. Iwase H, Takada T, litsuka C, Nomura $\mathrm{H}$, Abe A, Taniguchi $\mathrm{T}$, et al. Clinical significance of systematic retroperitoneal lymphadenectomy during interval debulking surgery in advanced ovarian cancer patients. Journal of Gynecologic Oncology. 2015;26(4):303-10.
22. Markauskas A, Mogensen O, Christensen $\mathrm{RD}$, Jensen PT. Primary surgery or interval debulking for advanced epithelial ovarian cancer: Does it matter? International Journal of Gynecological Cancer. 2014;24(8):14208.

23. May T, Comeau R, Sun P, Kotsopoulos J, Narod SA, Rosen B, et al. Comparison of survival outcomes in advanced serous ovarian cancer patients treated with primary debulking surgery versus neoadjuvant chemotherapy. International Journal of Gynecological Cancer. 2017;27(4):668-74.

24. Muraji M, Sudo $T$, Iwasaki S, Ueno S, Wakahashi S, Yamaguchi S, et al. Histopathology predicts clinical outcome in advanced epithelial ovarian cancer patients treated with neoadjuvant chemotherapy and debulking surgery. 2013;131(3):531-4.

25. Rosen B, Laframboise S, Ferguson S, Dodge J, Bernardini M, Murphy J, et al. The impacts of neoadjuvant chemotherapy and of debulking surgery on survival from advanced ovarian cancer. 2014;134(3):4627.

26. Rutten MJ, Sonke GS, Westermann AM, van Driel WJ, Trum JW, Kenter GG, et al. Prognostic value of residual disease after interval debulking surgery for figo stage iiic and iv epithelial ovarian cancer. Obstet Gynecol Int. 2015;2015:464123.

27. Griffiths CT. Surgical resection of tumor bulk in the primary treatment of ovarian carcinoma. Natl Cancer Inst Monogr. 1975;42:101-4.

28. Stuart $G C$, Kitchener $H$, Bacon $M$, duBois A, Friedlander $M$, Ledermann J, et al. 2010 gynecologic cancer intergroup (gcig) consensus statement on clinical trials in ovarian cancer: Report from the fourth ovarian cancer consensus conference. Int J Gynecol Cancer. 2011;21(4):750-5. 
29. Elattar A, Bryant A, Winter-Roach BA, Hatem M, Naik R. Optimal primary surgical treatment for advanced epithelial ovarian cancer. Cochrane Database Syst Rev. 2011(8):CD007565.

30. Crawford SC, Vasey PA, Paul J, Hay A, Davis JA, Kaye SB. Does aggressive surgery only benefit patients with less advanced ovarian cancer? Results from an international comparison within the scotroc-1 trial. J Clin Oncol. 2005;23(34):8802-11.

31. Horowitz NS, Miller A, Rungruang B, Richard $\mathrm{SD}$, Rodriguez N, Bookman MA, et al. Does aggressive surgery improve outcomes? Interaction between preoperative disease burden and complex surgery in patients with advanced-stage ovarian cancer: An analysis of gog 182. J Clin Oncol. 2015;33(8):937-43.

32. Chang SJ, Bristow RE, Chi DS, Cliby WA. Role of aggressive surgical cytoreduction in advanced ovarian cancer. J Gynecol Oncol. 2015;26(4):336-42.

33. Rodriguez N, Miller A, Richard SD, Rungruang B, Hamilton CA, Bookman MA, et al. Upper abdominal procedures in advanced stage ovarian or primary peritoneal carcinoma patients with minimal or no gross residual disease: An analysis of gynecologic oncology group (gog) 182. Gynecol Oncol. 2013;130(3):487-92.

34. Chi DS, Schwartz PE. Cytoreduction vs. Neoadjuvant chemotherapy for ovarian cancer. Gynecol Oncol. 2008;111(3):391-9.

35. Borley J, Wilhelm-Benartzi C, Brown R, Ghaem-Maghami S. Does tumour biology determine surgical success in the treatment of epithelial ovarian cancer? A systematic literature review. $\mathrm{Br} J$ Cancer. 2012;107(7):1069-74.

36. Barnett JC, Bean SM, Whitaker RS, Kondoh E, Baba T, Fujii S, et al. Ovarian cancer tumor infiltrating t-regulatory (t(reg)) cells are associated with a metastatic phenotype. Gynecol Oncol. 2010;116(3):556-62.
37. Berchuck A, Iversen ES, Lancaster JM, Dressman HK, West M, Nevins JR, et al. Prediction of optimal versus suboptimal cytoreduction of advanced-stage serous ovarian cancer with the use of microarrays. Am J Obstet Gynecol. 2004;190(4):910-25.

38. Bonome T, Levine DA, Shih J, Randonovich $M$, Pise-Masison CA, Bogomolniy F, et al. A gene signature predicting for survival in suboptimally debulked patients with ovarian cancer. Cancer Res. 2008;68(13):5478-86.

39. Bowtell DD. The genesis and evolution of high-grade serous ovarian cancer. Nat Rev Cancer. 2010;10(11):803-8.

40. Vernooij F, Heintz P, Witteveen E, van der Graaf Y. The outcomes of ovarian cancer treatment are better when provided by gynecologic oncologists and in specialized hospitals: A systematic review. Gynecol Oncol. 2007;105(3):801-12.

41. Woo YL, Kyrgiou M, Bryant A, Everett T, Dickinson HO. Centralisation of services for gynaecological cancers - a cochrane systematic review. Gynecol Oncol. 2012;126(2):286-90.

42. Harter P, Muallem ZM, Buhrmann C, Lorenz D, Kaub C, Hils R, et al. Impact of a structured quality management program on surgical outcome in primary advanced ovarian cancer. Gynecol Oncol. 2011;121(3):615-9.

43. Chi DS, Eisenhauer EL, Zivanovic O, Sonoda Y, Abu-Rustum NR, Levine DA, et al. Improved progression-free and overall survival in advanced ovarian cancer as a result of a change in surgical paradigm. Gynecol Oncol. 2009;114(1):26-31.

44. Aletti GD, Dowdy SC, Gostout BS, Jones MB, Stanhope CR, Wilson TO, et al. Aggressive surgical effort and improved survival in advanced-stage ovarian cancer. Obstet Gynecol. 2006;107(1):77-85. 
45. Chang SJ, Bristow RE, Ryu HS. Impact of complete cytoreduction leaving no gross residual disease associated with radical cytoreductive surgical procedures on survival in advanced ovarian cancer. Ann Surg Oncol. 2012;19(13):4059-67.

46. Luyckx $M$, Leblanc $E$, Filleron $T$, Morice P, Darai E, Classe JM, et al. Maximal cytoreduction in patients with figo stage iiic to stage iv ovarian, fallopian, and peritoneal cancer in day-to-day practice: A retrospective french multicentric study. International Journal of Gynecological Cancer. 2012;22(8):1337-43.

47. Chiva LM, Castellanos T, Alonso S, GonzalezMartin A. Minimal macroscopic residual disease $(0.1-1 \mathrm{~cm})$. Is it still a surgical goal in advanced ovarian cancer? Int J Gynecol Cancer. 2016;26(5):906-11.

48. Bookman MA, Brady MF, McGuire WP, Harper PG, Alberts DS, Friedlander $M$, et al. Evaluation of new platinum-based treatment regimens in advanced-stage ovarian cancer: A phase iii trial of the gynecologic cancer intergroup. J Clin Oncol. 2009;27(9):1419-25.

49. Rauh-Hain JA, Nitschmann CC, Worley MJ, Jr., Bradford LS, Berkowitz RS, Schorge JO, et al. Platinum resistance after neoadjuvant chemotherapy compared to primary surgery in patients with advanced epithelial ovarian carcinoma. Gynecol Oncol. 2013;129(1):638.

50. Winter WE, 3rd, Maxwell GL, Tian C, Carlson JW, Ozols RF, Rose PG, et al. Prognostic factors for stage iii epithelial ovarian cancer: A gynecologic oncology group study. J Clin Oncol. 2007;25(24):3621-7.

51. van der Burg $M E$, van Lent $M$, Buyse $M$, Kobierska A, Colombo N, Favalli G, et al. The effect of debulking surgery after induction chemotherapy on the prognosis in advanced epithelial ovarian cancer. Gynecological cancer cooperative group of the european organization for research and treatment of cancer. N Engl J Med. 1995;332(10):629-34.
52. Rose PG, Nerenstone S, Brady MF, Clarke-Pearson D, Olt G, Rubin SC, et al. Secondary surgical cytoreduction for advanced ovarian carcinoma. N Engl J Med. 2004;351(24):2489-97.

53. Chi DS, Ramirez PT, Teitcher JB, Mironov S, Sarasohn DM, Iyer RB, et al. Prospective study of the correlation between postoperative computed tomography scan and primary surgeon assessment in patients with advanced ovarian, tubal, and peritoneal carcinoma reported to have undergone primary surgical cytoreduction to residual disease $1 \mathrm{~cm}$ or less. J Clin Oncol. 2007;25(31):4946-51.

54. Lakhman $Y$, Akin O, Sohn MJ, Zheng J, Moskowitz CS, lyer RB, et al. Early postoperative ct as a prognostic biomarker in patients with advanced ovarian, tubal, and primary peritoneal cancer deemed optimally debulked at primary cytoreductive surgery. AJR Am J Roentgenol. 2012;198(6):1453-9.

55. Eskander RN, Kauderer J, Tewari KS, Mannel RS, Bristow RE, O'Malley DM, et al. Correlation between surgeon's assessment and radiographic evaluation of residual disease in women with advanced stage ovarian cancer reported to have undergone optimal surgical cytoreduction: An nrg oncology/gynecologic oncology group study. Gynecol Oncol. 2018.

56. Hynninen J, Lavonius M, Oksa S, Grenman S, Carpen O, Auranen A. Is perioperative visual estimation of intra-abdominal tumor spread reliable in ovarian cancer surgery after neoadjuvant chemotherapy? Gynecol Oncol. 2013;128(2):229-32.

57. van Driel WJ, Koole SN, Sikorska K, Schagen van Leeuwen JH, Schreuder HWR, Hermans $\mathrm{RHM}$, et al. Hyperthermic intraperitoneal chemotherapy in ovarian cancer. N Engl J Med. 2018;378(3):230-40. 


\section{SUPPLEMENTARY MATERIAL}

S1: PRISMA checklist

\begin{tabular}{|c|c|c|c|}
\hline Section/topic & $\#$ & Checklist item & $\begin{array}{l}\text { Reported } \\
\text { on page \# }\end{array}$ \\
\hline \multicolumn{4}{|l|}{ TITLE } \\
\hline Title & 1 & $\begin{array}{l}\text { Identify the report as a systematic review, meta-analysis, or } \\
\text { both. }\end{array}$ & 1 \\
\hline \multicolumn{4}{|l|}{ ABSTRACT } \\
\hline Structured summary & 2 & $\begin{array}{l}\text { Provide a structured summary including, as applicable: } \\
\text { background; objectives; data sources; study eligibility } \\
\text { criteria, participants, and interventions; study appraisal and } \\
\text { synthesis methods; results; limitations; conclusions and } \\
\text { implications of key findings; systematic review registration } \\
\text { number. }\end{array}$ & $2-3$ \\
\hline
\end{tabular}

\section{INTRODUCTION}

Rationale

Objectives
3 Describe the rationale for the review in the context of what is already known.

4 Provide an explicit statement of questions being addressed with reference to participants, interventions, comparisons, outcomes, and study design (PICOS).

\section{METHODS}

Protocol and registration

Eligibility criteria

Information sources

Search

Study selection

Data collection process

Data items

Risk of bias in individual studies
5 Indicate if a review protocol exists, if and where it can be accessed (e.g., Web address), and, if available, provide registration information including registration number.

6 Specify study characteristics (e.g., PICOS, length of follow-up) and report characteristics (e.g., years considered, language, publication status) used as criteria for eligibility, giving rationale.

7 Describe all information sources (e.g., databases with dates of coverage, contact with study authors to identify additional studies) in the search and date last searched.

8 Present full electronic search strategy for at least one database, including any limits used, such that it could be repeated.

9 State the process for selecting studies (i.e., screening, eligibility, included in systematic review, and, if applicable, included in the meta-analysis).

10 Describe method of data extraction from reports (e.g., piloted forms, independently, in duplicate) and any processes for obtaining and confirming data from investigators.

11 List and define all variables for which data were sought (e.g., PICOS, funding sources) and any assumptions and simplifications made.

12 Describe methods used for assessing risk of bias of individual studies (including specification of whether this was done at the study or outcome level), and how this information is to be used in any data synthesis. 


\begin{tabular}{|c|c|c|c|}
\hline Section/topic & $\#$ & Checklist item & $\begin{array}{l}\text { Reported } \\
\text { on page \# }\end{array}$ \\
\hline Summary measures & 13 & $\begin{array}{l}\text { State the principal summary measures (e.g., risk ratio, } \\
\text { difference in means). }\end{array}$ & 5 \\
\hline Synthesis of results & 14 & $\begin{array}{l}\text { Describe the methods of handling data and combining } \\
\text { results of studies, if done, including measures of consistency } \\
(\text { e.g., I') for each meta-analysis. }\end{array}$ & 5 \\
\hline Risk of bias across studies & 15 & $\begin{array}{l}\text { Specify any assessment of risk of bias that may affect } \\
\text { the cumulative evidence (e.g., publication bias, selective } \\
\text { reporting within studies). }\end{array}$ & 5 \\
\hline Additional analyses & 16 & $\begin{array}{l}\text { Describe methods of additional analyses (e.g., sensitivity } \\
\text { or subgroup analyses, meta-regression), if done, indicating } \\
\text { which were pre-specified. }\end{array}$ & 5 \\
\hline
\end{tabular}

\section{RESULTS}

Study selection

Study characteristics

Risk of bias within studies

Results of individual studies

Synthesis of results

Risk of bias across studies

Additional analysis
17 Give numbers of studies screened, assessed for eligibility, and included in the review, with reasons for exclusions at each stage, ideally with a flow diagram.

18 For each study, present characteristics for which data were extracted (e.g., study size, PICOS, follow-up period) and provide the citations.

19 Present data on risk of bias of each study and, if available, any outcome level assessment (see item 12).

20 For all outcomes considered (benefits or harms), present, for each study: (a) simple summary data for each intervention group (b) effect estimates and confidence intervals, ideally

Figure 2 with a forest plot.

21 Present results of each meta-analysis done, including confidence intervals and measures of consistency.

N.A.

22 Present results of any assessment of risk of bias across studies (see Item 15).

23 Give results of additional analyses, if done (e.g., sensitivity or subgroup analyses, meta-regression [see Item 16]).

Table 2

\section{DISCUSSION}

Summary of evidence

24 Summarize the main findings including the strength of evidence for each main outcome; consider their relevance to key groups (e.g., healthcare providers, users, and policy makers).

Limitations

25 Discuss limitations at study and outcome level (e.g., risk of bias), and at review-level (e.g., incomplete retrieval of identified research, reporting bias).

26 Provide a general interpretation of the results in the context of other evidence, and implications for future research.

7-10

Conclusions

\section{FUNDING}

Funding

27 Describe sources of funding for the systematic review and other support (e.g., supply of data); role of funders for the systematic review. 
(((/(“Ovarian Neoplasms”[Mesh]) OR (((ovar*[tiab] AND (neoplas*[tiab] OR cancer*[tiab] OR carcin*[tiab] OR tumor*[tiab] OR tumour*[tiab] OR metasta*[tiab] OR malig*[tiab] OR "Neoplasms"[Mesh])))) OR ((“Ovary”[Mesh] AND (neoplas*[tiab] OR cancer*[tiab] OR carcin*[tiab] OR tumor*[tiab] OR tumour*[tiab] OR metasta*[tiab] OR malig*[tiab] OR “Neoplasms"[Mesh]))))) AND (((((surg*[tiab] OR "Surgical Procedures, Operative"[Mesh])))) AND ((debulking[tiab] OR cytoreductive[tiab] OR debulking[tiab] OR cytoreductive[tiab])))) AND ((((“Neoadjuvant Therapy"[Mesh]) OR “Antineoplastic Agents"[Mesh]) OR ((chemotherap*[tiab] AND (primary[tiab] OR neoadjuvant[tiab])))))

S2: Systematic search in Medline 


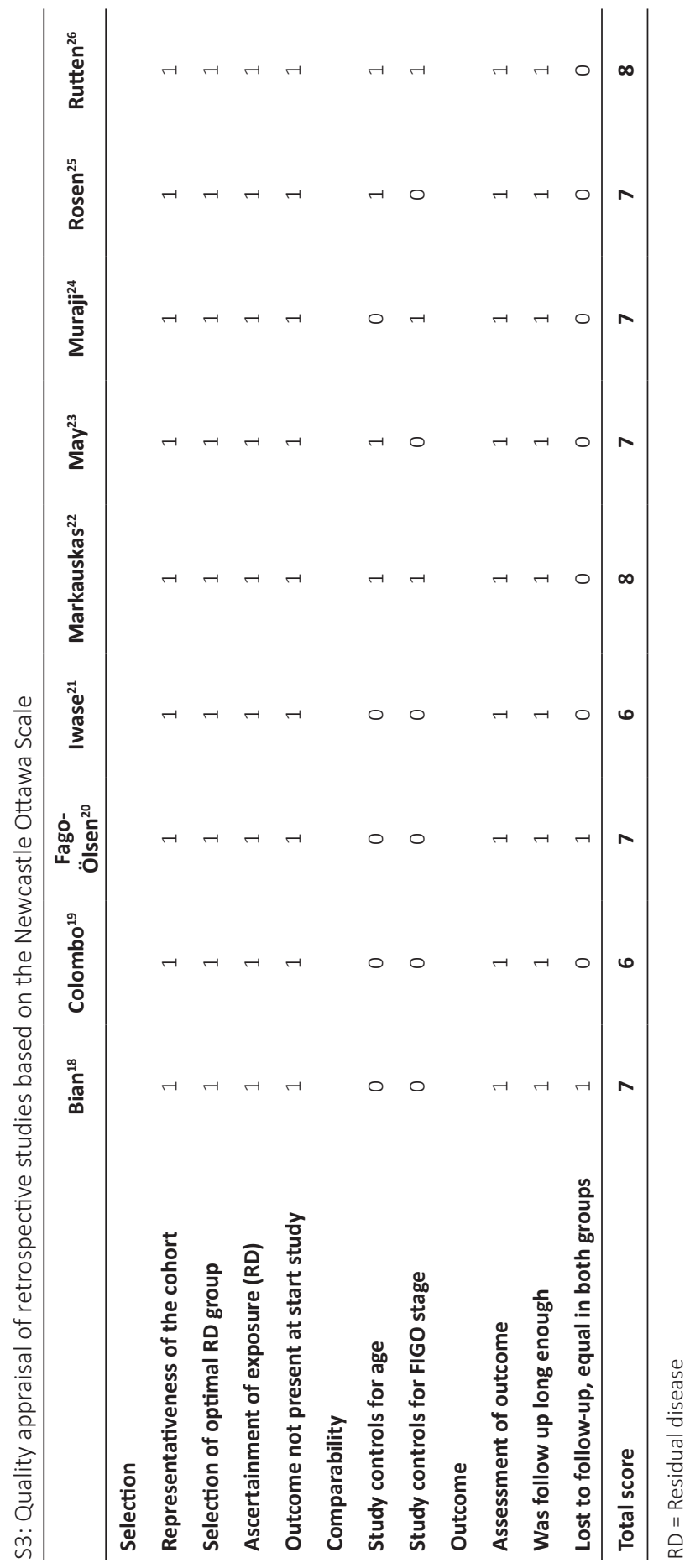


S4: Quality appraisal of the EORTC ${ }^{5}$ trial based on Cochrane Risk of Bias Assessment tool

\begin{tabular}{|c|c|c|}
\hline Domain & Qualification & Additional comments \\
\hline Random sequence generation & Low & $\begin{array}{l}\text { Use of a minimization technique to stratify for } \\
\text { important predictors; such as institution, FIGO } \\
\text { stage and largest preoperative tumor size }\end{array}$ \\
\hline Allocation concealment & Low & Centrally performed at EORTC headquarters \\
\hline Selective reporting & Low & $\begin{array}{l}\text { Study protocol is available as supplementary file at } \\
\text { the NEJM site, and the outcomes are reported as } \\
\text { intended }\end{array}$ \\
\hline Blinding of participants and personnel & High & $\begin{array}{l}\text { Patients and physicians are obviously aware of the } \\
\text { allocated treatment }\end{array}$ \\
\hline Blinding of outcome assessment & Low & $\begin{array}{l}\text { No blinding of the outcome assessment, but this is } \\
\text { not likely to influence the reported } \\
\text { outcomes (OS is primary endpoint, and can hardly } \\
\text { be influenced) }\end{array}$ \\
\hline Incomplete outcome data & Low & $\begin{array}{l}\text { In all analyses, the number of missing data are } \\
\text { (mostly) equally distributed, and is clearly reported } \\
\text { in tables and text (also in supplementary data) }\end{array}$ \\
\hline Other sources of bias & Low & No other biases detected \\
\hline Total quality of RCTs & Good quality & $\begin{array}{l}\text { Even though blinding was not possible in this } \\
\text { study, it is unlikely that it affected the main } \\
\text { outcomes. }\end{array}$ \\
\hline
\end{tabular}

S5: Quality appraisal of the $\mathrm{CHORUS}^{6}$ trial based on Cochrane Risk of Bias Assessment tool

\begin{tabular}{|c|c|c|}
\hline Domain & Qualification & Additional comments \\
\hline Random sequence generation & Low & $\begin{array}{l}\text { Use of a minimization method with a random } \\
\text { element, and stratified according to center, largest } \\
\text { tumor size, clinical FIGO stage and prespecified } \\
\text { chemotherapy regimen }\end{array}$ \\
\hline Allocation concealment & Low & Centrally by telephone, in a 1:1 randomization \\
\hline Selective reporting & Low & $\begin{array}{l}\text { Study protocol is available on the ISRCTN site, and } \\
\text { the outcomes are reported as intended }\end{array}$ \\
\hline Blinding of participants and personnel & High & $\begin{array}{l}\text { Patients and physicians were obviously aware of } \\
\text { the allocated treatment }\end{array}$ \\
\hline Blinding of outcome assessment & Low & $\begin{array}{l}\text { No blinding of the outcome assessment, but this is } \\
\text { not likely to influence the reported outcomes (OS } \\
\text { is primary endpoint, and can hardly be influenced) }\end{array}$ \\
\hline Incomplete outcome data & Low & $\begin{array}{l}\text { In all analyses, the number of missing data are } \\
\text { (mostly) equally distributed, and are clearly } \\
\text { reported. The number of patients with unknown } \\
\text { residual disease, being the most important } \\
\text { prognostic factor, is however rather high (8-9\% in } \\
\text { both groups) }\end{array}$ \\
\hline Other sources of bias & Low & No other biases detected \\
\hline Total quality of RCTs & Good quality & $\begin{array}{l}\text { Even though blinding was not possible in this } \\
\text { study, it is unlikely that it affected the main } \\
\text { outcomes. }\end{array}$ \\
\hline
\end{tabular}




11

Summary 

In the present chapter, the most important conclusions of this thesis are summarised. In part I we focused on the on differences in treatment patterns and survival outcomes. In part II we aimed to get insight into prognostic factors that affect clinical outcomes, and in the last part of this thesis, we highlighted the importance of patient selection for the primary treatment of ovarian cancer.

\section{PART I: SURVIVAL AND TREATMENT OF PRIMARY OVARIAN CANCER IN THE NETHERLANDS}

The vast majority of ovarian cancer patients is diagnosed with advanced stage disease. The combination of treatment consists of cytoreductive surgery and platinum-based chemotherapy. Over the last years, the timing of surgery became a subject of a heated debate, and neoadjuvant chemotherapy followed by interval cytoreductive surgery (NACTICS) is nowadays a reasonable alternative to primary cytoreductive surgery (PCS) for patients with advanced stage disease (FIGO IIIC and IV).

In chapter $\mathbf{2}$ we observed that more patients with advanced stage disease were treated according to contemporary guidelines with a combination of cytoreductive surgery and platinum-based chemotherapy (55\% in 1989-1993 to 67\% in 2009-2014). In addition, PCS was initially preferred as first-line treatment (65\% in 2004-2008), while in the most recent period, NACT-ICS was more frequently used compared to PCS (57\% in 2009-2014). Simultaneously, the outcome of cytoreductive surgery increased over time as well. Despite all these efforts in intensifying treatment, long-term survival has, however, not improved in the last 25 years. The lack of improvements in long-term survival urges us to put major efforts into improving cure rates for women with EOC.

Comparable to other tumour types, centralisation of surgical care has been proposed to improve surgical outcomes and, hence, survival rates for ovarian cancer. In chapter $\mathbf{3}$ we studied whether the hospital of diagnosis influenced the probability to surgical treatment. Centralisation of surgical care was initiated in two stages in the Netherlands. Firstly, registered gynaecological-oncologists were consulted to perform surgery together with regular gynaecologists in smaller hospitals. Secondly, a national consensus was reached to restrict the performance of surgery to hospitals which carried out a minimum of twenty cytoreductive surgeries on an annual basis. At baseline, the hospital of diagnosis was independently associated with the probability to surgical treatment. The first initiatives to centralisation already resulted in a decrease in hospital variation, although the initial hospital of diagnosis still significantly influenced treatment decisions. After a national consensus was reached, we observed no association between the initial hospital of 
diagnosis and the likelihood to surgical treatment anymore. This finding underscores that centralisation does not only contribute to improved surgical outcomes, but also to a more coherent treatment policy across individual hospitals.

In chapter 4 we aimed to describe treatment variation and its effect on patient outcome between geographical regions in the Netherlands. Overall, the percentage of patients that received no therapy did not differ between the geographical regions, while the percentage of patients that received chemotherapy in combination with cytoreductive surgery did differ significantly (range 61-71\%). In addition, the use of PCS and NACT-ICS differed significantly between regions and could not be (fully) explained by differences in patient populations (PCS: 24-48\%, NACT-ICS: 44-70\% and PCS+NACT-ICS: 5-13\%). Moreover, the probability of complete cytoreductive surgery was significantly associated with treatment region, even when accounting for possible confounders (including treatment sequence). This variation resulted in survival differences between geographical regions for patients that received either PCS or NACT-ICS. Survival of patients was the lowest in the region with the lowest number of complete cytoreductive surgeries. However, when all patients were analysed together (including those with no or limited therapy), survival was comparable between all regions. Patient selection to those who benefit from cytoreductive surgery and chemotherapy may explain this discrepancy, and this selection process may differ between regions.

\section{PART II: PROGNOSTIC FACTORS THAT AFFECT SURVIVAL IN OVARIAN CANCER PATIENTS}

The outcome of cytoreductive surgery is one of the most important factors for prolonged overall survival, while it is hampered by the surgeons' intraoperative assessment and therefore subject to inter- and intra-observer variability. In chapter $\mathbf{5}$ we searched for an objective prognostic factor to predict survival outcomes of patients who underwent PCS more accurately. We showed that the relative perioperative decline in CA125 is an independent prognostic factor for prolonged overall survival. This prognostic effect was also observed in patients with the same amount of residual disease, suggesting the need for a complementary model to predict clinical outcome more accurately in advanced ovarian cancer patients.

To prolong survival in advanced ovarian cancer, adjuvant chemotherapy is recommend after both primary and interval cytoreductive surgery. Currently, there is no advise about the optimal time interval between cytoreductive surgery and subsequent platinum-based chemotherapy. It is assumed that commencement of adjuvant chemotherapy should 
be initiated as soon as possible, as this may prevent early tumour growth within the before mentioned time interval. In chapter 6 we showed, predominantly after complete cytoreductive surgery, that delayed initiation of chemotherapy was associated with impaired overall survival after both PCS and NACT-ICS. Consequently, we advise to start adjuvant chemotherapy within the first five to six weeks after cytoreductive surgery.

The FIGO staging system was updated in 2014. This new classification distinguishes between patients with malignant pleural effusion (FIGO IVa), and patients with all other (extra)abdominal metastases (FIGO IVb). In chapter $\mathbf{7}$ we found that this new classification did not provide additional prognostic information, as survival was similar between FIGO IVa and FIGO IVb patients. Patients with extra-abdominal lymph node metastases as only site of distant disease, however, had the most favourable survival of all FIGO IV patients, and may suggest the need for another FIGO classification. In addition, we showed that NACT-ICS is probably the preferred treatment approach in FIGO IV patients. We observed comparable survival rates between PCS and NACT-ICS. and other studies already showed that postoperative complications were lower after NACT-ICS. However, we may have identified a subgroup of selected patients that may benefit from PCS over NACT-ICS. In a sensitivity analysis that excluded patients that died shortly after PCS in order to overcome immortal time bias, a more favourable outcome was observed in patients with FIGO IVa disease. Unfortunately, the number of FIGO IVa patients who underwent PCS is limited in our cohort. Moreover, PCS can only be beneficial if patients that die shortly after this extensive procedure could be identified pre-operatively.

\section{PART III: OPTIMISING PATIENT SELECTION FOR PRIMARY SURGERY OF CHEMOTHERAPY}

In chapter 8 we evaluated the current opinions of Dutch gynaecologists and medical oncologists. In total 167 participants responded to our survey. Among the responders, 82\% and gynaecologists and 93\% of medical oncologists adopted NACT-ICS as an alternative treatment approach. Moreover, even 62\% of medical oncologists preferred NACT-ICS to PCS as first line treatment, while only $33 \%$ of gynaecologists preferred NACT-ICS. The decision to schedule patients for PCS seems to depend on the probability of successful surgery in the primary setting. This emphasises the great importance of our selection processes to ensure that every patient undergoes the most optimal treatment.

It is thought that survival outcomes of advanced ovarian cancer patients can be improved through optimal patient selection. Observational data suggest that patients with no residual disease after PCS have the best survival outcomes compared to all other treatment 
groups. The decision to schedule patient for PCS is therefore, among others, based on the probability to complete cytoreductive surgery. However, it is well known that predicting the outcome of surgery is inaccurate. Therefore, we developed a prediction model to estimate the probability to achieve no macroscopic residual disease at primary surgery for advanced ovarian cancer patients (FIGO IIIC and IV) in chapter 9. This model was based on simple baseline characteristics and may improve patient selection in clinical daily practice after external validation of our model.

The probability to complete cytoreductive surgery increases after NACT, while this does not translate into prolonged survival rates. Moreover, randomised data suggest that there is no difference between optimal $(0.1-1.0 \mathrm{~cm}$ of residual disease) and suboptimal $(>1 \mathrm{~cm}$ of residual disease) cytoreductive surgery after NACT. This indicates that the prognostic effect of surgical outcomes is different when NACT is applied. In chapter 10, we summarised the currently available literature about the prognostic effect of surgical outcomes after NACT-ICS. We observed that patients with no residual disease after NACTICS had the best survival rates, comparable to PCS. The prognostic effect of optimal versus suboptimal cytoreduction, however, varied between the included studies. Based on a weighted average analysis, a six-month survival advantage was observed in case of an optimal outcome compared to a suboptimal outcome. The additional prognostic effect of optimal versus suboptimal cytoreductive surgery probably lengthens survival in the whole population, but macroscopic residual disease of any diameter should be avoided during interval cytoreductive surgery. 


12

Discussion 

In this thesis, we aimed to gain insight into factors that affect clinical outcomes of advanced ovarian cancer patients. In the present chapter, observed outcomes and future perspectives are discussed.

\section{PART I: SURVIVAL AND TREATMENT OF PRIMARY OVARIAN CANCER IN THE NETHERLANDS}

The prognosis of most cancer patients steadily increased over the last years, and is a result of different strategies ${ }^{1}$. First of all, prevention or early diagnosis are important factors to improve prognosis. A risk-reducing bilateral salpingo-oophorectomy reduces the risk of ovarian cancer with $85-95 \%$ in BRCA mutation carriers ${ }^{2}$. The lifetime risk to develop ovarian cancer in the general population, however, is rather low (1.3-2.0\%), and explains that riskreducing surgery is not effective in the general population ${ }^{3-5}$. The use of oral contraceptive pills is associated with a slight decrease in the incidence of ovarian cancer, while it has also been reported that the likelihood to develop breast cancer increases with longer use of oral contraceptives $^{6-8}$. The possibility to prevent the development of ovarian cancer is therefore limited, while early diagnosis may also contribute to improved prognosis. Early diagnosis can be established through screening programs. They are implemented if they meet a number of essential criteria, such as an evidence-based decline in mortality rates ${ }^{9,10}$. In the Netherlands, screening programs are implemented for breast-, cervical- and more recently also for colorectal cancer. The effectiveness of these programs is, among others, based on the ability to detect precursor lesions, such as cervical intraepithelial neoplasia (CIN) in the cervical screening program. The early detection of ovarian cancer, however, is complex and extensive efforts have failed to conduct an (cost)effective screening program ${ }^{11-13}$. Due to the aggressive nature of epithelial ovarian cancer, most pronounced in high grade ovarian cancer, screening in the general population is currently an ineffective strategy to decrease mortality rates for this patient population ${ }^{14}$.

Other factors that contributed to better outcomes of cancer patients in general are the improved treatment modalities, in which surgery, radiotherapy and systemic therapy are increasingly combined to be as effective as possible. For ovarian cancer, the combination of surgical treatment and platinum-based chemotherapy has been the standard of care since the mid 1990's. In chapter 2, we observed an increasing proportion of patients that received optimal treatment according to contemporary standards. Although this improvement in treatment resulted in better surgical outcomes, and prolonged disease control, we observed no improvement in long-term survival. Therefore, cure rates remain unfortunately as dismal as thirty years ago. This finding underscores the importance 
of gaining insights into treatment patterns and outcomes in our general population to ultimately improve clinical outcomes for ovarian cancer patients.

Next to platinum-based chemotherapy, surgical treatment is essential in the curative treatment of patients with ovarian cancer. Over the last years, a trend towards centralised oncological surgical care is observed in a variety of tumour types, especially in those tumours that are relatively rare and require complex surgical procedures. Several studies have consistently demonstrated that the outcome of complex surgical procedures improve if they are performed in high-volume hospitals by experienced surgical teams ${ }^{15,16}$. As such, surgical volume norms were introduced for pancreatic-, oesophageal- and stomach cancer in the Netherlands ${ }^{17-19}$. After a gradual centralisation process, cytoreductive surgery for ovarian cancer is nowadays also limited to those centres that perform a minimum of twenty cytoreductive surgeries annually in the Netherlands.

Ovarian cancer is an uncommon tumour type (1,300 newly diagnosed patients yearly), especially when compared to invasive breast- (14,500 patients yearly) and colorectal cancer $(15,000 \text { patients yearly })^{4}$. Due to its relative rare occurrence, clinical experience is expected to differ considerably across hospitals. Centralisation aims to increase the annual case-load in expert centres, which results in further reduction of clinical experience in non-expert centres. Ovarian cancer patients, however, are diagnosed in all Dutch hospitals regardless of their experience in treating ovarian cancer. On the premises of adequate referral, optimal surgical care should not depend on the hospital where the initial diagnosis is made. In chapter $\mathbf{3}$, we describe a steady decrease in the number of hospitals that perform surgery for ovarian cancer, and an ensuing increase in the mean annual case load in the remaining hospitals following formal centralisation. In the early days after centralisation, the hospital of diagnosis still impacted treatment variation, but this variation diminished after a national consensus on surgical volume norms was formed. In other tumour types, it has been observed that centralisation was associated with increasing treatment differences between surgical and non-surgical diagnosing hospitals ${ }^{20,21}$. This effect was, however, not observed for ovarian cancer. One of the explanations for the decrease in treatment variation, may be the introduction of (regional) multidisciplinary tumour board meetings. In such a meeting, all patients are discussed before the initiation of primary treatment with a variety of experts, such as gynaecological-oncologists, medical-oncologists, radiologists and pathologists. This may have resulted in a more coherent treatment policy across individual hospitals, as all patients are discussed in the same meeting. So, nowadays the decision to operate patients seems mainly attributable to patient and tumour characteristics, which supports the growing evidence in favour of 
centralising (surgical) treatment for a complex and heterogeneous disease such as ovarian cancer.

Centralisation of surgical treatment aims to improve the surgical outcomes, and hence survival outcomes of ovarian cancer patients. An improvement in surgical outcomes was observed in the most recent years (chapter 3 and chapter 4). On the one hand, centralisation may play a role in this phenomenon, as more specialised gynaecologicaloncologists operated on these patients in surgical-centres. As a consequence, their annual case load increased and may also explain improved surgical outcome. On the other hand, the introduction of neoadjuvant chemotherapy (NACT) was an important alteration in the treatment of ovarian cancer. A considerable number of patients is diagnosed with extensive disease, which is a limiting factor in achieving an optimal surgical result. NACT aims to reduce intra-abdominal tumour load, and is therefore associated with a higher number of complete cytoreductive surgeries ${ }^{22}$. So, by treating more patients with NACT, an improvement in surgical outcomes is expected in addition to centralisation effects. Finally, and this should not be overlooked, patient selection to those who undergo surgery, strongly influences surgical outcomes as well. In an extreme setting, if we only select those patients with the lowest tumour burden, and best performance status for cytoreductive surgery, our surgical success rates would increase massively, without actually improving our standard of care for the whole population. Therefore, it is of paramount importance to stratify patients to the adequate treatment option and ensure high quality surgical care for the entire population.

We observed a decrease in the number of patients that underwent an attempt to surgery between 2008 and 2015 (chapter 3 and chapter 4). Despite this decrease in surgically treated patients, overall survival in our whole population (including those with limited or no therapy) remained stable, while survival rates improved in our surgically treated patients. This is an indication that patient selection to those who actually benefit from surgery may have improved. Cytoreductive surgery is an extended procedure, with a high probability towards surgical complications and even postoperative mortality. Factors that were associated with abstaining surgical treatment were patients' age and disease stage at diagnosis. The probability towards surgical complications is higher in patients with extended disease, as more radical surgical interventions are necessary to achieve an optimal result ${ }^{23-25}$. Moreover, elderly patients have a higher likelihood of perioperative morbidity ${ }^{26,27}$. As such, not every patient may benefit from surgery in terms of prolonged survival, and by operating on them there is a possibility of only harming these patients. This underscores the importance of providing adequate treatment to our weakest and 
most fragile group of the population. Shared-decision making, and an increasing age at diagnosis, may result into even more patients that renounce any form of treatment. In itself it is not undesirable that well-informed patients balance the advantages and disadvantages for such an extensive treatment plan, but we should ensure that we further improve viable (palliative) treatment options for these patients as well. Improving postoperative rehabilitation services, and minimal invasive surgical techniques are essential for improving quality of life, and deserve our unconditional attention. The effectiveness of these new minimal invasive surgical procedures should be thoroughly evaluated, so that patients safety is guaranteed ${ }^{28}$.

Survival of ovarian cancer patients that are treated with the combination of surgery and chemotherapy largely depends on the ability to reduce abdominal tumour load during primary treatment ${ }^{29,30}$. Dutch patients are treated within eight geographical regions, and although no differences were present between individual hospitals on the probability towards surgical treatment (chapter $\mathbf{3}$ ), there may still be differences between geographical regions. The number of patients that underwent no therapy at all was similar between regions, while significant variation existed in the used treatment sequences (primary cytoreductive surgery (PCS) versus NACT and interval cytoreductive surgery (ICS) across geographical regions (chapter 4). Possible explanations include the fact that (inter)national guidelines support both treatment strategies, and the differences between regions in local preferences for either PCS or NACT-ICS ${ }^{31-34}$.

Complete resection of all macroscopic disease, independent of the timing of cytoreductive surgery, is the main objective for surgery in advanced ovarian cancer patients. The outcome of cytoreductive surgery differed greatly between regions, even if we adjusted our analyses for the timing of surgery. Variation in oncological care is not necessarily undesirable, since physicians should be able to adjust treatment to individual patients. It is, however, questionable why such an important prognostic factor varies to this extent between oncological regions. Especially since it seems to affect survival outcomes of those patients that underwent PCS or NACT-ICS. We observed the lowest survival outcomes of surgically treated patients in the region with the lowest number of complete cytoreductive surgeries (chapter 4). This did not, however, negatively affect survival outcomes of the entire population (including those with no or limited therapy) in the specific region compared with other regions. Patient selection to those who actually benefit from successful surgery may play a role in this discrepancy. 
The most important factors that affect the outcomes of surgery, are disease burden and the expertise of the surgical team. As the disease burden is hardly amendable, surgical expertise plays an important role in clinical outcomes. The EORTC trial of Vergote et al. showed, that the number of complete cytoreductive surgeries were the lowest among Dutch gynaecologists, while the number of optimal surgeries were similar when compared to other countries ${ }^{35}$. Although these surgeries were performed between 1998 and 2006, this may be an indication that surgical expertise could be optimised in the Netherlands. In more recent periods, a substantial increase in the number of patients with no residual disease after PCS has been observed (25\% in 2008-2009 to 55\% in 2014-2015, chapter 4). This is similar to other countries, where complete PCS is achieved in 19-65\% of patients ${ }^{36-40}$. We should, however, be careful in comparing these outcomes since the number of patients that undergoes NACT-ICS in the Netherlands is increasing up to 70\%. As stated before, if we only select those patients for PCS that have the lowest tumour burden, actual improvement has not been accomplished. In international literature is has been suggested that PCS is possible in up to $85 \%$ of the cases ${ }^{41}$. Since this is accompanied with a considerable number of suboptimal cytoreductions, the number will probably be lower but it remains questionable if $70 \%$ of our patients are unfit for successful PCS. In Germany for example, only $11 \%$ of patients undergoes NACT-ICS, and the number of complete cytoreductive surgeries is comparable (59\%) to the Dutch outcomes ${ }^{39}$.

A stricter implementation of surgical volume norms for hospitals, or even for individual gynaecologists, has been proposed to further improve surgical outcomes ${ }^{42}$. We showed that only $69 \%$ of the Dutch hospitals met the minimal requirement of twenty debulking surgeries annually in 2015 (chapter 3). It has, however, been recognised that surgical volume norms are an imprecise measure of healthcare quality, as volume probably acts as a proxy for other factors that are also associated with surgical outcomes ${ }^{43-46}$. An example of such a confounder may be the access to other surgeons during cytoreductive surgery, such as colorectal surgical oncologists or hepatobiliary surgeons. They are extensively trained in upper abdominal surgery, and are therefore more often capable to safely obtain resections of liver metastasis, diaphragmatic- and peritoneal disease. These collaborations may be more present in high-volume specialised centres, which underscores why centralisation of surgical care results into favourable clinical outcomes for ovarian cancer patients. Evaluation of those explaining factors may be helpful to improve quality of (surgical) oncological care, and hence to increase the number of complete cytoreductive surgeries. 


\section{PART II: PROGNOSTIC FACTORS THAT AFFECT SURVIVAL IN OVARIAN CANCER PATIENTS}

In treating cancer patients, it is important to provide realistic information about patients' treatment outcomes. Not only to determine the most optimal treatment plan, but also to adjust patients' expectations of their personal prognosis instead of mean survival outcomes. From earlier studies we learned that the outcome of cytoreductive surgery is one of the most important prognostic factors, and defines survival for individual patients. This prognostic factor is however hampered by its subjective character and does not account for the number of residual lesions ${ }^{47-49}$. Therefore, it is important to search for new prognostic factors that can predict patients' prognosis more accurately. We showed that the relative perioperative CA125 decline is an independent prognostic factor for clinical outcomes in patients who underwent upfront cytoreductive surgery (chapter 5). CA125 is an objective measure, and accounts for the change in tumour volume which may explain its additional value. Future research is, however, necessary to determine the ideal timing of CA125 measurements during treatment, and to develop an easily accessible nomogram that could be used in daily clinical practice. Moreover, when combined with serum human epididymis protein 4 (HE4), the prediction of survival could be further optimised ${ }^{50}$.

Realistic prognostic information is important for individual patients, but in case of modifiable prognostic factors, a gain in knowledge can actually induce improvements in survival for patient groups. In patients that undergo (interval) cytoreductive surgery, adjuvant chemotherapy is recommended to eliminate residual (microscopic) disease, and hence to improve clinical outcomes. Currently, there is no data available about the optimal time interval between surgery and subsequent chemotherapy. We observed that patients with a delayed initiation of adjuvant chemotherapy, defined as $>37$ days, experienced impaired overall survival compared to patients with an intermediate time interval (chapter 6). This was most pronounced in patients with no residual disease after surgery. Although we recognise that delaying chemotherapy is caused by postoperative complications and is more common in the elderly population, adjustment of our models for these confounders did not undo the independent effect. Consequently, survival outcomes may improve if adjuvant chemotherapy is administered within the first five to six weeks after cytoreductive surgery.

Initial disease burden, and therewith FIGO stage, influences therapy response and is an important prognostic factor. About $12-33 \%$ of patients is diagnosed with extra-abdominal 
disease during the initial presentation (FIGO stage IV disease). In the majority of these patients, FIGO stage IV disease is based on malignant pleural effusion (30-60\%). Other common sites are parenchymal liver metastases (10-25\%) and extra-abdominal lymph

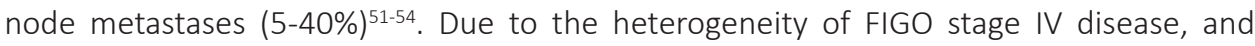
possible survival differences, the FIGO classification was altered in 2014 and resulted in a sub-classification of FIGO IVA and IVB. Patients with pleural malignant effusion as only site of distant disease are now classified as FIGO IVA, and all other sites of distant disease are classified as FIGO IVB. In chapter $\mathbf{7}$ we showed this renewed sub-classification does not provide additional prognostic information, as survival was similar between FIGO stage IVA and IVB disease. Patients with extra-abdominal lymph node metastases as only site of distant disease, however, experienced improved survival compared to all other FIGO IV patients. The latter is confirmed in other studies ${ }^{55-57}$. Moreover, it is in concordance with the new distinction in FIGO III patients, where patients with regional lymph node metastases as only sign of advanced stage disease, are nowadays classified as FIGO stage IIIA instead of FIGO stage IIIC ${ }^{58-60}$. These findings suggest that the FIGO classification should be revised. We propose a sub-classification in which patients with extra-abdominal lymph nodes should be considered as a separate group of FIGO IV patients, or even as FIGO III patients.

\section{PART III: OPTIMISING PATIENT SELECTION FOR PRIMARY SURGERY OR CHEMOTHERAPY}

Throughout this thesis, we focussed on clinical outcomes for advanced stage EOC patients. Currently, there is a lively debate about the optimal timing of surgery for advanced ovarian cancer patients. The use of NACT-ICS increased over the last years in the Netherlands, up to $73 \%$ in 2014-2015 in FIGO IIIC and IV patients (chapter 4). The uptake of this treatment sequence varies widely between hospitals, and this cannot be explained by differences in patient populations. To that extent, we conducted a survey study in which we evaluated the current opinions of gynaecologists and medical-oncologists about the optimal timing of cytoreductive surgery for this patient group. The majority of respondents adopted NACTICS as an alternative treatment approach, which is illustrated by the use of NACT-ICS for the majority of advanced ovarian cancer patients in the Netherlands. Moreover, the majority of medical-oncologists even prefer NACT-ICS over PCS, while gynaecologists still more often opt for PCS as first line treatment (chapter 8). This study is therefore a perfect illustration of the ongoing discussion about the results of the randomised clinical trials (RCTs) regarding this subject. 
The results of the RCTS that compared PCS and NACT-ICS showed that survival outcomes of NACT-ICS were non-inferior to PCS ${ }^{35,61}$. Importantly, perioperative morbidity was significantly lower after NACT-ICS, with similar quality of life after one year ${ }^{24,35,61,62}$. These results may suggest that NACT-ICS is therefore the preferred treatment for advanced stage ovarian cancer patients. Evidence-based medicine considers RCTs as the gold standard to establish the best treatment option. However, the most important limitation of an RCT is that the results are only generalisable to those patients that are represented in the study population. Both published studies were critically evaluated, and patient selection may be one of the explaining factors for the observed effects.

First of all, median overall survival was surprisingly low in both studies, predominantly in the PCS arms (23 months ${ }^{61}$ and 30 months $^{35}$ ). A recent meta-analysis showed an average median survival of 43 months after PCS, including those patients with residual disease of $>1 \mathrm{~cm}$ after cytoreduction ${ }^{36}$. The survival rates were more comparable for patients who underwent NACT-ICS, being $24^{61}$ and $29^{35}$ months in the RCTs, and 33 months in the same meta-analysis ${ }^{36}$. Although this meta-analysis was based on retrospective studies, and therefore complicates the comparison between PCS and NACT-ICS due to confounding by severity, it is striking that the PCS arm performs considerably better in retrospective series compared to RCT data. This, in combination with the published baseline characteristics, seems to indicate that only patients with very advanced stage disease were included. Another major limitation of the currently published randomised studies is that the surgical results were rather unsatisfiable, as only $21 \%^{61}$ and $34 \%^{35}$ had no residual disease after either PCS or ICS. This is reflected by the shorter than expected operating times in both trials, and explains the low survival rates in both studies. All taken together, it seems that the patient populations in both trials were skewed towards those patients with a high likelihood to macroscopic residual disease after upfront cytoreductive surgery. And even the most profound advocates of PCS agree that suboptimal PCS does not contribute to improved survival ${ }^{63}$. So, patients with very advanced stage ovarian cancer and a low likelihood towards complete cytoreductive surgery are probably better served by NACTICS. This seems to be confirmed by the unpublished SCORPION trial, in which patients with a high disease score (based on laparoscopy) were randomised between NACT-ICS and PCS. Again, in this trial, survival was similar between both treatment sequences and postoperative complications were lower after NACT-ICS ${ }^{62,64}$.

Patients with FIGO stage IV disease may represent another subgroup in which NACT-ICS may be the preferred treatment approach. The beneficial effect of cytoreductive surgery remains questionable if $>1 \mathrm{~cm}$ of residual disease has been left after surgery ${ }^{40,52}$. In case of extra-abdominal disease of $>1 \mathrm{~cm}$ at initial diagnosis, NACT provides insight in which patients 
cytoreductive surgery can be beneficial. In case of no response or progression during NACT, surgery should probably be omitted. Moreover, we observed that survival outcomes in patients with FIGO stage IV disease were comparable between PCS and NACT-ICS (chapter 7). In retrospective studies, confounding by severity plays a role when the outcomes of PCS and NACT-ICS are compared. Patients that are selected for PCS are probably diagnosed with a lower tumour burden and a higher probability towards complete cytoreductive surgery. As this favourable prognosis does not translate into better survival rates for patients with FIGO stage IV disease, PCS might not be the preferred treatment for these patients. Although the majority of patients underwent NACT-ICS in our population, we observed a possible survival advantage for patients diagnosed with malignant pleural effusion when they were treated with PCS. This was observed in a matching-criterion analysis to overcome immortal time bias, in which patients were excluded that died shortly after PCS ${ }^{65}$. Pleural malignant effusion might be caused by pleural metastases, or by trans-diaphragmatic migration of malignant cells through pleuroperitoneal communications. The latter usually responds well to adjuvant chemotherapy, and this might be a selection of FIGO IV patients that may be better served by PCS ${ }^{66}$. As the number of patients that underwent PCS was limited in our series, this finding needs to be confirmed in prospective studies.

Next to highly selected FIGO IV patients, observational data suggest that a specific subpopulation of advanced ovarian cancer patients still benefits from PCS over NACTICS $^{41,67-70}$. This beneficial effect is most pronounced in patients with no macroscopic residual disease after upfront cytoreductive surgery, where median survival can be improved up to 72 months $^{36,41,71}$. This leads to the question how we can identify this subgroup in order to select those patients that benefit from this radical procedure.

The prediction to achieve a complete cytoreductive surgery is most often based on imaging techniques, predominantly CT scans, but this seems to be an inaccurate method to establish the resectability of ovarian cancer ${ }^{72-74}$. Specific disease details, such as miliary spread, and the extent of intra-abdominal disease could be well established by diagnostic laparoscopy prior to cytoreductive surgery. The Dutch LAPOVCA trial showed that the number of futile laparotomies, i.e. suboptimal PCS, decreases when diagnostic laparoscopy is used in patients where PCS was deemed feasible $(\leq 1 \mathrm{~cm}$ residual disease) by conventional diagnostic workup ${ }^{75}$. This trial exemplifies that prediction of the outcome of surgery is unreliable, as only $53 \%$ of patients had an optimal surgical result, and $36 \%$ had no residual disease after the initial attempt to upfront PCS (with or without diagnostic laparoscopy). Moreover, the use of diagnostic laparoscopy does not ensure successful PCS, as false negative results range between $4-30 \%{ }^{76}$. In addition, the development of port- 
site metastases (16-47\%), can be a risk for additional perioperative morbidity and more complex subsequent cytoreductive surger $y^{40,77,78}$. Therefore, it is of the utmost importance to select those patients that have the highest chances to successful PCS, without exposing the whole population to the downsides of an invasive diagnostic procedure. A preoperative clinical prediction model based on simple baseline characteristics was therefore developed and internally validated on a large population-based dataset (chapter 9). The performance of the model is highly dependent on the chosen threshold for a positive test, and this probably varies between advocates of PCS and NACT-ICS. Nevertheless, after external validation, the implementation of a preoperative prediction model could be helpful in the process of shared-decision making where risk and benefits are more quantifiable for both physicians and patients. Moreover, it can help to select those patients in which diagnostic laparoscopy can contribute to the decision-making process.

Throughout this thesis, we focused on the outcome of surgical cytoreduction. The probability of no macroscopic residual disease is higher after NACT-ICS, but this does not translate into favourable survival rates. This indicates that the prognostic effect of surgical outcomes is different after NACT. Moreover, the randomised EORTC trial showed that there was no survival difference between patients with an optimal $(0.1-1 \mathrm{~cm}$ residual disease) versus a suboptimal result ( $>1 \mathrm{~cm}$ residual disease) after NACT-ICS ${ }^{35}$. Therefore, we performed a systematic review in which we summarised the currently available literature about the prognostic effect of surgical outcomes after NACT-ICS (chapter 10). Again, we observed that patients with no residual disease after cytoreductive surgery had the best survival rates. The prognostic effect of optimal versus suboptimal cytoreduction, however, varied between the included studies ${ }^{35,61,79-87}$. Based on a weighted average analysis, a sixmonth survival advantage was observed in case of an optimal outcome compared to a suboptimal outcome. Following the recognition that an increasing amount of residual disease limits survival, it seems reasonable that a cut-off in the amount of macroscopic residual disease for the entire population may be prognostically relevant. As mentioned before, the assessment of residual disease is subjective and varies between gynaecologicaloncologists, which may be one of the explaining factors for the observed results. In addition, after NACT, assessing the amount of residual disease is even more complex. Several studies showed that chemotherapy-induced fibrosis may lead to insufficient surgery, as lesions that appear to be benign may still contain vital tumour. Therefore, potentially resectable disease will not be removed and this inherently has a negative impact on survival. This may explain why the apparent better outcomes after NACT-ICS do not translate into prolonged survival compared to PCS. 
The concept of NACT could potentially be optimised. The most commonly mentioned downside of NACT-ICS is the increased probability to platinum resistance, which may be related to the time interval between the third pre-operative course, and fourth postoperative course. One could imagine that an interruption in chemotherapy administration may give the remaining, still vital, tumour cells the chance to protect themselves against subsequent adjuvant platinum-based chemotherapy. The administration of six cycles of NACT followed by cytoreductive surgery with no subsequent post-operative chemotherapy, comparable to gastro-intestinal and breast cancer, might be one of the options to increase the chemotherapy dose before surgery and to avoid an additional delay in chemotherapy administration. In addition, the concept of hyperthermic intra-peritoneal chemotherapy (HIPEC) has been proven to be effective in Dutch ovarian cancer patients. The OVHIPEC study showed a median survival advantage of twelve months with ICS + HIPEC compared to ICS alone in FIGO stage III ovarian cancer patients with complete or optimal NACT-ICS ${ }^{88}$. The use of HIPEC after six cycles of NACT and successful cytoreductive surgery may possibly be an alternative in order to avoid additional post-operative chemotherapy. Moreover, postoperative (immune)therapeutic options will probably expand in the upcoming years and will give additional options to subsequent therapy after cytoreductive surgery in the primary treatment for ovarian cancer patients ${ }^{89}$.

\section{FUTURE PERSPECTIVES}

Over the last decades, we seem to have focused on surgical outcomes as the holy grail to improve survival of ovarian cancer patients. Although we showed that surgical outcomes improved, whether caused by centralisation, the introduction of NACT-ICS or more extensive surgery, the cure rate did not substantially improve over the last 25 years. As a result, there is an unmet need for more effective treatment options for our general population. On the other hand, it is widely accepted that the current 'one size fits all' approach is inefficient, and improved patient selection is key in developing effective future-proof treatment strategies.

Tumour heterogeneity, even within the same histological subtype, may be responsible for the varying outcomes between patients with apparent similar baseline characteristics. The majority of advanced stage ovarian cancer patients is diagnosed with high grade serous ovarian cancer (HGSOC). With the exception of BRCA1/2, and ubiquitous TP53 mutations, other mutations are relatively uncommon in $\mathrm{HGSOC}^{90}$. Instead, the development of HGSOC is driven by structural genomic variation and results in a high density of copy number alterations ${ }^{91,92}$. 
In about 50\% of all HGSOC, there is evidence of mutational and functional inactivation of the homologous recombination (HR) DNA repair pathway ${ }^{91,93}$. The other half of HGSOC is poorly characterised, but a subset of these tumours have an amplification of Cyclin E1 (CCNE1), which is associated a higher likelihood towards platinum resistance, and therewith poor survival ${ }^{93-96}$. Moreover, it has been suggested that HR deficient tumours and CCNE1 amplification are nearly mutually exclusive $\mathrm{e}^{90,93}$. The origin of HR deficient tumours is for a substantial number of patients based on the previously mentioned BRCA mutations, either germline or somatic ${ }^{90,91,97}$. Normally, double stranded DNA breaks are recognised and repaired by the BRCA protein. HR deficiency plays an important role in platinum sensitivity, and explains the favourable survival of patients with a BRCA mutated tumour ${ }^{98-101}$. Moreover, HR deficiency serves as rationale for the effectiveness of poly (ADPribose) polymerase (PARP) inhibition. PARP is a protein that recognises and repairs single strand DNA breaks, but in case of PARP inhibition these single stranded DNA breaks are replicated into double stranded breaks which causes cell death by synthetic lethality in HR deficient cells. It has been demonstrated that survival of recurrent HGSOC improved with maintenance PARP inhibition. As expected, the highest efficacy was observed in patients with a somatic or germline BRCA mutation, but sensitivity analyses showed an effect in all HGSOCs $^{102-105}$. Recently, it has been shown that PARP inhibitors are also effective in patients with primary EOC and a BRCA mutation ${ }^{89}$.

Besides the genetic make-up of ovarian cancer, the immune system contributes to the development and control of HGSOC. As such, the tumour micro-environment is increasingly studied in order to predict clinical outcome and therapy response. The presence of tumour-infiltrating lymphocytes (TIL), predominantly CD8+ cytotoxic T cells, is associated with improved prognosis ${ }^{106,107}$. The interplay between the genetic make-up and presence of specific TILs is not completely understood. In a current ongoing study, we aim to gain more insight in the association between immune cells and the molecular characterisation (BRCA mutated tumours versus CCNE1 amplificated tumours), in order to ultimately select patients for more effective treatment options.

The immune system served as a basis for new immunotherapeutic strategies, such as checkpoint inhibitors and adoptive cell transfer. Responses to these new treatments may be disappointing at first, but it should be kept in mind that they are initially studied in heavily pre-treated patients ${ }^{108-110}$. In the coming years, it needs to be clarified whether these agents will play a prominent role in the treatment of ovarian cancer, and whether they are more effective during primary of recurrent disease. Furthermore, the optimal combination of immunotherapeutic strategies with platinum-based chemotherapy, PARP inhibition and/or cytoreductive surgery needs to be elucidated in order to increase 
the treatment effect and establish an improvement in the outcomes of ovarian cancer patients.

\section{CONCLUDING REMARKS}

Over the last 25 years, an improvement in the treatment of ovarian cancer has been achieved, with more patients receiving optimal treatment according to contemporary standards. The introduction of NACT-ICS ensured a safe and effective treatment option for at least a selection of advanced stage ovarian cancer patients. In addition, it is probably even first choice for the vast majority of FIGO stage IV patients. The use of NACT-ICS in all other advanced stage ovarian cancer patients should however be reserved for those patients in which successful primary surgery is considered impossible, and NACT is not, and should not be, the opposite of high-quality surgical care ${ }^{22,111}$. More insight in the interplay between tumour biology, therapy response and clinical outcomes must guide us to select patients for the right treatment at the right time. 


\section{REFERENECES}

1. Allemani C, Matsuda T, Di Carlo V, Harewood R, Matz M, Niksic M, et al. Global surveillance of trends in cancer survival 2000-14 (concord-3): Analysis of individual records for 37513025 patients diagnosed with one of 18 cancers from 322 population-based registries in 71 countries. Lancet. 2018;391(10125):1023-75.

2. Marchetti C, De Felice F, Palaia I, Perniola $G$, Musella A, Musio D, et al. Risk-reducing salpingo-oophorectomy: A meta-analysis on impact on ovarian cancer risk and all cause mortality in brca 1 and brca 2 mutation carriers. BMC Womens Health. 2014;14:150.

3. Cancer research uk, https://www. Cancerresearchuk.Org/health-professional/ cancer-statistics/statistics-by-cancer-type/ ovarian-cancer/risk-factors. Accessed december 2018.

4. Intergraal kankercentrum nederland nederlandse kankerregistratie. Https:// www.Cijfersoverkanker.NI/nkr/. Accessed august 2018.

5. American cancer society. Https://www. Cancer.Org/cancer/ovarian-cancer/about/ key-statistics.Html. Accessed december 2018.

6. Collaborative Group on Epidemiological Studies of Ovarian C, Beral V, Doll R, Hermon C, Peto R, Reeves G. Ovarian cancer and oral contraceptives: Collaborative reanalysis of data from 45 epidemiological studies including 23,257 women with ovarian cancer and 87,303 controls. Lancet. 2008;371(9609):303-14.

7. Webb PM, Green AC, Jordan SJ. Trends in hormone use and ovarian cancer incidence in us white and australian women: Implications for the future. Cancer Causes Control. 2017;28(5):365-70.
8. Morch LS, Skovlund CW, Hannaford PC, Iversen L, Fielding S, Lidegaard $O$. Contemporary hormonal contraception and the risk of breast cancer. N Engl J Med. 2017;377(23):2228-39.

9. Andermann A, Blancquaert I, Beauchamp S, Dery V. Revisiting wilson and jungner in the genomic age: A review of screening criteria over the past 40 years. Bull World Health Organ. 2008;86(4):317-9.

10. Wilson JM, Jungner YG. [principles and practice of mass screening for disease]. Bol Oficina Sanit Panam. 1968;65(4):281-393.

11. Jacobs IJ, Skates SJ, MacDonald N, Menon U, Rosenthal AN, Davies AP, et al. Screening for ovarian cancer: A pilot randomised controlled trial. Lancet. 1999;353(9160):1207-10.

12. Buys SS, Partridge E, Black A, Johnson CC, Lamerato L, Isaacs C, et al. Effect of screening on ovarian cancer mortality: The prostate, lung, colorectal and ovarian (plco) cancer screening randomized controlled trial. JAMA. 2011;305(22):2295-303.

13. Jacobs IJ, Menon U, Ryan A, GentryMaharaj A, Burnell M, Kalsi JK, et al. Ovarian cancer screening and mortality in the uk collaborative trial of ovarian cancerscreening (ukctocs): A randomised controlled trial. Lancet. 2016;387(10022):945-56.

14. Henderson JT, Webber EM, Sawaya GF. Screening for ovarian cancer: Updated evidence report and systematic review for the us preventive services task force. JAMA. 2018;319(6):595-606.

15. Vernooij F, Heintz P, Witteveen E, van der Graaf $Y$. The outcomes of ovarian cancer treatment are better when provided by gynecologic oncologists and in specialized hospitals: A systematic review. Gynecol Oncol. 2007;105(3):801-12. 
16. Woo $Y L$, Kyrgiou $M$, Bryant $A$, Everett $T$, Dickinson HO. Centralisation of services for gynaecological cancers - a cochrane systematic review. Gynecol Oncol. 2012;126(2):286-90.

17. Lemmens VE, Bosscha $K$, van der Schelling G, Brenninkmeijer S, Coebergh JW, de Hingh $\mathrm{IH}$. Improving outcome for patients with pancreatic cancer through centralization. $\mathrm{Br}$ J Surg. 2011;98(10):1455-62.

18. van de Poll-Franse LV, Lemmens VE, Roukema JA, Coebergh JW, Nieuwenhuijzen GA. Impact of concentration of oesophageal and gastric cardia cancer surgery on longterm population-based survival. Br J Surg. 2011;98(7):956-63.

19. Jensen LS, Nielsen H, Mortensen PB, Pilegaard HK, Johnsen SP. Enforcing centralization for gastric cancer in denmark. Eur J Surg Oncol. 2010;36 Suppl 1:S50-4.

20. van Putten M, Koeter M, van Laarhoven HW, Lemmens VE, Siersema PD, Hulshof MC, et al. Hospital of diagnosis influences the probability of receiving curative treatment for esophageal cancer. Ann Surg. 2016.

21. van Putten $M$, Verhoeven $R H$, van Sandick JW, Plukker JT, Lemmens VE, Wijnhoven BP, et al. Hospital of diagnosis and probability of having surgical treatment for resectable gastric cancer. Br J Surg. 2016;103(3):23341.

22. Kang S. Neoadjuvant chemotherapy for ovarian cancer: Do we have enough evidence? Lancet. 2015;386(9990):223-4.

23. Benedetti Panici P, Di Donato V, Fischetti M, Casorelli A, Perniola G, Musella A, et al. Predictors of postoperative morbidity after cytoreduction for advanced ovarian cancer: Analysis and management of complications in upper abdominal surgery. Gynecol Oncol. 2015;137(3):406-11.
24. Yang L, Zhang B, Xing G, Du J, Yang B, Yuan $Q$, et al. Neoadjuvant chemotherapy versus primary debulking surgery in advanced epithelial ovarian cancer: A meta-analysis of peri-operative outcome. PLoS One. 2017;12(10):e0186725.

25. Chi DS, Zivanovic O, Levinson KL, Kolev $\mathrm{V}$, Huh J, Dottino J, et al. The incidence of major complications after the performance of extensive upper abdominal surgical procedures during primary cytoreduction of advanced ovarian, tubal, and peritoneal carcinomas. Gynecol Oncol. 2010;119(1):3842.

26. Kumar A, Bakkum-Gamez JN, Weaver AL, McGree ME, Cliby WA. Impact of obesity on surgical and oncologic outcomes in ovarian cancer. Gynecol Oncol. 2014;135(1):19-24.

27. Aletti GD, Eisenhauer EL, Santillan A, Axtell A, Aletti G, Holschneider C, et al. Identification of patient groups at highest risk from traditional approach to ovarian cancer treatment. Gynecol Oncol. 2011;120(1):238.

28. Ramirez P, Frumovitz M, Pareja R, Lopez A, Vieira M, Ribeiro R. Phase iii randomized trial of laparoscopic or robotic vs. Abdominal radical hysterectomy in patients with earlystage cervical cancer: Lacc trial. SGO 2018 - Late Breaking Abstract 1.

29. Bristow RE, Tomacruz RS, Armstrong DK, Trimble EL, Montz FJ. Survival effect of maximal cytoreductive surgery for advanced ovarian carcinoma during the platinum era: A meta-analysis. J Clin Oncol. 2002;20(5):1248-59.

30. Chang SJ, Hodeib M, Chang J, Bristow RE. Survival impact of complete cytoreduction to no gross residual disease for advancedstage ovarian cancer: A meta-analysis. Gynecol Oncol. 2013;130(3):493-8. 
31. Integraal kanker centrum nederland - epitheliaal ovariumcarcinoom versie $2.0 \quad$ (2012). Https://www.Oncoline.NI/ ovariumcarcinoom. Accessed september 2018. .

32. National institute for health and clinical excellence - recognition and initial management of ovarian cancer (2011). Www.Nice.Org.Uk/cg122. Accessed september 2018.

33. Federaal kenniscentrum voor de gezondheidszorg- eierstokkanker: Diagnose, behandeling en follow-up (2016). Https:// kce.Fgov.Be/sites/default/files/atoms/files/ kce_268as_eierstokkanker_samevatting. Pdf. Accessed september 2018.

34. Wagner $U$, Harter $P$, Hilpert F, Mahner S, Reuss A, du Bois A, et al. S3-guideline on diagnostics, therapy and follow-up of malignant ovarian tumours: Short version 1.0- awmf registration number: 032/035ol, june 2013. Geburtshilfe Frauenheilkd. 2013;73(9):874-89.

35. Vergote I, Trope CG, Amant F, Kristensen GB, Ehlen T, Johnson N, et al. Neoadjuvant chemotherapy or primary surgery in stage iiic or iv ovarian cancer. N Engl J Med. 2010;363(10):943-53.

36. Chiva L, Lapuente F, Castellanos T, Alonso S, Gonzalez-Martin A. What should we expect after a complete cytoreduction at the time of interval or primary debulking surgery in advanced ovarian cancer? Ann Surg Oncol. 2016;23(5):1666-73.

37. Harter P, Muallem ZM, Buhrmann C, Lorenz D, Kaub C, Hils R, et al. Impact of a structured quality management program on surgical outcome in primary advanced ovarian cancer. Gynecol Oncol. 2011;121(3):615-9.
38. Luyckx M, Leblanc E, Filleron T, Morice P, Darai E, Classe JM, et al. Maximal cytoreduction in patients with figo stage iiic to stage iv ovarian, fallopian, and peritoneal cancer in day-to-day practice: A retrospective french multicentric study. International Journal of Gynecological Cancer. 2012;22(8):1337-43.

39. Sehouli J, Savvatis K, Braicu El, Schmidt SC, Lichtenegger W, Fotopoulou C. Primary versusinterval debulking surgeryinadvanced ovarian cancer: Results from a systematic single-center analysis. International journal of gynecological cancer : official journal of the International Gynecological Cancer Society. 2010;20(8):1331-40.

40. Ataseven B, Grimm C, Harter P, Heitz F, Traut A, Prader $S$, et al. Prognostic impact of debulking surgery and residual tumor in patients with epithelial ovarian cancer figo stage iv. Gynecol Oncol. 2016;140(2):21520.

41. Makar AP, Trope CG, Tummers P, Denys $H$, Vandecasteele K. Advanced ovarian cancer: Primary or interval debulking? Five categories of patients in view of the results of randomized trials and tumor biology: Primary debulking surgery and interval debulking surgery for advanced ovarian cancer. Oncologist. 2016;21(6):745-54.

42. Querleu D, Planchamp F, Chiva L, Fotopoulou C, Barton D, Cibula D, et al. European society of gynaecologic oncology quality indicators for advanced ovarian cancer surgery. Int J Gynecol Cancer. 2016;26(7):1354-63.

43. Mesman R, Faber MJ, Berden B, Westert GP. Evaluation of minimum volume standards for surgery in the netherlands (20032017): A successful policy? Health Policy. 2017;121(12):1263-73.

44. Birkmeyer JD, Siewers AE, Finlayson EV, Stukel TA, Lucas FL, Batista I, et al. Hospital volume and surgical mortality in the united states. N Engl J Med. 2002;346(15):112837. 
45. Halm EA, Lee C, Chassin MR. Is volume related to outcome in health care? A systematic review and methodologic critique of the literature. Ann Intern Med. 2002;137(6):511-20.

46. Mesman R, Westert GP, Berden BJ, Faber MJ. Why do high-volume hospitals achieve better outcomes? A systematic review about intermediate factors in volumeoutcome relationships. Health Policy. 2015;119(8):1055-67.

47. Eskander RN, Kauderer J, Tewari KS, Mannel RS, Bristow RE, O'Malley DM, et al. Correlation between surgeon's assessment and radiographic evaluation of residual disease in women with advanced stage ovarian cancer reported to have undergone optimal surgical cytoreduction: An nrg oncology/gynecologic oncology group study. Gynecol Oncol. 2018.

48. Kang S. Do we need a better marker for successful ovarian cancer surgery? J Gynecol Oncol. 2017;28(1):e21.

49. Prefontaine $M$, Gelfand AT, Donovan JT, Powell JL. Reproducibility of tumor measurements in ovarian cancer: A study of interobserver variability. Gynecol Oncol. 1994;55(1):87-90.

50. Karlsen MA, Fago-Olsen C, Hogdall E, Schnack TH, Christensen IJ, Nedergaard $L$, et al. A novel index for preoperative, non-invasive prediction of macro-radical primary surgery in patients with stage iiic-iv ovarian cancer-a part of the danish prospective pelvic mass study. Tumour Biol. 2016;37(9):12619-26.

51. Ataseven B, Chiva LM, Harter P, GonzalezMartin A, du Bois A. Figo stage iv epithelial ovarian, fallopian tube and peritoneal cancer revisited. Gynecol Oncol. 2016;142(3):597607.
52. Aletti GD, Dowdy SC, Podratz KC, Cliby WA. Analysis of factors impacting operability in stage iv ovarian cancer: Rationale use of a triage system. Gynecol Oncol. 2007;105(1):84-9.

53. Cormio G, Rossi C, Cazzolla A, Resta L, Loverro G, Greco P, et al. Distant metastases in ovarian carcinoma. Int J Gynecol Cancer. 2003;13(2):125-9.

54. Ogawa K, Yoshii Y, Aoki Y, Nagai Y, Tsuchida $Y$, Toita $T$, et al. Treatment and prognosis of brain metastases from gynecological cancers. Neurol Med Chir (Tokyo). 2008;48(2):57-62; discussion-3.

55. Hjerpe E, Staf C, Dahm-Kahler P, Stalberg $K$, Bjurberg $M$, Holmberg $E$, et al. Lymph node metastases as only qualifier for stage iv serous ovarian cancer confers longer survival than other sites of distant disease- a swedish gynecologic cancer group (swegcg) study. Acta Oncol. 2017:1-7.

56. Nasioudis D, Chapman-Davis E, Frey MK, Caputo TA, Witkin SS, Holcomb K. Should epithelial ovarian carcinoma metastatic to the inguinal lymph nodes be assigned stage ivb? Gynecol Oncol. 2017;147(1):81-4.

57. Tajik $\mathrm{P}$, van de Vrie R, Zafarmand MH, Coens C, Buist MR, Vergote I, et al. The figo stage iva versus ivb of ovarian cancer: Prognostic value and predictive value for neoadjuvant chemotherapy. Int J Gynecol Cancer. 2018.

58. Cliby WA, Aletti GD, Wilson TO, Podratz KC. Is it justified to classify patients to stage iiic epithelial ovarian cancer based on nodal involvement only? Gynecol Oncol. 2006;103(3):797-801.

59. Ferrandina G, Scambia G, Legge F, Petrillo $M$, Salutari V. Ovarian cancer patients with "node-positive-only" stage iiic disease have a more favorable outcome than stage iiia/b. Gynecol Oncol. 2007;107(1):154-6. 
60. Onda T, Yoshikawa H, Yasugi T, Mishima M, Nakagawa S, Yamada M, et al. Patients with ovarian carcinoma upstaged to stage iii after systematic lymphadenctomy have similar survival to stage i/ii patients and superior survival to other stage iii patients. Cancer. 1998;83(8):1555-60.

61. Kehoe S, Hook J, Nankivell M, Jayson GC, Kitchener H, Lopes $T$, et al. Primary chemotherapy versus primary surgery for newly diagnosed advanced ovarian cancer (chorus): An open-label, randomised, controlled, non-inferiority trial. The Lancet. 2015;386(9990):249-57.

62. Fagotti A, Ferrandina G, Vizzielli G, Fanfani F, Gallotta V, Chiantera V, et al. Phase iii randomised clinical trial comparing primary surgery versus neoadjuvant chemotherapy in advanced epithelial ovarian cancer with high tumour load (scorpion trial): Final analysis of peri-operative outcome. Eur J Cancer. 2016;59:22-33.

63. Cowan RA, Chi DS, Fagotti A, Scambia G. Point/counterpoint: Primary debulking surgery vs neoadjuvant chemotherapy for newly diagnosed advanced ovarian cancer. Oncology (Williston Park). 2017;31(6):45358, 60-61.

64. Fagotti A, Vizzielli G, Ferrandina G, Fanfani F, Gallotta V, Chiantera V, et al. Survival analyses from a randomized trial of primary debulking surgery versus neoadjuvant chemotherapy for advanced epithelial ovarian cancer with high tumor load (scorpion trial). J Clin Oncol. 2018;36(suppl; abstr 5516).

65. Lai TY, Hu YW. Neoadjuvant therapy in resectable pancreatic cancer: Immortal time bias and its correction. J Clin Oncol. 2017;35(14):1623.

66. Porcel JM, Diaz JP, Chi DS. Clinical implications of pleural effusions in ovarian cancer. Respirology. 2012;17(7):1060-7.
67. Meyer LA, Cronin AM, Sun CC, Bixel K, Bookman MA, Cristea MC, et al. Use and effectiveness of neoadjuvant chemotherapy for treatment of ovarian cancer. Journal of Clinical Oncology. 2016;34(32):3854-63.

68. Bristow RE, Chi DS. Platinum-based neoadjuvant chemotherapy and interval surgical cytoreduction for advanced ovarian cancer: A meta-analysis. Gynecol Oncol. 2006;103(3):1070-6.

69. Elattar A, Bryant A, Winter-Roach BA, Hatem M, Naik R. Optimal primary surgical treatment for advanced epithelial ovarian cancer. Cochrane Database Syst Rev. 2011(8):CD007565.

70. Morrison J, Haldar K, Kehoe S, Lawrie TA. Chemotherapy versus surgery for initial treatment in advanced ovarian epithelial cancer. Cochrane Database Syst Rev. 2012(8):CD005343.

71. Winter WE, 3rd, Maxwell GL, Tian C, Carlson JW, Ozols RF, Rose PG, et al. Prognostic factors for stage iii epithelial ovarian cancer: A gynecologic oncology group study. J Clin Oncol. 2007;25(24):3621-7.

72. Gerestein CG, van der Spek DW, Eijkemans MJ, BakkerJ, KooiGS, Burger CW. Prediction of residual disease after primary cytoreductive surgery for advanced-stage ovarian cancer: Accuracy of clinical judgment. Int J Gynecol Cancer. 2009;19(9):1511-5.

73. Rutten IJ, van de Laar R, Kruitwagen RF, Bakers FC, Ploegmakers MJ, Pappot TW, et al. Prediction of incomplete primary debulking surgery in patients with advanced ovarian cancer: An external validation study of three models using computed tomography. Gynecol Oncol. 2016;140(1):22-8. 
74. Rutten $M J$, van de Vrie $R$, Bruining $A$, Spijkerboer AM, Mol BW, Kenter GG, et al. Predicting surgical outcome in patients with international federation of gynecology and obstetrics stage iii or iv ovarian cancer using computed tomography: A systematic review of prediction models. Int J Gynecol Cancer. 2015;25(3):407-15.

75. Rutten MJ, van Meurs HS, van de Vrie R, Gaarenstroom KN, Naaktgeboren CA, van Gorp T, et al. Laparoscopy to predict the result of primary cytoreductive surgery in patients with advanced ovarian cancer: A randomized controlled trial. J Clin Oncol. 2017;35(6):613-21.

76. Rutten MJ, Leeflang MM, Kenter GG, Mol BW, Buist M. Laparoscopy for diagnosing resectability of disease in patients with advanced ovarian cancer. Cochrane Database Syst Rev. 2014(2):CD009786.

77. Ataseven B, Grimm C, Harter P, Heikaus S, Heitz F, Traut A, et al. Prognostic impact of port-site metastasis after diagnostic laparoscopy for epithelial ovarian cancer. Ann Surg Oncol. 2016;23(Suppl 5):834-40.

78. Heitz F, Ognjenovic D, Harter P, Kommoss $\mathrm{S}$, Ewald-Riegler N, Haberstroh $\mathrm{M}$, et al. Abdominal wall metastases in patients with ovarian cancer after laparoscopic surgery: Incidence, risk factors, and complications. Int J Gynecol Cancer. 2010;20(1):41-6.

79. Bian C, Yao K, Li L, Yi T, Zhao X. Primary debulking surgery vs. Neoadjuvant chemotherapy followed by interval debulking surgery for patients with advanced ovarian cancer. Archives of Gynecology and Obstetrics. 2016;293(1):163-8.

80. Colombo PE, Mourregot $A$, Fabbro $M$, Gutowski M, Saint-Aubert B, Quenet F, et al. Aggressive surgical strategies in advanced ovarian cancer: A monocentric study of 203 stage iiic and iv patients. European Journal of Surgical Oncology. 2009;35(2):135-43.
81. Fago-Olsen $\mathrm{CL}$, Ottesen $\mathrm{B}$, Kehlet $\mathrm{H}$, Antonsen SL, Christensen IJ, Markauskas A, et al. Does neoadjuvant chemotherapy impair long-term survival for ovarian cancer patients? A nationwide danish study. 2014;132(2):292-8.

82. Iwase H, Takada T, litsuka C, Nomura $H$, Abe A, Taniguchi $T$, et al. Clinical significance of systematic retroperitoneal lymphadenectomy during interval debulking surgery in advanced ovarian cancer patients. Journal of Gynecologic Oncology. 2015;26(4):303-10.

83. Markauskas A, Mogensen O, Christensen $\mathrm{RD}$, Jensen PT. Primary surgery or interval debulking for advanced epithelial ovarian cancer: Does it matter? International Journal of Gynecological Cancer. 2014;24(8):14208.

84. May T, Comeau R, Sun P, Kotsopoulos J, Narod SA, Rosen B, et al. Comparison of survival outcomes in advanced serous ovarian cancer patients treated with primary debulking surgery versus neoadjuvant chemotherapy. International Journal of Gynecological Cancer. 2017;27(4):668-74.

85. Muraji M, Sudo T, Iwasaki S, Ueno $S$, Wakahashi S, Yamaguchi $S$, et al. Histopathology predicts clinical outcome in advanced epithelial ovarian cancer patients treated with neoadjuvant chemotherapy and debulking surgery. 2013;131(3):531-4.

86. Rosen B, Laframboise S, Ferguson S, Dodge J, Bernardini M, Murphy J, et al. The impacts of neoadjuvant chemotherapy and of debulking surgery on survival from advanced ovarian cancer. 2014;134(3):4627.

87. Rutten MJ, Sonke GS, Westermann AM, van Driel WJ, Trum JW, Kenter GG, et al. Prognostic value of residual disease after interval debulking surgery for figo stage iiic and iv epithelial ovarian cancer. Obstet Gynecol Int. 2015;2015:464123. 
88. van Driel WJ, Koole SN, Sikorska K, Schagen van Leeuwen JH, Schreuder HWR, Hermans RHM, et al. Hyperthermic intraperitoneal chemotherapy in ovarian cancer. N Engl J Med. 2018;378(3):230-40.

89. Moore K, Colombo N, Scambia G, Kim BG, Oaknin A, Friedlander $M$, et al. Maintenance olaparib in patients with newly diagnosed advanced ovarian cancer. N Engl J Med. 2018.

90. Cancer Genome Atlas Research N. Integrated genomic analyses of ovarian carcinoma. Nature. 2011;474(7353):60915.

91. Bowtell DD, Bohm S, Ahmed AA, Aspuria PJ, Bast RC, Jr., Beral V, et al. Rethinking ovarian cancer ii: Reducing mortality from high-grade serous ovarian cancer. Nat Rev Cancer. 2015;15(11):668-79.

92. Macintyre G, Goranova TE, De Silva D, Ennis D, Piskorz AM, Eldridge $M$, et al. Copy number signatures and mutational processes in ovarian carcinoma. Nat Genet. 2018;50(9):1262-70.

93. Patch AM, Christie EL, Etemadmoghadam D, Garsed DW, George J, Fereday S, et al. Whole-genome characterization of chemoresistant ovarian cancer. Nature. 2015;521(7553):489-94.

94. Kanska J, Zakhour M, Taylor-Harding B, Karlan BY, Wiedemeyer WR. Cyclin e as a potential therapeutic target in high grade serous ovarian cancer. Gynecol Oncol. 2016;143(1):152-8.

95. Nakayama N, Nakayama K, Shamima Y, Ishikawa M, Katagiri A, lida K, et al. Gene amplification ccne1 is related to poor survival and potential therapeutic target in ovarian cancer. Cancer. 2010;116(11):262134.
96. Etemadmoghadam D, deFazio A, Beroukhim R, Mermel C, George J, Getz $G$, et al. Integrated genome-wide DNA copy number and expression analysis identifies distinct mechanisms of primary chemoresistance in ovarian carcinomas. Clin Cancer Res. 2009;15(4):1417-27.

97. Mukhopadhyay A, Plummer ER, Elattar A, Soohoo S, Uzir B, Quinn JE, et al. Clinicopathological features of homologous recombination-deficient epithelial ovarian cancers: Sensitivity to parp inhibitors, platinum, and survival. Cancer Res. 2012;72(22):5675-82.

98. Moule R, Sohaib A, Eeles R. Dramatic response to platinum in a patient with cancer with a germline brca2 mutation. Clin Oncol (R Coll Radiol). 2009;21(6):4447.

99. Strickland $\mathrm{K} H \mathrm{~B}$, Rodig $\mathrm{S}$, Ritterhouse L, D'Andrea A, Matulonis U, Konstantinopoulos P. Tumor infiltrating and peritumoral $t$ cells and expression of pd-I1 and brca1/2-mutated high grade serous ovarian cancers. Journal of Clinical Oncology. 2015;33(15):5512.

100. Zhong Q, Peng HL, Zhao X, Zhang L, Hwang WT. Effects of brca1- and brca2-related mutations on ovarian and breast cancer survival: A meta-analysis. Clin Cancer Res. 2015;21(1):211-20.

101. Bolton KL, Chenevix-Trench G, Goh C, Sadetzki S, Ramus SJ, Karlan BY, et al. Association between brca1 and brca2 mutations and survival in women with invasive epithelial ovarian cancer. JAMA. 2012;307(4):382-90.

102. Mirza MR, Monk BJ, Herrstedt J, Oza AM, Mahner S, Redondo A, et al. Niraparib maintenance therapy in platinumsensitive, recurrent ovarian cancer. N Engl J Med. 2016;375(22):2154-64. 
103. Ledermann J, Harter P, Gourley C, Friedlander M, Vergote I, Rustin $\mathrm{G}$, et al. Olaparib maintenance therapy in patients with platinum-sensitive relapsed serous ovarian cancer: A preplanned retrospective analysis of outcomes by brca status in a randomised phase 2 trial. Lancet Oncol. 2014;15(8):852-61.

104. Coleman RL, Oza AM, Lorusso D, Aghajanian C, Oaknin A, Dean A, et al. Rucaparib maintenance treatment for recurrent ovarian carcinoma after response to platinum therapy (ariel3): A randomised, double-blind, placebo-controlled, phase 3 trial. Lancet. 2017;390(10106):1949-61.

105. Pujade-Lauraine E, Ledermann JA, Selle F, Gebski V, Penson RT, Oza AM, et al. Olaparib tablets as maintenance therapy in patients with platinum-sensitive, relapsed ovarian cancer and a brca1/2 mutation (solo2/ engot-ov21): A double-blind, randomised, placebo-controlled, phase 3 trial. Lancet Oncol. 2017;18(9):1274-84.

106. Zhang L, Conejo-Garcia JR, Katsaros D, Gimotty PA, Massobrio M, Regnani G, et al. Intratumoral t cells, recurrence, and survival in epithelial ovarian cancer. N Engl J Med. 2003;348(3):203-13.
107. Tothill RW, Tinker AV, George J, Brown R, Fox SB, Lade S, et al. Novel molecular subtypes of serous and endometrioid ovarian cancer linked to clinical outcome. Clin Cancer Res. 2008;14(16):5198-208.

108. Pakish JB, Jazaeri AA. Immunotherapy in gynecologic cancers: Are we there yet? Curr Treat Options Oncol. 2017;18(10):59.

109. Hamanishi J, Mandai M, Ikeda T, Minami M, Kawaguchi A, Murayama T, et al. Safety and antitumor activity of anti-pd-1 antibody, nivolumab, in patients with platinumresistant ovarian cancer. J Clin Oncol. 2015;33(34):4015-22.

110. Pujade-Lauraine E, Fujiwara K, Dychter SS, Devgan G, Monk BJ. Avelumab (anti-pd-I1) in platinum-resistant/refractory ovarian cancer: Javelin ovarian 200 phase iii study design. Future Oncol. 2018;14(21):210313.

111. Chi DS, Bristow RE, Armstrong DK, Karlan BY. Is the easier way ever the better way? J Clin Oncol. 2011;29(31):4073-5. 

13

Valorisatie 

Het doel van dit hoofdstuk is het beschrijven wat de samenleving heeft aan de uitkomsten van de studies gebundeld in dit proefschrift. De valorisatiegedachte is geen verwonderlijke, gezien KWF Kankerbestrijding dit onderzoek heeft gesubsidieerd. Publiceren van de opgedane kennis is een verantwoordelijkheid naar de subsidieverstrekker en de mensen daarachter. De opdracht van een valorisatiehoofdstuk impliceert echter dat nieuw opgedane kennis, of bevestiging van bestaande hypothesen, niet voldoende 'opbrengst' zou zijn van een proefschrift. Het idee achter valorisatie is dat wetenschap ook zou moeten leiden tot economisch gewin of een concreet toepasbare dienst of product. Indien dit het geval zou zijn is dat een mooi resultaat, maar het impliceert tegelijkertijd dat proefschriften die dit niet kunnen bieden van mindere kwaliteit zouden zijn. De geneeskunde is een vakgebied waarin we veelal toegepast onderzoek kunnen verrichten, waardoor valorisatie makkelijker te verwezenlijken is. Het toegepaste onderzoek zou echter niet bestaan zonder fundamenteel onderzoek. De waarde van fundamenteel onderzoek zit hem vaak niet in een concreet toepasbare dienst of product, maar wel in het beter begrijpen van de wereld om ons heen, en het mogelijk maken van toegepast onderzoek jaren later.

In dit proefschrift is population-based onderzoek verricht met behulp van de Nederlandse Kankerregistratie. In tijden van 'evidence-based medicine' is gerandomiseerd onderzoek echter de gouden standaard om de effectiviteit van behandelingen aan te tonen. Gerandomiseerd onderzoek verdeelt twee groepen patiënten 'at random' tussen twee behandelingen met als doel dat de effectiviteit van behandeling A ten opzichte van behandeling B kan worden geobjectiveerd. Dit type onderzoek wordt echter sterk beïnvloed door de in- en exclusiecriteria die worden opgesteld. Bepaalde patiëntengroepen worden daarom vooraf uitgesloten van het onderzoek, met als resultaat dat de uitkomsten niet voor elke patiënt toepasbaar zijn in de dagelijkse praktijk. Population-based onderzoek is daarom een unieke mogelijkheid om de effecten van behandelingen te onderzoeken in de dagelijkse praktijk, juist ook bij patiëntengroepen die niet in gerandomiseerde onderzoeken zijn opgenomen.

leder jaar ontwikkelen ongeveer 1300 vrouwen eierstokkanker in Nederland. Wereldwijd is eierstokkanker bovendien de meest dodelijke vorm van alle gynaecologische tumoren. Losse tumorcellen verspreiden zich makkelijk vanuit de eierstokken door de buikholte, met grote consequenties voor de prognose. Na vijf jaar is $80-95 \%$ van de patiënten met een vroeg stadium nog in leven, terwijl dit voor patiënten met een gevorderd stadium slechts 30 $45 \%$ betreft. Het opsporen van eierstokkanker in een vroeg stadium zou derhalve van grote waarde zijn voor de prognose van patiënten, maar aspecifieke symptomen en ontbreken 
van accurate screeningsmethoden verhinderen dit vaak. Het belang van populationbased onderzoek naar eierstokkanker wordt uiteengezet in het eerste hoofdstuk van dit proefschrift, waarin duidelijk wordt dat de lange-termijn overleving van patiënten met eierstokkanker in de afgelopen 25 jaar niet is verbeterd. Er is wel vooruitgang geboekt in het langer controleren van ziekteactiviteit, wat zich uit in een verbeterde vijfjaarsoverleving. De behandeling van deze patiënten bestaat uit een combinatie van uitgebreide chirurgie en chemotherapie. De beste ziektecontrole ontstaat wanneer alle zichtbare tumor wordt verwijderd bij een operatie.

Dit proefschrift beschrijft population-based onderzoek dat is verricht naar de optimale behandeling voor patiënten met eierstokkanker in een gevorderd stadium. Met behulp van de Nederlandse Kankerregistratie is meer inzicht verkregen in de organisatie van zorg voor patiënten met eierstokanker in Nederland. Hiervoor zijn alle patiënten die tussen 2008 en 2015 zijn gediagnosticeerd met eierstokkanker onderzocht. Van alle patiënten met eierstokkanker wordt ongeveer $75 \%$ gediagnosticeerd in een gevorderd stadium. Niet alle patiënten komen in aanmerking voor een uitgebreide operatie, onder meer door te uitgebreide tumormassa, co-morbiditeit of omdat zij geen operatie wensen te ondergaan. Dit betekent dat er ongeveer 650-700 patiënten per jaar worden geopereerd en dat expertise op het gebied van deze operaties essentieel is gezien deze relatief kleine groep patiënten. Uit eerder onderzoek is gebleken dat de chirurgische zorg voor vrouwen met eierstokkanker verbetert wanneer deze wordt uitgevoerd door gynaecoloog-oncologen in gespecialiseerde ziekenhuizen. Dit heeft geleid tot centralisatie van chirurgische zorg voor patiënten met eierstokkanker. Uit een van onze studies blijkt dat patiënten in Nederland sinds de centralisatie dezelfde chirurgische zorg krijgen aangeboden onafhankelijk van het eerste ziekenhuis waar zij binnenstapt, waarbij rekening gehouden wordt met patiënt- en tumorkarakteristieken. Dit verklaart voor een gedeelte waarom centralisatie van zorg heeft bijgedragen aan betere ziektecontrole in de algehele populatie.

In Nederland worden patiënten binnen acht oncologische regio's behandeld. Omdat de kans op een operatie niet hetzelfde is als de kans op een succesvolle operatie (gedefinieerd als geen macroscopische restlaesies), is er in dit proefschrift ook geëvalueerd of de kans op een succesvolle operatie afhangt van de regio waarin patiënten geopereerd worden. Uit deze studie bleek dat er wel degelijk verschillen bestaan in de kans op een succesvolle operatie tussen regio's. Dit vertaalt zich bovendien voor een deel in verschil in prognose tussen regio's. Een van de redenen die hieraan ten grondslag kan liggen is dat de centralisatie van de chirurgische zorg, ten tijde van ons onderzoek, nog niet door elk ziekenhuis was 
opgevolgd. In 2015 is geobserveerd dat 30\% van de ziekenhuizen zich niet hield aan de minimale normen voor het aantal operaties per jaar. Voorstanders van gecentraliseerde zorg gaan daarom nog een stap verder en beargumenteren dat deze normen niet per ziekenhuis, maar per gynaecoloog zouden moet gelden. Ziekenhuisvolume is een makkelijk meetbare indicator, en derhalve populair in wetenschappelijk onderzoek, maar heeft als nadeel dat het slechts een globaal beeld van de kwaliteit van zorg weergeeft. Het blijven ophogen van volumenormen, per ziekenhuis of per gynaecoloog, zonder andere kwaliteitsindicatoren in ogenschouw te nemen, zal hoogstwaarschijnlijk niet leiden tot een blijvende toename in kwaliteit van zorg. Een voorbeeld hiervan is al geleverd in de darmkankerchirurgie, waaruit blijkt dat de overleving na een chirurgische darmresectie niet beter is in ziekenhuizen die 100 operaties per jaar uitvoeren in vergelijking met ziekenhuizen die 50 operaties per jaar uitvoeren. De verbeterde zorg wordt veelal verklaard door andere factoren die geassocieerd zijn met een hoog ziekenhuisvolume, zoals het beschikbaar zijn van gespecialiseerde (gastro-intestinale) chirurgen tijdens de operatie in consult kunnen worden gevraagd, de aanwezigheid van gespecialiseerde verpleegkundigen, uitgebreide multidisciplinaire overleggen, en de aanwezigheid van gespecialiseerde gynaecoloogoncologen. De variatie die we hebben geobserveerd in uitkomsten tussen de oncologische regio's moet ons stimuleren om van elkaar te leren, zodat patiënten de hoogst mogelijk kwaliteit aan oncologische zorg krijgen ongeacht waar zij worden gediagnosticeerd en behandeld.

Naast de centralisatie van zorg, kan ook de volgorde van de behandeling ervoor zorgen dat de uitkomsten van de chirurgie zijn verbeterd over de afgelopen jaren. Traditioneel werden patiënten met eierstokkanker primair geopereerd gevolgd door zes kuren adjuvante chemotherapie. Een alternatief is drie kuren neoadjuvante chemotherapie gevolgd door interval-chirurgie en nogmaals drie kuren adjuvante chemotherapie. Neoadjuvante chemotherapie kan potentieel het initiële tumorvolume verkleinen waardoor de kans op een succesvolle operatie wordt vergroot. Uit gerandomiseerd onderzoek blijkt dat de overlevingsuitkomsten vergelijkbaar zijn tussen de twee behandelingsstrategieën, met minder morbiditeit na neoadjuvante chemotherapie. Dit heeft in Nederland geleid tot een aanzienlijke toename in het gebruik van neoadjuvante chemotherapie, met daarbij ook een stijging in het aantal complete operaties. Zoals eerder benoemd is de vijfjaars overleving in dezelfde periode ook gestegen, echter is de algehele overleving na tien jaar nog steeds vergelijkbaar met de uitkomsten rond 1990. Dat brengt ons tot de vraag of de kwaliteit van zorg wel daadwerkelijk verbeterd is in de afgelopen jaren en of neoadjuvante chemotherapie een gelijkwaardig alternatief is in de behandeling van gevorderde eierstokkanker. Dat 
antwoord is niet simpel te geven, maar is wel uitgebreid beschreven in de voorgaande hoofdstukken van het huidige proefschrift. Inzicht geven in de daadwerkelijke uitkomsten van de oncologische zorg is een belangrijk onderdeel om de dagelijkse praktijk te kunnen verbeteren. Veelal is er een globaal inzicht in de eigen uitkomsten, maar niet in die van de omliggende ziekenhuizen of van andere regio's. De kracht, en het nut, van dit proefschrift ligt dan ook in het inzichtelijk maken van de kwaliteit van zorg en de evaluatie van de effecten van veranderingen in de zorg voor patiënten met gevorderd ovariumcarcinoom over de afgelopen jaren. 


14

Epilogue 



\section{DANKWOORD}

Het is zover, na drie jaar promoveren ligt er een boekje. Dat het een unieke ervaring is geworden komt door alle mensen die hieraan hebben bijgedragen, waarvan ik er een aantal in het bijzonder wil bedanken.

Prof. dr. Kruitwagen, beste Roy, na een conisatie op de OK in het MUMC+ vroeg je me of ik al plannen had voor het komende jaar. Ik kreeg de kans om te solliciteren op een ontzettend mooi project wat heeft geleid tot dit boekje. Je betrokkenheid vanuit het warme zuiden heb ik enorm gewaardeerd. Er zijn weinig promotoren die zo betrokken zijn bij hun promovendi, waarbij ik je snelle, klinisch-relevante en waardevolle feedback altijd binnen enkele dagen kon verwachten. Een bezoekje aan Maastricht resulteerde standaard in een veelvoud aan nieuwe ideeën, waarbij je mijn motivatie continue wist aan te wakkeren om het nog verder uit te zoeken. Je enthousiasme, tactvolle benadering, klinische expertise, en rust (ook aan de operatietafel), maakt je tot een enorme inspirator. Ik hoop dat we in de toekomst nog vaak samen mogen werken!

Dr. van der Aa, lieve Maaike, toen je op mijn eerste mail, waarin ik je aansprak met dr. van der Aa, antwoordde "Hahahaha noem me maar Maaike" wist ik dat het wel goed zat. Een goede co-promotor is aanwezig als het moet, maar kan iemand tegelijkertijd ook ruimte geven. Je hebt ons KWF-project echt aan me toevertrouwd, waardoor ik me heb kunnen ontwikkelen tot een volwaardig lid van ons team. Ik heb je steun tijdens onze strubbelingen rondom de registratie als heel waardevol ervaren. Je betrokkenheid, toewijding, enthousiasme en vooral ook gezelligheid heb ik enorm gewaardeerd. Onze congresbezoeken waren memorabel, waarbij je je taak als begeleider tot in de late uurtjes heel serieus hebt genomen.

Dr. Sonke, beste Gabe, ik weet nog goed dat ik mijn eerste abstract voor een congres van je heb teruggekregen met de tekst; "Hele mooie eerste opzet", en vervolgens een volledig rood document. Sindsdien is het iets minder rood geworden, maar hebben je klinische expertise, epidemiologische kennis en gave om een boodschap te verkopen enorm bijgedragen aan de kwaliteit van mijn manuscripten. Toen ik na twee jaar promoveren graag weer terug naar de kliniek wilde was jij heel duidelijk, en daarvoor ben ik je nu, met boekje op zak, erg dankbaar. 
Prof. dr. Van de Vijver, beste Koen, het fundamentele gedeelte van dit project sprak mij in eerste instantie het minste aan. Maar na een aantal keer met jou gesproken te hebben, en samen achter de microscoop naar al die ovariumcarcinomen gekeken te hebben, heb je met weten te overtuigen van de mooie aspecten van de (moleculaire) pathologie. Je enthousiasme is aanstekelijk, en ook al ging je nog net iets zuidelijker dan Roy zitten, je betrokkenheid werd gelukkig niet minder.

Prof. dr. Amant, dr. De Boer, prof. dr. Dejong, prof. dr. Lemmens en prof. dr. Speel, dank voor het beoordelen van mijn proefschrift en het zitting nemen in de commissie. Ook veel dank aan alle co-auteurs voor de hulp bij het schrijven van de studies.

Zonder de Nederlandse Kankerregistratie en onze toegewijde afdeling registratie was dit boekje er niet geweest. De HOOGSTOC-registratie was voor velen een blok aan het been, maar jullie hebben een enorme hoeveelheid werk verzet, waarvoor veel dank. Nacio, Christien en Mirjam, veel dank voor jullie enorme inzet bij het opstarten en begeleiden van de HOOGSTOC-registraties, jullie hebben me laten zien dat registreren een vak apart is! Reini, dank voor het maken van alle HOOGSTOC-bestanden en eerste hulp bij noodgevallen. Dr. Visser, beste Otto, er zijn weinig mensen die zoveel van kankerregistraties weten als jij. Ondanks onze meningsverschillen, en misschien wel dankzij, heb ik ontzettend veel respect voor de manier waarop je iedere keer de kwaliteit van de NKR weet te verbeteren en op een hoog niveau weet te houden.

Dank aan alle collega's in het NKI-AVL die me wegwijs hebben gemaakt in de wondere wereld van het fundamentele onderzoek. Dr. Horlings, beste Hugo, dank voor het waarnemen van Koen z'n taken in het NKI-AVL toen hij naar Gent vertrok. Je enthousiasme en ideeën zijn onuitputtelijk. Dr. Rosenberg, beste Efraim, dank voor je tijd, aanstekelijke enthousiasme, uitgebreide colleges die ik tussendoor kreeg en je nauwkeurigheid in het begeleiden van onze BRCA-mutatie analyses. Zonder jou en je team was ons manuscript er niet geweest. Rianne, veel dank voor je hulp bij het isoleren van het DNA, het opzetten van onze experimenten en me wegwijs maken in het lab. Michiel, wat hebben we genoten van de FISH-analyses, dank voor je doorzettingsvermogen. Lauri, ontzettend veel dank voor de enorme hoeveelheid werk die je hebt verzet gedurende jouw eindstage. Juliette, we werden door Koen bij elkaar gezet omdat we eigenlijk dezelfde onderzoeksvraag hadden, hij had het niet beter kunnen bedenken. Ik denk dat we zonder elkaar nog steeds aan de tekentafel hadden gezeten, op naar jouw promotie! 
Lieve collega's van IKNL, zonder jullie had mijn promotietijd er heel anders uitgezien. Wat een fijne organisatie om je boekje te mogen schrijven. Lieve Mirian, samen stonden we bij Amanda haar promotie, en wat hebben we elkaar goed leren kennen in die periode. Je bent een topper! Vincent, er zijn weinig mensen die de epidemiologische principes echt begrijpen en het ook nog kunnen uitleggen. Dank voor je geduld en je volwaardige docentschap om me eerst 864 regels syntax te laten schrijven waar ik er ook met 10 had kunnen zijn. Jan Maarten, dank voor alle inside information en het vertrouwen dat je sinds dag 1 in me had. Lieve Marilyn en Rowena, m'n Rotterdamse buddies, dank voor alle gezellige lunches in én buiten het HNK-kantoor.

Lieve Marissa, Willemieke, en Kay, met echt goede collega's kun je op elk moment in de week biertjes drinken en slechte grappen maken, en dat hebben we veelvuldig gedaan!

Dank aan alle collega's van de afdeling Gynaecologie en Obstetrie van het Hagaziekenhuis, wat een fijne plek om te mogen starten als ANIOS. Het is hard werken, maar net zo hard genieten met nachtelijke koffietjes en regelmatige etentjes. Dank voor jullie geduld en veelvuldige overleg om me wegwijs te maken in het ziekenhuis.

Werk is maar werk, en zonder alle lieve vrienden en familie die me zo nu en dan uit de bubbel van promoveren hebben getrokken, had ik het allemaal vast nog veel serieuzer genomen. Een aantal mensen wil ik graag in het bijzonder noemen; SUBLIMERS, Esther, Eva, Fabiola, Lisa, Malon, Marit, Tessa en Yvette, we vieren dit jaar ons 10-jarig jubileum, maar eigenlijk is het altijd feest om met elkaar te zijn. Onze maandelijkse borrels, Sinterklaasavondjes (nooit in december) en JC-weekendjes worden standaard gevuld met koffietjes, een overload aan eten, en af en toe een klein misthoorntje. Het is genieten met jullie!

Lieve Anne-Wil, Manja en Yavanne, al sinds de middelbare school zijn we een team, en het is heerlijk om zulke fijne vriendinnen te hebben.

Lieve Nandi, je verruilde huize Hoograamstraat ooit voor Eindhoven (nooit begrepen), maar gelukkig weten we elkaar nog steeds regelmatig te vinden in Maastricht of Rotterdam. Je bent een fantastisch mens.

Lieve Anja, Johan, Noor, Freek, Gijs en Sanne, dank voor jullie Brabantse gezelligheid, enorme voorraad aan worstenbroodjes, carnavalsfeestjes en etentjes. Ik voel me enorm thuis bij jullie. Lieve Gijs, dankjewel voor mijn prachtige boekje, je hebt jezelf overtroffen!! 
Als je uit zo'n kleine familie komt, kun je ze beter maar allemaal noemen, lieve oma, oma en Jolanda, dank voor jullie interesse en fijne weekendjes in Groningen en Maastricht. Lieve Sandra, je bent een echte aanvulling op Mathijs en ons gezin, succes met het afronden van jouw promotie. Lieve Mathijs, mijn kleine (stiekem grote) broertje, na onze middelbare schoolperiode zijn we elkaar echt gaan waarderen. Het feit dat je oprecht trots was toen ik mocht beginnen aan mijn promotietraject, terwijl jij dat nog veel liever wilde, heb ik echt gewaardeerd. Onze lunches, etentjes, weekendjes in Zeeland en wintersportvakanties zijn een genot, waarbij we even helemaal onszelf kunnen zijn.

Lieve paranimfen, Amanda en Marit, wat fijn dat jullie vandaag naast me staan. Lieve Amanda, sinds dag 1 bij IKNL zijn we partners-in-crime en hebben we aan een blik meer dan genoeg. Paashaasoren, blote voeten en alle andere bijzondere gewaarwordingen konden we met gepaste verbazing waarderen. De werkdagen werden zoveel leuker met onze veelvuldige koffiepauzes, veel te lange lunches, (vrijdagmiddag)borrels, en etentjes. Er zijn weinig mensen die zo hard kunnen knokken als jij, je bent een topper!

Lieve Marit, sinds je (uiteraard te laat) binnenkwam in onze eerste werkgroep, en er veelvuldig slagroom koffietjes werden gedronken waren we vriendinnen. Na ons eerste jaartje GW (inclusief drie Musketiers tripje naar Berlijn met Es), de daaropvolgende jaren met ons liefste clubje, samenwonen in Huize Hoograamstraat en talloze koffietjes, GT's en borrels (inclusief onverwachte slaapjes), ben ik super trots dat je hier vandaag naast me staat. Ook al zien we elkaar niet meer dagelijks, je blijft m'n liefste vriendinnetje uit het zuiden!!

Papa en mama, het rotsvaste vertrouwen, de onvoorwaardelijke steun, maar ook de noodzaak om dingen af te maken waar je aan begint hebben me geholpen om dit boekje (af) te schrijven. Lieve mama, je Groningse nuchterheid, onvoorwaardelijke liefde, lichte push in het kiezen van GW in plaats van Technische Bedrijfskunde (thank god for that...), en de wetenschap dat je er altijd voor me bent als ik het even niet meer zie zitten waardeer ik enorm. Lieve papa, je hebt ons geleerd om altijd nieuwsgierig te zijn. Antwoorden op simpele vragen gaf je niet, maar de boeken waar het in stond werden in veelvoud aangereikt. Op dat moment niet echt gewaardeerd, maar inmiddels zie ik in hoeveel je me hebt geleerd. Daarnaast hebben jullie samen voor een warm thuis gezorgd, waar we allemaal graag en veelvuldig naar terug komen (inclusief ons jaarlijkse wintersport tripje). 
Lieve Joep, jij bent de enige die net zoveel van debulkingen, ziekenhuizen van diagnoses en FIGO IV weet als mijn co-auteurs, dank voor je onuitputtelijke interesse en aanhoren van mijn monologen. Lieverd, je hebt alle ups en downs meegemaakt, waarbij elk geaccepteerd manuscript altijd met een fles champagne werd gevierd (ongeacht dag en tijdstip) en de downs met een knuffel, ontnuchterend gesprek én een borrel. Jij weet me altijd weer met beide benen op de grond te zetten. Daarnaast is het een feest om met jou samen te zijn. We gaan enorm genieten van deze dag, en van de komende periode zonder het submitten van artikelen!

Maite

Augustus 2019 



\section{CURRICULUM VITAE}

Maite Timmermans werd geboren op 24 september 1990 in Zierikzee. Zij behaalde haar VWO diploma in 2008 aan de Pontes Scholengroep locatie Pieter Zeeman in Zierikzee. Nadat zij was uitgeloot voor Geneeskunde, startte zij met de opleiding Algemene Gezondheidswetenschappen aan de Universiteit Maastricht. Na opnieuw uitgeloot te zijn in het jaar daarop maakte ze haar bachelor opleiding af en werd ze toegelaten tot de Research master Arts-Klinisch Onderzoeker (A-KO) aan de Universiteit Maastricht. In het laatste jaar van haar opleiding verrichte zij haar wetenschappelijke en klinische semi-arts stage op de afdeling gynaecologische oncologie onder begeleiding van dr. Brigitte Slangen in het Maastricht Universitair Medisch Centrum (MUMC+). Nadat ze in augustus 2015 haar artsexamen behaalde ging ze als promovendus werken bij het Integraal Kankercentrum Nederland (IKNL) in samenwerking met het MUMC+ en het Nederlands Kanker Instituut - Antoni van Leeuwenhoek Ziekenhuis (NKI-AVL). Zij werd in dit traject begeleid door Prof. dr. Kruitwagen, Prof. dr. Van de Vijver, Dr. van der Aa en Dr. Sonke, en de belangrijkste resultaten van het onderzoek zijn beschreven in dit proefschrift. Na drie jaar promoveren werd het tijd om terug te gaan naar de klinische praktijk. Zij is inmiddels werkzaam als ANIOS gynaecologie en obstetrie in het Hagaziekenhuis in Den Haag. 



\section{PUBLICATIONS INCLUDED IN THIS THESIS}

Timmermans $\mathrm{M}$, Sonke GS, Van de Vijver KK, van der Aa MA, Kruitwagen RFPM. No improvement in long-term survival for epithelial ovarian cancer patients; a populationbased study between 1989 and 2014 in the Netherlands. European Journal of Cancer 2018; 88: 31-37.

Timmermans M, Schuurman MS, Ho, VK, Massuger LF, Nijman HW, van Gorp T, Sonke GS, Kruitwagen RFPM, van der Aa MA. Centralization of ovarian cancer in the Netherlands: hospital of diagnosis no longer determines patients' probability of undergoing surgery. Gynecologic Oncology 2018; 148(1): 56-61.

Timmermans $\mathrm{M}$, Sonke GS, Slangen, BFM, Van de Vijver KK, van der Aa MA, Kruitwagen RF. Outcome of surgery in advanced ovarian cancer varies between oncological regions; opportunities for improvement in the Netherlands. European Journal of Surgical Oncology 2019 (Epub ahead of print)

Timmermans M, Zwakman N, Sonke GS, Van de Vijver KK, Duk MJ, van der Aa MA, Kruitwagen RF. Perioperative change in CA125 is an independent prognostic factor for improved clinical outcome in advanced ovarian cancer (submitted).

Timmermans $\mathrm{M}$, van der Aa MA, Lalisang RI, Witteveen PO, Van de Vijver KK, Kruitwagen RF, Sonke GS. Interval between debulking surgery and adjuvant chemotherapy is associated with overall survival in patients with advanced ovarian cancer. Gynecologic Oncology 2018; 150(3): 446-450

Timmermans M, Sonke GS, Van de Vijver KK, Ottevanger PB, Nijman HW, van der Aa MA, Kruitwagen RF. Localisation of distant metastases defines prognosis and treatment efficacy in patients with FIGO stage IV ovarian cancer. International Journal of Gynecological Cancer 2019 (Epub ahead of print)

Timmermans $\mathrm{M}$, Sonke GS, van Driel WJ, Lalisang RI, Ottevanger PB, de Kroon CD, Van de Vijver KK, van der Aa MA, Kruitwagen RFPM. Neoadjuvant chemotherapy or primary debulking surgery in FIGO IIIC and IV patients; results from a survey study in the Netherlands. European Journal of Obstetrics and Gynecologic Reproductive Biology 2018; 223: 98-102.

Timmermans M, van Kuijk SMJ, Sonke GS, Van de Vijver KK, van der Aa MA, Kruitwagen RF. A preoperative clinical model to assess the probability of complete primary cytoreductive surgery for advanced stage ovarian cancer patients (submitted).

Timmermans $\mathrm{M}$, van der Hel O, Van de Vijver KK, Sonke GS, van der Aa MA, Kruitwagen RF. The prognostic value of residual disease after neoadjuvant chemotherapy in advanced ovarian cancer; a systematic review. Gynecologic Oncology 2019; 153(2): 445-451 


\section{OTHER PUBLICATIONS}

Vermeulen C, Tadasse W, Timmermans M, Kruitwagen RFPM. Only complete tumour resection after neoadjuvant chemotherapy offers benefit over suboptimal debulking in advanced ovarian cancer. Eur J Obstet Gynecol Reprod Biol 2017; 219; 100-105.

de Groot JJA, Timmermans M, Maessen JMC, Winkens B, Dirksen CD, Slangen BFM, van der Weijden T. Quality improvement strategies for organizational change: A multiphase observational study to increase insight into nonparticipating organizations. BMC Health Serv Res. 2018;18(1):1011.

Burg LC, Timmermans M, van der Aa MA, Boll D, Rover K, de Hingh IHJT, van Altena AM. Incidence and predictors of peritoneal metastases of gynecological origin - a population based study in the Netherlands (submitted).

Burg LC, Timmermans $M$, van der Aa MA, Boll D, Rover K, de Hingh IHJT, van Altena AM. Trends in treatment and survival of patients with peritoneal metastases of gynecological origin - a population based study in the Netherlands (submitted).

Schuurman MS, Timmermans M, Van de Vijver KK, van Gorp T, Kruitwagen RFPM, van der Aa MA, Lemmes VEPP. Borderline ovarian tumors; a nationwide overview of incidence, survival and risk of subsequent invasive tumors. Acta Oncologica 2019 (Epub ahead of print) van der Hel O, Timmermans M, van Altena AM, Kruitwagen RF, Slangen BS, Sonke GS, Van de Vijver KK, van der Aa MA. Non-epithelial ovarian cancer; incidence and survival in the Netherlands. European Journal of Cancer 2019 (Epub ahead of print)

Zijlstra M, Timmermans M, Fransen HP, van der Aa MA, Reyners AKL, Raijmakers NJH, van de Poll-Franse LV. Treatment patterns and associated factors in patients with advanced epithelial ovarian cancer: a population-based study between 2008 and 2016. Gynecologic Oncology 2019 (Epub ahead of print) 